UNIVERSIDADE DE SÃO PAULO

INSTITUTO DE QUÍMICA

\title{
SELENOFOSFORANAS E SELENOFOSFONATOS: \\ PREPARAÇÃO E REATIVIDADE. \\ SELENETOS VINÍLICOS
}

\author{
JOÃO VALDIR COMASSETO \\ TESE DE DOUTORAMENTO \\ Prof. NICOLA PETRAGNANI \\ ORIENTADOR
}

SAO PAULO

1978 
Os intransigentes e simplörios

Não suportam, è claro, nossas dúvidas.

o mundo é superficie, explicam simplesmente,

E um disparate a lenda dos abismos.

HERMANN HESSE 
II.

Ao Professor NICOLA, meu reconhecimento pela confiança e pelà liberdade com que me permitiu desenvolver este trabalho. 
Ao Prof. Dr. PAUL BAKER e seus colaboradores, pela gentileza com que nos receberam, registrando os espectros de rmp a $100 \mathrm{MHz}$ apresentados neste trabalho.

Ao Sr. JOSE INÁCIO BERTANHA, do Laboratório de Meios Auxiliares da Universidade Federal de São Carlos, pela execução dos desenhos.

À CAPES, BNDE e à NAS, pela ajuda financeira. 
IV.

\section{ABREVIAÇÕES}

$\begin{array}{ll}\text { rmp } & \text { ressonância magnëtica protônica } \\ \text { iv } & \text { infravermelho } \\ \text { cgl } & \text { cromatografia gás-líquido } \\ \text { pf } & \text { ponto de fusão } \\ \text { pe } & \text { ponto de ebulição } \\ \text { LDA } & \text { diisopropil amideto de lítio } \\ \text { HMPA } & \text { hexametilfosforamida } \\ \text { DME } & \text { dimetoxietano } \\ \text { DMF } & \text { dimetilformamida } \\ \text { THF } & \text { tetrahidro-furano } \\ \text { LAH } & \text { hidreto de lítio e aluminio } \\ \text { n-BuLi } & \text { butil litio normal }\end{array}$

Para indicar a configuração das olefinas usaremos os símbolos Z (zusammen) e E (entgegen) conforme normas da IUPAC $[22,47]$. 


\section{INTRODUÇÃO E OBJETIVOS DO TRABALHO}

o presente trabalho reúne os resultados experimentais obtidos durante nossa permanência no Instituto de Quimica da Universidade de São Paulo, no período compreendido entre agosto de 1973 a agos to de 1977 .

Na primeira parte desta tese fazemos um resumo de nossa dis sertação de mestrado, apresentada ao Instituto de Química da Universidade de são Paulo em março de 1975. O objetivo dessa dissertação foi o estudo de espécies pentacoordenadas do telúrio(IV), pouco descritas na literatura. Nesse trabalho foram preparados compostos de förmula geral $\left[\mathrm{Y}^{+}\right]\left[\operatorname{ArTeX}_{4}^{-}\right]$, tendo sido estudadas suas propriedades químicas e espectrais, interessantes no sentido da elucidação da estereoquímica dos elementos de não transição.

Na segunda parte da tese apresentamos estudos sistemāticos que visam a obtenção de selenetos vinílicos. Quando iniciamos este estudo apenas um método de preparação de selenetos vinílicos era encontrado na literatura. Neste trabalho desenvolvemos três mëtodos de preparação desta classe de compostos e iniciamos o estudo para sua aplicação sintētica.

Com relação à aplicação de compostos orgânicos do selênio em sintese orgânica, cumpre-nos sallentar que, no início de nossos estudos (1973), este ramo da química orgânica era considerado por - 
muitos como mera curiosidade química ou mesmo un "exercício fútil". No entanto, em poucos anos, os compostos orgânicos do selênio se transformaram em valiosos intermediārios sintéticos, aparecendo constantemente na literatura química novas aplicações desses compos tos como "synthons", tanto que já se faz necessāria uma revisão bibliogrāfica sobre esse particular.

Por outro lado, descobriu-se ser o selēnio um elemento vital do metabolismo animal, existindo inúmeros estudos sobre a ativi dade biológica de compostos orgānicos e inorgānicos do selênio [56]. Portanto, qualquer esforço visando a introdução do selênio em uma molécula orgānica é plenamente justificado, e aquilo que era considerado um "exercício fútil" passou a ser a experiência valiosa que serviu de base para o desenvolvimento atual deste ramo da quími ca. 
VII.

\section{INDICE}

pg •

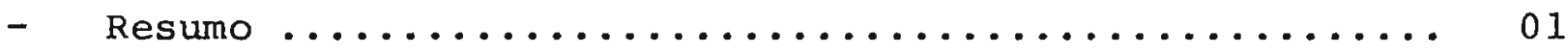

- Abstract ............................... 03

\section{PRIMEIRA PARTE}

Tetrahalogenoarilteluratos (IV)

- Sobre a preparação de complexos penta coordenados do te

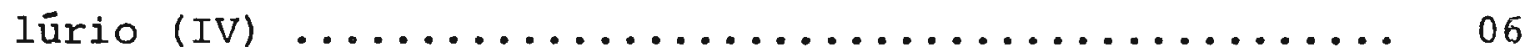

- Sobre a estrutura dos ânions complexos do telūrio (IV). 09

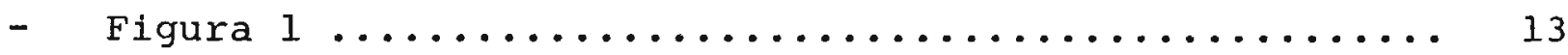

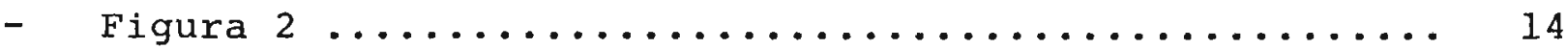

- Bibliografia .......................... 15

\section{SEGUNDA PARTE \\ Selenetos Vinilicos}

CAPITULO I

- Introdução ...........................

CAPITULO II

- Reações de Wittig

A - Fosforanas. 
VIII.

pg.

B - Reação entre fosforanas e compostos carbonílicos -

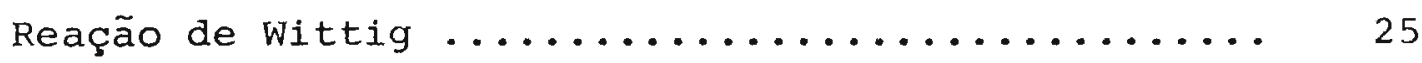

C - Transilidação ....................... 30

CAPITULO III

- Reação de Wittig entre selenofosforanas e compostos -

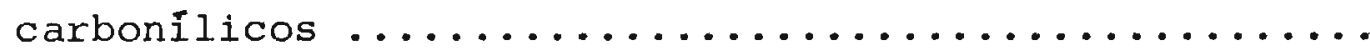

CAPITULO IV

- Resultados e discussão

A - Reação de (fenilseleno) fosforanas com cetonas ...

1. Reação do enolato da ciclohexanona com sal de (fenilseleno) fosfônio ................

2. Reação da $\alpha$-(fenilselenó) ciclohexanona com me-

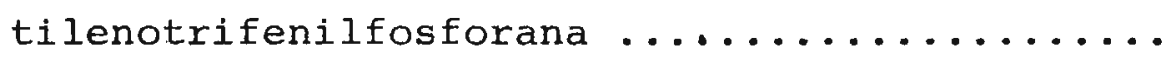

3. Tratamento da mistura de reação entre (fenilse leno)metilenotrifenilfosforana e 3-pentanona com iodeto de metila $\ldots \ldots \ldots \ldots \ldots \ldots \ldots \ldots$

B - Reação de (fenilseleno)fosforanas com esteres e compostos $\beta$-dicarbonilicos ..............

C - Reação de Horner-Emmons entre (fenilseleno) fosfonatos e compostos carbonilicos .............. 
D - Selenetos vinilicos a partir de acetilenos.

1. Adição de selenofenol a acetilenos: Selenetos ví

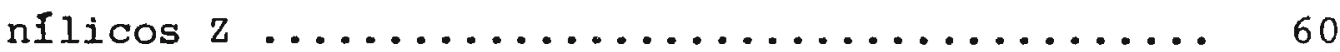

2. Redução de (fenilseleno) acetilenos: Selenetos ví

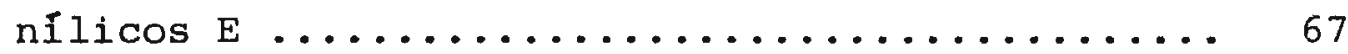

E - Hidrólise de selenetos vinilicos: Cetonas ........ 71

F - Determinação da configuração dos selenetos vinílicos

1. rmp de selenetos vinílicos dissubstituídos de -

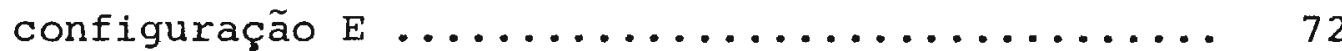

2. rmp de selenetos vinilicos dissubstituídos de -

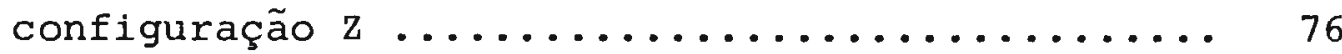

3. Selenetos vinilicos trissubstituído .......... 81

\section{CAPITULO $\mathrm{V}$}

- Estereoquímica da Réação de Wittig e Horner-Emmons ... 8

A - Fosforanas estabilizadas ................... 91

1. Em solvente apolar e na ausência de sais de lítio: predominância do isômero $E \ldots \ldots . . . \ldots . . . . . .91$

2. Em solvente apolar e na presença de sais de littio ou em solvente polar prótico: aumenta a percentạ gem de isômero $z \ldots \ldots \ldots \ldots \ldots . \ldots \ldots \ldots$

3. Em solvente polar aprótico: baixa seletividade, mas predominantemente $\mathrm{E}$ 
B -Fosforanas não estabilizadas ................ 103

C -Estereoquímica da reação de Wittig modificada (reação de Horner-Emmons) .................... 109

CAPITULO VI

- Estereoquímica da reação de Wittig e Horner-Emmons entre (fenilseleno) fosforanas e aldeídos ........... 115

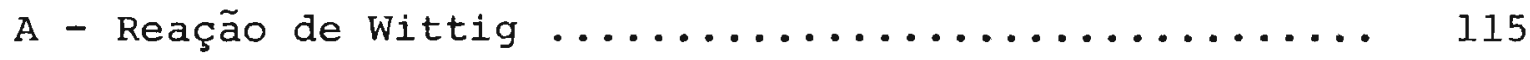

1. Reação na ausência de sais de lítio em solvente apolar

a. Aldeídos alifáticos: maior quantidade de ole

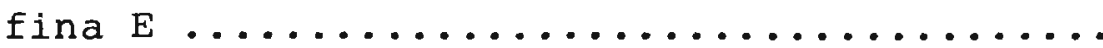

b. Aldeídos aromāticos: maior quantidade de ole fina $\mathrm{Z}$, mas com baixa seletividade ....... 118

2. Reação na presença de sais de lítio .......... 119

a. Aldeídos alifáticos: ausência de estereosele

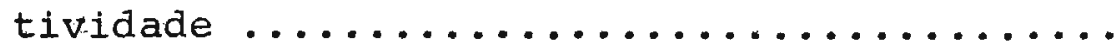

b. Aldeídos aromāticos: maior quantidade de isô mero $E$, mas com baixa seletividade ........

3. Reação de benzaldeído em HMPA na presença de sais de litio: elevada seletividade com relação

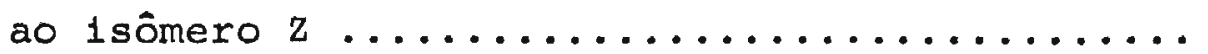


D - Reação de Horner-Emmons .................. 122

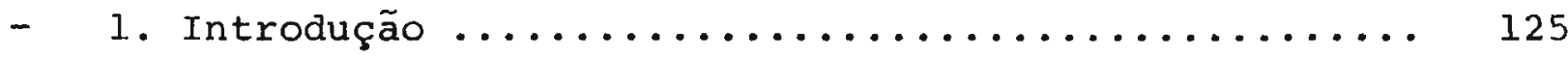

- 2. Matērias primas (geral) ................. 128

I - Reação de Wittig entre (fenilseno)fosforanas e com postos carbonílicos.

A - Preparação das matérias primas.

1. Fenil(bromometil) seleneto .

a. A partir de selenofenóxido de sódio e di

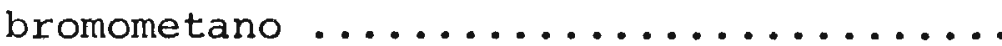

b. A partir de brometo de fenilselenenila e

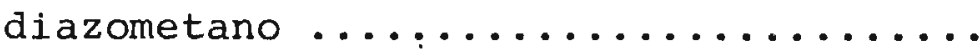

2. Fenil(1-bromoetil) seleneto

a. Tentativas de obtenção a partir de 1,1-dihalogenoetano e selenofenóxido de sō

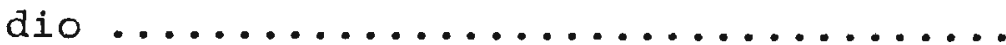

b. A partir de brometo de fenilselenenila e

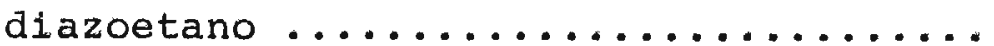

3. Brometo de (fenilseleno)metiltrifenilfosfônio

4. Brometo de (fenilseleno)etiltrifenilfosfô- 
XII.

pg •

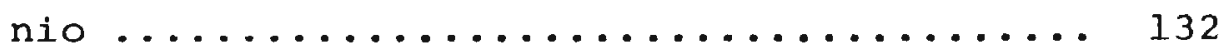

B - Reação de (fenilseleno)fosforanas com aldeídos: se lenetos vinílicos.

1. Via transilidação .................... 133

2. A partir de sais de (fenilseleno)fosfônio ..... 134

3. Preparação de butil-fenilseleneto .......... 135

C - Reação de (fenilseleno)fosforanas com cetonas: $\alpha$ -(fenilseleno) cetonas.

1. Via transilidação ................... 136

2. A partir do sal de (fenilseleno)fosfōnio ..... 137

3. Provas do mecanismo.

a. Reação do enolato da acetofenona com brometo de metiltrifenilfosfônio: 2-fenilpropeno 137

b. $\alpha$ (fenilseleno) ciclohexanona a partir de ciclohexanona ...................... 138

c. Reação do enolato da ciclohexanona com brometo de (fenilseleno)metiltrifenilfosfônio

d. Tratamento da mistura de reação entre (fenilselenolmetiltrifenilfosforana e dietilcetona com $\mathrm{CH}_{3} \mathrm{I}$ : formação de 2-met11-3-(fenilselenof-3-pentanona $\ldots \ldots \ldots \ldots \ldots \ldots$ 
XIII.

$\mathrm{pg} \cdot$

D - Reação de (fenilseleno)metılenotrifenilfosforana com acetato de etila .....................141

E - Reação de (fenilseleno)metilenotrifenilfosforana com compostos $\beta$-dicarbonílicos.

1. Reação efetuada em THF ................. 142

2. Reação efetuada em HMPA ................ 142

3. Preparação de amostras autênticas de $\alpha$-fentlseleno derivados de compostos $\beta$-dicarbonilicos .. 143

II - Reação de Horner-Emmons entre (fenilseleno) fosfó natos e compostos carbonilicos.

A - Preparação das matērias primas.

1. (fenilseleno)metildietilfosfonato ....... 145

2. Alquilação do (fenilseleno)metildietilfosfonato $\ldots \ldots \ldots \ldots \ldots \ldots \ldots \ldots \ldots \ldots \ldots \ldots$

3. (fenilseleno)difentlbenzilfosfinöxido .... 147

4. Seleneto de bis-(dietilfosfometila) ..... 147

B - Reação de (fentlseleno)fosfonatos com compostos carbonilicos: selenetos vinilicos.

1. Usando hidreto de sódio como base ....... 148

2. Usando butil lítio como base .......... 149 
$X I V$

$\mathrm{pg} \cdot$

3. Seleneto de bis-( $\beta$-estirila) ............ 149

4. Tentativa de reação entre (fenilseleno) benzildifenilfosfinóxido e benzaldeído ...... 150

C - Hidrólise de 1-fenil-2-(fenilseleno) 1-buteno: 1-fe nil-3-pentanona.

1. hidrólise efetuada com ācido trifluoroacético . 151

2. hidrölise efetuada com cloreto de mercūrio .... 151

III - Selenetos vinilicos a partir de acetilenos.

A - Preparação de acetilenos dissubstituídos .... 153

B - Adição de selenofenol a acetilenos

1. (fenilseleno) estireno $\mathrm{z} \ldots \ldots \ldots \ldots \ldots \ldots$

2. Adição de selenofenol a acetilenos mono- e

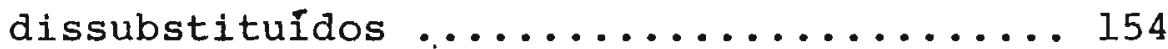

C - Preparação de (fenilseleno) acetilenos ...... 155

D - Redução de (fenilseleno) acetilenos: Selenetos vinílicos $E \ldots \ldots \ldots \ldots \ldots \ldots \ldots \ldots \ldots \ldots$

ESPECTROS DE rmp E iv 157

BIBLIOGRAFIA ..................... 190

ESQUEMAS

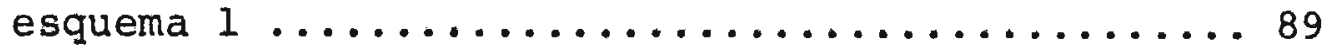

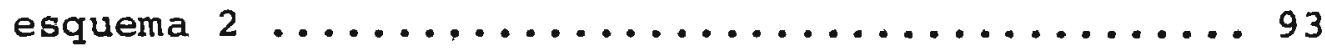


XV.

$\mathrm{pg}$.

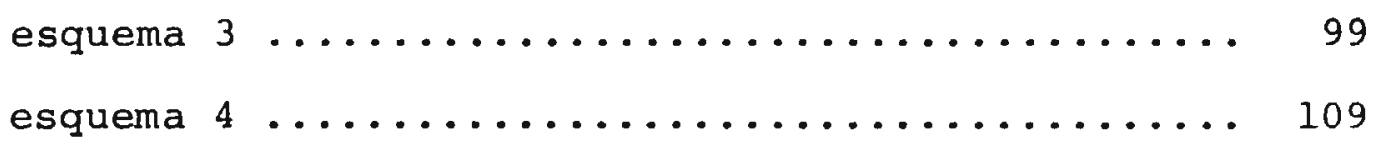

FIGURAS

$\begin{array}{lll}\text { Figura 1-24 } & \text { figura 7-83 } & \text { figura 13-95 } \\ \text { Figura 2-73 } & \text { figura 8-84 } & \text { figura 14-103 } \\ \text { Figura 3-75 } & \text { figura 9-85 } & \text { figura 15-104 } \\ \text { Figura 4-77 } & \text { figura 10-87 } & \text { figura 16-105 } \\ \text { Figura 5-78 } & \text { figura 11-92 } & \text { figura 17-105 } \\ \text { Figura 5-80 } & \text { figura 12-94 } & \text { figura 18-106 }\end{array}$

figura 19-107

figura $20-110$

figura 21-113

figura 22-118

figura 23-120

figura 24-123

figura 25-123

TABELAS

pg •

TABELA I

36

TABELA II

43 
XVI.

pg •

TABELA III 50

TABELA IV 54

TABELA V 56

TABELA VI 64

TABELA VII $\quad 65$

TABELA VIII 69

TABELA IX $\quad 70$

$\begin{array}{ll}\text { TABELA X } & 100\end{array}$

$\begin{array}{ll}\text { TABELA XI } & 101\end{array}$

TABELA XII 111

TABELA XIII 112

TABELA XIV $\quad 116$

$\begin{array}{ll}\text { TABELA XV } & 122\end{array}$ 
$\underline{\text { RESUMO }}$

Tetrahalogenoarilteluratos (IV) foram preparados e suas propriedades químicas e espectrais estudadas. Com base nos espectros Raman e infravermelho foi sugerida a estrutura piramidal quadrada para o ânion complexo.

A reação de Wittig entre (fenilseleno)fosforanas e compostos carbonilicos foi investigada. A reação com cetonas, $B-d \underline{1}$ cetonas e $\beta$-ceto-ēsteres, ao invēs do produto normal de uma reaÇão de Wittig, forneceu compostos carbonilicos $\alpha$-fenilseleno substituidos. o mecanismo desta reação foi estudado.

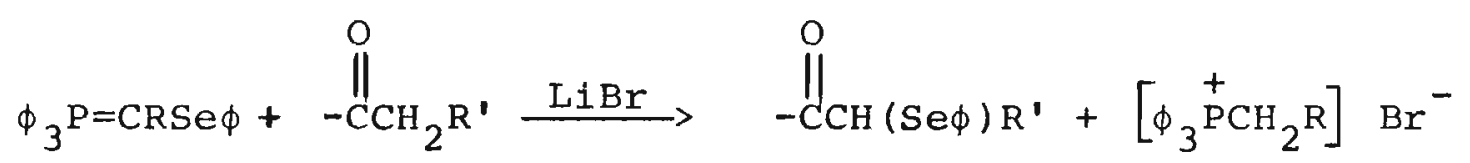

(Fenilseleno) fosfonatos substituidos foram preparados por alquilação do (fenilseleno)metildietilfosfonato, obtido pela reação entre selenofenóxido de sódio e lodometildietilfosfonato.

$$
\begin{gathered}
(\mathrm{EtO}){ }_{2} \mathrm{P}(\mathrm{O}) \mathrm{CH}_{2} \mathrm{I} \\
(\mathrm{EtO})_{2} \mathrm{P}(\mathrm{O}) \mathrm{CH}(\mathrm{Se} \phi) \mathrm{R}
\end{gathered}
$$

Reação do carbânion (fenilseleno) fosfonato com compostos carbonilicos forneceu os selenetos vinilicos esperados com bons rendimentos.

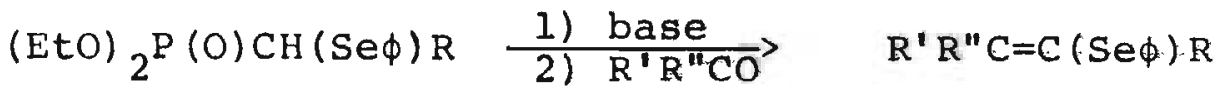


Estudou-se a influência do solvente e da presença de sais de lítio no decurso estérico das reaçöes de (fenilseleno)fosforanas e fosfonatos com aldeídos. Foi realizado um estudo crítico dos modelos propostos na literatura para explicar o decurso estéri co das reações de Wittig e Horner Emmons.

Investigou-se a adição de selenofenol a acetilenos. $\bar{A}$ tem peratura ambiente formou-se exclusivamente o isômero $\mathrm{Z}$, à temperatura elevada $\left(130^{\circ}\right)$ formou-se uma mistura de estereoisômeros.

$$
\mathrm{R}^{\prime} \mathrm{C} \equiv \mathrm{CR} \stackrel{\phi \mathrm{SeH}}{\longrightarrow} \mathrm{R}^{\prime} \mathrm{CH}=\mathrm{C}(\mathrm{Se} \phi) \mathrm{R}
$$

Redução de (fenilseleno) acetilenos, preparados a partir dos acetiletos de lítio correspondentes e brometo de fenilseleneni la, forneceu selenetos vinílicos de configuração $\mathrm{E}$.

$\mathrm{R}^{\prime} \mathrm{C} \equiv \mathrm{CH} \frac{\text { 1) } \mathrm{n}-\mathrm{BuLi}}{\text { 2) } \phi \mathrm{SeBr}} \longrightarrow \mathrm{R}^{\prime} \mathrm{C} \equiv \mathrm{CSe} \phi \stackrel{\mathrm{LAH}}{\longrightarrow} \mathrm{R}^{\prime} \mathrm{CH}=\mathrm{CHSe} \phi$

Selenetos vinílicos nos quais $\mathrm{R} \neq \mathrm{H}$ são hidrolisados facilmente, usando-se ācido trifluoroacético ou cloreto de mercúrio em acetonitrila e água, fornecendo as cetonas correspondentes com bons rendimentos.

$$
R^{\prime} R^{\prime \prime} C=C(\operatorname{Se} \phi) R \underset{\mathrm{HgCl}_{2} / \mathrm{CH}_{3} \mathrm{CN} / \mathrm{H}_{2} \mathrm{O}}{\stackrel{\mathrm{CF}_{3} \mathrm{COOH} \text { ou }}{\mathrm{HgCl}^{\prime}}} \quad \mathrm{R}^{\prime} \mathrm{R}^{\prime} \mathrm{CHCOR}
$$




\section{ABSTRACT}

Tetrahalogenoariltelurates (IV) were prepared and their chemical and spectral properties studied. On the basis of Raman and infrared spectral data, the square pyramidal structure was suggested for the complex anion.

The wittig reaction between (phenylseleno)phosphoranes and carbonyl compounds was investigated. The reaction with ketones, $\beta$-diketones and $\beta$-ketoesters furnished the $\alpha$-phenylseleno substituted carbonyl compound instead of the normal Wittig product. The mechanism of this reaction was studied.

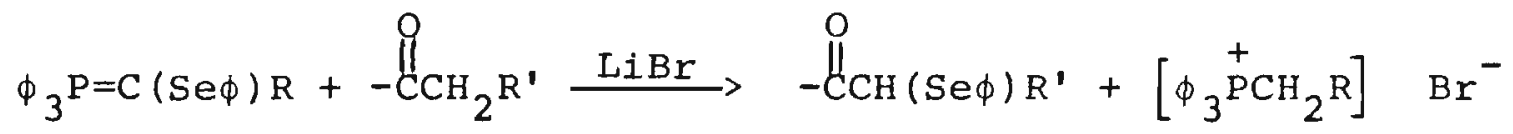

Substituted (phenylseleno)phosphonates were prepared by alkylation of (phenylseleno)methyldiethylphosphonate, the latter obtained by reaction of sodium selenophenoxide with iodomethyldiethylphosphonate.

$$
\begin{aligned}
\left(\text { EtO }{ }_{2} \mathrm{P}(\mathrm{O}) \mathrm{CH}_{2} \mathrm{I} \stackrel{\text { SSeNa }}{\longrightarrow}\right. & \left(\text { EtO }{ }_{2} \mathrm{P}(\mathrm{O}) \mathrm{CH}_{2} \mathrm{Se} \phi \frac{1) \mathrm{BuLi} /-78^{\circ}}{2) \mathrm{RX}}>\right. \\
& \left(\text { EtO }{ }_{2} \mathrm{P}(\mathrm{O}) \mathrm{CH}(\mathrm{Se} \phi) \mathrm{R}\right.
\end{aligned}
$$

Reaction of the (phenylseleno) phosphonate carbanion with carbonyl compounds furnished the expected vinylic selenides in good 
yield.

$\left(\right.$ EtO) ${ }_{2} P(O) C H(\operatorname{Se} \phi) R \quad \frac{\text { l) base }}{2) R^{\prime} R^{\prime \prime} C O} \quad R^{\prime} R^{\prime \prime} C=C(\operatorname{Se} \phi) R$

The influence of the solvent and the presence of lithium salts on the steric course of the reaction of (phenylseleno)phosphoranes and phosphonates with aldehydes was investigated. The results were analysed in accord with the models proposed in the literature to explain the steric course of the wittig and Horner-Emmons reactions.

The addition of selenophenol to acetylenes was investigated. At room temperature there was exclusive formation of the $\mathrm{z}$ isomer; at high temperatures $\left(130^{\circ}\right.$ ) a mixture of stereoisomers was formed.

$$
\mathrm{R}^{\prime} \mathrm{C} \equiv \mathrm{CR} \stackrel{\phi \mathrm{SeH}}{\longrightarrow} \mathrm{R}^{\prime} \mathrm{CH}=\mathrm{C}(\mathrm{Se} \phi) \mathrm{R}
$$

Reduction of (phenylseleno)acetylenes, prepared from the corresponding lithium acetylides and phenylselenenyl bromide, furnished vinylic selenides with the E configuration.

$$
\mathrm{R}^{\prime} \mathrm{C} \equiv \mathrm{CH} \underset{\text { 2) } \phi \mathrm{SeBr}}{\longrightarrow} \quad \mathrm{R}^{\prime} \mathrm{C} \equiv \mathrm{CSe} \phi \stackrel{\mathrm{LAH}}{\longrightarrow} \mathrm{R}^{\prime} \mathrm{CH}=\mathrm{CHSe} \phi
$$

Vinylic selenides with $\mathrm{R} \neq \mathrm{H}$ are easily hydrolised using trifluoroacetic acid or mercurio chloride in aqueous acetonitrile, furnishing the corresponding ketones in good yields.

$$
R^{\prime} R^{\prime \prime} C=C(\operatorname{Se} \phi) R \frac{\mathrm{CF}_{3} \mathrm{COOH} \text { or }}{\mathrm{HgCl}_{2} / \mathrm{CH}_{3} \mathrm{CN} / \mathrm{H}_{2} \mathrm{O}}>R^{\prime} \mathrm{R}^{\prime \prime} \mathrm{CHCOR}
$$


PRIMEIRA PARTE 
Complexos pentacoordenados do telúrio, ao contrário das espécies hexacoordenadas [21], são muito pouco conhecidos. Os pentafluoroteluratos (IV), são conhecidos desde o início do século [21],sendo os mais estáveis [18]. Complexos aniônicos, contendo cloro, bromo ou iodo como ligantes foram preparados apenas recentemente[10], $[17,25,26,27]$. Embora Aynsley e col. tenham relatado sua prepara ção e caracterização em $1957[2,3]$, em trabalho posterior $[4]$ os au tores ratificam seus resultados, aftrmando que as espécies por eles obtidas eram hexa- e não pentacoordenadas.

Ao contrārio das espécies pentacoordenadas contendo apenas halogênio, complexos aniônicos contendo um radical orgânico como ligante são estáveis. O primeiro exemplo dessa classe a ser preparado foi o tetraiodometiltelurato de trimetiltelurônio [31], identificado como tal em 1927 [11]. Em 1967 sua estrutura total foi determinada por difração de raios $x[13]$.

Os estudos dessas espécies aniōnicas ficou sem prosseguimen to atē recentemente, quando, em trabalhos sistemáticos realizados em nosso laboratórto, foram preparados complexos derivados de trihaletos de ariltelūrio $[9,28,29,30]$.

Os trihaletos de ariltelūrio, do contrário de seus análogos alifáticos; são relativamente estáveis. Isso despertou interesse no sentido da preparação de complexos aniônicos pentacoordenados deriva 
dos desses haletos, de fácil obtenção e de interesse estrutural con siderável.

Nesses trabalhos foram preparados vārios tetrahalogenoarilteluratos (IV) de fórmula geral

$$
\left[\mathrm{Y}^{+}\right]\left[\operatorname{ArTeX}_{4}^{-}\right]
$$
Ar-
$\mathrm{X}$
$Y^{+}$
Ref.

$\mathrm{C}_{6} \mathrm{H}_{5}{ }^{-} \quad \mathrm{Cl} \quad \phi_{3} \mathrm{P}^{+} \mathrm{R}, \phi_{3} \mathrm{Te}^{+}, \quad[29,30]$

$\mathrm{Br}$

p-EtoC ${ }_{6} \mathrm{H}_{4}^{-}$

$I$

$$
\begin{aligned}
& \phi_{3} \mathrm{Se}^{+}, \phi_{3} \mathrm{~S}^{+}, \mathrm{R}_{4} \mathrm{~N}^{+} \\
& \phi_{2} \mathrm{I}^{+}, \phi_{4} \mathrm{As}^{+}
\end{aligned}[9,28]
$$

Os complexos podem ser preparados de vārias maneiras:

a) Em solvente orgânico

$$
\operatorname{ArTeX}_{3}+\mathrm{Y}^{+} \mathrm{X}^{-} \stackrel{\text { solvente }}{\longrightarrow}\left[\mathrm{Y}^{+}\right]\left[\operatorname{ArTeX}_{4}^{-}\right] ;
$$

b) Em solução aquosa do ãcido halogenídrico correspondente

$$
\operatorname{ArTeX}_{3}+\mathrm{HX} \longrightarrow\left[\mathrm{H}^{+}\right]\left[\operatorname{ArTeX}_{4}^{-}\right] \stackrel{\mathrm{Y}^{+} \mathrm{X}^{-}}{\longrightarrow}\left[\mathrm{Y}^{\mp}\right]\left[\operatorname{ArTeX}_{4}^{-}\right]+\mathrm{HX}
$$

c) Por reação de troca iōnica

$$
\left[\mathrm{Y}^{+}\right]\left[\operatorname{ArTeX}_{4}^{-}\right] \stackrel{\mathrm{HX}^{\prime} \longrightarrow}{\longrightarrow}\left[\mathrm{Y}^{+}\right]\left[\operatorname{ArTeX}_{4}^{-}\right]+\mathrm{HX}
$$


8.

Provas do carāter iônico dos tetrahalogenoarilteluratos (IV) foram obtidas através de medidas de condutância molar $(64,5-91,9$ $\left.\mathrm{ohm}^{-1} \mathrm{~cm}^{2} \mathrm{~mol}^{-1}\right)$. Os valores se encontram dentro da faixa esperada para eletrólitos $1: 1$ [14]. Outra maneira de demonstrar o caráter iôni co dessas substâncias foi pelo tratamento com resinas de troca iônica, conforme podemos observar no esquema abaixo.

$$
\begin{aligned}
{\left.\left[\mathrm{Y}^{+}\right]\left[\operatorname{ArTeX}_{4}^{-}\right]+\operatorname{Res}^{+}\right] \mathrm{Cl}^{-} \stackrel{\text { solvente }}{\longrightarrow} } & {\left[\operatorname{Res}^{+}\right]\left[\operatorname{ArTeX}_{4}^{-}\right]+\mathrm{Y}^{+} \mathrm{Cl}^{-} } \\
& \mid\left[\mathrm{Y}^{+}\right] \mathrm{X}^{-} / \text {solvente } \\
& {\left.\left[\mathrm{Y}^{\prime}\right]\left[\operatorname{ArTeCl}_{4}^{-}\right]+\mathrm{Res}^{+}\right] \mathrm{X}^{-} }
\end{aligned}
$$

Por eluição da resina com uma solução do tetrahalogenoarilte lurato (IV) obtivemos o sal de -ônio correspondente ao cátion do complexo, ficando o ànion telurato retido na resina. Tratamento da mesma com grande excesso de um sal de -ônio deslocou o ânion sob a forma do tetrahalogenoariltelurato (IV) correspondente. 
SOBRE A ESTRUTURA DOS ANIONS COMPLEXOS DO TELORIO (IV)

Os elementos da familia VI b apresentam caráter essencialmente covalente e não metálico, com exceção do polônio e, em menor extensão, do telūrio. A medida em que avançamos na sērie $\mathrm{S}, \mathrm{Se}, \mathrm{Te}$, Po, verificamos um aumento na tendência em fórmax complexos aniônicos. O número de coordenação característico do telúrio é seis. A estrutura dos complexos aniônicos do telūrio com esse número de coordenação desperta grande interesse, visto constituirem, juntamen te com o ânton $\operatorname{sex}_{6}^{2-}[8]$ e $\operatorname{sbBr}_{6}^{2-}[1,20]$, exceção à teoria das repulsões entre os pares de elétrons da camada de valência.

De acordo com essa teoria, a forma de uma molēcula ou ion depende basicamente do número de pares de elétrons ligantes ou não ligantes da camada de valência do átomo central, não sendo influenciada consideravelmente pela natureza dos ligantes $[15,16]$.

Desse modo, deveríamos esperar para o ion Tex ${ }_{6}^{2-}$ uma estru tura octaédrica distorcida, com um par de elétrons num dos vértices $[16]$.

No entanto, todos os estudos sobre o ânion Tex ${ }_{6}^{2-} \quad(\mathrm{X}=\mathrm{C} 1$, $\mathrm{Br}, \mathrm{I})$, contrariamente ao esperado, sugerem para o mesmo uma estrura octaédrica regular $[1,5,6,8,19,24]$.

A explicação däa por Gillespie [15] é que, quando temos um nümero de coordenação elevado e ligantes volumosos, a influêncla da repulsão entre os mesmos na estereoquímica da molécula se torna pronun 
ciada. Os ātomos de bromo se encontram muito próximos uns dos outros, forçando desse modo o par de elétrons não ligantes a se acomodar numa camada mais interna. Com isso os ligantes podem se dis por num arranjo regular em torno do átomo de telúrio.

o ânion $\operatorname{TeX}_{5}^{-}$com seis pares de elétrons (cinco ligantes e um não ligante) em torno do átomo de telúrio deve possuir um arran jo octaédrico, com o par de elétrons não ligantes num vértice e os ligantes dispostos de modo a formar uma pirāmide de base quadrada. Apenas recentemente apareceram na literatura dados sobre a estrutura dessas espēcies. Espectros vibracionais dos ànions $\mathrm{TeF}_{5}^{-}[18], \mathrm{Te}(\mathrm{OH}) \mathrm{F}_{4}^{-}[23], \mathrm{TeCl}_{5}^{-}[26],[10], \mathrm{TeBr}_{5}^{-}[26], \mathrm{TeCl}_{2} \mathrm{Br}_{3}^{-}$ $[10,26], \mathrm{TeClBr}_{4}^{-}, \mathrm{TeCl}_{3} \mathrm{Br}_{2}^{-}[26]$ e $\mathrm{CH}_{3} \mathrm{TeCl}_{4}^{-}[7]$ são relatados,mas foi possível atribuir a estrutura piramidal quadrada apenas ao ānion $\mathrm{TeF}_{5}^{-}$. Nas outras investigações os resultados não são conclusivos.

Estudos de difração de raios $x$ levaram à conclusão de que os íns $\mathrm{CH}_{3} \mathrm{TeI}_{4}^{-}[13]$, e $\mathrm{TeF}_{5}^{-}$[12] possuem a forma de pirâmide de base quadrada.

Espera-se que o ânion $\mathrm{ArTeX}_{4}^{-}$tambēm apresente essa estrutura, com os halogênios na base e o grupo arila no äpice, resultan do uma simetria $\mathrm{C}_{4 \mathrm{v}}$.

12 modos normais de vibração são esperados para o ânion - 
$\operatorname{ArTeX}_{4}^{-}$exibindo essa simetria $[9]$. No entanto, os modos correspondentes ao estiramento $D_{1}(\mathrm{Te}-\mathrm{C})\left(\mathrm{A}_{1}\right)$ e à deformação ${ }_{8}(\mathrm{C}-\mathrm{Te}-\mathrm{X})(\mathrm{E})$ não foram identificados, devido, talvez, ao fato destas vibrações em frequências baixas originarem absorções ou espalhamentos de frä ca intensidade. Dessa maneira, 9 modos normais são esperados. To dos são ativos no Raman, ao passo que apenas' 6 são ativos no infravermelho.

Comentaremos os espectros Raman e infravermelho dos tetracloroarilteluratos (IV), dos quais possuimos maior número de dados.

No espectro Raman do composto em solução observamos uma banda fortemente polarizada na região de $286 \mathrm{~cm}^{-1}$. No espectro dos compostos em estado sōlido, esta banda aparece na mesma região com intensidade forte, enquanto que no espectro infravermelho ela aparece como um ombro ou como uma banda fraca, podendo ser atribuí da ao estiramento simētrico $D_{2}(\mathrm{Te}-\mathrm{Cl})\left(\mathrm{A}_{1}\right)$. Nos ânions com ligante $\mathrm{Ar}=\mathrm{p}$-EtOC ${ }_{6} \mathrm{H}_{4}$-este modo aparece em fréquências mais baixas, por volta de $278 \mathrm{~cm}^{-1}$. Salientamos que bandas na região de 283$256 \mathrm{~cm}^{-1}$ foram observadas no espectros Raman e infravermelho do ânion $\mathrm{CH}_{3} \mathrm{TeCl}_{4}^{-}$, sendo a banda em $283 \mathrm{~cm}^{-1}$, do espectro Raman em solução igualmente polarizada $[7]$. O estiramento antissimétrico $\nu_{7}(\mathrm{Te}-\mathrm{Cl})(\mathrm{E})$ è observado no espectro infravermelho na região de - 
$265 \mathrm{~cm}^{-1}$ como uma banda de intensidade média ou forte. No espectro Raman este modo se apresenta como uma banda de intensidade mé dia ou como um ombro e, em alguns casos, não aparece. A banda em $250 \mathrm{~cm}^{-1}$ no espectro Raman poderia ser atribuida ao estiramento ${ }_{4}$ $(T e-C l)\left(B_{1}\right)$, uma vez que não observamos banda correspondente no es pectro infravermelho. O ombro observado em àlguns casos no espec tro infravermelho poderia ser explicada pela pequena distorção da simetria $\mathrm{C}_{4 \mathrm{v}}$, causada pelo grupamento aromático axial [23].

Examinando as figuras 1 e 2 notamos a existência de três bandas em frequēncias baixas, na região de $150 \mathrm{~cm}^{-1}, 130 \mathrm{~cm}^{-1} \mathrm{e}$ $95 \mathrm{~cm}^{-1}$. Atribuímos tentativamente estas bandas à deformação $\mathrm{Cl}-$ Te-Cl, respectivamente $\nu_{5}, \nu_{6}$ e $\nu_{3}$. Estas atribuições foram feitas por analogia às efetuadas para as deformações de ângulo correspondentes no ânion $\operatorname{TeCl}_{6}^{2-}[5,10,19]$ e $\operatorname{TeCl}_{5}^{-}[26]$. 


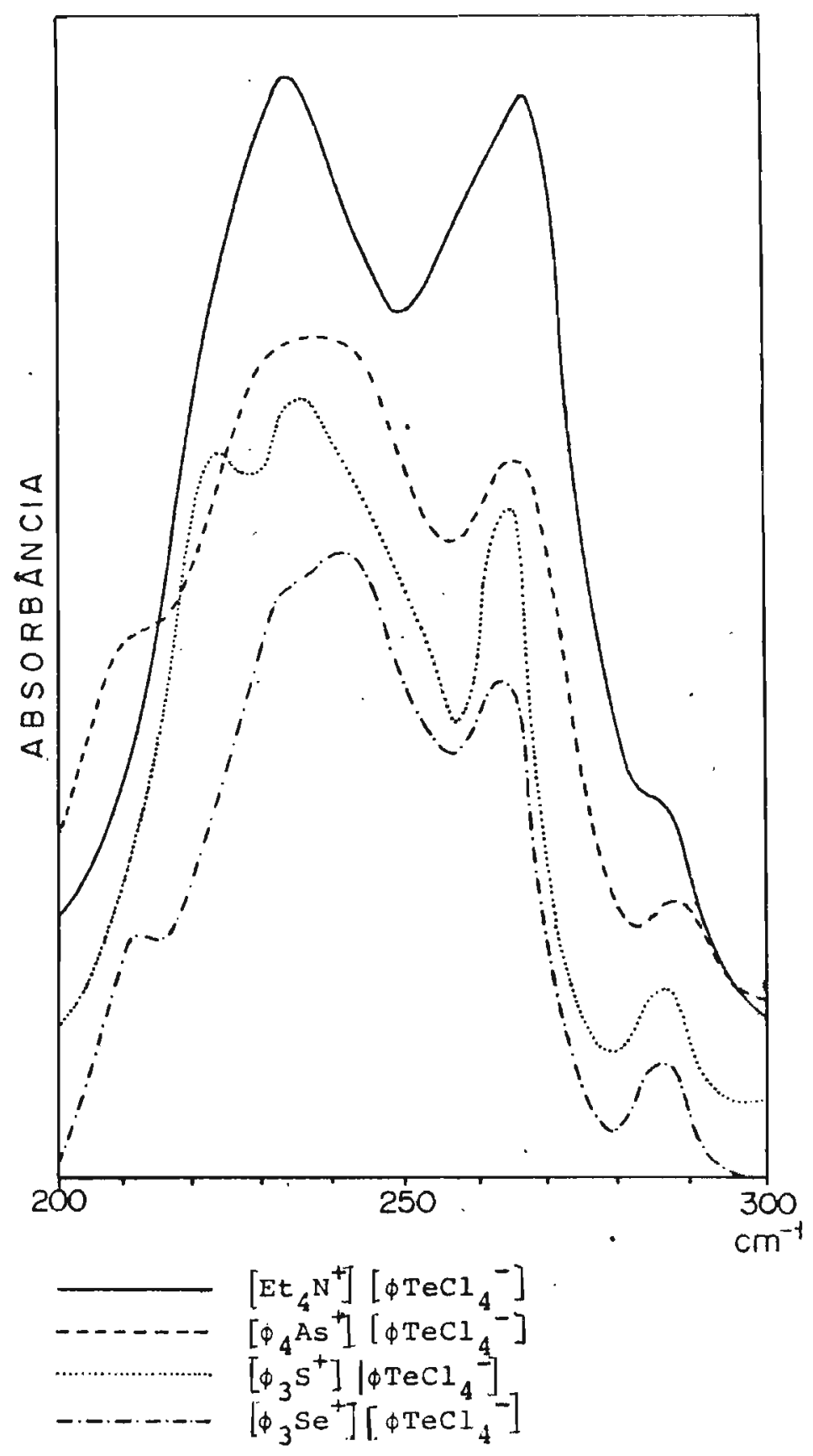

FIGURA 1.

Espectros no infravermelho afastado dos tetracloroarilteluratos (IV) em estado sólido (ver p 125). 


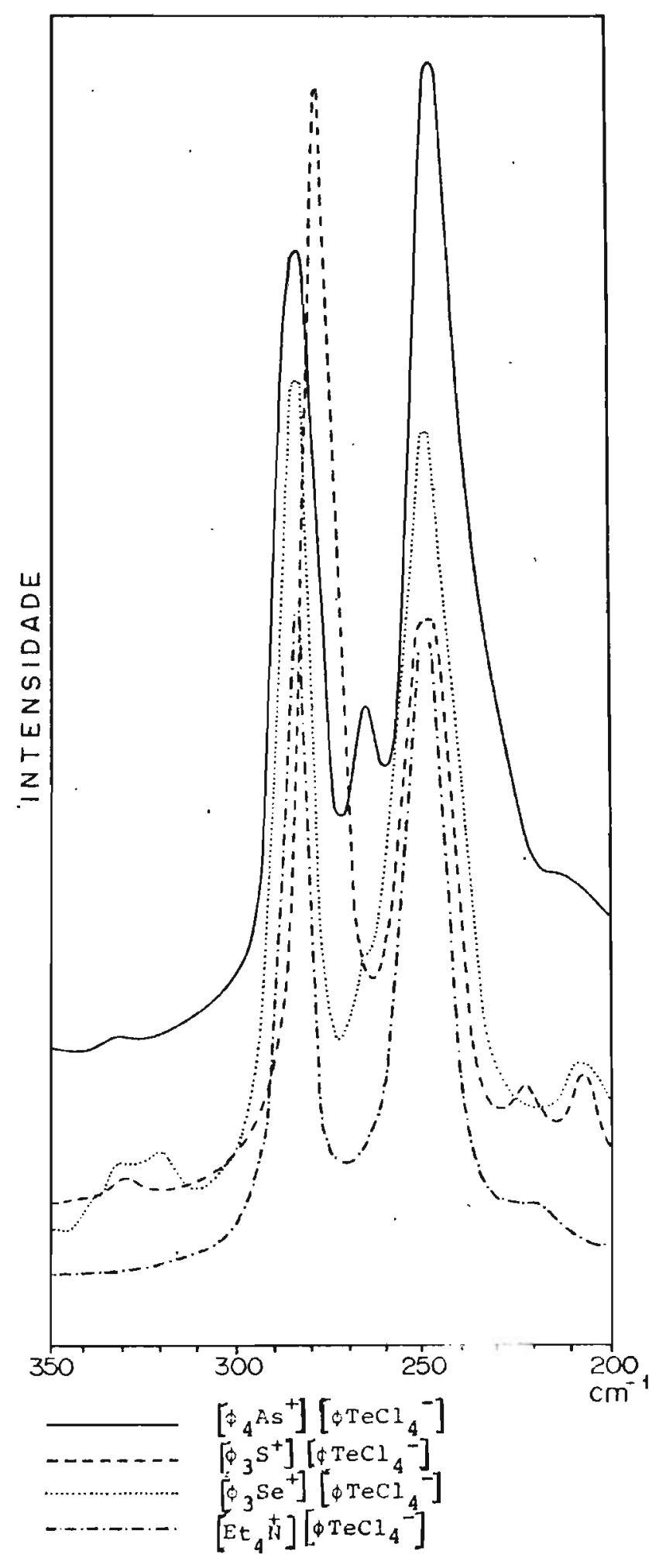

14 .

FIGURA 2 .

Espectros Raman dos tetracloroarilteluratos (IV) em estado sōlido (ver p 125 ). 


\section{BIBLIOGRAFIA}

1. Adams, C.J. e Dawns, A.J., Chem. Comm., 1699 (1970).

2. Aynsley, E.E. e Campbel1, W.A., J. Chem. Soc., 832 (1957).

3. Aynsley e Hazell, A.C., Chem. and Ind., 611 (1963).

4. Aynsley e Hazel1, A.C., Chem. and Ind., 1842 (1963).

5. Barrowcliffe, T., Beattie, I.R., Day, P. e Livingston, K., J. Chem. Soc., (A), 1810 (1967).

6. Beattie, I.R. e Chudszynska, J. Chem. Soc. (A), 984 (1967).

7. Beattie, I.R., Stokes, F.C. e Alexander, E.E., J. Chem. Soc. (Dalton), 465 (1973).

8. Brown, I.D., Canad. J. Chem., 42 2758 (1964).

9. Comasseto, J.V., "Novas Espëcies Aniônicas do Telúrio (IV)", Dissertação de Mestrado apresentada ao Instituto de Química da Universidade de São Paulo - São Paulo, 1975.

10. Creighton, J.A. e Green, J.H., S., J. Chem. Soc. (A), 808 $(1968)$.

11. Drew, H.D.K., J. Chem. Soc., 560 (1929).

12. Edwards, A.J. e Mouty, M.A., J. Chem. Soc. (A), 703 (1969).

13. Einstein, F., Trotter, J. e Wilisston, C., J. Chem. Soc. (A), 2018 (1967). 
14. Geary, W.J., Coord. Chem. Rev., 7, 81 (1971).

15. Gillespie, R.J., J. Chem. Educ., 47, 18 (1970).

16. Gillespie, R.J., Nyholm, R.S., Quart. Rev., 11, 338 (1957).

17. Goyal, K., Paul, R.C., e Sandhu, S.S., J. Chem. Soc., $323(1959)$.

18. Greenwood, N.N., Sarma, A.C., Straughan, B.P., J. Chem. Soc. (A), 1561 (1968).

19. Hendra, P.J. e Jovic, Z., J. Chem. Soc. (A), 600 (1968).

20. Lowton, S.L., Jacobston, R.A., Inorg. Chem., 5, 743 (1966).

21. Mellor, J.W., "A Compreensive Treatise of Inorganic and Theoretical Chemistry", vol. XI, Longmans, London, 1948, p 98 .

22. Milne, J.B. e Moffett, D., Inorg. Chem., 12, 2240 (1973).

23. Milne, J.B. e Moffett, D., Inorg: Chem., 13, 2750 (1974).

24. Nakamura, D., Ito, K. e Kubo, M., J.'Ame. Chem. Soc., 84, $163(1962)$.

25. Ozin, G.A. e Vander Voet, A., Canad. J. Chem., 49, 704 (1971).

26. Ozin, G.A. e Vander Voet, A., J. Mol. Structure, 13, 435 (1972) .

27. Paul, R.C., Chander, K. e Singh, G., J. Indian. Chem. Soc., $\underline{35}, 869$ (1958). C.A. $\underline{53}, 17746$ (1959). 
28. Petragnani, N., Comasseto, J.V. e Kawano, Y., J. Inorg. Nucl. Chem. 38, 607 (1976).

29. Petragnani, N., Torres Castellanos, L., Wynne, K.J. e Maxwell, W., J. Organometal. Chem., 55, 295 (1973).

30. Torres Castellanos, L., "Novas Espēcies Aniōnicas do Telürio (IV) ", Dissertação de Mestrado apresentada ao Instituto de Química da Universidade de São Paulo - São Paulo, 1972.

31. Vernon, R.H., J. Chem. Soc., 86 (1920). 
18.

SEGUNDA PARTE

SELENETOS VINILICOS 


\section{CAPITULO I}

\section{Introdução}

A síntese e as aplicações de selenetos vinílicos foram até agora objeto de poucos estudos.

o primeiro método desenvolvido para a obtenção de selenetos vinílicos foi a adição de selenóis a acetilenos, desenvolvido por Chierici e Montanari em $1956[27,39]$.

$$
\mathrm{RC} \equiv \mathrm{CR}^{\prime} \stackrel{\mathrm{RSeH}}{\longrightarrow} \mathrm{RCH}=\mathrm{C}(\mathrm{SeR}) \mathrm{R}^{\prime}
$$

A seguir outros autores, principalmente os russos, efetua ram um estudo mais completo da reação $[4,8,39,40,52,53,118]$. Todos os trabalhos relatam a formação preferencial do isōmero $\mathrm{z}$.

Recentemente quatro novos métodos de preparação de selene tos vinilicos foram descritos.

Alil fenil seleneto, quando aquecido com etóxido de sódio em etanol, rearranja fornecendo 1-propenil fenilseleneto $[2,102]$. Esta reação era conhecida para sulfetos alílicos $[110]$, tendo sido adaptada para selenetos por Krief e col.

$$
\mathrm{CH}_{2}=\mathrm{CH}-\mathrm{CH}_{2}-\mathrm{Se} \phi \quad \text { EtONa } / \mathrm{EtOH} \longrightarrow \mathrm{CH}_{3}-\mathrm{CH}=\mathrm{CHSe} \phi
$$

Reich e Chow [81] efetuaram a adição de $\alpha$-lítio selenetos 
a compostos carbonilicos, obtendo $\alpha$-hidroxiselenetos, os quais são convertidos por eliminação em selenetos vinílicos,
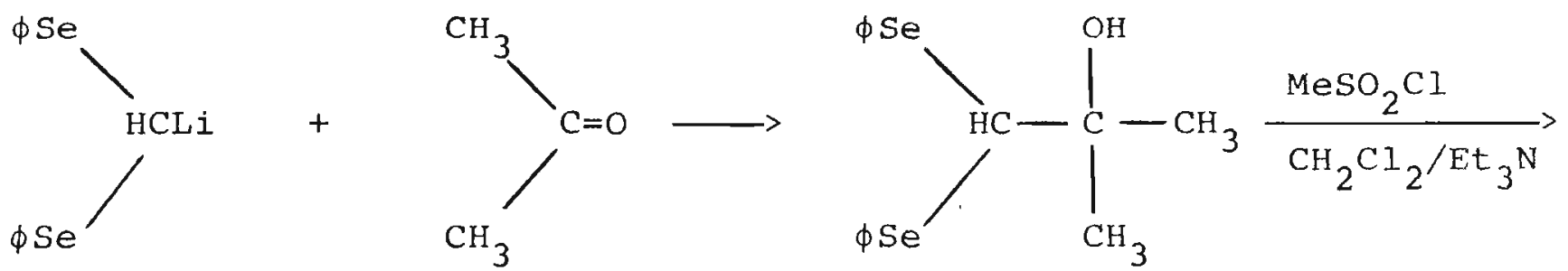

$\phi \mathrm{SeCH}=\mathrm{C}\left(\mathrm{CH}_{3}\right)_{2}$

Um método semelhante foi desenvolvido por Krief e col. [102]. Adição de selenofenol a compostos carbonílicos fornece selenocetais que, ao reagir com iodeto de metila em DMF, formam o seleneto vinílico correspondente.<smiles>[R]C(=O)C([R])[R]</smiles>

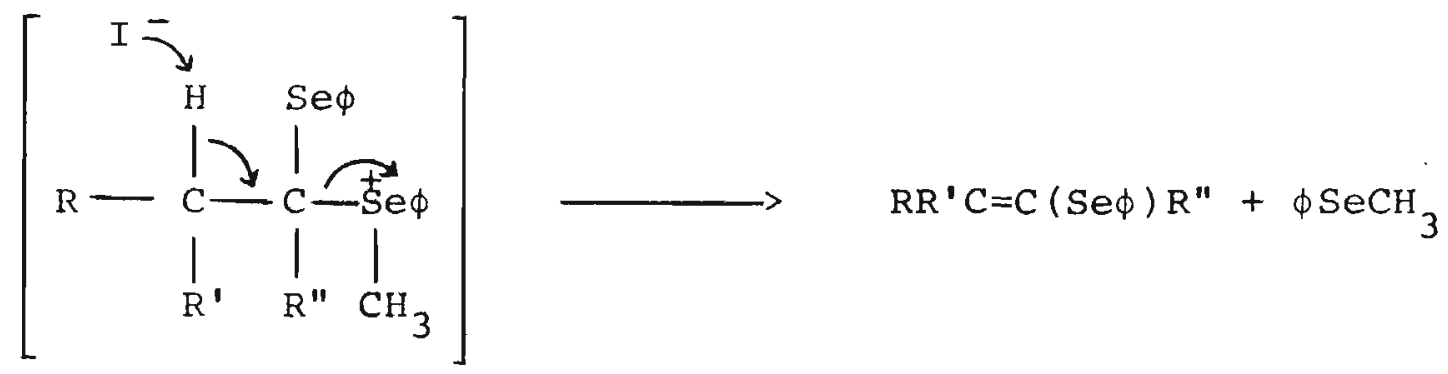


Um quarto método, desenvolvido por Raucher [78], consiste na adição de brometo de fenilselenenila a olefinas, seguida de eliminação. Esse método, no entanto, não é regioespecífico, podendo,em alguns casos, fornecer misturas de olefinas isômeras.

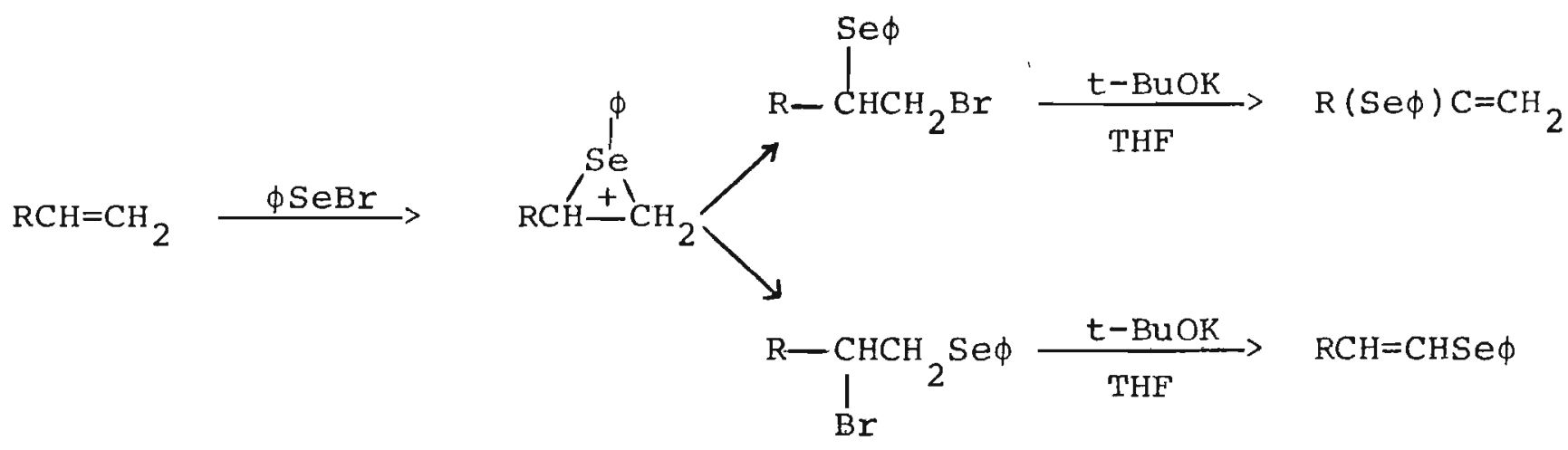

Neste trabalho apresentamos a síntese de selenetos vinilicos através das reações de Wittig e Horner-Emmons.

$$
\begin{aligned}
& \phi_{3} \mathrm{P}=\mathrm{C}(\mathrm{Se} \phi) \mathrm{R}+\mathrm{R}^{\prime} \mathrm{R}^{\prime \prime} \mathrm{CO} \longrightarrow \mathrm{R}^{\prime} \mathrm{R}^{\prime \prime} \mathrm{C}=\mathrm{C}(\mathrm{Se} \phi) \mathrm{R}+\phi_{3} \mathrm{PO} \\
& (\mathrm{EtO})_{2} \mathrm{P}(\mathrm{O}) \mathrm{C}(\operatorname{Se} \phi) \mathrm{R}+\mathrm{R}^{\prime} \mathrm{R}^{\prime \prime} \mathrm{CO} \longrightarrow \mathrm{R}^{\prime} \mathrm{R}^{\prime \prime} \mathrm{C}=\mathrm{C}(\mathrm{Se} \phi) \mathrm{R}+\text { (EtO) }_{2} \mathrm{PO}_{2}{ }^{-}
\end{aligned}
$$

Alēm desses métodos, desenvolvemos um estudo sistemático sobre a adição de selenofenol a acetilenos, estendendo e ratificando resultados já existentes.

$$
\mathrm{RC} \equiv \mathrm{CR}^{\prime} \stackrel{\phi \mathrm{SeH}}{\longrightarrow} \mathrm{RCH}=\mathrm{C}(\mathrm{Se} \phi) \mathrm{R}^{\prime}
$$

Um quarto mētodo de preparação de selenetos viníl1cos, a 
redução de selenetos acetilênicos, tambēm forneceu bons resultados. $\mathrm{RC} \equiv \mathrm{CSe} \phi \frac{\mathrm{LAH}}{\mathrm{THF}}>\mathrm{RCH}=\mathrm{CHSe} \phi$

Como a parte principal de nosso trabalho trata da obtenção de selenetos vinílicos por intermédio das reações de wittig e Horner-Emmons, apresentaremos a seguir um apanhado geral sobre as mesmas, dando um enfoque especial ao problema da estereoquímica. 


\section{CAPITULO II}

\section{REAÇÕES DE WITTIG}

\section{A. Fosforanas}

Reação entre uma fosfina terciária (geralmente trifenilfos fina) e um haleto de alquila, fornece um sal de fosfônio.

$$
\mathrm{R}_{3} \mathrm{P}+\mathrm{R}^{\prime} \mathrm{CH}_{2} \mathrm{X} \longrightarrow\left[\mathrm{R}_{3} \mathrm{PCH}_{2} \mathrm{R}^{\prime}\right] \mathrm{X}^{-}
$$

Os sais de fosfônio são suficientemente ācidos para serem desprotonados por uma base conveniente, formando uma fosforana*, a qual pode ser representada como um híbrido de ressonância entre duas estruturas canōnicas $[58]$.

$$
\left[\mathrm{R}_{3}^{+}{ }_{\mathrm{PCH}} \mathrm{R}^{\prime}\right] \mathrm{X}^{-} \stackrel{\mathrm{B}}{\longrightarrow} \mathrm{R}_{3}^{+} \mathrm{P}^{-}-\overline{\mathrm{CHR}}^{\prime} \longleftrightarrow \mathrm{R}_{3} \mathrm{P}=\mathrm{CHR}^{\prime}
$$

A força da base necessāria para efetuar a desprotonação de pende fundamentalmente da natureza de $R^{\prime}$. Qualquer substituinte ca paz de deslocalizar carga negativa do carbono facilitará a remoção do próton. Assim, carbonato de sódio é base suficientemente forte

* o termo ilida tambēm é utilizado. Neste texto utilizaremos apenas o termo fosforana. 
para transformar o sal de bisfosfónio na fosforana correspondente $[112]$.

$$
\left[\left(\phi_{3}^{\mathrm{P}}\right)_{2} \mathrm{CH}_{2}\right] \mathrm{Br}^{-} \stackrel{\mathrm{Na}_{2} \mathrm{CO}_{3}}{\longrightarrow} \quad \stackrel{+}{\left(\phi_{3}\right)_{2}}{ }_{2}^{-}
$$

Já os sais de carboximetiltrifenilfosfônio requerem tratamento com hidrōxido de potássio para se transformar em fosforanas[112].

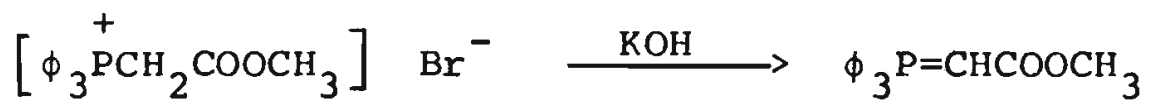

Essas fosforanas são estabilizadas não só pela sobreposição do orbital p do carbono com os orbitais $3 d$ do fósforo, mas também pela conjugação com o agrupamento $R^{\prime}$, podendo ser isoladas e armazenadas para uso posterior.

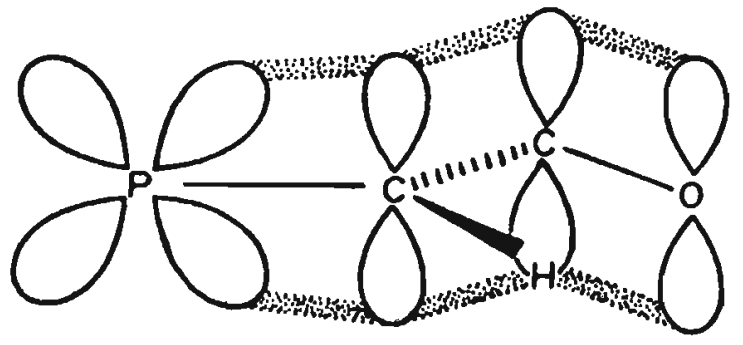

Fosforana estabilizada

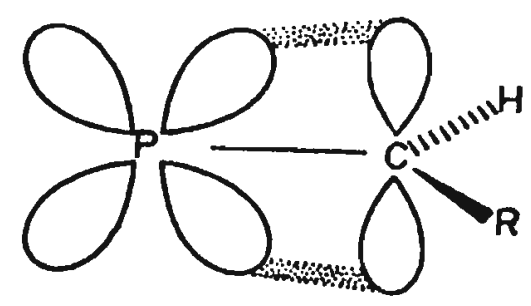

Fosforana não estabilizada

Figura 1 
$\mathrm{Na}$ ausência de grupos capazes de estabilizar cargas negativas, apenas uma base muito forte, geralmente alquil ou fenil lítio, pode efetuar a desprotonação.*

$$
\left[\phi_{3}^{+} \mathrm{PCH}_{3}\right] \quad \mathrm{Br}^{-} \stackrel{\mathrm{BuLi}}{\longrightarrow} \quad \phi_{3} \mathrm{P}=\mathrm{CH}_{2}+\mathrm{LiBr}
$$

Dessa falta de estabilidade resultam propriedades importantes, que serão discutidas mais tarde: as fosforanas não estabilizadas são muito reativas e, embora já tenham sido isoladas em es tado sōlido $[92,95,96,99]$, são geralmente utilizadas "in situ" pa ra reações posteriores. Como consequência teremos sais de lítio na mistura de feação (originados na reação ācido-base), o que irá influir na estereoquímica do produto.

B. Reação entre Fosforanas e Compostos Carbonílicos - Reação de Wittig

Embora conhecidas desde $1894^{\cdot}[62]$, as fosforanas só despertaram interesse após 1953, quando wittig as introduziu como rea gentes para obtenção de olefinas a partir de compostos carboníli-

* Desprotonação, usando hidróxido de sōdio em sistemas bifásicos, tem sido efetuada com sucesso $[30,115]$. 
$\cos [120]$

A reação de Wittig pode ser considerada como um ataque da fosforana à carbonila, formando um intermediārio denominado betaina

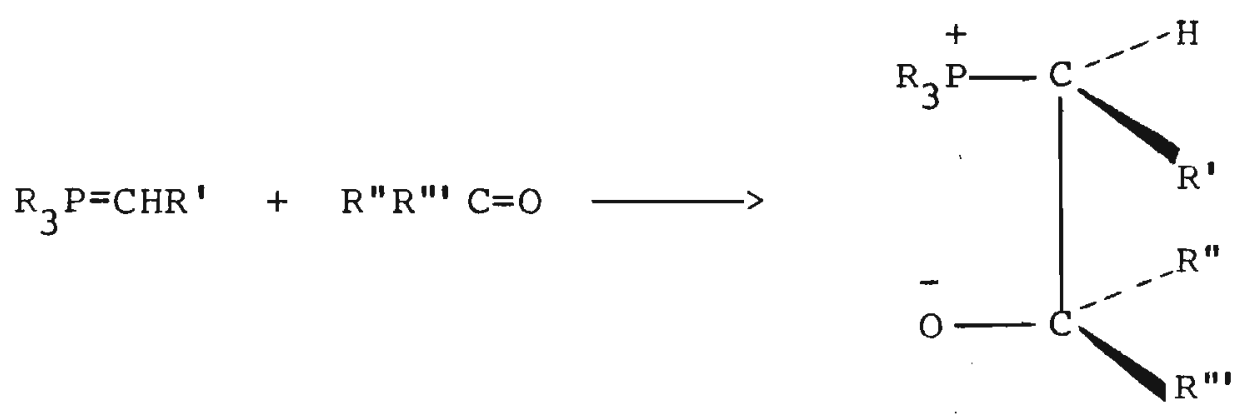

A betaina decompõem-se, supostamente através de um estado de transição cíclico de quatro membros, formando uma olefina e o fosfinōxido correspondente.

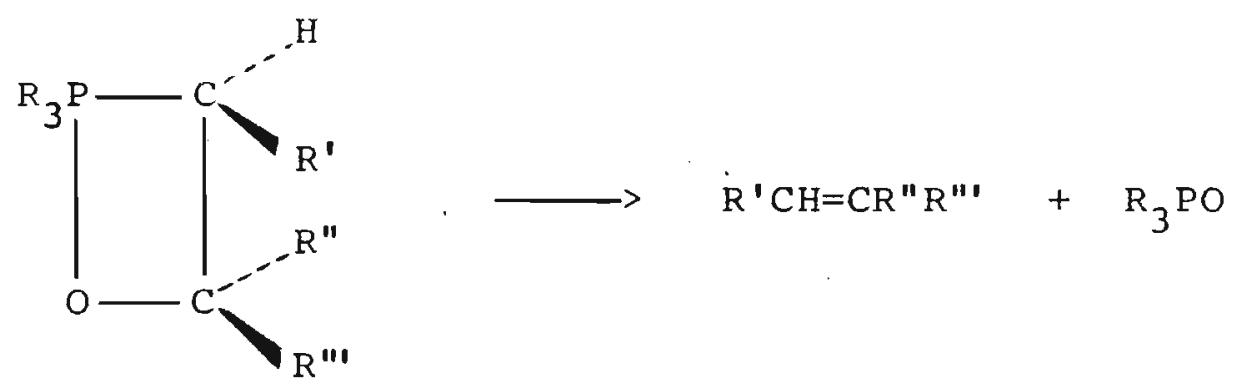

Como podemos ver pela sequência reacional acima, a posição da dupla ligação carbono-carbono é inequívoca, o que não ocorre no método antigo de transformar compostos carbonilicos em olefinas (reação de Grignard seguida de desıdratação), o qual, usualmente, - 
fornece misturas de isômeros.

Outra grande vantagem desta reação é ser efetuada em meio bāsico e em condições suaves, constituindo, portanto, um excelente método de síntese de olefinas sensíveis.*

Apesar da especificidade estrutural, a reação de Wittig pode fornecer mais de um isômero, caso o produto exiba isomeria cis-trans. No início dos estudos sobre a reação acreditava-se que a mesma não fosse estereoseletiva, mas atualmente, como veremos no capítulo $V$, existem maneiras de controlar seu decurso estérico.

Apesar de sua grande versatilidade, existem limitações à reação de Wittig $[24]$, conforme descreveremos mais adiante. Essas limitações levaram ao desenvolvimento de formas modificadas da rea ção, as quais envolvem o uso de outros compostos de fósforo capa zes de formar carbânions estabilizados, semelhantes às fosforanas. Os mais importantes desses reagentes são os fosfinōxidos e os fosfonatos, utilizados pela primeira vez na sintese de olefinas por Horner $[43]$ e por Wadsworth e Emmons [119.].

E geralmente aceito $[24]$ que a reação do carbānion fosfinóxido ou fosfonato com compostos carbonílicos ocorra de maneira -

* Para obter maiores detalhes sobre as condições, aplicações e li mitações da reação de Wittıg ver ref. $[19,26,44,49,59,112,113]$. 
anāloga à reação de Wittig, levando à olefina por eliminação de foṣ fato.

$$
\begin{aligned}
& \mathrm{R}_{2} \mathrm{P}(\mathrm{O}) \mathrm{CH}_{2} \mathrm{R}^{\prime} \frac{\text { l) base }}{\text { 2) } \mathrm{R}^{\prime \prime} \mathrm{R}^{\prime \prime} \mathrm{C}=\mathrm{O}}> \\
& \mathrm{R}^{\prime} \mathrm{CH}=\mathrm{CR} \mathrm{R}^{\prime \prime \prime}+ \\
&
\end{aligned}
$$
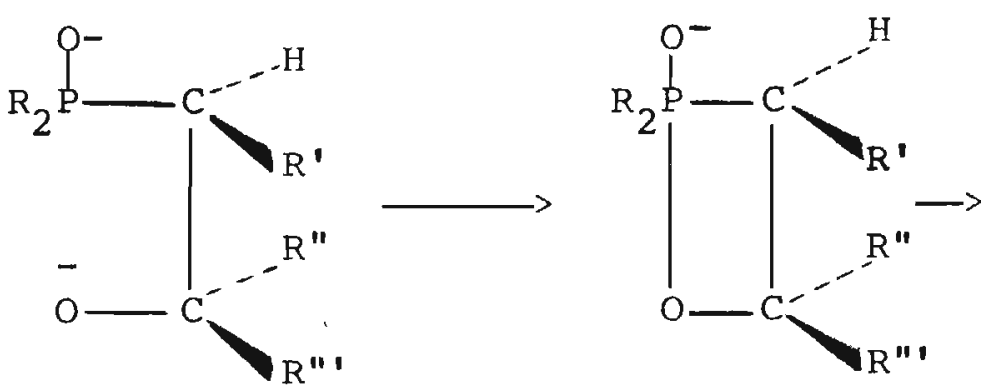

A força da base utilizada na formação do carbânion depende da natureza de $R^{\prime}$. Quando $R^{\prime}$ é um agrupamento capaz de estabilizar cargas negativas, hidreto de sódio é geralmente utilizado. Quando $R^{\prime}$ è um grupo alquila ou um agrupamento fracamente estabilizante,já se faz necessāria uma base mais forte, geralmente alquil ou fenil litio. *

A principal vantagem da reação de Horner-Emmons sobre a reação de Wittig é a maior reatividade dós fosfinóxidos e fosfonatos comparada com a das fosforanas $[24,49]$ como jā foi dito, a estạ bilização do carbânton nas fosforanas se dá pela sobreposição do or bital p do carbono com os orbitais $3 d$ do fósforo. Nös fosfinóxidos

* Sobre as condições experimentais para efetuar a reação de Horner-Emmons ver ref. [24]. Recentemente a desprotonação de fosfona tos fracamente ācidos foi efetuada com hidróxido de sódio, utili zando-se catalisadores de transferência de fase $[10,30,63,64]$. 
e fosfonatos esse entrosamento é menor, tendo em vista a ocorrência de "back donattion" do oxigênio ao fósforo [49], resultando daí uma menor estabilidade e, consequentemente, maior reatividade do carbānion.

Fosfinóxidos e fosfonatos não fornecem olefina pela reação de Horner-Emmons se não possuirem, ligado ao carbono em a ao fósforo, um agrupamento capaz de estabilizar carga negativa. Neste caso forma-se apenas um intermediārio semelhante à betaina, o qual, no entanto, é estável, isto é, não origina a olefina por eliminação de fosfato.

$$
\mathrm{R}_{2} \mathrm{P}(\mathrm{O}) \mathrm{CH}_{2} \mathrm{R}^{\prime} \frac{\text { 1) base }}{\text { 2) } \mathrm{R}^{\prime \prime} \mathrm{R} \text { ' } \mathrm{C}=\mathrm{O}}
$$
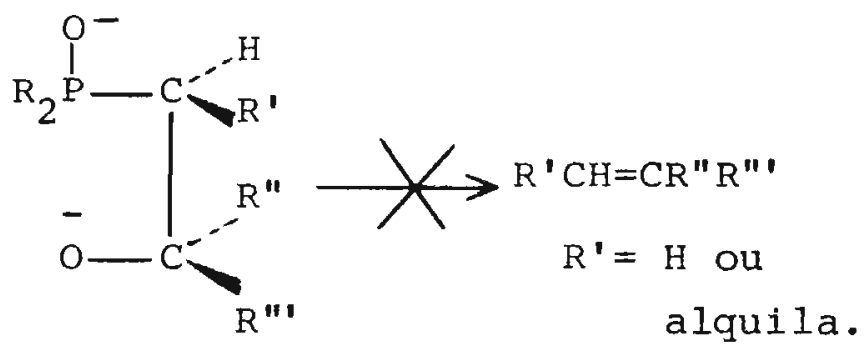

Uma explicação para esse fato é que ocorre uma elevada con centração de carga negativa no carbono em $\alpha$ ao fósforo no estado de transição, dificultando a eliminação $[24]^{\circ}$.

Cálculos teóricos [111] sugerem que a ligação fōsforo-carbono é rompida antes da ligação carbono-oxigênio, o que leva a uma espécie com caräter de carbânion. Isso explicaria porque um grupo atraente de elētrons facilita a decomposição do intermediārio em olefina e no fosfato correspondente. 

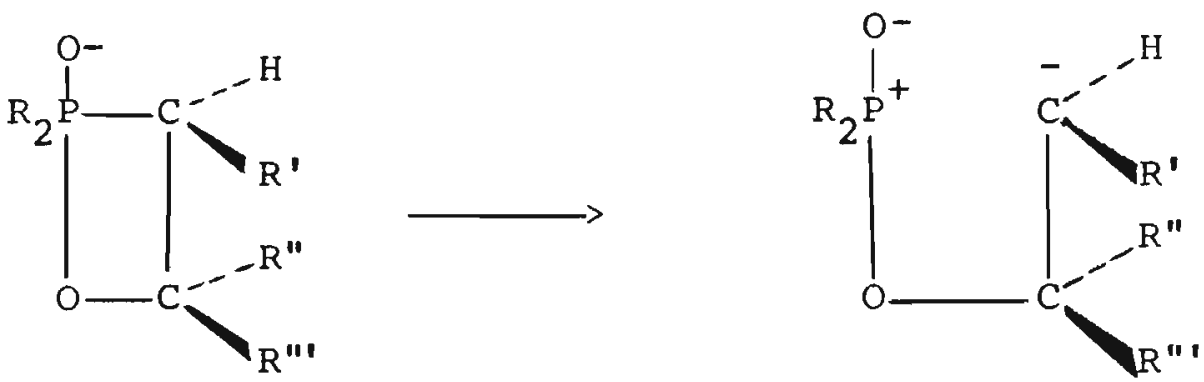

\section{Transilidação}

Sais de fosfônio, como jā vimos, funcionam como ācidos de Bronsted, sendo as fosforanas suas bases conjugadas.

$$
\left[\mathrm{R}_{3}{ }^{+} \mathrm{PCH}_{2} \mathrm{R}^{\prime}\right] \quad \mathrm{x}^{-} \underset{+\mathrm{HX}}{\stackrel{-\mathrm{HX}}{\rightleftharpoons}} \quad \mathrm{R}_{3} \mathrm{P}=\mathrm{CHR} \mathrm{CH}^{\prime}
$$

A força ācido-base dos sais de fosfónio e das fosforanas correspondentes depende principalmente do substituinte $R^{\prime}$. Grupos atraentes de elétrons aumentam a acidez do sal de fosfônio e diminuem a basicidade da fosforana.

Em vista dessa relação ácido-base entre sal de fosfônio e fosforana, podemos escrever o seguinte equilíbrio

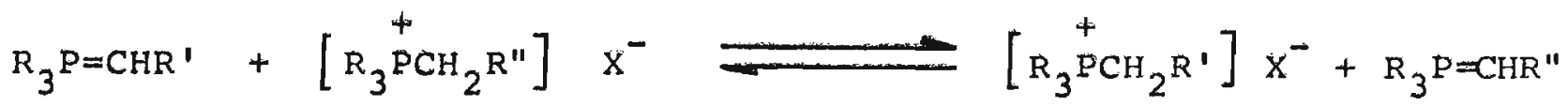

A posição de equilíbrio será determinada pela natureza - 
dos grupos $R^{\prime}$ e $R^{\prime \prime}$. Se a diferença de acidez entre o primeiro e o segundo sal de fosfônio, ou a diferença de basicidade entre a primeira e a segunda fosforana, for muito pronunciada, o equilibrio sempre favorecerá a formação da fosforana menos básica e do sal de fosfônio menos ácido.

ex.:

$$
\phi_{3} \mathrm{P}=\mathrm{CH}_{2}+\left[\phi_{3}^{+}{ }^{+} \mathrm{PCH}_{2} \mathrm{CO} \phi\right] \mathrm{Br}^{-} \rightleftharpoons\left[\phi_{3}^{+} \mathrm{PCH}_{3}\right] \mathrm{Br}^{-}+\phi_{3} \mathrm{P}=\mathrm{CHCO} \phi
$$

Este processo é denominado reação de transilidação.

A nucleofilicidade das fosforanas revela-se não apenas nas reações com compostos carbonílicos como também com outros reagentes eletrofílicos, formando sais de fosfönio. Quando o sal de fosfōnio apresentar grupos atraentes de elētrons, uma reação de transilidação com a fosforana intcial pode ocorrer, originando-se uma fosforana substituida.

$$
\begin{aligned}
& \left.\mathrm{R}_{3} \mathrm{P}=\mathrm{CHR}^{\prime}+\mathrm{EX} \longrightarrow \mathrm{R}_{3}^{+} \mathrm{PCHR}^{\prime} \mathrm{E}\right] \mathrm{X}_{\cdot}^{-} \stackrel{\mathrm{R}_{3} \mathrm{P}=\mathrm{CHR}^{\prime}}{\longrightarrow} \\
& {\left[\mathrm{R}_{3}{ }^{+} \mathrm{PCH}_{2} \mathrm{R}^{\prime}\right] \mathrm{X}^{-}+\mathrm{R}_{3} \mathrm{P}=\mathrm{CR}{ }^{\prime} \mathrm{E}} \\
& \mathrm{Ex} \cdot: 2 \phi_{3} \mathrm{P}=\mathrm{CH}_{2}+\phi \mathrm{COCl} \longrightarrow \phi_{3} \mathrm{P}=\mathrm{CHCO} \phi+\left[\phi_{3}{ }^{+} \mathrm{PCH}_{3}\right] \mathrm{Cl}^{-}
\end{aligned}
$$

Haletos organometálicos ou não metálicos, ou simplesmente haletos metálicos ou não metálicos, podem atuar como agentes ele- 
trofilicos na presença de fosforanas, dando origem a sais de fosfōnio.

$$
\mathrm{R}_{3} \mathrm{P}=\mathrm{CHR}^{\prime}+\mathrm{MX} \longrightarrow\left[\mathrm{R}_{3}^{+} \mathrm{PCHR} \mathrm{M}^{\prime}\right] \mathrm{X}^{-}
$$

Alguns desses sais de fosfônio podem participar de reações de transilidação, outros se transformam nas respectivas fosforanas apenas apōs tratamento com bases convenientes.

$$
\left[\mathrm{R}_{3}^{+} \mathrm{PCHR}^{\prime} \mathrm{M}\right] \mathrm{X}^{-}+\mathrm{R}_{3} \mathrm{P}=\mathrm{CR}^{\prime} \longrightarrow\left[\mathrm{R}_{3} \mathrm{PCH}_{2} \mathrm{R}^{\prime}\right] \mathrm{X}^{-}+\mathrm{R}_{3} \mathrm{P}=\mathrm{CR} \mathrm{R}^{\prime} \mathrm{M}
$$

Reações desse tipo foram efetuadas com Si $[38,94,98,103,107]$; $\mathrm{P}[45,46,50,97,103,104] ; \mathrm{Sn}[54,103,105] ; \mathrm{Ge}[105] ; \mathrm{Sb}[94,97] ;$ As $[94,97] ; \quad \operatorname{Hg}[93,103,107] ; \quad \mathrm{B}[103,106] ; \quad \mathrm{S}[63,66,114,121,122]$. *

* A seguir iniciaremos a apresentação dos resultados das reações de Wittig e Horner-Emmons de selenofosforanas e fosfonatos com compostos carbonilicos. Para uma visão geral da reação, antes de se ler a apresentação dos resultados, pode-se continuar a leitura na pägina 86 , onde prosseguimos o estudo das reações de Wittig e Horner-Emmons, discutindo sua estereoquimica. 


\section{CAPITULO III}

\section{REAÇÃO DE WITTIG ENTRE SELENOFOSFORANAS E COMPOSTOS CARBONILICOS}

Hã alguns anos foram efetuadas em nosso laboratōrio reações de transilidação entre carbetoxitrifenilfosforanas e brometos de arilselenenila $[74]$.

$2 \phi_{3} \mathrm{P}=\mathrm{CHCOOE} \mathrm{t}+\mathrm{ArSeBr} \longrightarrow \phi_{3} \mathrm{P}=\mathrm{C}(\mathrm{SeAr}) \mathrm{COOE} t+\left[\phi_{3}{ }^{+} \mathrm{PCH}_{2} \mathrm{COOEt}\right] \mathrm{Br}^{-}$ Entretanto, as (arilseleno)fosforanas obtidas se revelaram estáveis frente'a compostos carbonílicos, não fornecendo a olefina esperada.

$\phi_{3} \mathrm{P}=\mathrm{C}(\mathrm{SeAr}) \mathrm{COOEt}+\mathrm{RCOR}^{\prime} \longrightarrow \mathrm{RR}^{\prime} \mathrm{C}=\mathrm{C}(\mathrm{SeAr}) \mathrm{COOEt}+\phi_{3} \mathrm{PO}$

O insucesso da ūltima reação pode ser explicado como con sequência da baixa nucleofilicidade da fosforana, altamente estabilizada. Neste caso o carbânion é estabilizado não só pela conjugação com o agrupamento carbetoxi mas também pelo orbitais 4 d do selênio $[76]$ *

* A estabilização de carbânion em $\alpha$ a átomos de enxôfre tem sido atribuido não à sobreposição com os orbitais d, mas à polariza bilidade do ätomo de enxôfre $[18,42,109]$. Um fenômeno anālogo poderia ser responsável pela estabilização pelo selênto. 
Numa investigação seguinte $[84]$ foram estudadas as reações entre fosforanas não estabilizadas e brometo de fenilselenenila, e sua reação "in situ" com compostos carbonillicos. Esta reação, ao contrārio da anterior, foi bem sucedida, fornecendo, com aldeídos aromāticos e alifāticos, os selenetos vinilicos esperados.

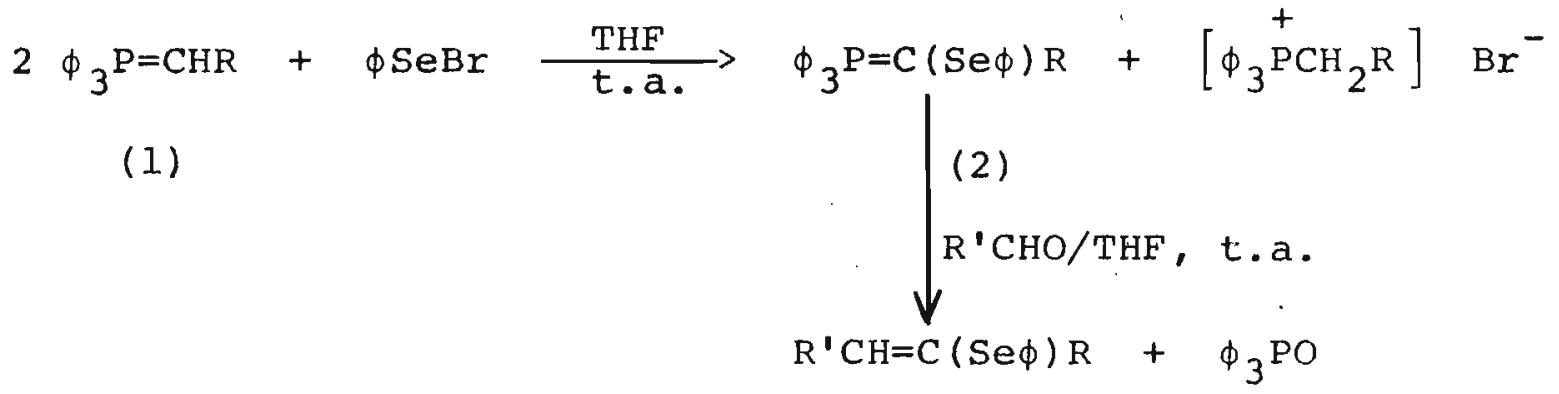

$Z+E$

Outra maneira de preparar a (fenilseleno)fosforana consiste em tratar uma suspensão do sal de (fenilseleno)fosfônio correspondente,em THF ou éter etílico,com n-BuLi à temperatura ambiente.

$$
\left[\phi_{3}^{+}{ }^{+} \mathrm{CH}(\operatorname{Se} \phi) \mathrm{R}\right] \mathrm{Br}^{-} \quad \frac{\mathrm{n}-\mathrm{BuLi} / \mathrm{THF}}{\mathrm{t} \cdot \mathrm{a} \cdot}>\phi_{3} \mathrm{P}=\mathrm{C}(\operatorname{Se} \phi) \mathrm{R}
$$

(4)

Os sais de (fenilseleno)fosfônio utilizados na preparação das (fenilseleno) fosforanas foram obtidos, com ótimos rendimentos, pela quaternização de trifenilfosfina com bromoalquilfenilselenetos. 


$$
\phi_{3} \mathrm{P}+\phi \operatorname{SeCHRBr} \longrightarrow\left[\phi_{3}^{+}{ }^{\mathrm{PCH}}(\operatorname{Se} \phi) \mathrm{R}\right] \mathrm{Br}^{-}
$$

$$
\begin{array}{ll}
\text { (4a) } & \mathrm{R}=\mathrm{H} \\
\text { (4b) } & \mathrm{R}=\mathrm{CH}_{3}
\end{array}
$$

Dois métodos foram desenvolvidos para obter os bromoalquil fenilselenetos:

19) Reação entre selenofenóxido de sódio e dibromometano

$$
\phi \mathrm{SeNa}+\mathrm{CH}_{2} \mathrm{Br}_{2} \longrightarrow \phi \mathrm{SeCH}_{2} \mathrm{Br}
$$

28) Reação entre brometo de fenilselenenila e diazoalcanos

$$
\begin{aligned}
& \phi \mathrm{SeBr}+\mathrm{CHRN}_{2} \longrightarrow \phi \mathrm{SeCHRBr} \quad \text { (5) } \quad \mathrm{R}=\mathrm{H} \\
& \text { (6) } \quad \mathrm{R}=\mathrm{CH}_{3}
\end{aligned}
$$

No presente trabalho estas reações foram repetidas para ob tenção de matérias primas usadas nas investigações seguintes.

Ao se repetir a preparação de (fenilseleno)fosforanas a partir do sal de (fenilseleno)fosfōnio em benzeno, observamos a for mação de butilfenilseleneto como produto secundārio (308) [76]. Es se resultado pode ser explicado como consequência de um ataque nucleofilico do $n$-BuLl ao ătomo de selênio, o qual se encontra menos solvatado em benzeno do que em THF, facilitando o ataque.

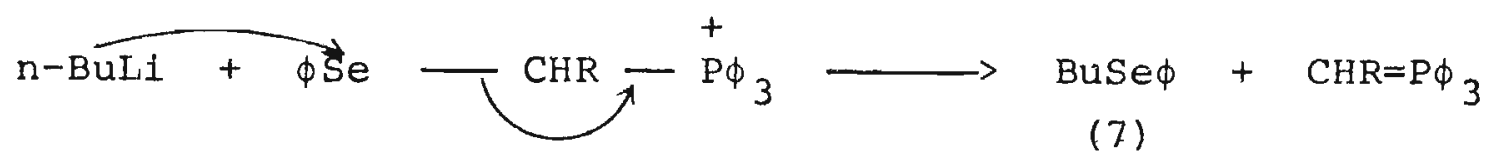


36.

\section{TABELA I}

Selenetos vinilicos preparados pela reação de Wittig entre selenofosforanas e aldeidos. $\phi_{3} \mathrm{P}=\mathrm{C}(\mathrm{Se} \phi) \mathrm{R}+\mathrm{R}^{\prime} \mathrm{CHO} \longrightarrow \mathrm{R}^{\prime} \mathrm{CH}=\mathrm{C}(\mathrm{Se} \phi) \mathrm{R}$

\begin{tabular}{|c|c|c|c|}
\hline$R^{\prime}$ & Metodo & Rendimento $(q)$ & $\begin{array}{l}\text { p.e. p.f. } \\
\left({ }^{\mathrm{O}} \mathrm{C} / \mathrm{mmHg}\right)\end{array}$ \\
\hline
\end{tabular}

\begin{tabular}{|c|c|c|c|c|}
\hline 3. $\mathrm{a} \quad \mathrm{H}$ & $\phi$ & $\mathrm{a}$ & 98 & $100-105 / 0.05$ \\
\hline $3 . \mathrm{b} \quad \mathrm{H}$ & $\mathrm{p}-\mathrm{CH}_{3} \phi$ & $\begin{array}{l}\mathrm{b} \\
\mathrm{a}\end{array}$ & $\begin{array}{l}99 \\
95\end{array}$ & $122 / 0.01^{b}$ \\
\hline 3. C H & $\mathrm{p}-\mathrm{NO}_{2} \phi$ & $\begin{array}{l}\mathrm{a} \\
\mathrm{b}\end{array}$ & $\begin{array}{l}87 \\
90\end{array}$ & $70-100$ \\
\hline 3. d H & $\mathrm{CH}_{3} \mathrm{CH}_{2}$ & $\mathrm{a}$ & 66 & $60-65 / 1$ \\
\hline $3 . e$ & $\mathrm{CH}_{3}\left(\mathrm{CH}_{2}\right)_{5}$ & $a$ & 65 & $81-85 / 0.01^{b}$ \\
\hline 3. $\mathrm{f} \quad \mathrm{CH}_{3}$ & $\phi$ & $\mathrm{a}$ & 99 & $110-115 / 0.005$ \\
\hline $3 . \mathrm{g} \quad \mathrm{CH}_{3}$ & $\mathrm{p}-\mathrm{CH}_{3} \phi$ & $\mathrm{a}$ & 95 & $127 / 0.05^{\mathrm{b}}$ \\
\hline $3 . \mathrm{h} \quad \mathrm{CH}_{3}$ & $\mathrm{p}-\mathrm{NO}_{2} \phi$ & $\mathrm{a}$ & $\begin{array}{l}91 \\
90\end{array}$ & $54-84$ \\
\hline $3 . i \quad \mathrm{CH}_{3}$ & $\mathrm{CH}_{3} \mathrm{CH}_{2}$ & $\mathrm{a}$ & 65 & $75-80 / 5$ \\
\hline $3 \cdot j \quad \mathrm{CH}_{3}$ & $\mathrm{CH}_{3}\left(\mathrm{CH}_{2}\right)_{5}$ & $\mathrm{a}$ & 63 & $65-70 / 0.25$ \\
\hline
\end{tabular}

a. transilidação; b. sal de (fenilseleno)fosfônto + n-BuLi. 
37.

Reação entre (fenilseleno)fosforanas e cetonas, ao contrārio da reação com aldeídos, não forneceu os selenetos vinílicos esperados, mas surpreendentemente $\alpha$-(fenilseleno)cetona e o sal de fosfônio livre de selènio [84].

$$
\phi_{3} \mathrm{P}=\mathrm{C}(\mathrm{Se} \phi) \mathrm{R}+-\mathrm{COCH}_{2} \mathrm{R}^{\prime} \quad \frac{\mathrm{THF}}{\text { t.a. }} \longrightarrow-\mathrm{COCH}(\mathrm{Se} \phi) \mathrm{R}^{\prime}+\left[\phi_{3}{ }^{+} \mathrm{PCH}_{2} \mathrm{R}\right] \mathrm{Br}^{-}
$$




\section{CAPITULO IV}

\section{RESULTADOS E DISCUSSÃO}

\section{$\underline{\text { A. Reação de (fenilseleno) fosforanas com cetonas }[73]}$}

No presente trabalho desenvolvemos um estudo sistemático da reação entre (fenilseleno)fosforanas e cetonas, completando também a investigação de seu mecanismo.

O resultado desta reação foi interpretado da seguinte forma: Em vista da menor nucleofilicidade das cetonas em relação aos aldeídos, a (fenilseleno)fosforana, ao invēs de se adicionar à carbonila, abstrai um próton da cetona, formando o enolato correspondente e o sal de (fenilseleno)fosfônio:

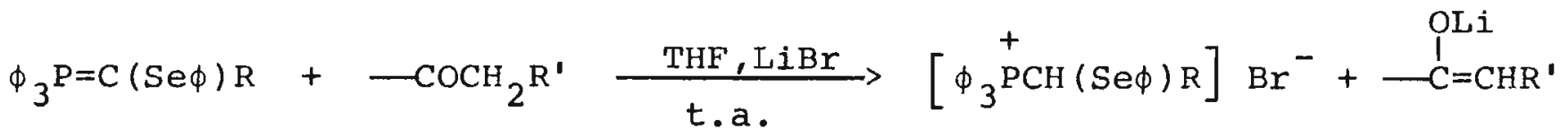

$\mathrm{R}=\mathrm{H}, \mathrm{CH}_{3}$

A seguir o enolato ataca ó selênio do sal de (fenilseleno)fosfônio, expulsando a fosforana livre de selểnio (que funciona como "leaving group"):

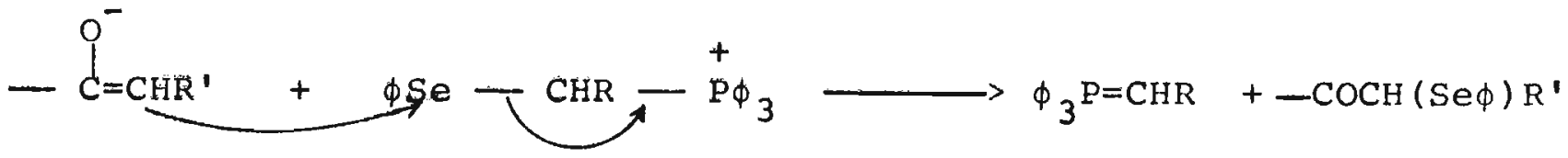


o fato do enolato preferir atacar o selènio, ao invés de participar de uma condensação aldólica, pode ser explicado pela reatividade do selènio frente a reações de substituição nucleofílica, bem como à pequena energia da ligação carbono-selênio (58 $\mathrm{Kcal} / \mathrm{mol}[39]$ ).

Na etapa seguinte a fosforana livre de selênio abstrai um próton do carbono em a à carbonila ao qual o grupo fenilseleno está ligado, dando origem a um sal de fosfônio e ao enolato da $\alpha$-(fenilseleno) cetona. Uma protonação final completa a sequência:

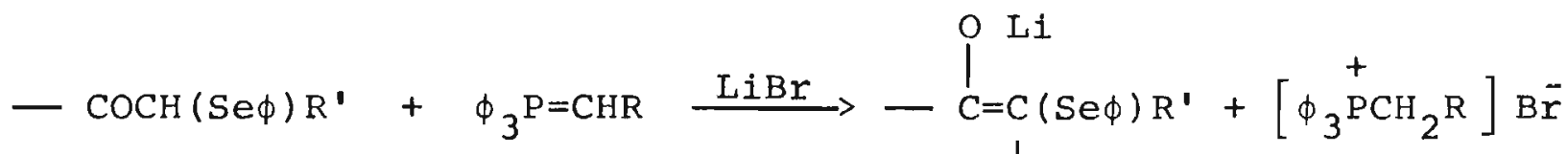

$$
\begin{aligned}
& \mathrm{H}^{+} \\
& \text {- }{\stackrel{O}{C H}(\operatorname{Se} \phi) R^{\prime}}
\end{aligned}
$$

Este equilíbrio se encontra deslocado para a direita devido à estabilização do enolato da $\alpha$-(fenilseleno)cetona pelos or bitais 4 d do selênio, bem como à insolubilidade do sal de fosfônio livre de selènio.

Todas as etapas acima foram comprovadas investigando-as separadamente, conforme descrito a seguir. 
1) Reação do enolato da ciclohexanona com sal de (fenilseleno)fosfônio $[84]$.

Pela reação do enolato da ciclohexanona com brometo de (fe nilseleno)metiltrifenilfosfônio, seguida de tratamento com água, ob teve-se a $\alpha$-(fenilseleno)ciclohexanona e o brometo de metiltrifenil fosfônio.

$\left[\phi_{3} \stackrel{+}{\mathrm{PCH}}{ }_{2} \mathrm{Se} \phi\right]$

$\mathrm{Br}^{-}$<smiles>CCOC1CCCCC1</smiles>

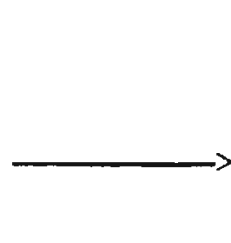

$\overbrace{}^{\mathrm{OLi}}+\left[\phi_{3} \stackrel{+}{\mathrm{PC}} \mathrm{CH}_{3}\right] \mathrm{Br}^{-}$<smiles>CN(C)C1CCCCC1[Se+]</smiles>

2) Reação da $\alpha$-(fenilseleno) ciclohexanona com metilenotrifenilfosforana $[84]$.

Reação entre $\alpha$-(fenllseleno) clclohexanona e metiltrifenilfosforana forneceu brometo de metiltrifenilfosfônio. Após tratamento com água a $\alpha$-(fenilseleno) ciclohexanona foi regenerada. 
$\phi_{3} \mathrm{P}=\mathrm{CH}_{2}+$

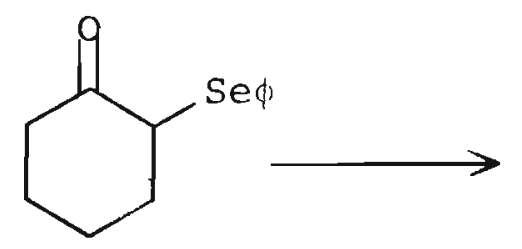

$\overbrace{}^{\mathrm{OLi}} \mathrm{Se \phi}+\left[\phi_{3}{ }^{+} \mathrm{PCH}_{3}\right] \mathrm{Br}^{-}$

$\mathrm{H}_{2} \mathrm{O} / \mathrm{H}^{+}$<smiles>O=C1CCCCC1[Se]</smiles>

3) Tratamento da mistura de reação entre (fenilseleno)metilenotrifenilfosforana e 3-pentanona com iodeto de metila.

Apōs o tratamento da mistura de reação entre (fenilseleno) metiltrifenilenofosforana e 3-pentanona com iodeto de metila, isolou-se brometo de metiltrifenilfosfônio e 2-metil-2-(fenilseleno)3-pentanona.

$$
\begin{aligned}
& \phi_{3} \mathrm{P}=\mathrm{CHSe} \phi+\mathrm{CH}_{3} \mathrm{CH}_{2} \mathrm{COCH}_{2} \mathrm{CH}_{3} \stackrel{\mathrm{THF}}{\longrightarrow} \mathrm{CH}_{3} \mathrm{CH}_{2} \mathrm{C}=\mathrm{C}(\mathrm{Se} \phi) \mathrm{CH}_{3}+\left[\phi_{3} \stackrel{+}{\mathrm{PCH}}{ }_{3}\right] \mathrm{Br}^{-} \\
& \downarrow \mathrm{CH}_{3} \mathrm{I} \\
& \mathrm{CH}_{3} \mathrm{CH}_{2} \mathrm{COC}\left(\mathrm{CH}_{3}\right)_{2} \mathrm{Se} \phi
\end{aligned}
$$


Com a finalidade de verificar seu caräter geral, a reação foi efetuada com 7 cetonas diferentes e, em todos os casos, obtive mos como produto principal a $\alpha$-(fenilseleno) cetona, mesmo quando a reação foi efetuada entre acetofenona ou ciclopentanona, as quais apresentam grande tendência a sofrer autocondensação. Os resultados obtidos encontram-se na tabela II. 


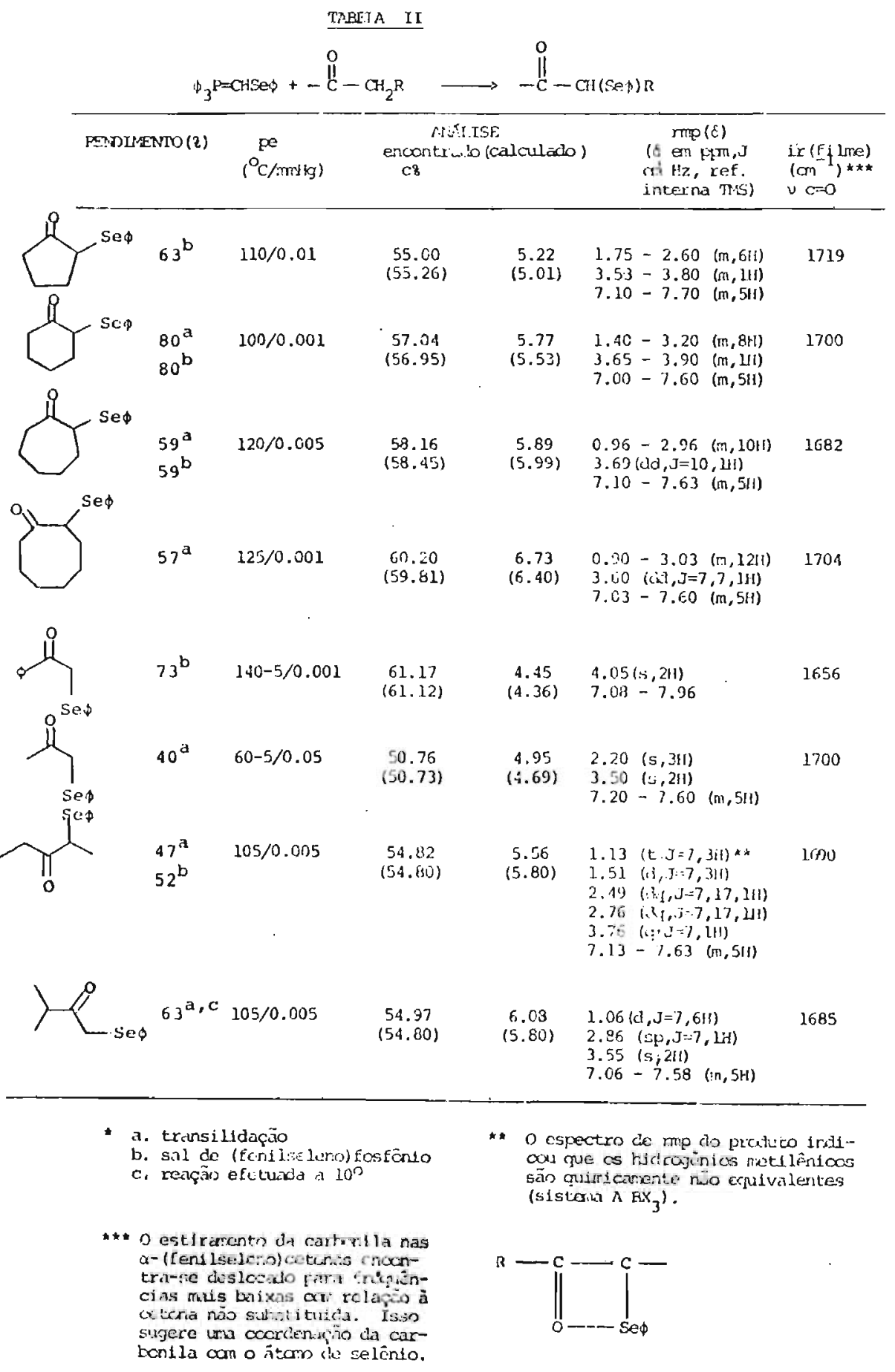


2-metil-3-butanona apresentou uma preferēncia marcante pelo enolato cinético $\left(\sim 9: 1\right.$ a $\left.10^{\circ} \mathrm{C}\right)$, fornecendo a $\alpha$-(fenilseleno) ceto na substituída no grupo metila. Elevando-se a temperatura, aumentou a proporção do produto termodinâmico.

Quando a (fenilseleno)fosforana foi preparada por transili dação observamos, em algumas reações, que a permanência dos sais de fosfônio isentos de selênio no meio reacional determinava uma diminuição no rendimento final. Este fato, juntamente com a formação de pequena quantidade de 2-fenilpropeno na reação com acetofenona,levou-nos a sugerir que o enolato da acetofenona, alēm de agir como nucleófilo, atacando o selênto, agiria como base, abstraindo um prọ ton do sal de fosfônto livre de selênio (esquema abaixo). A seguir a fosforana assim formada reagiria com a acetofenona, dando origem ao 2-fenilpropeno. A possibilidade de uma troca protōnica entre o enolato da acetofenona e o sal de fosfônio, gerando uma fosforana e a cetona de origem, foi confirmada experimentalmente ao se fazer reagir o enolato da acetofenona com brometo de metiltrifenilfosfónio, em THF (formação de 2-fenilpropeno em $30 \%$ de rendimento).

$$
\begin{aligned}
& 2 \phi_{3} \mathrm{P}=\mathrm{CHR}+\phi \mathrm{SeBr} \longrightarrow \phi_{3} \mathrm{P}=\mathrm{CRSe} \phi+\left[\phi_{3}^{+} \mathrm{P}-\mathrm{CH}_{2} \mathrm{R}\right] \mathrm{Br}^{-} \\
& \text {LiBr } \mid-\mathrm{CH}_{2}-\stackrel{\mathrm{C}}{\mathrm{C}-} \\
& {\left[\phi_{3}{ }^{+}-\text {CHRSe } \phi\right] \mathrm{Br}^{-}+\mathrm{HC}^{\mathrm{C}} \mathrm{C}^{-}} \\
& \phi_{3} \mathrm{P}=\mathrm{CHR}+\phi \mathrm{SeCH}-\stackrel{O}{\mathrm{O}} \\
& \begin{array}{l}
\mathrm{CH}_{2}-\mathrm{C}-\mathrm{C}+\phi_{3} \mathrm{P}=\mathrm{CHR} \\
-\mathrm{CH}_{2} \mathrm{C}=\mathrm{CHR}
\end{array}
\end{aligned}
$$


No entanto, estas explicações devem ser interpretadas com cuidado, uma vez que 2-fenilpropeno foi identificado como produto secundário mesmo quando utilizamos uma fosforana preparada a partir de sal de (fenilseleno)fosfônio. Devemos lembrar, contudo,que com o progresso da reação passa a existir no melo reacional sal de fosfônio livre de selênio, o qual poderia competir com o sal de (fenilseleno) fosfônto pelo enolato, chegando a resultados semelhan tes aos do esquema acima. 
B. Reação de (fenilseleno)fosforanas com ésteres e compostos B-dicarbonílicos.

Com a finalidade de verificar se a reação que acabamos de descrever, entre (fenilseleno)fosforanas e compostos carboní licos pouco eletrofílicos, è de carāter geral ou se é aplicável apenas a cetonas, efetuamos a reação de (fenilseleno)fosforanas com ēsteres e compostos $\beta$-dicarbonilicos.

A reação entre (fenilseleno)metiltrifenilfosforana e acetato de etila fol muito lenta. Apenas após prolongado aquecimento observou-se precipitação de sal de fosfōnio, indício de que a reação estava se processando. Isso é compreensíve1, em vista da menor acidez dos ésteres (pKa 25 ) em relação às cetonas (pKa 20).

Já com compostos $\beta$-dicarbonilicos a troca protônica en tre a (fenilseleno)fosforana e o composto carbonílico foi imediata. No entanto, quando a reação foi efetuada em THF, as eta pas subsequentes ou não ocorreram ou foram muito lentas. Isso se deve, em parte, à baixa nucleofillcidade do enolato do composto B-dicarbonIlico e, em parte, à sua insolubilidade em THF.

Na reą̧̃o com a 2,4-pentanodiona, o enolato do composto $\beta$-dicarbonIlico e o sal de (fentlseleno)fosfônio foram isola 
dos e identificados, constituindo prova adicional do mecanismo pro posto.

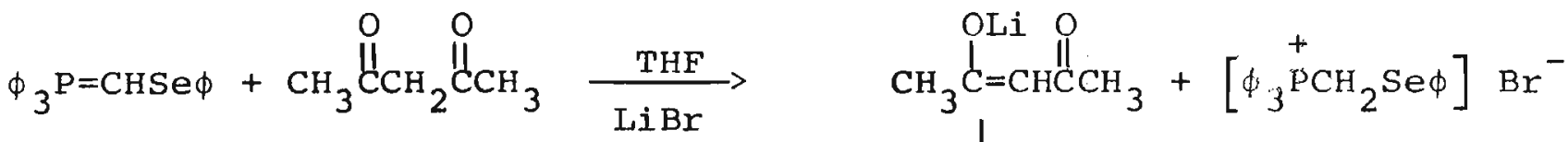

$$
\begin{aligned}
& \mathrm{CH}_{3} \stackrel{\mathrm{O}}{\mathrm{CCCH}}_{2} \stackrel{\mathrm{CCH}}{\mathrm{CCl}}_{3}^{\mathrm{HCH}}
\end{aligned}
$$

Quando efetuada em HMPA a reação seguiu seu curso normal, conforme descrito para cetonas, resultado este compativel com o au mento da nucleofilicidade do enolato pelo uso de solvente polar aprōtico.

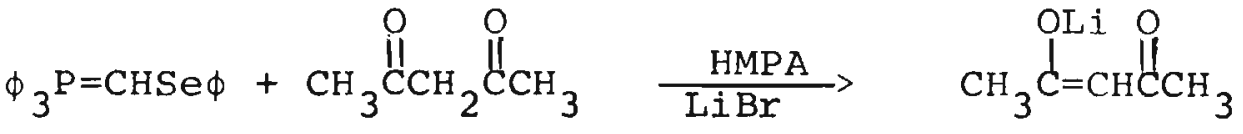

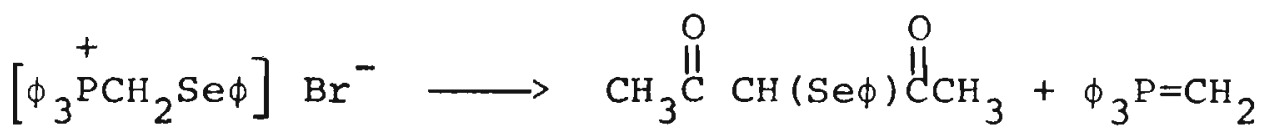$$
\mathrm{CH}_{3} \stackrel{\mathrm{OLi}}{\stackrel{\mathrm{C}}{\mathrm{C}} \mathrm{C}(\mathrm{Se} \phi)} \stackrel{\stackrel{O}{\mathrm{C}} \mathrm{CH}_{3}}{+}+\left[\stackrel{+}{\phi_{3} \mathrm{PCH}_{3}}\right] \mathrm{Br}^{-}
$$

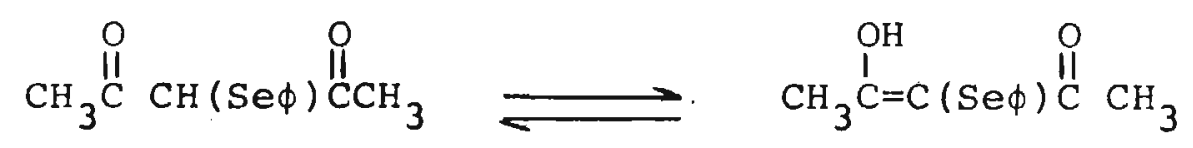

o produto final se apresentou totalmente na forma enólica 
(verificado por rmp).

Nas condições empregadas, 3-meti1-2,4-pentanodiona forneceu o produto de substituição no carbono 1, ao invēs do carbono 3 , certamente devido a razões estéricas.

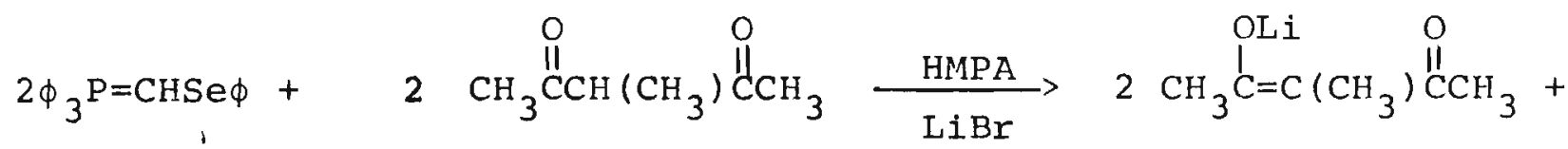

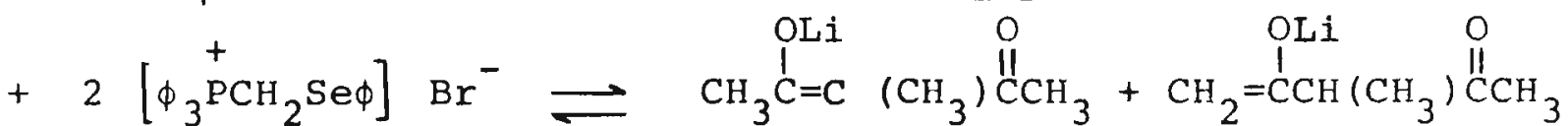

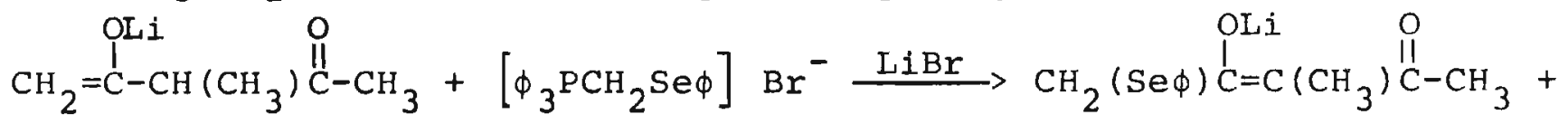
$+\left[\phi_{3}^{+} \mathrm{PCH}_{3}\right] \mathrm{Br}^{-}$

$\mathrm{CH}_{2}(\mathrm{Se} \phi) \stackrel{\mathrm{OH}}{\mathrm{C}}=\mathrm{C}\left(\mathrm{CH}_{3}\right) \stackrel{\text { II }}{\mathrm{C}} \mathrm{CH}_{3}$ (12a)

$$
\mathrm{CH}_{2}(\mathrm{Se} \phi) \stackrel{\mathrm{O}}{\mathrm{I}} \mathrm{H}_{2} \mathrm{O}-\mathrm{CH}\left(\mathrm{CH}_{3}\right) \stackrel{\text { I }}{\mathrm{C}}-\mathrm{CH}_{3}
$$

$30 \%$ do produto final se encontra na forma enólica (por $\mathrm{rmp})$.

As reações de (fenilseleno)metiltrifenilfosforanas com acetoacetato de metila e malonato de dietila forneceram misturas de produtos de composição Indefinida, embora se tenha isolado da mistura de reação brometo de metiltrifenilfosfônio. Comparação dos espectros de rmp dos produtos com os de uma amostra autêntica 
indicou não se tratar dos $\alpha$-(fenilseleno)derivados.

As amostras autênticas foram preparadas, para comparação, a partir do enolato do composto $\beta$-dicarbonílico e brometo de fenilselenenila [82].
$\mathrm{RCCH}_{2} \prod_{\mathrm{CR}}$

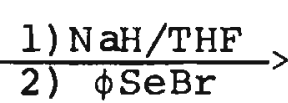

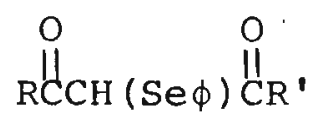

(13) 


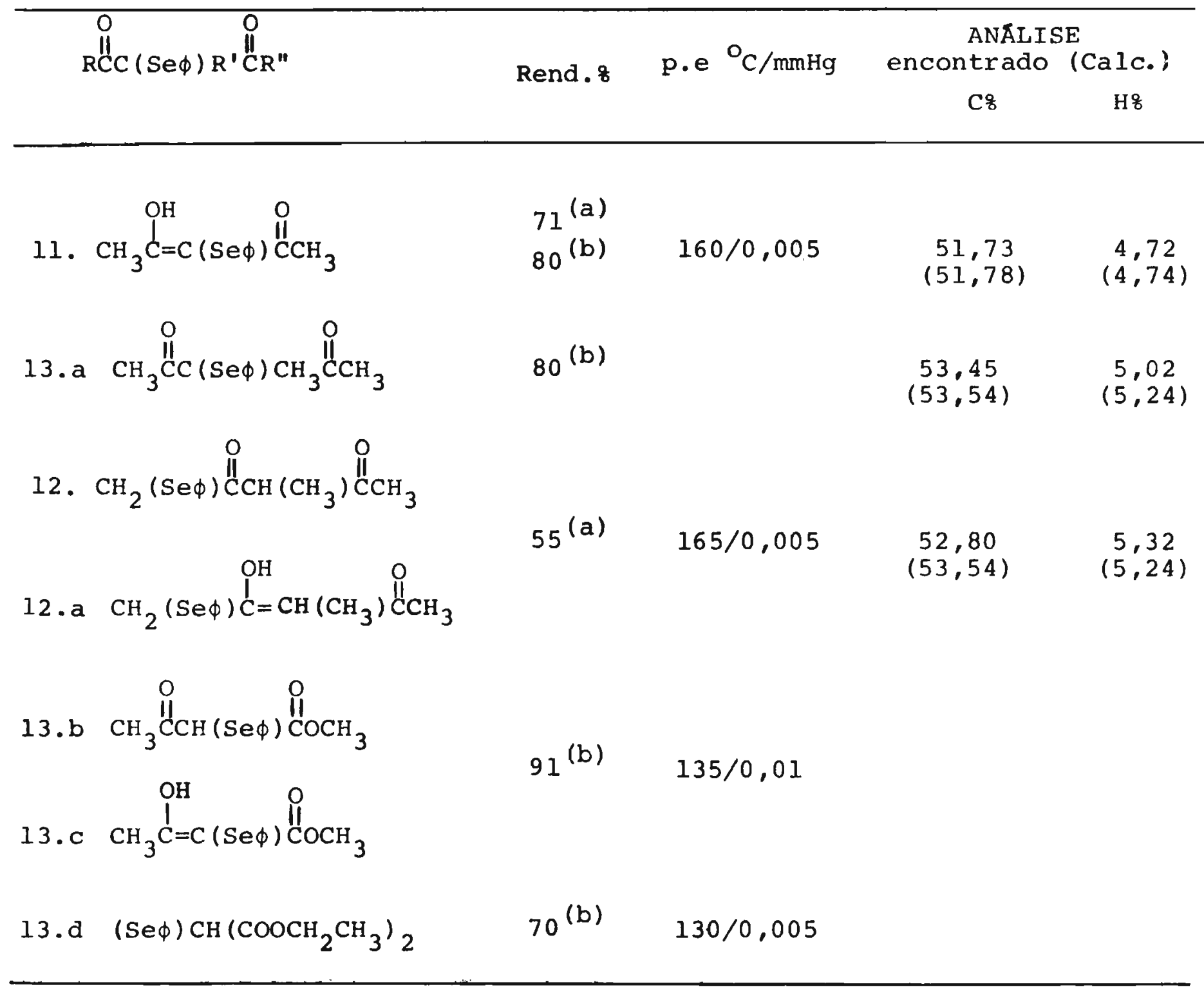

(a) Via sal de selenofosfônio em HMPA (parte experimental I-E.1 e I-E. 2)

(b) Via enolato/brometo de fentlselenila (parte experimental I-E.3) 
C. Reação de Horner-Emmons entre (fenilseleno) fosfonatos e compostos carbonilicos $[28,72]$.

Tendo em vista o fato de cetonas não reagirem com seleno fosforanas e, portanto, selenetos vinílicos tetrasubstituídos não serem acessíveis por esse método, decidimos investigar a reação entre (fenilseleno)fosfonatos e compostos carbonilicos, já que fosfonatos são mais reativos do que fosforanas $[24,49]$. Além disso os fosfonatos, contrariamente às fosforanas, podem ser alquilados facilmente, permitindo a obtenção de uma variedade de fosfonatos substituidos $[24]$.

(Fenilseleno)metildietilfosfonato è facilmente obtido atravēs da reação de selenofenóxido de sódio e iodometildietilfos fonato (preparado por uma reação de Arbuzov entre trietilfosfito e diiodometano $[25]$.

$$
\text { (EtO) }{ }_{2} \mathrm{P}(\mathrm{O}) \mathrm{CH}_{2} \mathrm{I}+\phi \mathrm{SeNa} \frac{\mathrm{THF}}{\text { t.a. }}>(\mathrm{EtO}){ }_{2} \mathrm{P}(\mathrm{O}) \mathrm{CH}_{2} \mathrm{Se} \phi
$$

Sabe-se que, embora os fosfonatos estabilizados (os que contêm um grupo capaz de estabilizar cargar negatıvas na posição $\alpha$ ao fósforol possam ser facilmente desprotonados à temperatura ambiente com hidreto de sódio, fornecendo o respectivo carbânion, fosfonatos não estabilizados não formam carbânion nas mesmas condições $[24]$. Há alguns anos, no entanto, Corey e shulman [31], 
efetuaram a desprotonação de tio-fosfonatos empregando n-BuLi (a $-78^{\circ}$ ) como base.

Aplicação desse método ao (fenilseleno)metildietilfosfonato, permitiu obter os (fenilseleno)fosfonatos substituídos com rendimentos elevados $[28,72]$.

$$
\text { (EtO) }{ }_{2} \mathrm{P}(\mathrm{O}) \mathrm{CH}_{2} \operatorname{Se} \phi \frac{\text { l) } \mathrm{n}-\mathrm{BuL1} / \mathrm{THF},-78^{\circ}}{2) \mathrm{RX}} \quad(\mathrm{EtO}){ }_{2} \mathrm{P}(\mathrm{O}) \mathrm{CH}(\mathrm{Se} \phi) \mathrm{R}
$$

Os selenofosfonatos constituem material de partida para a obtenção de selenetos vinilicos. o carbānion fosfonato fol preparado conforme descrito anteriormente, tratando-se o (fenilseleno) fosfonato com $n$-BuLi em THF a $-78^{\circ}$. Reação subse quente $\left(\mathrm{a}-78^{\circ}\right)$ com compostos carbonilicos, seguida de aquecimento, forneceu os selenetos vinilicos com bons rendimentos $[28$, $71,72,75]$.

$$
\begin{array}{ll}
\text { (Eto) }{ }_{2} \mathrm{P}(\mathrm{O}) \mathrm{CH}(\mathrm{Se} \phi) \mathrm{R} \frac{\text { 1) } \mathrm{n}-\mathrm{BuL} i / \mathrm{THF},-78^{\circ}}{\text { 2) } \mathrm{R}^{\prime} \mathrm{R}^{\prime \prime} \mathrm{CO}} & \mathrm{R}^{\prime} \mathrm{R}^{\prime \prime} \mathrm{C}(\mathrm{Se} \phi) \mathrm{R}+(\mathrm{EtO}) \mathrm{PO}_{2}^{\prime} \\
& \text { (3) } \mathrm{R}^{\prime}=\mathrm{H} \\
& \text { (17) } \mathrm{R}^{\prime}=\text { alquila }
\end{array}
$$

Outro método de efetuar a reação consistiu em se aquecer uma mistura de (fenilseleno)fosfonato com hidreto de sódio em THF e HMPA, na presença do composto carbonilico. 
$(\mathrm{EtO}){ }_{2} \mathrm{P}(\mathrm{O}) \mathrm{CH}(\mathrm{Se} \phi) \mathrm{R}+\mathrm{NaH}+\mathrm{R}^{\prime} \mathrm{R}^{\prime \prime} \mathrm{CO} \frac{\mathrm{THF} / \mathrm{HMPA}}{80^{\circ}}>\mathrm{R}^{\prime} \mathrm{R}^{\prime \prime} \mathrm{C}=\mathrm{C}(\mathrm{Se} \phi) \mathrm{R}+(\mathrm{EtO}){ }_{2} \mathrm{PO}_{2}^{-}$

$$
\begin{aligned}
\text { (3) } R^{\prime} & =H \\
(17) R^{\prime} & =a l q u i l a
\end{aligned}
$$

Este procedimento foi aplicado por Green [41] na preparação de sulfetos vinílicos. Mais recentemente Lavielle e sturtz [57] observaram que o uso de solventes básicos, como o HMPA, aumenta a velocidade da reação. Deve-se salientar que na ausência do composto carbonílico não ocorre formação do carbânion fosfonato $[24,57]$. Estes resultados foram confirmados no presente trabalho. Aquecimento de uma mistura de (fenilseleno) fosfonato e hidreto de sódio em THF e HMPA não causou despreendimento de hidrogênio.

Esse comportamento foi interpretado como sendo devido à formação inicial de um "complexo" entre o fosfonato e o hidreto de sódio, o qual seria destruído pela reação com o composto carboníli $\operatorname{co}[24]$.

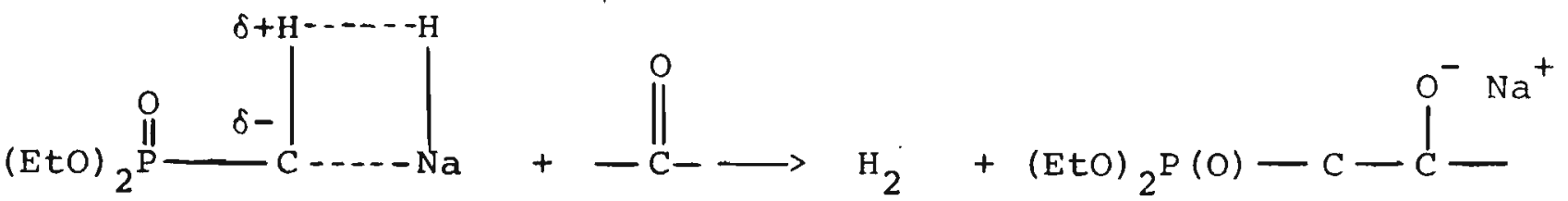

E fácil perceber que este método não é aplicável a compos tos carbonilicos que possuem hidrogênto em $\alpha$, os quais podem sofrer facilmente reação de condensação aldólica.

Ambos os métodos forneceram preferencialmente os selene- 


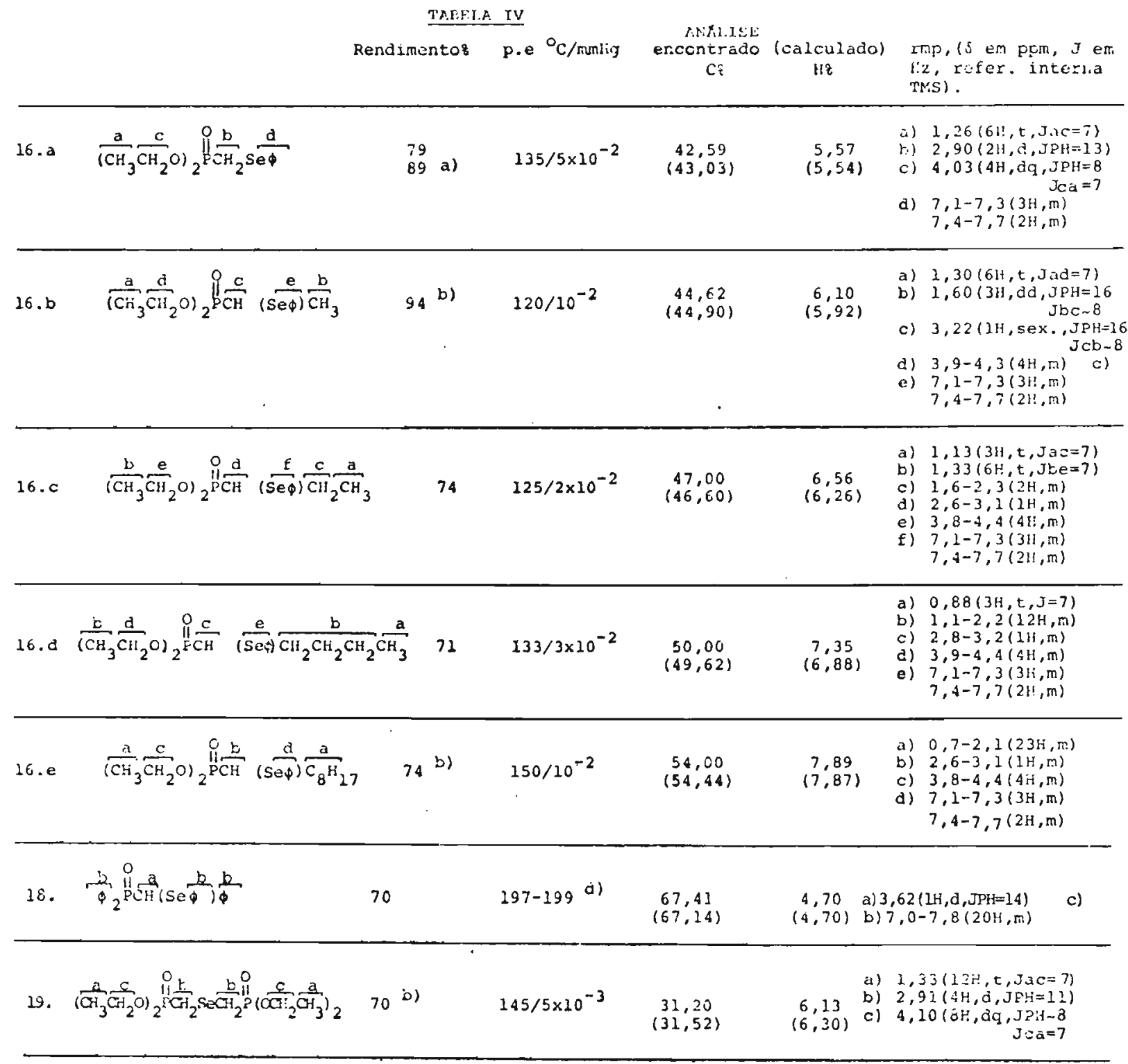
a) Preparado peio métedo b (ver parte experimental II-A.l.b). Fendimento apös purificação
per cromatogiafia em coluna.

b) Dastilaco er. "Kugelrëhr".

c) Espectro en CDCl, num espectronetro XI 100.

d) Pecristalizádo de otaiol. 
tos vinilicos de configuração E (ver capítulo VI).

Outro reagente potencial de selenoolefinação seria o (fenilseleno)benzildifenilfosfinóxido, preparado facilmente pelo tratamento sucessivo de benzildifenilfosfinóxido com n-BuLi e brometo de fenilselenenila.

$$
\phi_{2} \mathrm{P}(\mathrm{O}) \mathrm{CH}_{2} \phi \stackrel{\mathrm{n}-\mathrm{BuLi}}{\mathrm{THF}, \mathrm{t.a} \cdot} \underset{\mathrm{THF} /-78^{\circ}}{\stackrel{\phi \mathrm{SeBr}}{\mathrm{TH}}} \phi_{2} \mathrm{P}(\mathrm{O}) \mathrm{CH}(\mathrm{Se} \phi) \phi
$$

No entanto a reação de olefinação não se processou quando tratamos o (fenilseleno)fosfinóxido com NaH em presença de benzaldeído.

Com relação às reações de (fenilseleno)fosfonatos com com postos carbonílicos, salientamos que reações análogas envolvendo tio-fosfonatos e fosfinóxidos se encontram descritas na literatura. No entanto, certas discrepâncias devem ser apontadas. Enquanto al guns autores descrevem a reação de olefinação ocorrendo com aldeídos e cetonas $[31,39,41]$, outros restringem a reatividade apenas a aldeÍdos aromáticos $[64,65]$. Por outro lado, a falta de reatividạ de do (fenilseleno)benzildıfentlfosfinóxido, em contraposição à reatıvidade dostiofosfinōxidos [23], pode ser atribuída à estabili zação do carbânion pelo grupo fenila.

Uma extensão deste trabalho foi a preparação do seleneto de bis(dietilfosfometila), a partir de iodometildietilfosfonato e 
56.

7.11:19: V

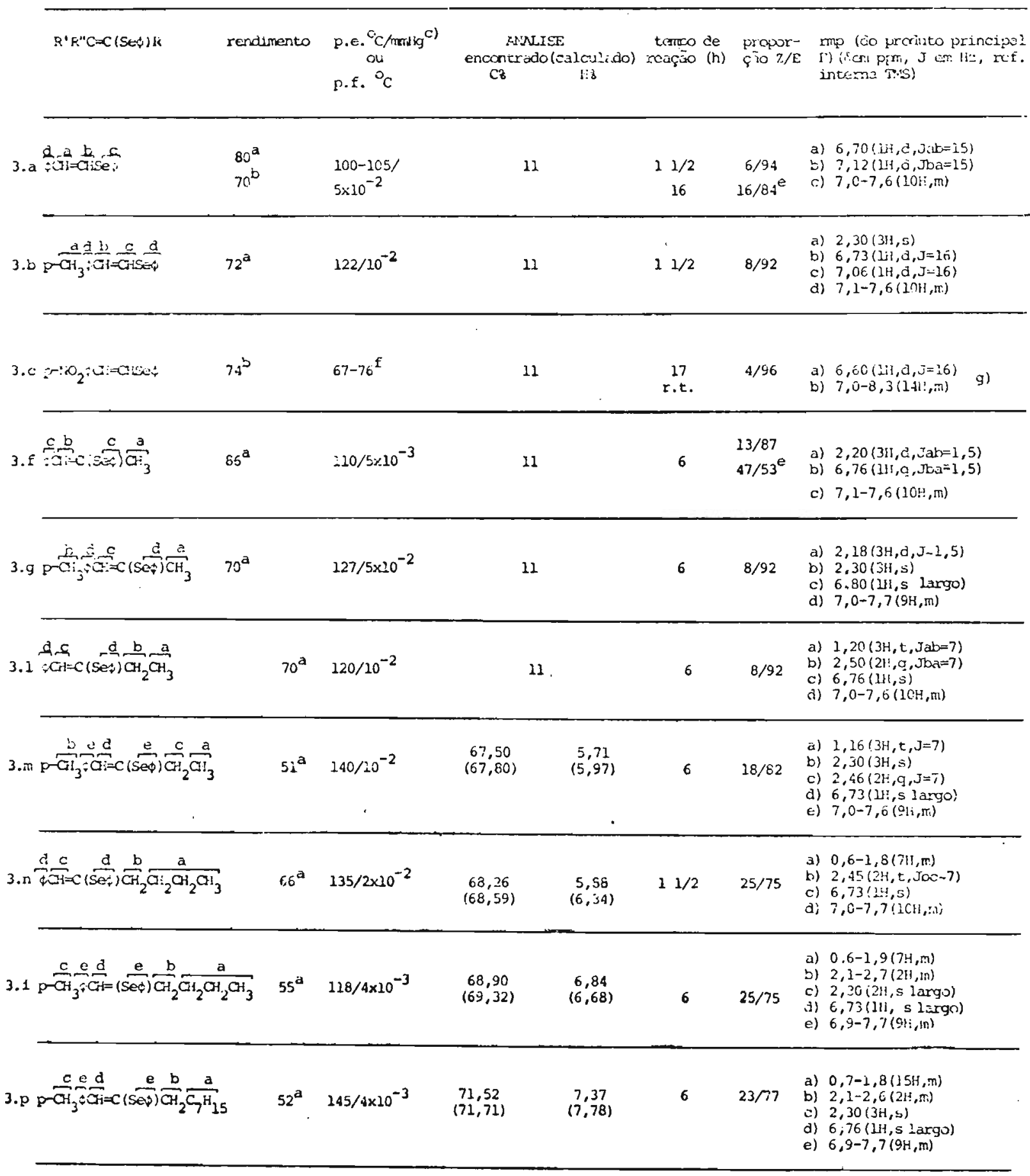




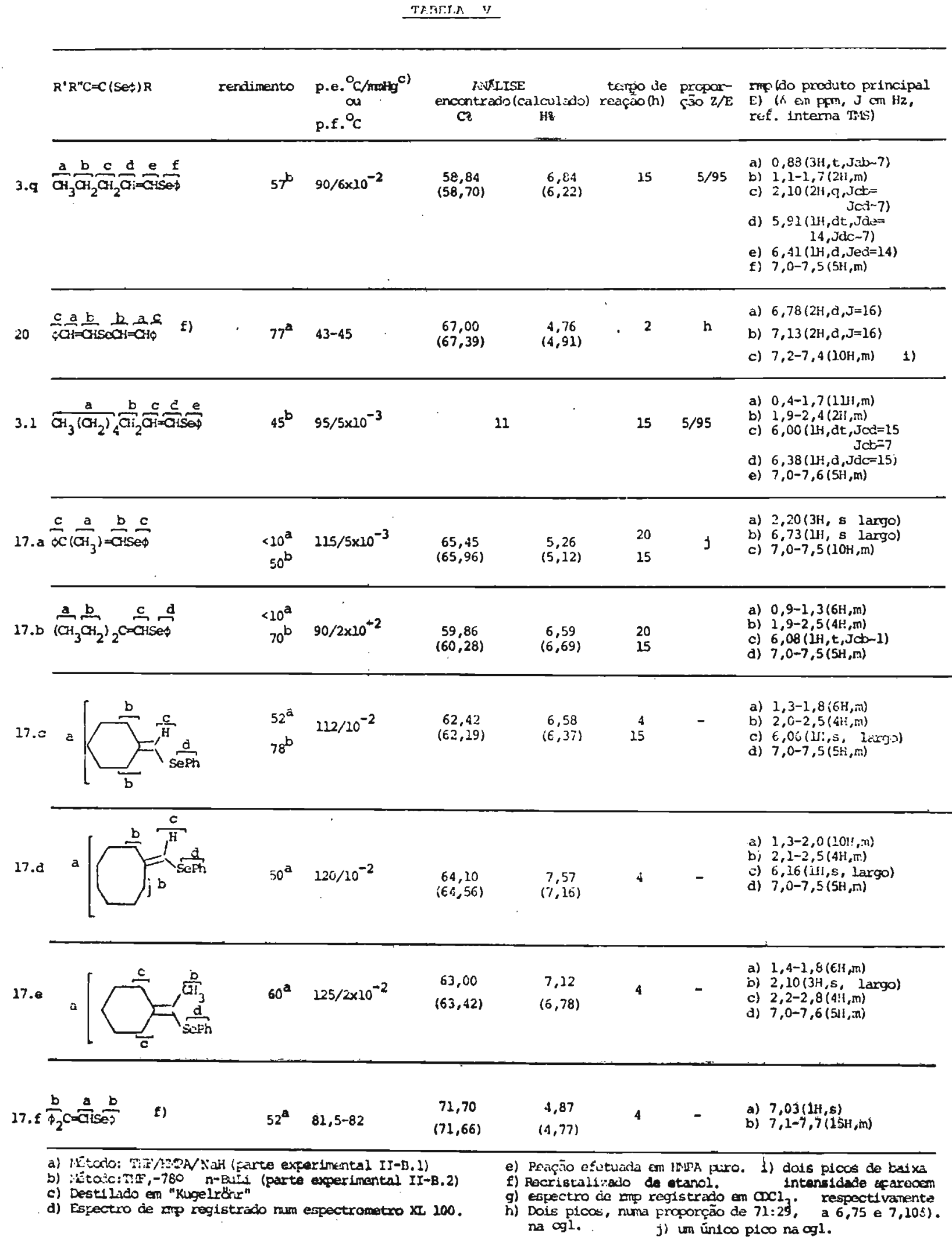


seleneto de sódio.

$$
2(\mathrm{EtO}){ }_{2} \mathrm{P}(\mathrm{O}) \mathrm{CH}_{2} \mathrm{I}+\mathrm{Na}_{2} \mathrm{Se} \frac{\mathrm{THF}}{\text { t.a. }} \quad\left(\mathrm{EtO}_{2} \mathrm{P}(\mathrm{O}) \mathrm{CH}_{2} \mathrm{SeCH}_{2}(\mathrm{O}) \mathrm{P}(\mathrm{OEt})_{2}\right.
$$

O seleneto de bis(dietilfosfometila) ao reagir com benzaldeỉo em presença de hidreto de södio forneceu o seleneto de bis ( $\beta$ estirila).

$$
(\mathrm{EtO}) 2_{2}^{\mathrm{P}(\mathrm{O}) \mathrm{CH}_{2} \mathrm{SeCH}_{2}(\mathrm{O}) \mathrm{P}(\mathrm{OEt})} 2 \frac{\mathrm{NaH}, \phi \mathrm{CHO}, \mathrm{THF} / \mathrm{HMPA}}{80^{\circ}}>\underset{(20)}{\phi \mathrm{CH}=\mathrm{CHSeCH}=\mathrm{CH} \phi}
$$

Embora sejam possiveis três isômeros deste composto, a análise por cgl indicou formação de apenas dois (proporção de isômeros: $71 / 29$ ).
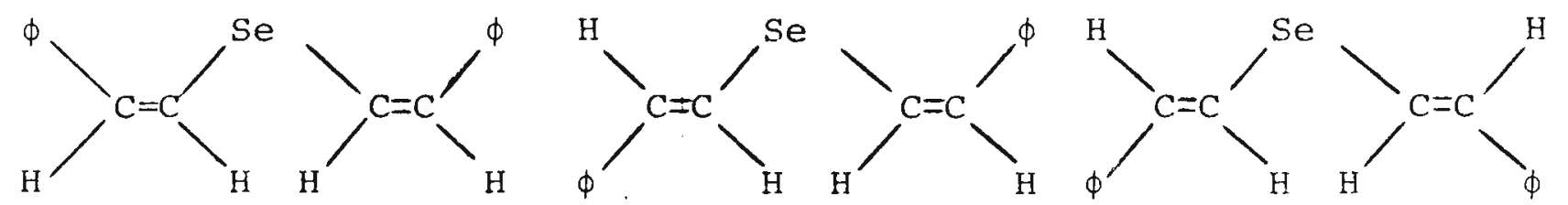

Podemos supor que o isômero mais abundante seja o terce $\underline{i}$ ro, uma vez que no mesmo todos os grupos volumosos se encontram em trans (ver rmp).

O seleneto de bis(dietilfosfometila)poderia ser aplicado para preparar compostos cíclicos contendo selênio como hetero ātomo, os quais são de grande interesse teórico no campo da quí- 
59.

mica de compostos aromáticos [117].
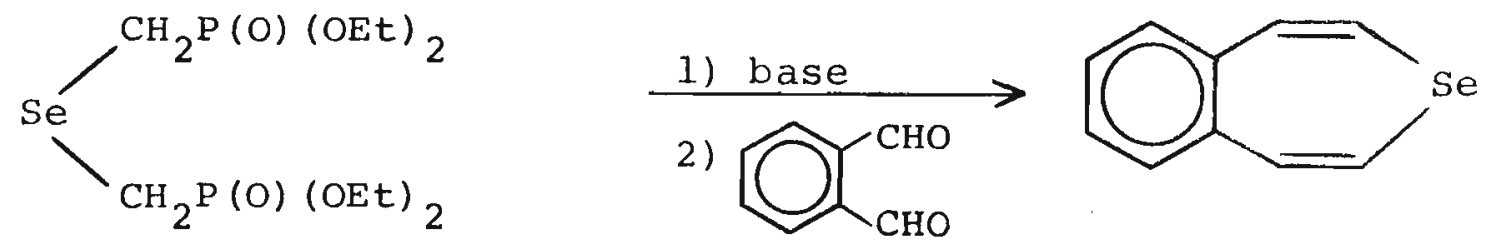
60 .

D. Selenetos vinilicos a partir de acetilenos $[29]$

1. Adição de selenớenol a acetilenos : Selenetos vinílicos z

o primeiro método de preparação de selenetos vinilicos descrito na literatura foi a adição de selenóis a acetilenos $[27,39,40$, 118 ]. Posteriormente autores russos continuaram essas investigaçóes utilizando principalmente acetilenos substituídos por grupos hidroxi-, alcoxi-e amino- $[4-8]$. No entanto, no presente trabalho, vai ncs interessar a adição de selenofenol a acetilenos substituidos por agrupamentos alquila e fenila. O último trabalho sobre esse particu lar data de $1962[52,53]$, no qual autores russos descrevem a adição de selenofenol a acetilenos monossubstituídos e ao difenilacetilenc. A reação com fenilacetileno levou predominantemente ao isômero $\mathrm{Z}$. Já na reação com 1-hexino a natureza dos produtos não foi claramente de finida pelos autores.

Como era nosso objetivo obter selenetos vinílicos de configuração $\mathrm{Z}$ (ver seção 6 deste capitulo), decidimos reinvestigar a rea ção de adição de selenofenol a acetilenos, estendendo-a a acetilenos dissubstituídos.

Adição de selenofenol ao fenilacetileno, conforme descrito na literatura $[52]$, ocorreu rapidamente, à temperatura ambiente, com desprendimento de calor, formando o seleneto vinilico de conf $\underline{i}$ 
guração $\mathrm{Z}$. Adição de selenofenol a acetilenos aromáticos dissubstituídos ocorreu lentamente, à temperatura ambiente, levando também ao isômero de configuração 2 . o mesmo resultado foi obtido com acetilenos alifāticos terminais. Salientamos que trabalhos an teriores [52] afirmam que esta reação não ocorre à temperatura ambiente.

$$
\begin{array}{cc}
\mathrm{RC} \equiv \mathrm{CR}^{\prime} \underset{\mathrm{t.a} .}{\stackrel{\phi \mathrm{SeH}}{\longrightarrow}} \quad \mathrm{RCH}=\mathrm{C}(\mathrm{Se} \phi) \mathrm{R}^{\prime} \\
\mathrm{z}
\end{array}
$$

Efetuando-se a reação à temperatura mais elevaḍa (ampola fechada, $130^{\circ} \mathrm{C}$ ), a adição tornou-se mais rápida. No entanto a estereoseletividade diminuiu, formando-se grandes quantidades de ole fina $E$ (ver tabela VI).

$$
\begin{gathered}
\mathrm{RC} \equiv \mathrm{CR}^{\prime} \frac{\phi \mathrm{SeH}}{130^{\circ}} \quad \mathrm{RCH}=\mathrm{C}(\operatorname{Se} \phi) \mathrm{R}^{\prime} \\
\mathrm{Z}+\mathrm{E}
\end{gathered}
$$

Como podemos observar na tabela VI à medida em que $\mathrm{R}^{\prime}$ se torna mais volumoso o rendimento da reação diminui.

$\mathrm{Na}$ reação com acetilenos alifáticos terminals formou-se apenas o etileno 1,2-substituído (3), ao contrário do que afirmam autores russos [52]. segundo os quais se formaria também o etileno 1,1-substituído (21). 


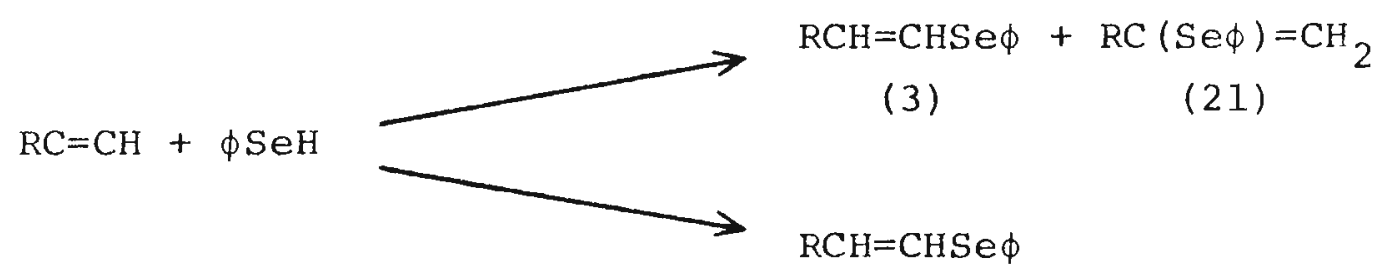

(3)

Conforme sugestões precedentes $[39,53]$, o seguinte mecanismo pode ser proposto para explicar a formação preferencial do -isômero $\mathrm{Z}$.

Uma molécula de selenofenol se adicionaria à ligação tripla, orientando a entrada do próton de outra molécula de selenofenol pelo lado oposto.
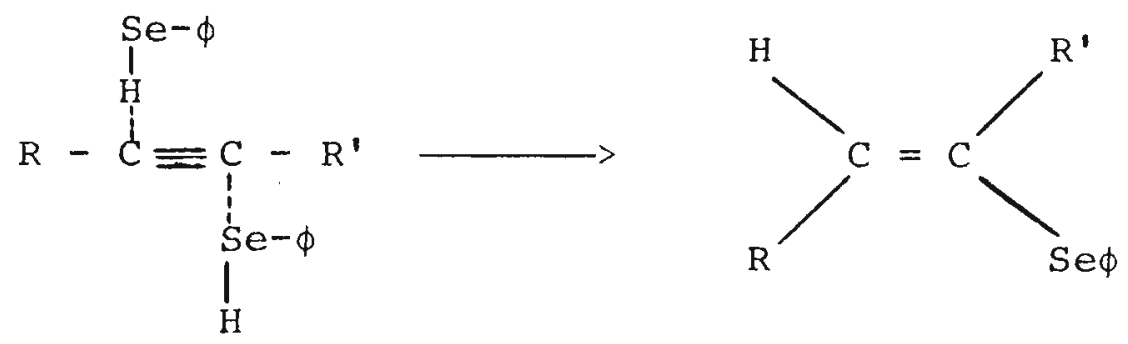

Por outro lado, a presença do isômero E na mistura de prô dutos, nas reações sob aquecimento, poderia ser explicada pelo mecanismo indicado no esquema abaixo, [53].

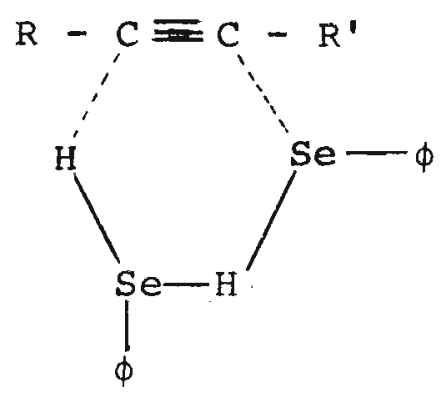


Este estado de transição, no entanto, teria um conteŭdo energético maior do que o que leva ao isômero 2 , o que determina a formação preferencial deste.

A regioespecificidade da adição a acetilenos aromäticos pode ser explicada facilmente, admitindo-se que os esquemas precedentes envolvem estados de transição com caráter de carbânion, o qual se formaria de preferência no carbono benzílico.

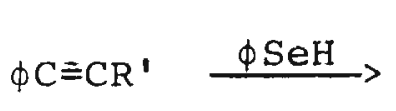<smiles>[R]C([Se]C)=[Se]O</smiles><smiles>O=CC[SeH]</smiles>

Já os acetilenos alifáticos não apresentariam essa estạ bilização. Pelo contrário, em vista do efeito indutivo tI do agrupamento alquila, o carbānion incipiente, no carbono 2 da dupla em formação, seria desestabilizado.<smiles>[R][C-]=[SbH]</smiles>

A formação exclusiva de etilenos 1,2-substituídos vem, portanto, sugerir que fatores estéricos são preponderantes, determinando o ataque Inicial no carbono menos impedido. Em apoio a esse argumento chamamos atenção sobre o fato de que um aumento no tamanho de $R^{\prime}$ diminui os rendimentos da adição de selenofenol 
TABEILA VI

$R C=C^{\prime} \stackrel{\text { Seif }}{\longrightarrow} \operatorname{RCH}=\mathrm{C}($ Seq $) R^{\prime}$

\begin{tabular}{|c|c|c|c|c|c|c|c|c|}
\hline $\begin{array}{c}\text { temperatura }\left({ }^{\circ} \mathrm{C}\right) / \text { tempo }(\mathrm{r}) \\
\text { de reacialo }\end{array}$ & \multicolumn{2}{|c|}{$\frac{120 / 11 / 2}{\text { zendiner:toz } 2 / \mathrm{Lq}}$} & \multicolumn{2}{|c|}{$\frac{120 / 3}{\text { rendimento\& } 2}$} & $\frac{120 / 48}{\text { ndimentos }}$ & $2 / x^{2}$ & $\frac{\text { t.a. } / 240}{\text { rendinertc? }}$ & $2 / E_{8}$ \\
\hline 3.a $\quad$ CCH=Crised $(a)$ & & & & & & & & \\
\hline 3.f $\quad \forall \mathrm{CH} \simeq \mathrm{C}(\mathrm{S} 3 ;) \mathrm{CH}_{3}$ & 62 & $53 / 47$ & 76 & $57 / 43$ & - & - & 960 & $92 / 3$ \\
\hline $3.1 \mathrm{pCE}=\mathrm{C}\left(\mathrm{Se}_{r}^{-}\right) \mathrm{CH}_{2} \mathrm{CH}_{3}$ & & $31 / 7$ & & $71 / 9$ & & $25 / 23$ & 50 & $>952$ \\
\hline $22.3 \quad \mathrm{Oi}_{2}$ (Se:) $\mathrm{COOK \textrm {O } _ { 3 }}$ & & $4 / 8$ & & $8 / 12$ & & $35 / 26$ & - & \\
\hline 3.n. $: a_{1}=C(\mathrm{Se}) \mathrm{CH}_{2} \mathrm{al}_{2} \mathrm{al}_{2} \mathrm{CH}_{3}$ & $<5$ & $>902$ & 25 & $>902$ & & $\sim 2: 1$ & $<5$ & $>902$ \\
\hline 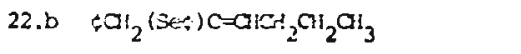 & - & & - & & & $\sim 2: 1$ & - & \\
\hline 3.q $\quad \mathrm{Ci}_{3} \mathrm{Ol}_{2} \mathrm{Cr}_{2} \mathrm{Ci}=\mathrm{Cl} \mathrm{Se}$ & 58 & & 71 & & 78 & $54 / 40$ & 35 & $>90 z$ \\
\hline 3.r $\quad \mathrm{CH}_{3} \mathrm{CH}_{2} \mathrm{Cl}_{2} \mathrm{CH}_{2} \mathrm{Cl}=\mathrm{OSSC}$ & 79 & $59 / 41$ & 64 & $69 / 31$ & 81 & $54 / 46$ & 60 & $>952$ \\
\hline 3.s $\mathrm{Cr}_{3} \mathrm{CH}_{2} \mathrm{OH}_{2} \mathrm{CH}_{2} \mathrm{CH}=\mathrm{C}\left(\mathrm{S} \mathrm{H}_{1}\right) \mathrm{CH}_{2} \mathrm{CH}_{2} \mathrm{CH}_{2} \mathrm{CH}_{3}$ & - & & - & & 27 & $70 / 30$ & - & \\
\hline
\end{tabular}

a) reaşäo incdicta à t.a. rend.: $90 \mathrm{~B}$ (parte experimer.tol III-B.L). 
TABELA VII

rmp do isômero $\mathrm{Z}\left(\mathrm{CCl}_{4}, \delta\right.$ em $\mathrm{ppm}, \mathrm{J}$ em $\mathrm{Hz}$, ref. interna TMS $)$

$\mathrm{Z}$
3. a $\stackrel{\mathrm{c}}{\underset{\phi}{\mathrm{CH}} \mathrm{a}} \underset{\mathrm{CH}}{\stackrel{\mathrm{b}}{\mathrm{e} \phi}} \stackrel{\mathrm{c}}{\frac{\mathrm{C}}{\mathrm{C}}}$
a. $6,67(1 \mathrm{H}, \mathrm{d}, \mathrm{Jab}=10)$
b. $6,87 \quad(1 \mathrm{H}, \mathrm{d}, \mathrm{Jba}=10)$
c. $7,0-7,6(10 \mathrm{H}, \mathrm{m})$

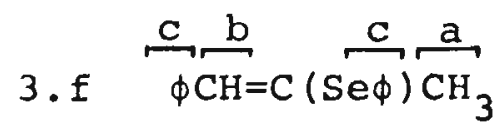

a. $2,03(3 \mathrm{H}, \mathrm{d}, \mathrm{Jab}=1,5)$
b. $6,73(1 \mathrm{H}, \mathrm{q}, \mathrm{Jab}=1,5)$
c. $7,0-7,6(10 \mathrm{H}, \mathrm{m})$

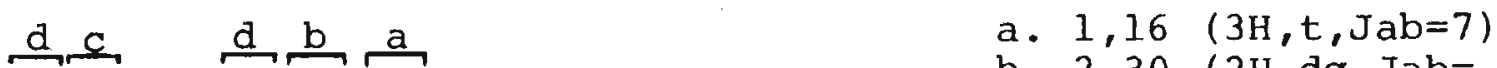

b. $2,30(2 \mathrm{H}, \mathrm{dq}, \mathrm{Jab}=7)$

$3.1 \phi \mathrm{CH}=\mathrm{C}(\mathrm{Se} \phi) \mathrm{CH}_{2} \mathrm{CH}_{3}$

c. $6,80(1 \mathrm{H}, t, \mathrm{Jcb} \propto 1)$

d. $7,1-7,6(10 \mathrm{H}, \mathrm{m})$

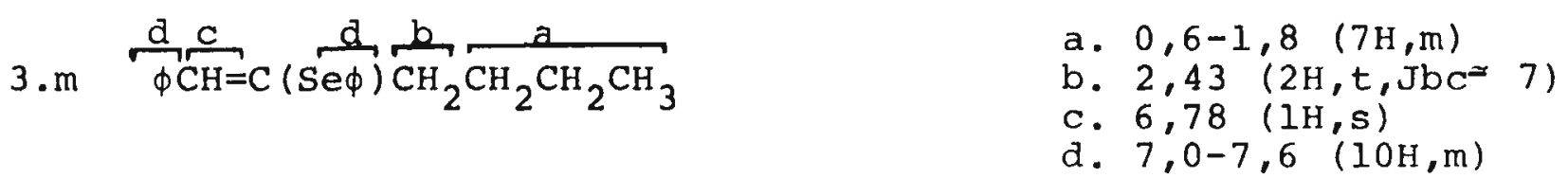

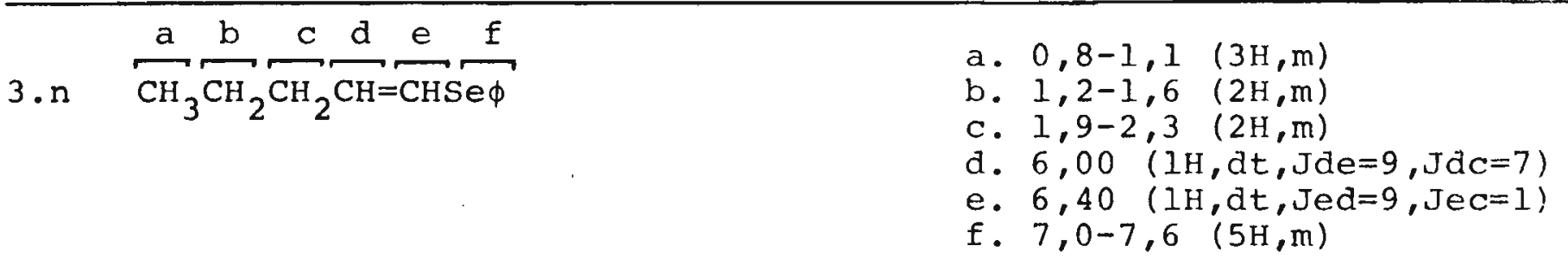

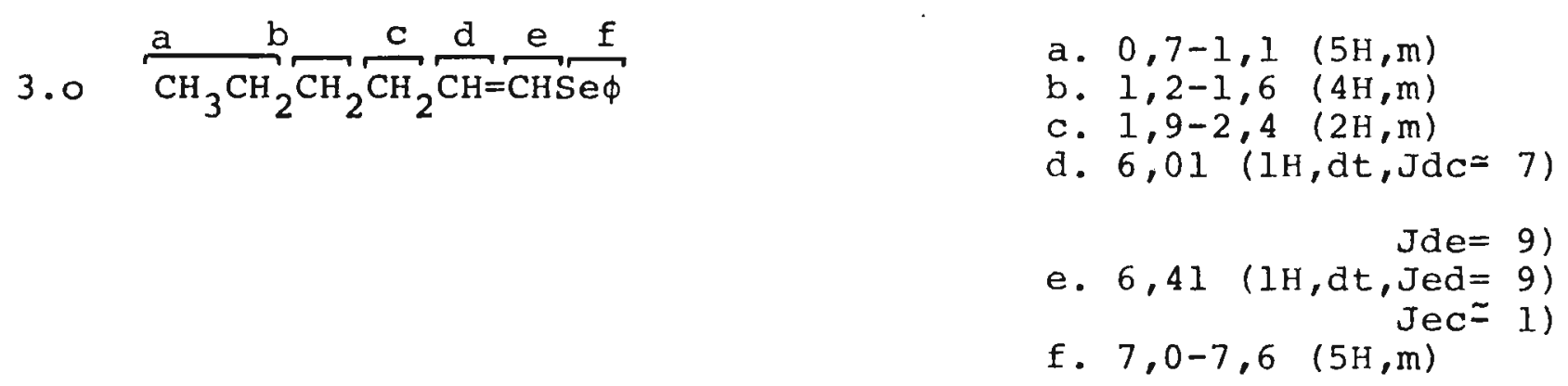

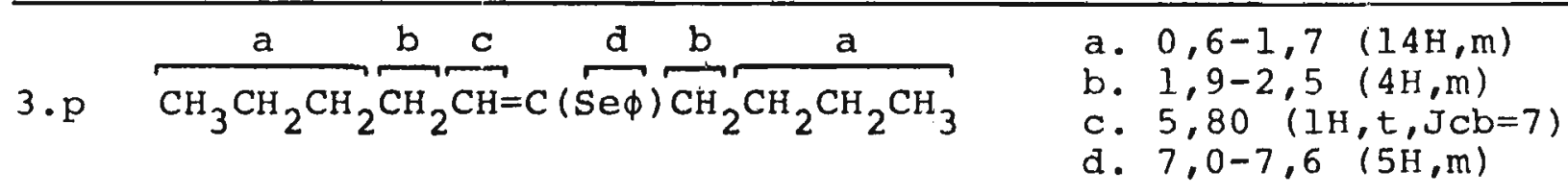


66.

a acetilenos aromáticos dissubstituídos.

Um resultado inesperado foi obtido na reação entre acetile nos aromāticos dissubstituídos $\left(\mathrm{R}^{\prime}>\mathrm{CH}_{3}\right)$ e selenofenol, quando a reação foi efetuada a $130^{\circ}$. Além do produto normal de adição (3) houve a formação de 2-alquil-1-benzil-1-fenilseleno etilenos (22).

$$
\phi \mathrm{C} \equiv \mathrm{CR}^{\prime} \frac{\phi \mathrm{SeH}}{130^{\circ}}>\quad \phi \mathrm{CH}_{2} \mathrm{C}(\operatorname{Se} \phi)=\mathrm{CHR} R^{\prime}+\phi \mathrm{CH}=\mathrm{C}(\operatorname{Se} \phi) \mathrm{R}^{\prime}
$$

Sabendo-se que acetilenos podem sofrer rearranjo em presen ça de bases, fornecendo alenos $[85]$, esse resultado pode ser interpretado da seguinte forma:

o Ion selenofenóxido, agindo como base, promove a conversão do acetileno em aleno, o qual sofre ataque de uma segunaa molécula de selenofenol.

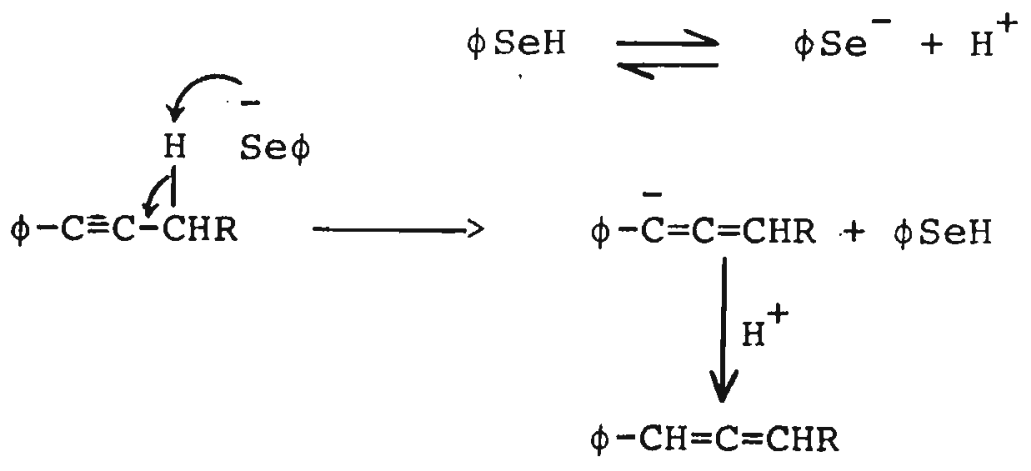

A orientação da adição seria determinada pela estabiliza- 
67.

ção do carbânion intermediário.

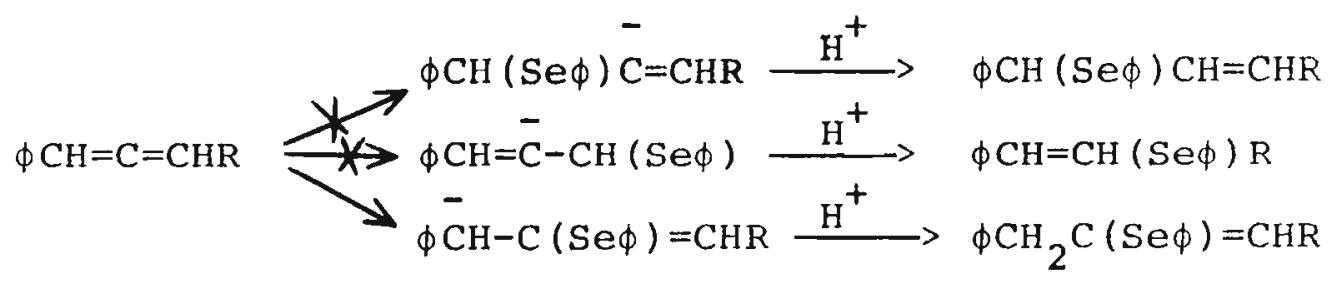

2. Reducão de (fenilseleno)acetilenos: Selenetos vinílicos E

Redução de acetilenos com hidreto de litio e alumínio fornece olefinas de configuração $E[60,108]$. E de se esperar que sele netos acetilênicos (24) possam ser reduzidos da mesma forma, produzindo selenetos vinílicos de configuração $E$.

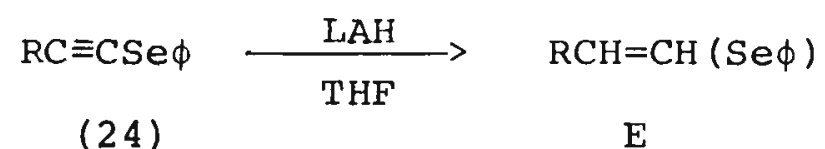

$$
\text { E }
$$

Selenetos acetilênicos (24) são facilmente preparados, com elevado rendimento, tratando-se os respectivos acetiletos de lítio com brometo de fenilselenenila.

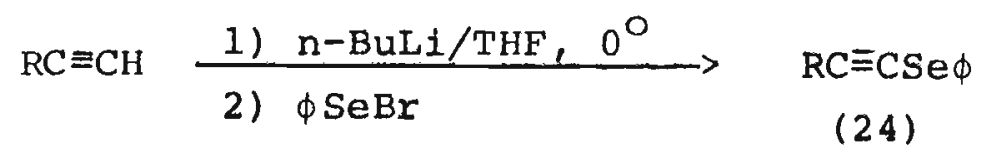

A redução dos (fenilseleno) acetilenos ocorreu conforme o * esperado, levando aos selenetos vinilicos de configuração E. Peque nas quantidades de isômero $\mathrm{z}$ foram detectadas por cgl. No entanto, 
68.

é possível que nas condições da reação (refluxo em THF por duas horas) tenha ocorrido isomerização.

Com relação ao mecanismo da redução podemos considerar um ataque do íon hidreto à ligação tripla, levando a um intermediārio no qual osagrupamentos volumosos se encontram o mais afastado possí vel.<smiles>[R]C=C([SeH])[Se][R9]</smiles>

$\mathrm{Na}$ redução de (fenilseleno)acetilenos alifáticos, alēm do produto esperado, formou-se difenildisseleneto. Certamente ocorreu ruptura da ligação carbono-selênio (ataque de íon hidreto ao selênio), com formação de selenofenol seguida de oxidação durante o iso lamento do produto.

$$
\mathrm{RC} \equiv \mathrm{CSe} \phi \frac{\mathrm{LAH}}{\mathrm{THF}} \longrightarrow \mathrm{RC} \equiv \mathrm{C}^{-}+\phi \mathrm{SeH} \longrightarrow \phi \operatorname{SeSe} \phi+\mathrm{RC} \equiv \mathrm{CH}
$$




\section{TABELA VIII}

$$
\begin{aligned}
& \mathrm{RC} \equiv \mathrm{CH} \stackrel{\text { 1) } \mathrm{BuLi}}{\longrightarrow} \mathrm{RC} \equiv \mathrm{CSe} \phi \\
& \text { 2) } \phi \mathrm{SeBr} \text { (24) }
\end{aligned}
$$

$\mathrm{RC} \equiv \operatorname{CSe} \phi \quad$ rendimento 8 p.e. ${ }^{\circ} \mathrm{C} / \mathrm{mmHg} \frac{\text { Anälise, encont. (Calc.) }}{\mathrm{C} q}$

24. $\mathrm{a} \phi \mathrm{C} \equiv \operatorname{CSe} \phi \quad 90 \quad 130-137 / 1,5 \times 10^{-2}$

\begin{tabular}{|c|c|c|c|c|}
\hline & $\mathrm{CH}_{3} \mathrm{CH}_{2} \mathrm{CH}_{2} \mathrm{CH}_{2} \mathrm{C} \equiv \mathrm{CSe} \phi$ & 93 & $107 / 7 \times 10^{-2}$ & $\begin{array}{c}60,53 \\
(60,79)\end{array}$ \\
\hline
\end{tabular}

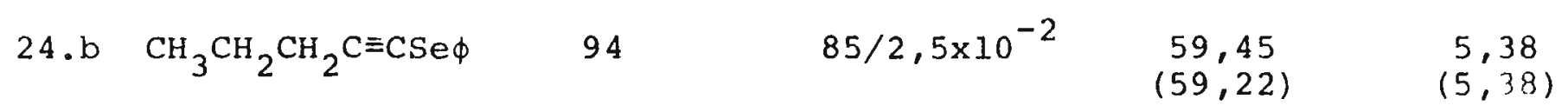


70.

\section{TABELA IX}

$\mathrm{RC} \equiv \mathrm{CSe} \phi \stackrel{\mathrm{LAH}}{\longrightarrow} \mathrm{RCH}=\mathrm{CHSe} \phi$

(24) (3)

$\mathrm{RCH}=\mathrm{CHSe} \phi$

rendimento p.e. ${ }^{\circ} \mathrm{C} / \mathrm{mmHg}$ Análise, encont. (Calc.)

$\mathrm{C} 8$

$\mathrm{H}$ 웅

3. $\mathrm{a} \phi \mathrm{CH}=\mathrm{CHSe} \phi \quad 92 \quad 130-137 / 1,5 \times 10^{-2}$

3. n $\quad \mathrm{C}_{3} \mathrm{H}_{7} \mathrm{CH}=\mathrm{CHSe} \phi$

60

$75 / 10^{-2}$

58.84

6,84

$(58,70)$

$(6,22)$

$3.0 \quad \mathrm{C}_{4} \mathrm{H}_{9} \mathrm{CH}=\mathrm{CHSe} \phi$

48

$95 / 5 \times 10^{-2}$

60.51

6,69

$(60.28)$

$(6,69)$ 
E. Hidrōlise de selenetos vinilicos: cetonas

A conversão hidrolitica de sulfetos vinilicos a cetonas encontra-se descrita na literatura $[42,31,23]$. Como agentes hi drolisantes são utilizados ácido trifluoroacético [23] ou cloreto de mercúrio em acetonitrila e água [31].

Ut1lizando os mesmos reagentes efetuamos com sucesso a hidrólise de selenetos vinilicos

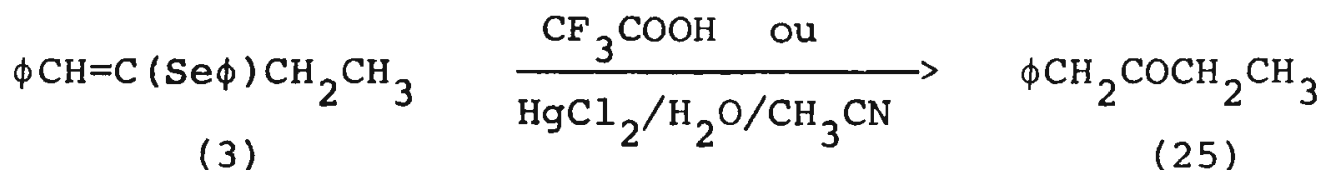




\section{F. Determinação da Configuração dos Selenetos Vinilicos}

Existem poucos estudos de rmp de compostos de selênio [56]. Até iniciarmos este trabalho nenhum dado de rmp de selenetos vinilicos existia na literatura. Portanto, determinar a configuração de selenetos vinilicos em misturas apenas por rmp seria uma tarefa arris cada. Por outro lado, esse conhecimento se fazia necessārio a fim de determinarmos as proporções 1soméricas nas misturas de produtos das reações de Wittig e Horner-Emmons de (fenilseleno)fosforanas e fosfonatos com compostos carbonilicos.

Em vista disso, fez-se necessário preparar selenetos viníli cos estereosseletivamente e, posteriormente, comparar os espectros dos compostos de uma mesma estrutura, mas de configurações opostas,preparados por métodos diferentes.

Passaremos a comentar separadamente os espectros de rmp dos compostos de configurações. diferentes.*

1. rmp de selenetos vinílicos dissubstituídos de configuração E

No capitulo precedente relatamos que selenetos vinilicos de configuração $\mathrm{E}$ podem ser preparados por redução de selenetos acetiliê

* Os deslocamentos químicos serão dados em untdades $\delta$. 
nicos com LAH. Por outro lado, é geralmente aceito que a reação de Horner-Emmons também conduz preferencialmente à olefina de configuração E $[24]$.

A análise dos espectros de rmp levou à conclusão de que es sas asserções são verdadeiras.

Todos os selenetos vinÍlicos alifáticos dissubstituídos, preparados tanto por redução dos respectivos selenetos acetilênicos como pela reação de Horner-Emmons, apresentaram espectros de rmp muito semelhantes na região olefinica. Analisaremos a região olefi nica de um espectro típico, o do 1-(fenilseleno)-1-penteno (figura 2).

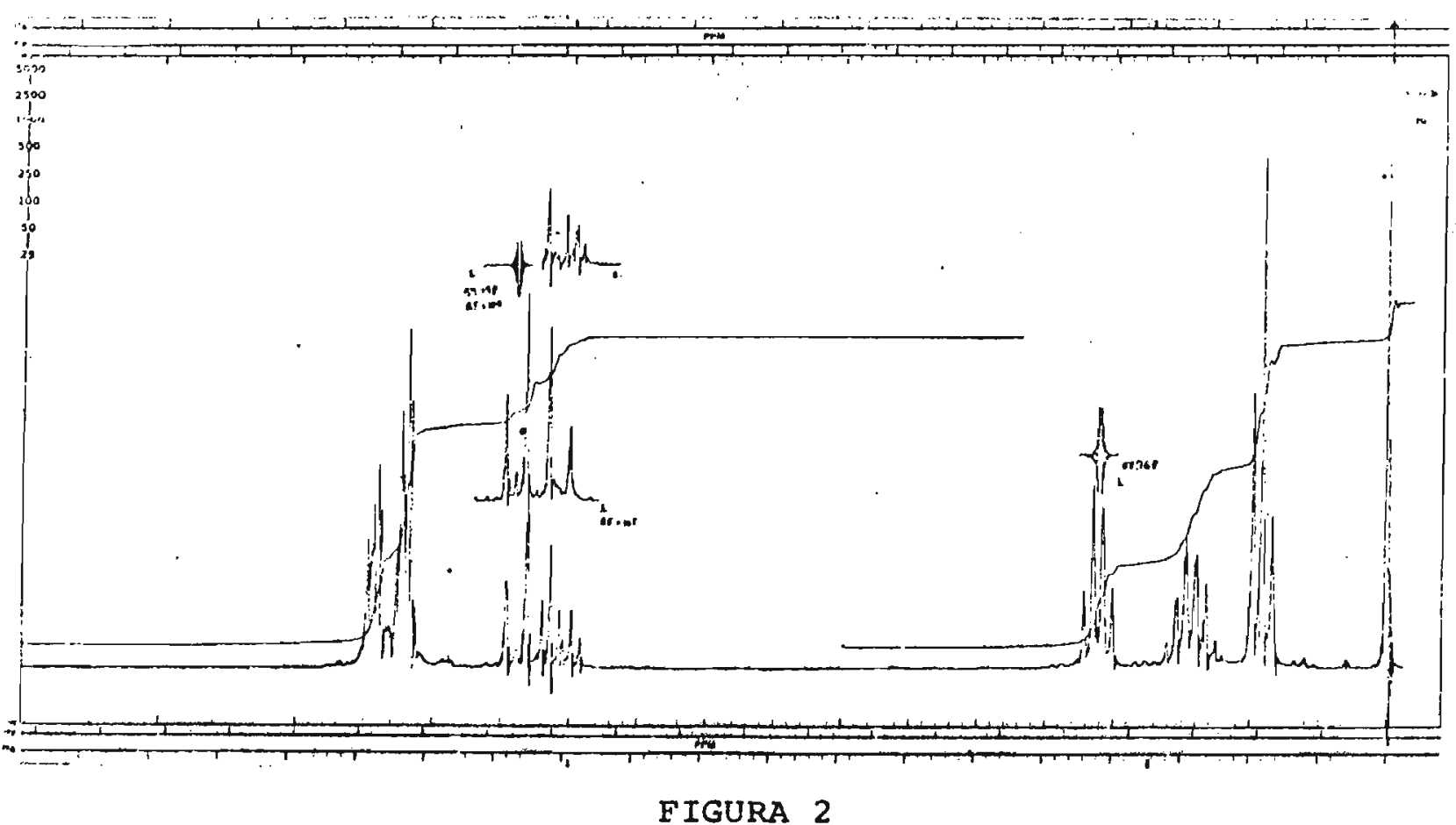

Espectro de rmp do 1-(fenilseleno)-1-penteno (isömero E) registrado a $100 \mathrm{MHz}$, usando como solvente $\mathrm{CDCl}_{3} \cdot$ 
2,10

(c)

(e)

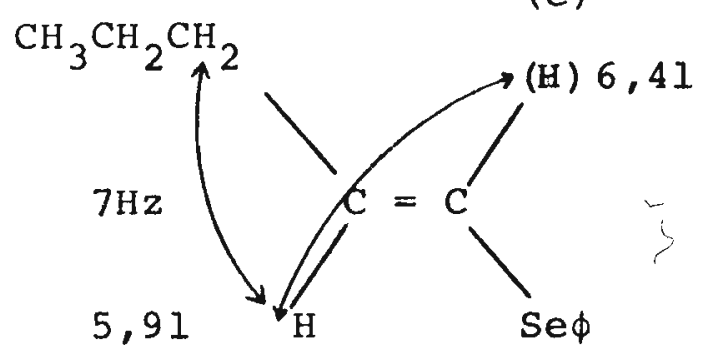

(d)

Em campo mais elevado $(5,91 \delta)$ observamos um duplo triplete com constantes de acoplamento de $14 \mathrm{~Hz}$ e $7 \mathrm{~Hz}$. Essa felção espectral só pode corresponder ao próton $\mathrm{H}_{\mathrm{d}}\left(\mathrm{J}_{\mathrm{dc}}=7, \mathrm{~J}_{\mathrm{da}}=14\right)$. Dupla irradiação do quarteto em 2,108 ( $\left.\mathrm{H}_{c}\right)$ transformou o duplo triplete em $5,91 \delta$ num dublete com congtante de acoplamento de $14 \mathrm{~Hz}$, característica de acoplamento trans [48]. Com isso fica demonstrado inequívocamente que o dublete com constante de acoplamento de $14 \mathrm{~Hz}$ em $6,41 \delta$ corresponde ao próton $\mathrm{H}_{e}$ (geminal ao grupo fenilseleno).0 grupo fenilseleno exerce, portanto, um efeito anisotrópico pronuncia do.

Apesar da literatura indicar um valor médio de 1,5 Hz para o acoplamento alfilco cisóide [9], não observamos acoplamento entre $\mathrm{H}_{\mathrm{e}}$ e $\mathrm{H}_{\mathrm{C}} \cdot$

Os selenetos vinílicos aromáticos, como seria de esperar,- 
apresentam um espectro de rmp bem mais simples do que os alifáticos.

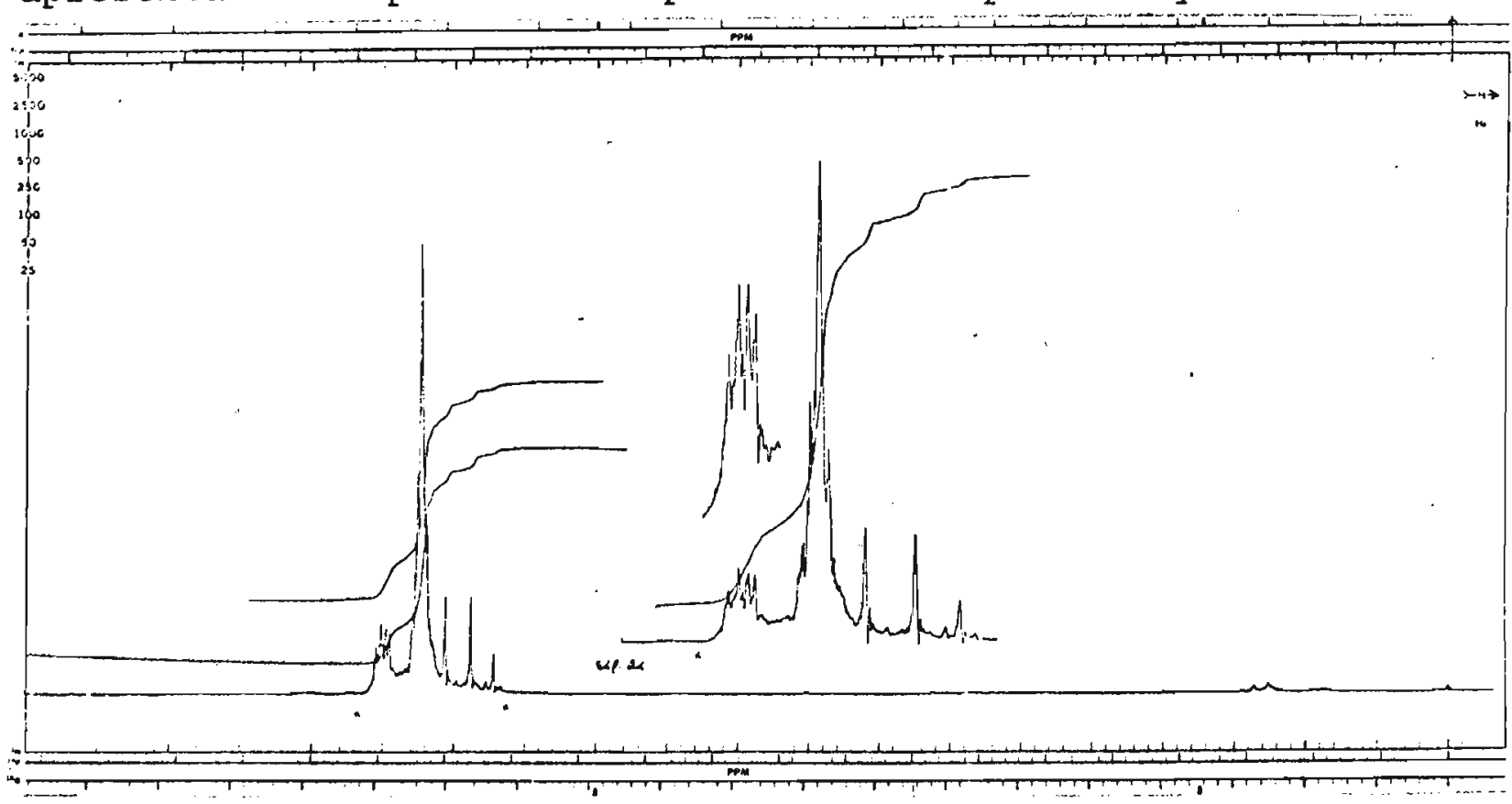

FIGURA 3

Espectro de rmp do 1-(fenilseleno)-2-fenileteno (isômero E) registra do a $100 \mathrm{MHz}$, usando como solvente $\mathrm{CDCl}_{3}$.

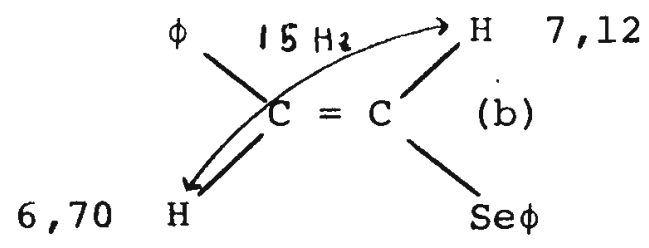

(a)

o 1-(fenilseleno)-2-fenileteno, preparado tanto por redução do (fenilseleno) fentlacetileno como pela reação de Horner-Emmons, apresentou um duplo dublete centrado em $6,97 \delta$, com uma constante de 
acoplamento de $15 \mathrm{~Hz}$, característica de acoplamento trans [48]. O dublete em campo mais baixo $(7,12 \delta)$ foi atribuỉo ao próton $\mathrm{H}_{\mathrm{b}}$ (devi do à anisotropia do grupo fenilseleno, em analogia à análise feita para o 1-(fenilseleno)-1-penteno); o dublete em campo mais alto $(6,70 \delta)$ corresponde ao próton $\mathrm{H}_{\mathrm{a}}$.

2. rmp de selenetos vinilicos dissubstituídos de configuração $Z$

A configuração dos selenetos vinilicos de configuração $\mathrm{Z}$, preparados por adição de selenofenol a acetilenos, à temperatura ambiente, foi atribuída pela análise dos espectros de rmp conforme se segue:

Adição de selenofenol ao 1-pentino ou ao 1-hexino, à tempe ratura ambiente, forneceu o seleneto vinílico cujo espectro de rmp se mostrou semelhante ao do mesmo composto de configuração $\mathrm{E}$. 


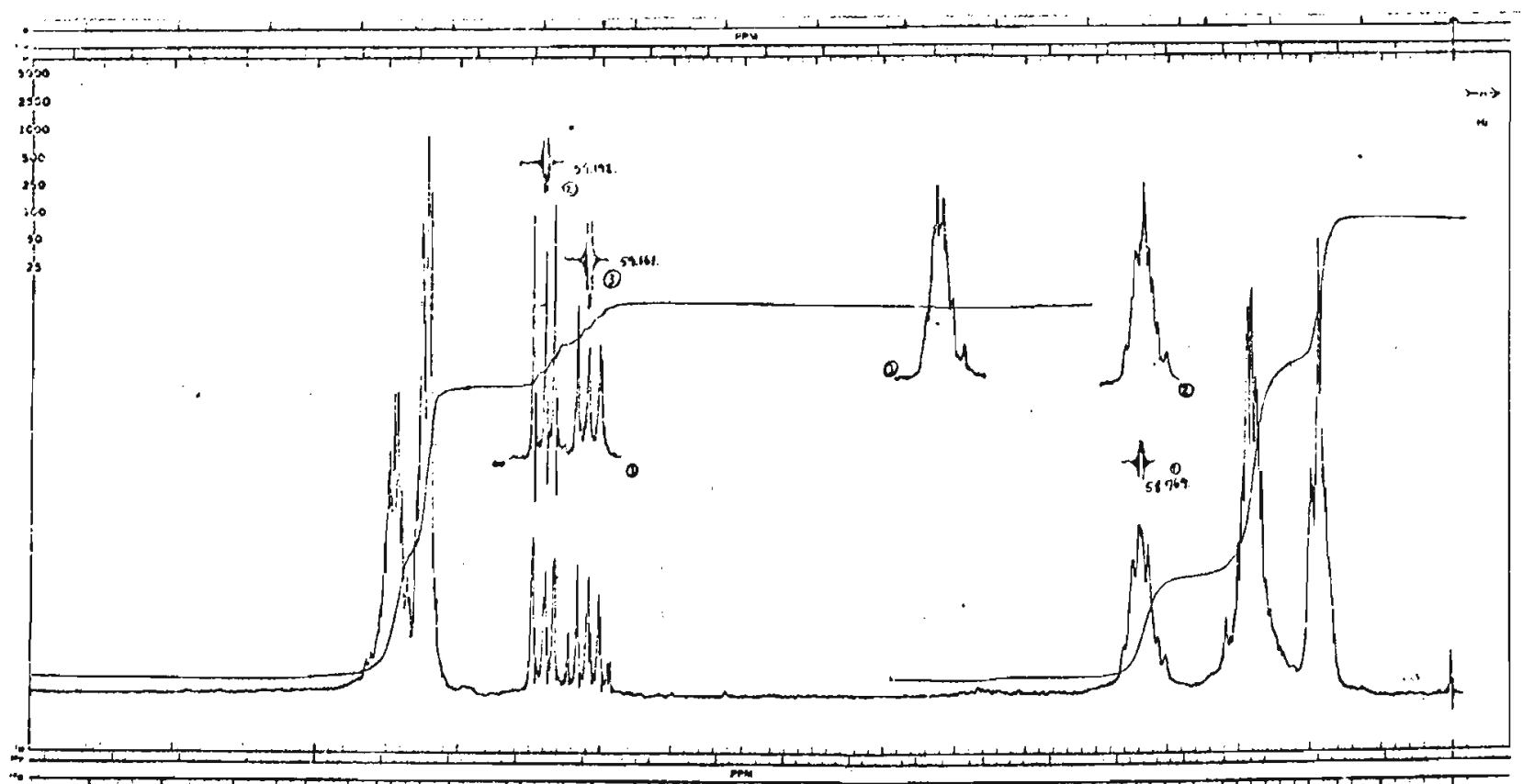

FIGURA 4

Espectro de rmp do 1 -(fenilseleno)-1-hexeno $(\mathrm{Z}+\mathrm{E})$ registrado a 100 $\mathrm{MHz}$, usando como solvente $\mathrm{CDCl}_{3}$. 
78 .

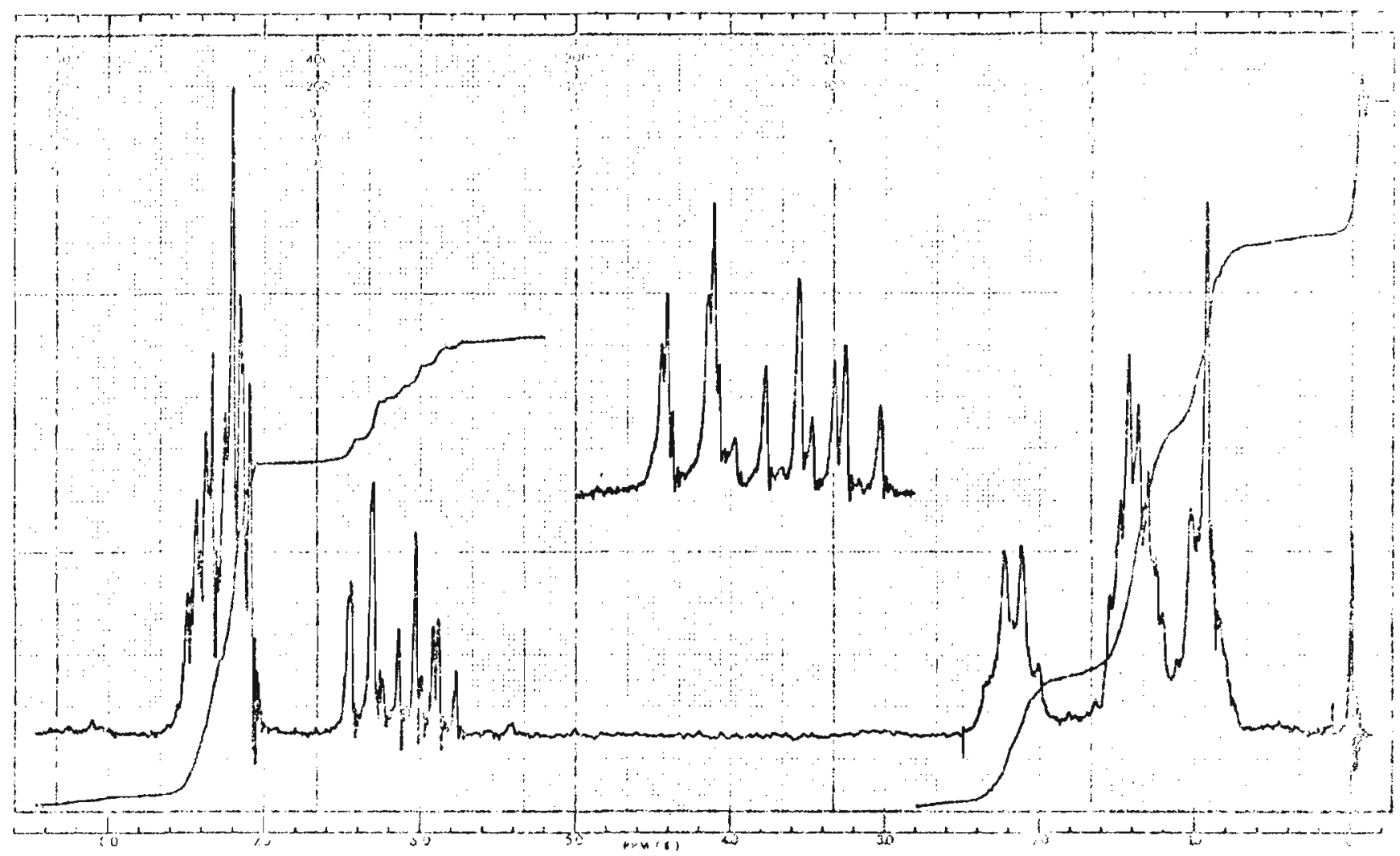

FIGURA 5

Espectro de rmp do 1-(fenilseleno)-l-hexeno (isômero $\mathrm{Z}$ ) registrado a $60 \mathrm{MHz}$, usando como solvente $\mathrm{CCl}_{4}$.

$$
1,9-2,3
$$

(c)

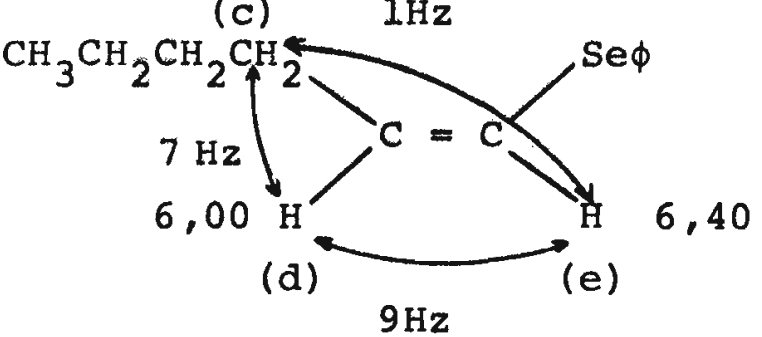


Em 6,008 observamos um duplo triplete com constantes de acoplamento de $9 \mathrm{~Hz}$ e $7 \mathrm{~Hz}$. Dupla irradiação do multiplete a $1,9-2,3 \delta$ transformou o duplo triplete num dublete com constante de acoplamento de $9 \mathrm{~Hz}$, típica de acoplamento cis [48].* Pelas mesmas razões que as consideradas para o composto de configuração $E$, esse sinal deve corresponder ao prōton $\mathrm{H}_{\mathrm{d}} \cdot \mathrm{Em} 6,40 \delta$ aparece um duplo triplete com constantes de acoplamento de $9 \mathrm{~Hz}$ e $\sim \mathrm{Hz}$. Esse sinal foi atribuido ao próton $\mathrm{H}_{\mathrm{e}}$. Ao contrārio do composto de configuração $\mathrm{E}$, neste caso observamos um acoplamento alílico com uma constante de acoplamento transóide de $\sim$ lHz entre $\mathrm{H}_{e}$ e $\mathrm{H}_{\mathrm{C}}$. O espectro de rmp do produto da reação entre fenilacetileno e selenofenol também se mostrou semelhante (na região olefinica) ao espectro do produto de configuração E.

* A dupla irradiação foi efetuada com uma amostra constituída por uma mistura de selenetos vinilicos Z e E. As conclusões foram tIradas por comparação com um espectro do isômero E puro. 0 1øômero 2 isomeriza facilmente, fornecendo uma mistura de isômeros (50:50 por cgl), de modo que só foi possível obter o espectro do isômero $\mathrm{Z}$ puro a $60 \mathrm{MHz}$. 


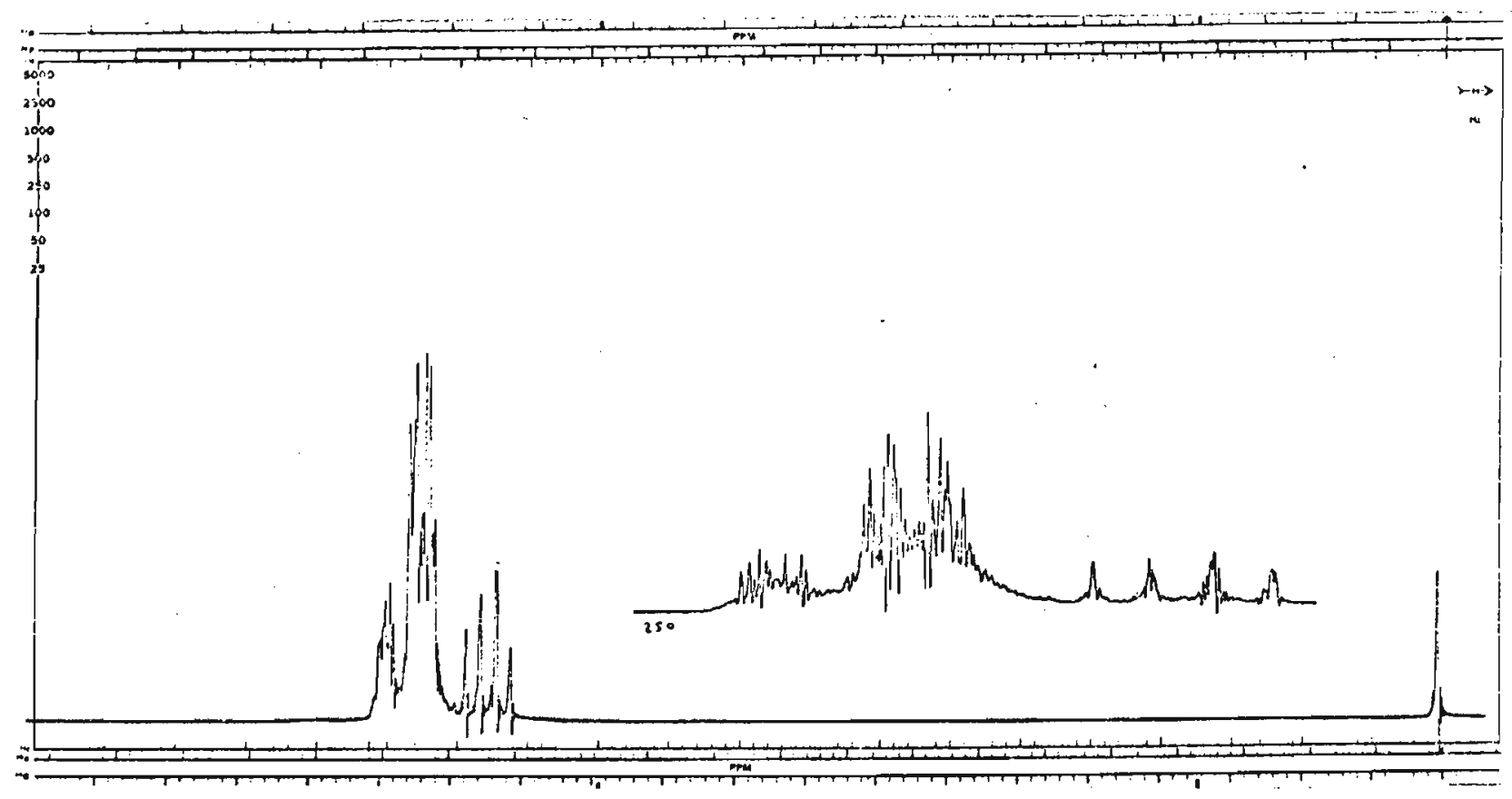

FIGURA 6

Espectro de rmp do 1-(fenilseleno)-2-fenileteno (isômero Z) registrado a $100 \mathrm{MHz}$ usando $\mathrm{CCl}_{4}$ como solvente

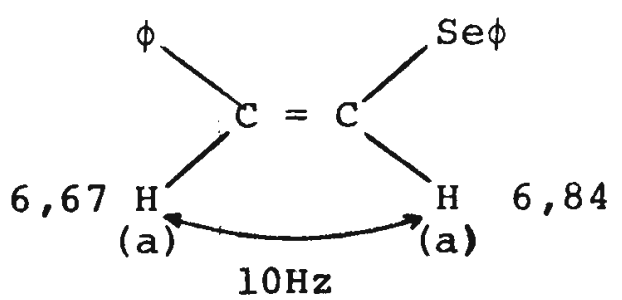

A região olefínica se constitui num duplo dublete com constante de acoplamento de $10 \mathrm{~Hz}$ centrado em 6,76 $\delta$. O dublete em $6,67 \delta$ deve corresponder ao próton $\mathrm{H}_{\mathrm{a}} \mathrm{e} \circ$ dublete em $6,84 \delta$ ao 
prōton $\mathrm{H}_{\mathrm{b}}$, tendo em vista a anisotropia do grupo fenilseleno.

Em apoio ao que foi dito acima salientamos que os espectros de absorção no iv dos selenetos vinílicos dissubstituídos, preparados por redução de (fenilseleno) acetilenos, ou através da reação de Horner-Emmons, apresentaram uma banda forte em $945 \mathrm{~cm}^{-1}$ (dobramento fora do plano em olefina E dissubstituía [68]). Essa banda se encon tra ausente nos produtos da reação de adição de selenofenol a acetilenos à temperatura ambiente (isômero $\mathrm{Z}$ ).

\section{Selenetos Vinilicos Trissubstituídos}

Não foi possivel determinar a configuração de selenetos vinilicos trissubstituídos da mesma forma com que procedemos com os se lenetos vinilicos dissubstituídos, pelo fato dos primeiros não apresentarem diferenças marcantes nas constantes de acoplamento entre os isômeros $\mathrm{Z}$ e $\mathrm{E}$.

Portanto, preparamos selenetos vinílicos idênticos, mas de configurações opostas, pela adição de selenofenol a acetilenos dissubs t1tuldos ( $(Z)$ e pela reação de Horner-Emmons (E). Os deslocamentos químicos, tanto dos prótons vinilicos como dos prótons alilicos, mos traram-se diferentes nos compostos preparados por mëtodos diferentes. Supondo-se uma estereosseletividade constante (isto é, a adıção de selenofenol a acetilenos fornecendo sempre a olefina de configuração $Z$ e a reação de Horner-Emmons fornecendo sempre a olefina de configu 
ração E), podemos fazer as atribuições que se seguem.

Produto da adição de selefenol

a acetilenos.

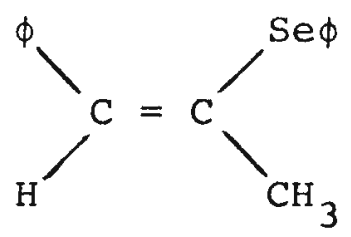

6,73

2,03

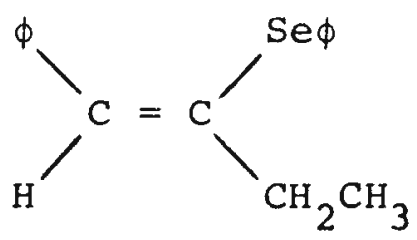

6,80

2,30

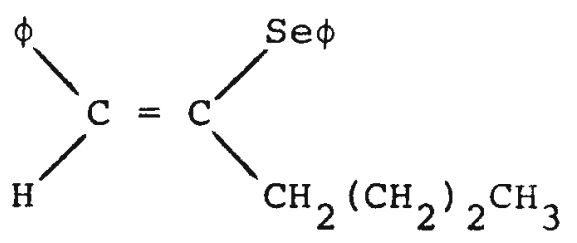

6,78

2,43
Produto da reação de Horner-Emmons.
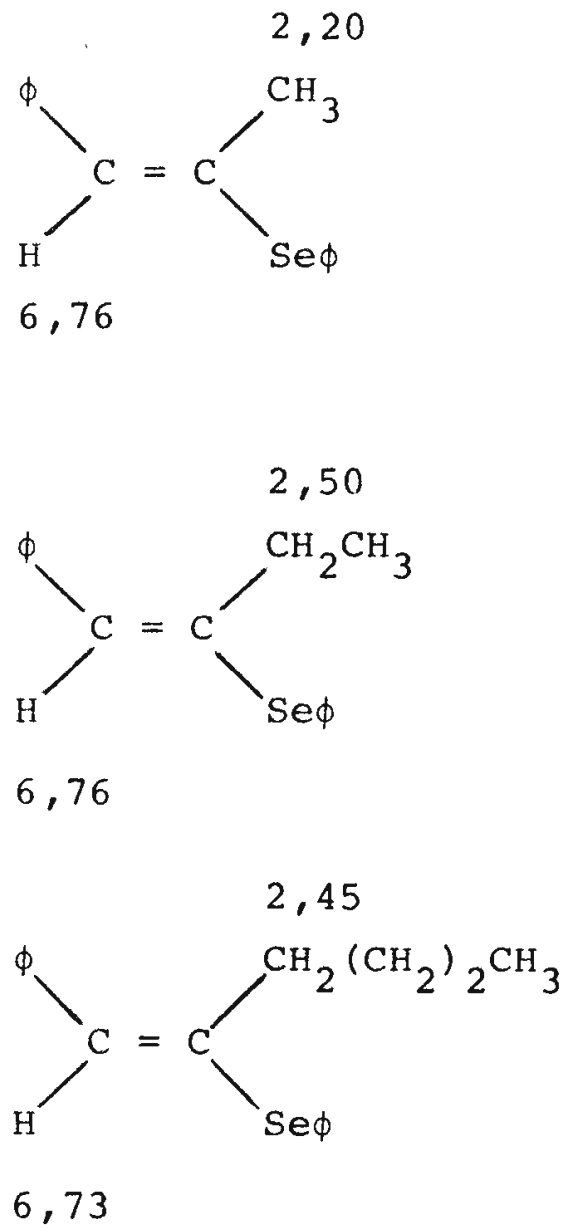
83.

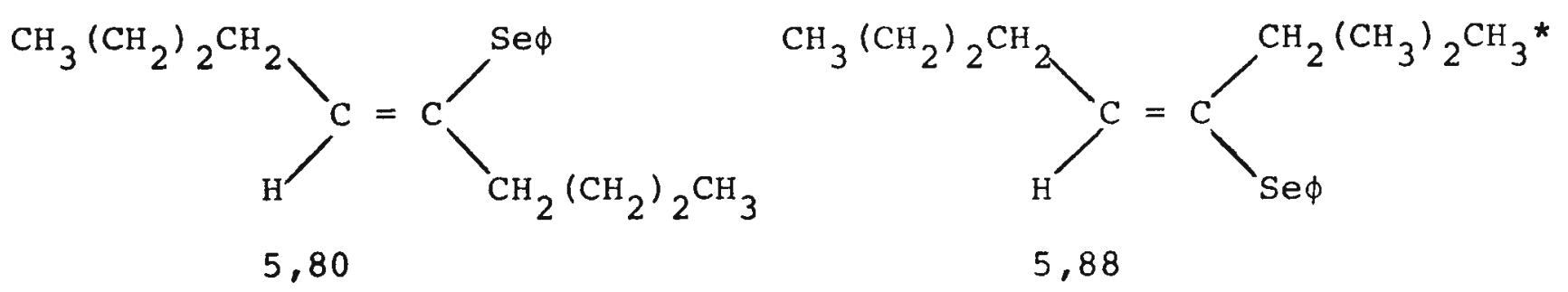

Como podemos observar, nos selenetos vinílicos aromāticos o próton vinílico do isômero $\mathrm{z}$ é mais protegido do que o do isômero $E_{\text {, }}$ quando o substituinte alquila é $\mathrm{CH}_{3}$. O prōton vinilico sofre a influência da anisotropia do selènio, sendo menos protegido quando se encontra em cis ao grupo fenilseleno.

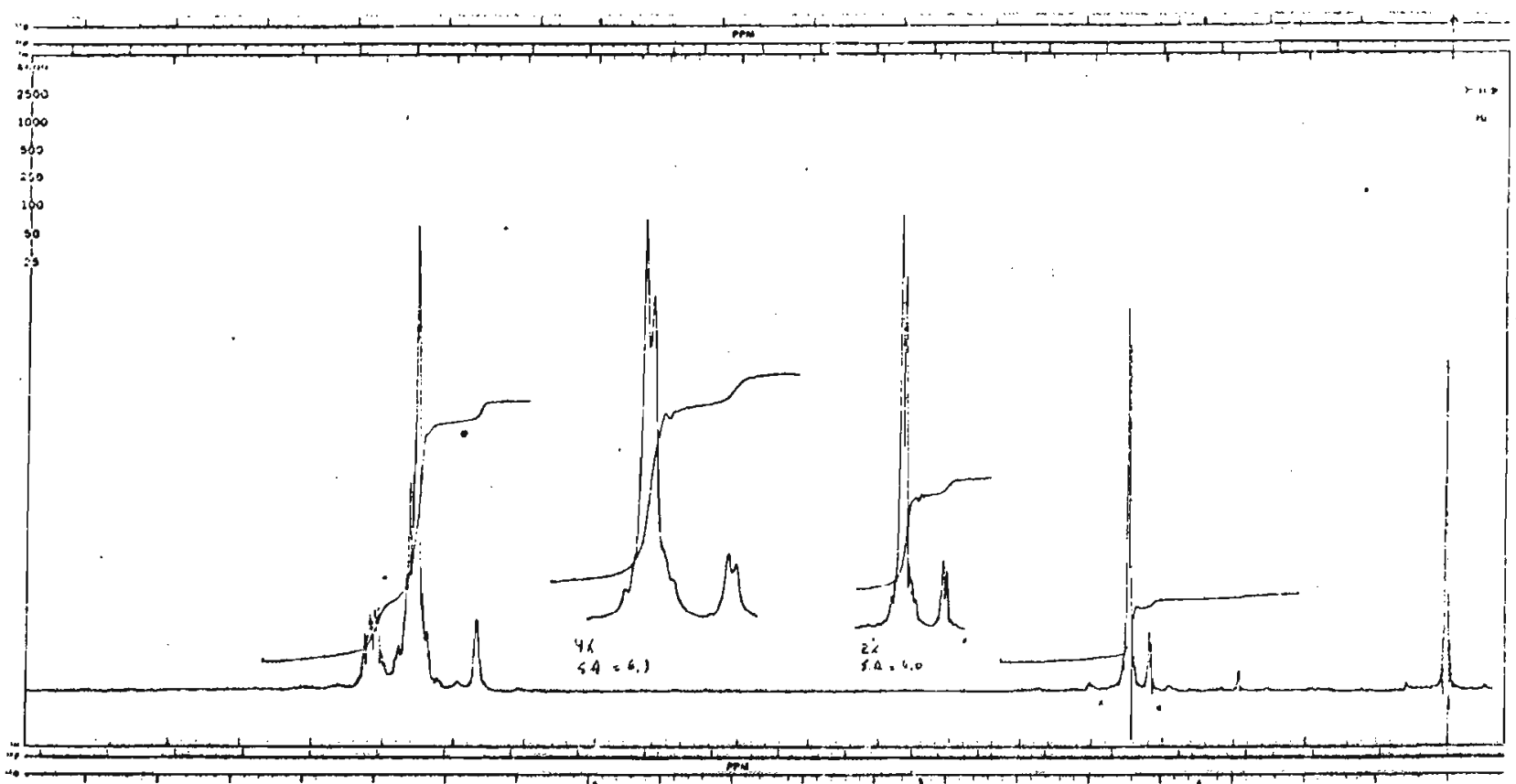

FIGURA 7

Espectro de rmp do 2-(fenilseleno)-3-fenil-2-propeno (isômero E) registrado a $100 \mathrm{MHz}$, usando como solvente $\mathrm{CDCl}_{3}$.

* Isômero menos abundante da mistura de reação entre 5-decino e selenofenol. 
84 .

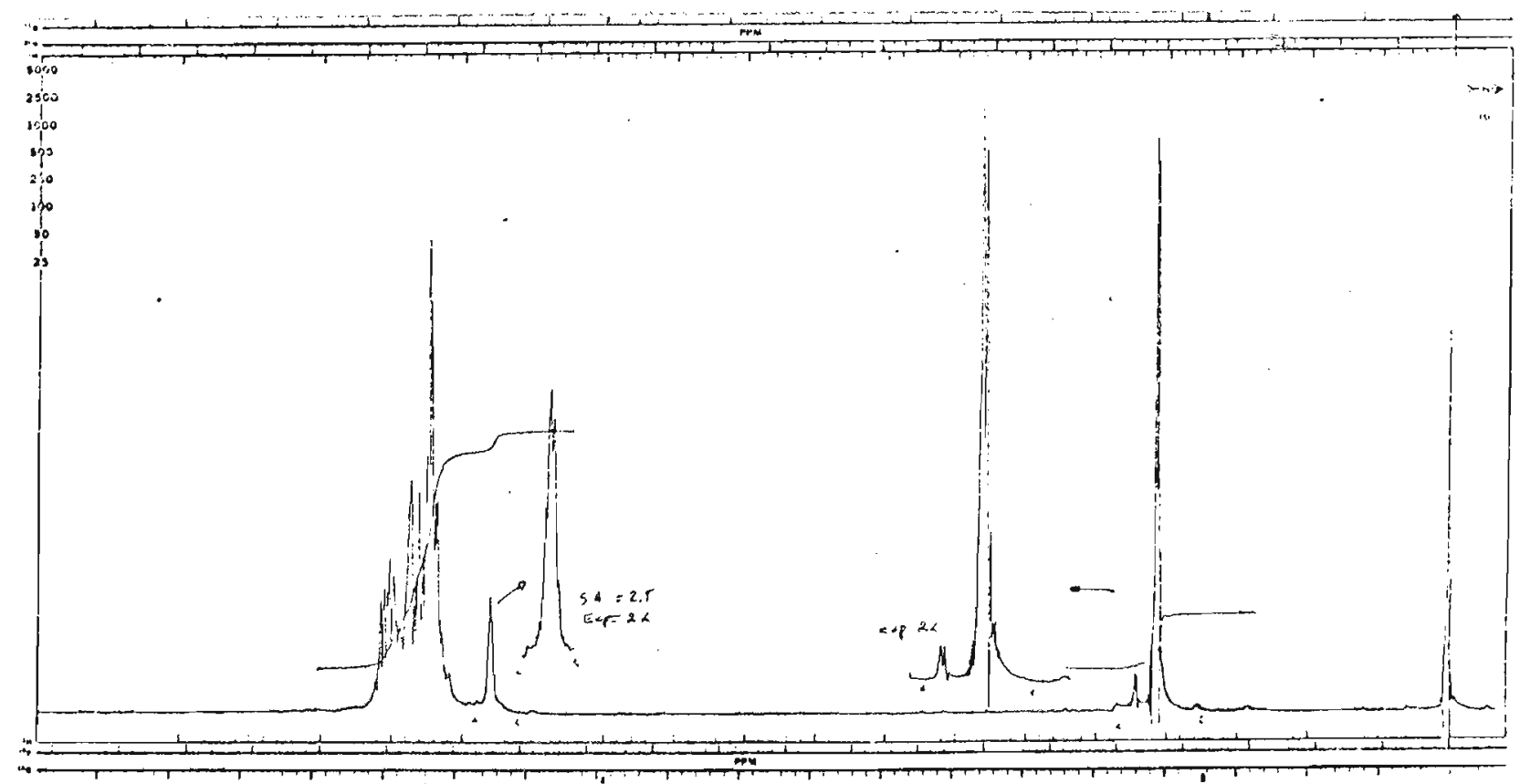

FIGURA 8

Espectro de rmp do 2-(fenilseleno)-3-fenil-2-propeno (isômero Z) registrado a $100 \mathrm{MHz}$, usando como solvente $\mathrm{CDCl}_{3}$.

Quando o tamanho do substituinte alquila aumenta, essa ordem se inverte. Tal fato pode ser explicado pela existência de uma conformação onde o grupo fenila doagrupamento fenilseleno (no composto de configuração E) è forçado para baixo pelo grupo alquila mais volumoso. 

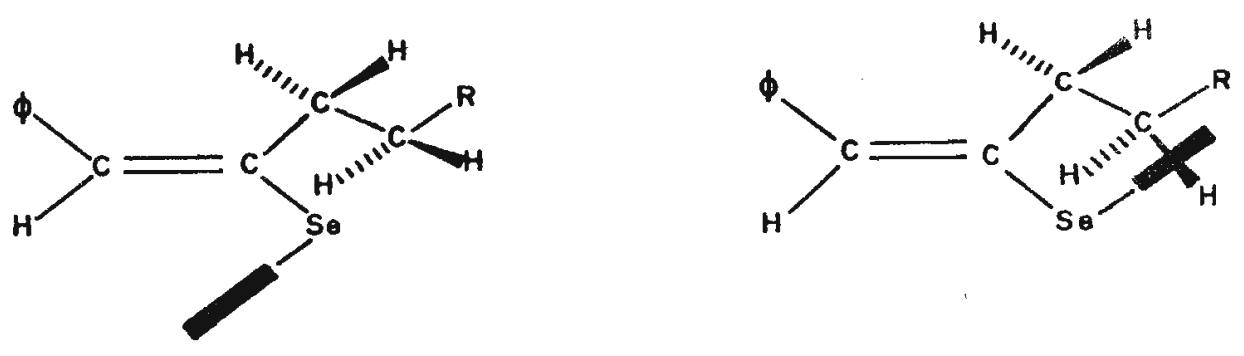

FIGURA 9

Isso faz com que o prōton vinílico se localize na região de proteção do grupo fenila, provocando a inversão de sinais.

Exame dos modelos das duas conformações indicou que, realmente, existem sérias interações entre os grupos etila e butila e o grupo fenilseleno, interações essas Inexistentes no composto substituido por metila.

Por outro lado, $\mathrm{cgl}$ dos selenetos vinilicos que tiveram suas configurações determinadas inequívocamente por $\mathrm{rmp}$, apresentou sempre um tempo de retenção maior para o isômero E. Essa propriedade foi exibida também pelos selenetos vinilicos trissubstituidos. O isômero principal da reação de Horner-Emmons apresentou sempre tempo de retenção maior do que o isômero principal produzido pela reação de adição de selenofenol a acetilenos. 


\section{CAPITULO V}

\section{EstereoguImica da Reação de Wittig e Horner-Emmons}

A seguir discutiremos os fatores que determinam a estereosseletividade das reações de Wittig e Horner-Emmons. Este capítulo não pretende ser uma revisão bibliogräfica, mas um estudo crítico dos pontos de vista sobre a estereoquimica dessas reações, baseado em revisões bibliogräficas e em artigos originais recentes.

Apesar de terem se passado mais de duas décadas desde a introdução da reações de wittig como método de olefinação a partir de compostos carbonilicos, seu mecanismo e, consequentemente, as explicações de seu decurso estérico, permanecem quase que exclusivamente em bases especulativas.

A literatura química apresenta vārias interpretações, das quais algumas apolam plenamente, outras apenas parcialmente, os dados experimentais. Schlosser, em revisão publicada em 1970 [90] e re publicada em 1975 [61], utiliza o conceito de "perfis energéticos" da reação, sem contudo construir um modelo para o estado de transição. Parece-nos necessárto, no entanto, sugerir modelos concretos que per mitam visualizar o estado de transição, tornando małs fácil a previsão da estereoguímica dessas reações.

Afirmou-se acertadamente [61] que o problema da estereoquí- 
87.

mica da reação de Wittig è "mais uma arte do que uma ciência". Neste trabalho apresentaremos o problema sob esse ângulo, tentando cor relacionar os modelos existentes na literatura sempre que os mesmos se mostrarem em concordāncia com os fatos experimentais $[15,16,17,-$ $44,49,83,90]$.

Inicialmente é necessário postular as espēcies envolvidas no decorrer da reação, sem o que não poderemos discutir seu decurso estérico.

E ainda motivo de especulação se o sistema reacional (fosforana e composto carbonflicol fornece olefina e fosfinóxido passan do por um "zwitterion" de cadela aberta (betaina), por um intermedi ário cíclico (oxifosfetana) ou por ambos consecutivamente $[36,111,-$ 116 ]. A sequência apresentada a seguir não tem confirmação experi mental.

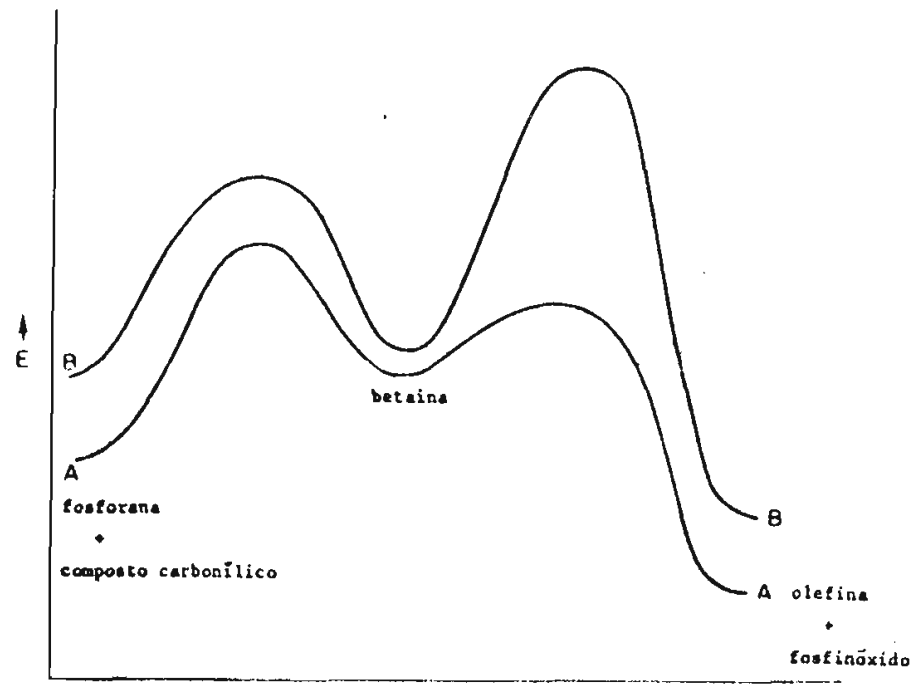

FIGURA 10 
88.

Conforme o esquema acima, o primeiro passo da reação consiste no ataque nucleofílico da fosforana à carbonila, levando à betaina. Esse ataque será tanto mais rápido quanto: 19) mais nucleófila (reativa) for a fosforana; 29) mais eletrófila for a carbonila.

Dependendo da face da carbonila pela qual se dā o ataque, dois intermediārios diferentes podem ser obtidos, um de configuração exitro e outro de configuração treo. Esses dois intermediārios forneceriam, respectivamente, a olefina z e a olefina E. Por mo tivos ainda não explicados a betaina eritro se forma preferencialmente.

Experimentalmente observa-se que a reação de uma fosforana estabilizada com um composto carbonílico fornece preferencialmente olefina E 90 . Com referência ao esquema abaixo, isso significa que as relações $k_{3} / k_{1}, k_{6} / k_{5} e k_{6} / k_{3}$ são elevadas, ou seja,a betaina treo é favorecida e sua decomposição em olefina e fosfinóxido é mais rápida do que a da betaina eritro.

Por outro lado, fosforanas não estabilizadas, nas mesmas condições, fornecem preferencialmente a olefina $z$. Nos termos do esquema abaixo 1 sso signiflca que as relações $\mathrm{k}_{1} / \mathrm{k}_{3}, \mathrm{k}_{5} / \mathrm{k}_{6}$ e $\mathrm{k}_{5} / \mathrm{k}_{1}$ são elevadas, ou seja, a betaina eritro é favorecida e/ou sua decomposição em olefina e fosfinōxido deverá ser rápida [37]. 
89.

ESQUEMA 1.

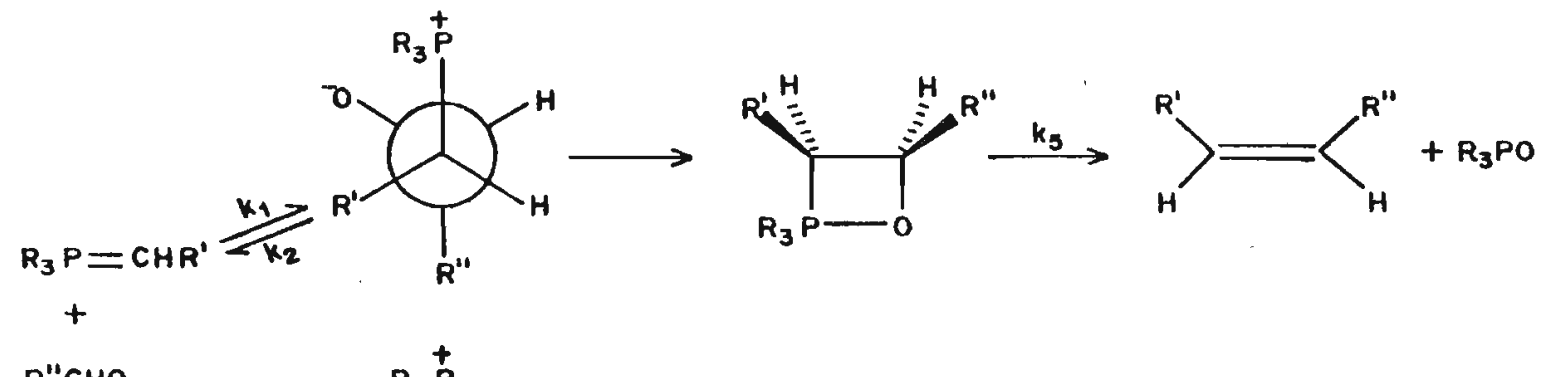

R"CHO

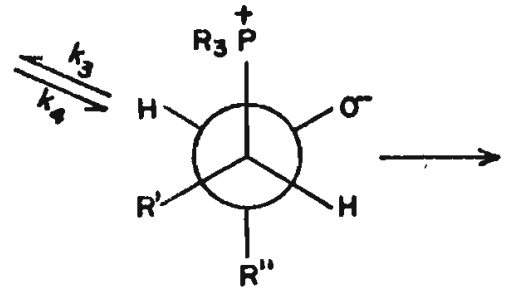

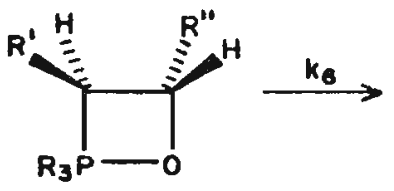<smiles>[R]C=C[P]</smiles>

Um balanço envolvendo fatores eletrônicos e estéricos irá determinar as magnitudes relativas das constantes de equilíbrio, de finindo a proporção $\mathrm{Z} / \mathrm{E}$ no produto.

Evidências experimentais da validade do esquema acima, $1 \underline{\underline{s}}$ to é, reversibilidade da reação fosforana-composto carboniliico, fo ram obtidas [91]. o deslocamento do equilibrio dependerá de uma série de fatores, o mals importante dos quais, certamente, è a estabilidade relativa das betainas eritro e treo. Essa estabilidade, além dos fatores eletrōnlcos e estéricos, irá depender do meio em 
que a reação é efetuada (solventes e sais de lítio).

Apresentaremos a seguir um resumo dos fatos experimentalmente observados, que atualmente parecem ser de aceitação geral $[44,83]$. Usando argumentos baseados em fatores eletrônicos e es truturais, apresentaremos modelos condizentes com esses resultados gerais. No entanto, salientamos que o quadro abaixo é uma generalização e seria pouco racional pensarmos que incluindo determinada fosforana numa ou noutra categoria, a mesma fosse se comportar rigorosamente segundo essas generalizações. Cada reação é única, pô dendo, algumas vezes, uma fosforana estabilizada se comportar segundo os padrões estabelecidos para fosforanas não estabilizadas e vice-versa.

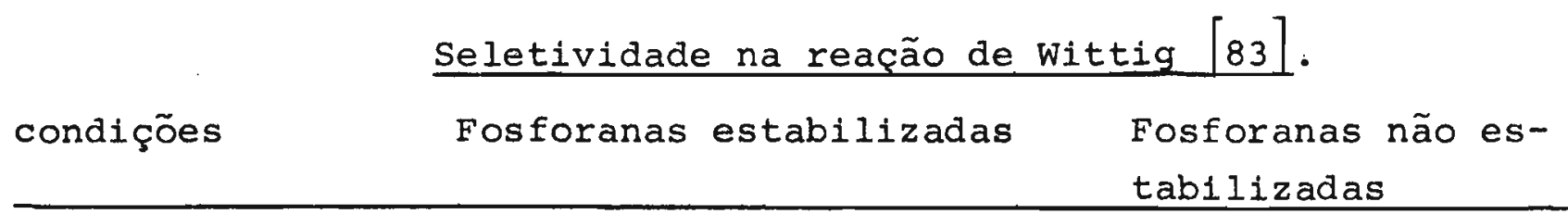

solvente polar
a) aprótico
baixa seletividade, mas
baixa seletividade principalmente $\mathrm{E}$
b) prōtico
seletividade aumentada com relação ao isômero $\mathrm{z}$.
seletividade aumenta da com relação ao - isōmero $\mathrm{E}$.

solvente apolar
a) Solução livre
de sal de litio
elevada seletividade com relação ao isômero $\mathrm{E}$. elevada seletividade com relação ao isôme ro 2 .
b) Solução com
seletividade aumentada sal de litio com relação ao isômero seletividade aumenta da com relação ao - isômero $\mathrm{E}$. 
E um fato comprovado que o ataque da fosforana ao composto carbonílico leva preferencialmente à formação inicial da betaina menos estável eritro: "... No entanto, parece ser um princípio fundamental (embora obscuro) em química orgânica que a ligação cạ bono-carbono se faça de maneira a formar preferencialmente o isôme ro termodinâmicamente menos estável" [90].

O fato de ocorrer, em alguns casos, elevadas percentagens do isômero E, significa que um equilibrio entre a forma eritro (cí nética) e treo (termodinâmica) deve realmente existir; as razões da preferência por um ou outro isômero, em diferentes condições,serão discutidas a seguir.

\section{A. Fosforanas estabilizadas}

1. Em solvente apolar e na ausência de sais de litio: predominància do isômero E.

Supondo-se que a primeira etapa da reação seja a formação lenta da ligação carbono-carbono, entre a fosforana e a carbonila, e a segunda etapa a decomposição räpida do intermediārio em olefina e fosfinōxido [49], podemos escrever o seguinte perfil energético. 
92.

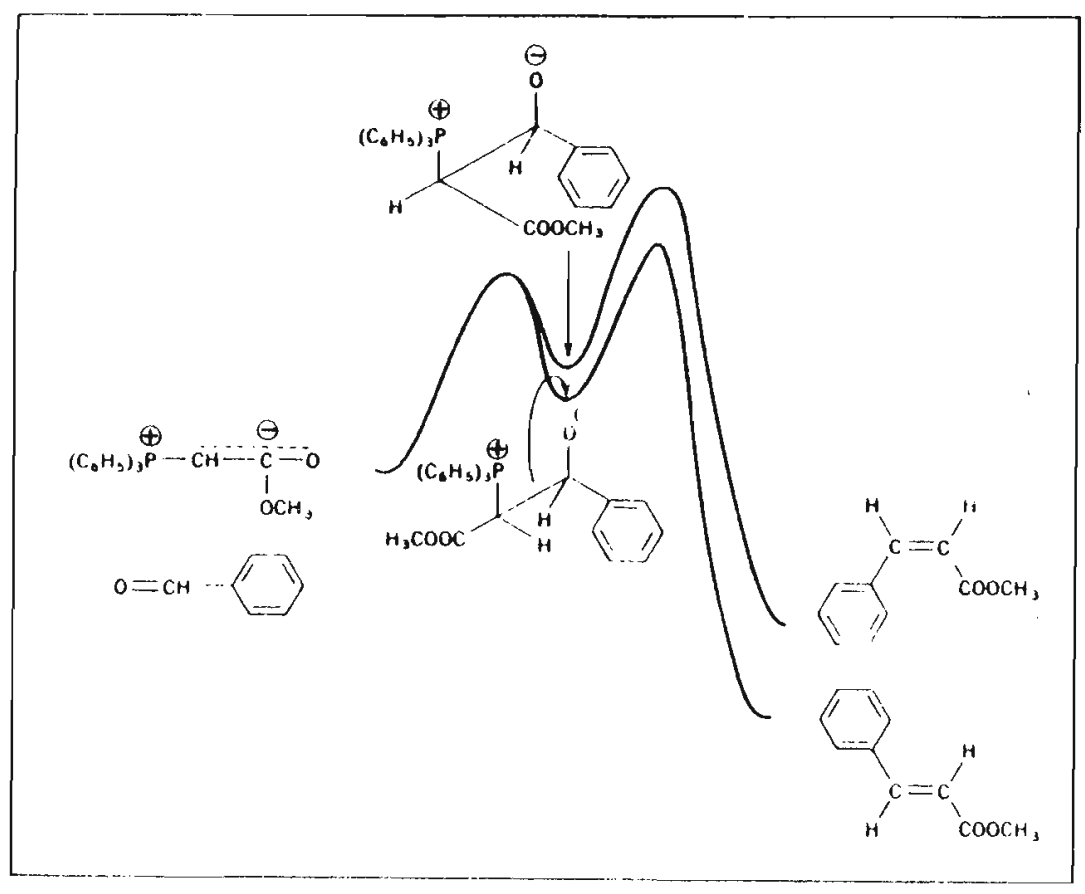

FIGURA 11

Podemos considerar a conformação escalonada como a mais estável para as betainas, ficando o àtomo de oxigênio, portador da car ga negativa, o mais próximo possivel do átomo de fósforo positivo,já que a estabilização por solvatação não se faz presente (solvente apo lar). Desse modo é fácil constatar que a forma eritro, alēm de ser estericamente desfavorecida, apresenta uma interação dipolo-dipolo entre o oxigênio negativo do aldeido e oagrupamento rico em elétrons da fosforana. A forma treo, alēm de possuir menos interações estēri cas do que a forma eritro, não apresenta interação desfavorável dipo lo-dipolo $[17]$. 
ESQUEMA 2

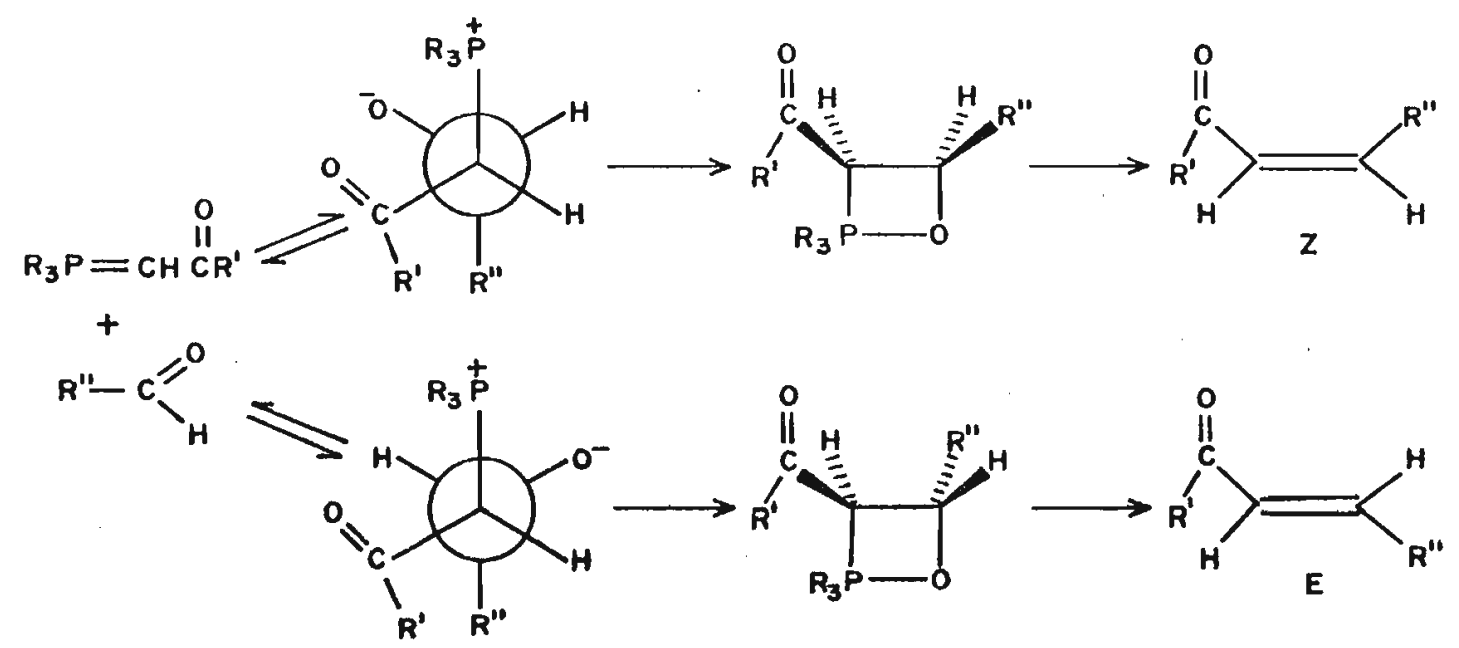

Por outro lado, a decomposição da betaina treo em olefina E e fosfinóxido seria mais rāpida do que a decomposição da betaina eritro. Isso se deve ao fato do estado de transição loxifosfetana) da forma treo apresentar menos interações estëricas, permitindo maior sobreposição de orbitais e, portanto, maior estabilização da olefina incipiente. No estado de transição proveniente da forma eritro as interações estēricas provocariam um desvio da coplana ridade, diminuindo a estabilidade [44]. 


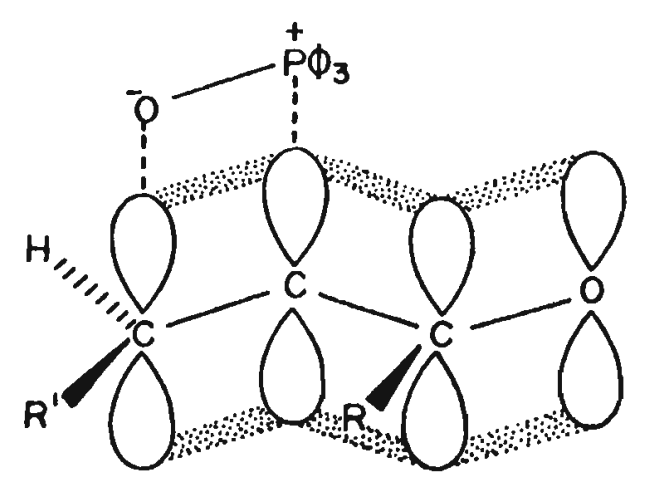

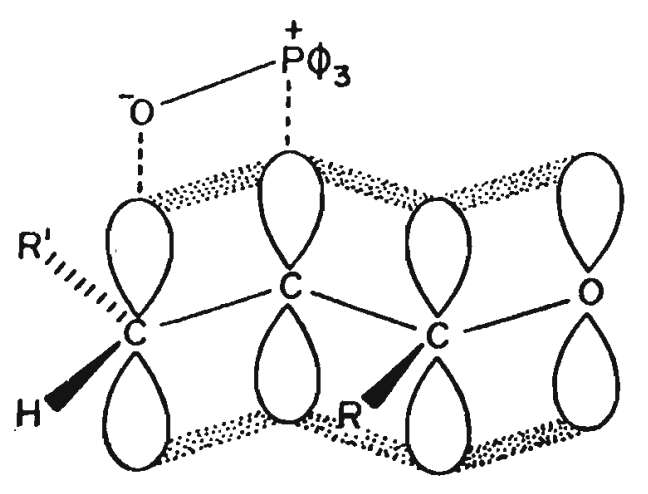

FIGURA 12

Os fatores discutidos acima seriam responsáveis pela predominância do isômero $\mathrm{E}$ na mistura de produtos.

As considerações anteriores partem do pressuposto de que as fosforanas reagem com compostos carbonIlicos de modo a se formar in $\underline{1}$ clalmente uma ligação carbono-carbono. No entanto, principalmente quando estamos frente a fosforanas estabilizadas, è válido considerar uma segunda hipótese, em que o ataque inicial se dará por parte do oxigênio da carbonila ao fósforo positivo (formação inicial de ligaçāo fôsforo-oxigênio) [100].

Considerando que no intermediário o fósforo possui uma configuração de bipirâmide trigonal com o oxigênio carbonílico numa po- 
sição axial e o carbono da fosforana numa posição equatorial (necessário para a formação posterior da ligação carbono-carbono), a conformação mais provável é a indicada na figura abaixo [100].

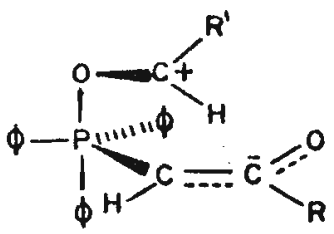

FIGURA 13

Apesar das interferências estéricas com o grupo carbetoxi,o resto aldeídico coordenado com o fósforo se localizarā na trissecção entre um grupo fenila e o grupo carbetoxi, devido à considerável atração eletrostática entre o carbono positivo e o grupo carbetoxi, rico em elétrons. O grupo R" (volumoso) estará dirigido para cima e - $\mathrm{H}$ para baixo. Uma leve rotação no sentido anti-horário fará com que os grupos fiquem em posição favorável à formação do intermediário cíclico (oxifosfetana) que levarā à olefina E. Esta rotação no sentido anti-horário, como podemos observar no modelo, não causarã interações estéricas pronunciadas, as quals ocorreriam caso a rotação se desse no sentido horário, o que levaria à olefina $\mathrm{z}$. 
Salientamos, no entanto, que este mecanismo só è válido quan do a reação ocorre em solventes apolares e na ausência de sais de lítio, uma vez que estes poderiam coordenar com o oxigènio mais facilmente do que o fósforo, impedindo a formação inicial da ligação fósforo-oxigênio.

Um ponto de vista totalmente diverso dos precedentes foi expresso recentemente $[116]$. A oxifosfetana se formaria antes da betaina, através de uma cicloadição, o que se daria de modo a minimizar as interações oxigênio-oxigênio. Essa cicloadição levaria à olefina E.

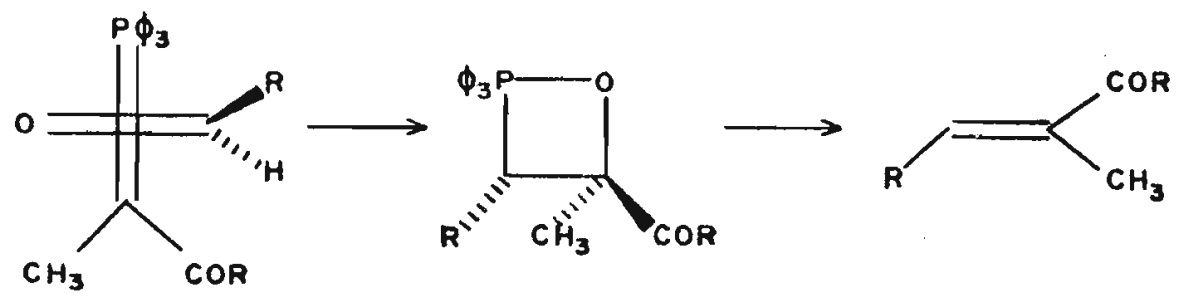

No entanto, se considerarmos esta hipótese, teremos que proceder a uma total revisão da estereoquímica da reação de wittig, prin cipalmente no que diz respeito. à Influêncla do solvente e de sais ae IItio.

Todos os raciocínios e modelos acima estão em perfeito acor 
97.

do com o fato experimentalmente comprovado: reação entre fosforanas estabilizadas e compostos carbonílicos leva preferencialmente à ole fina $E$.

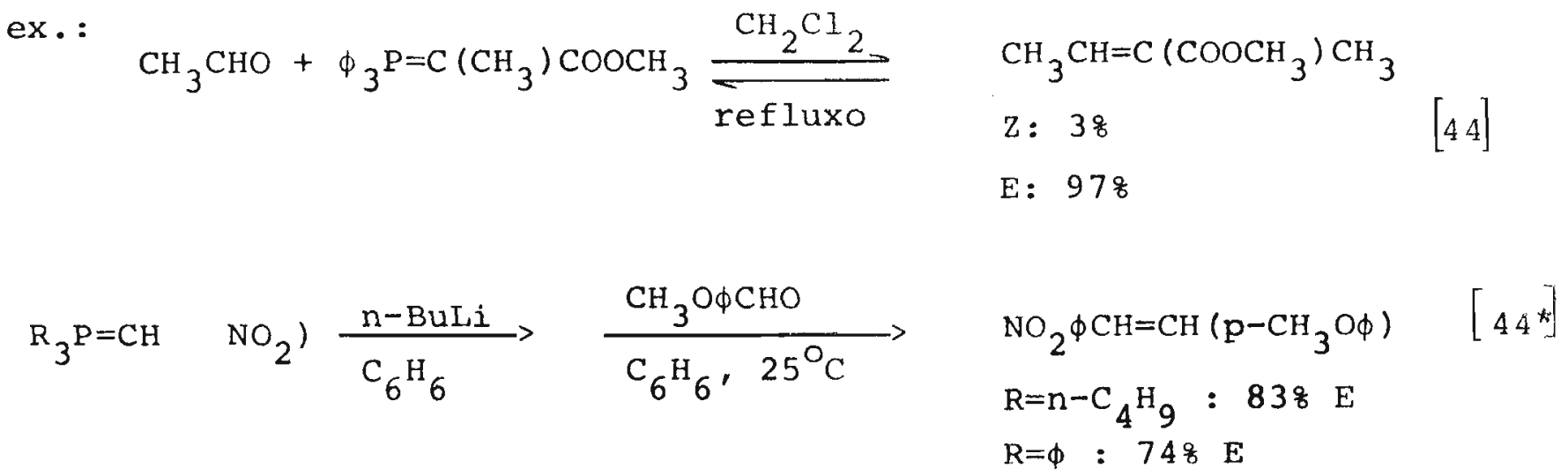

* A seletividade com relação ao isômero $E$ aumenta quando substituimos os ligantes fenila por substituintes alquila [90]. 
2. Em solvente apolar e na presença de sais de lítio ou em solvente polar prótico: Aumenta a percentagem de isômero $\mathrm{Z}$.

Quando a reação é efetuada em solventes polares próticos ou em solventes apolares em presença de sais de litio, observamos um au mento na percentagem de olefina $z$ no produto final. Esse fato foi interpretado da seguinte forma:

Como vimos anteriormente, a betaina tende a adotar uma conformação sinclinal devido à estabilização conferida pela atração entre o oxigênio negativo e o fósforo positivo. Entretanto na betaina "complexada" os ácidos de Lewis (solvente polar prótico e cātions metálicos) estarão espalhando a carga negativa do oxigênio, di minuindo com isso a atração eletrostática entre este e o fósforo. A betaina irá agora preferir a conformação anti-periplanar, estericamente mais favorāvel, o que levarā a um aumento (mas não preponderān cia) do isômero $\mathrm{z}[83]$. 
99.

ESQUEMA 3

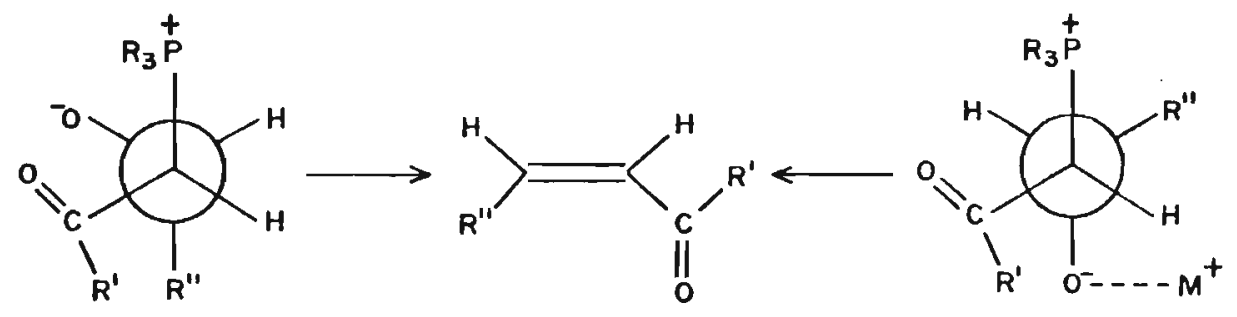

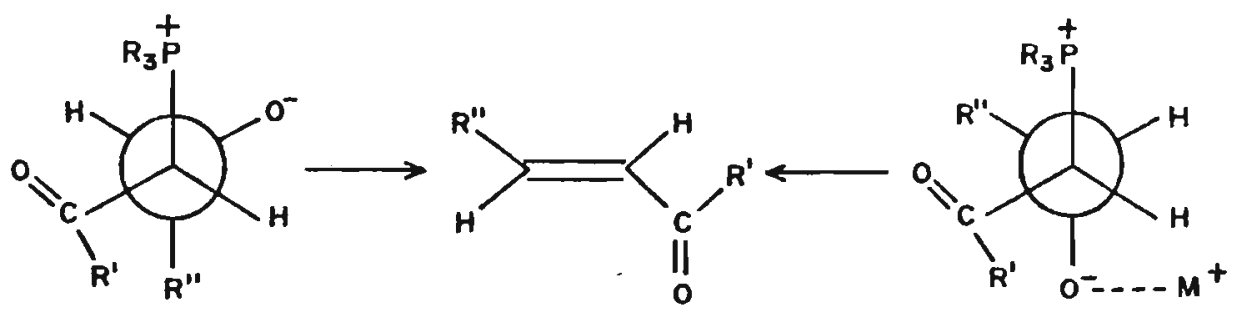

E fácil verificar pelo desenho que das duas formas complexadas a mais estável é a eritro, havendo, portanto, tendência em se formar uma porcentagem maior de olefina $\mathrm{Z}$.

Com relação à influência do solvente na estereosseletividạ. de, um ponto de vista diferente fol expresso por schlosser [90]. Ba seado no fato de que a substitulção de DMF por etanol aumenta a velocidade da reação de um fator de 100 , o autor sugere que a 2 a bar reira energética tenha diminuído, aumentando a velocidade de decomposição da oxifosfetana, o que levarià ao produto cinético (Z). Nc 
entanto nos parece mais lógico que um solvente polar prótico exerça influência na $1^{\text {a }}$ etapa (formação da betaina, etapa lenta) diminuindo a 1 . barreira energética, uma vez que ocorre formação de cargas no estado de transição que leva à betaina [49].

Ex.:

\section{TABELA X}

$$
\begin{array}{ccc}
\mathrm{CH}_{3} \mathrm{CHO}+\phi_{3} \mathrm{P}=\mathrm{CHCO}_{2} \mathrm{CH}_{3} \quad \underset{25^{\circ} \mathrm{C}}{\longrightarrow} & \mathrm{CH}_{3} \mathrm{CH}=\mathrm{CHCO}_{2} \mathrm{CH}_{3} \\
\mathrm{E}+\mathrm{Z} & {[44]}
\end{array}
$$

$\left(\mathrm{CH}_{3}\right)_{2} \mathrm{NCHO}, \mathrm{LiX}$

$\left(\mathrm{X}=\mathrm{Br}, \mathrm{Cl}, \mathrm{CLO}_{4}, \mathrm{NO}_{3}\right)$ 
TABELA XI

$$
\mathrm{CH}_{3} \mathrm{CH}_{2} \mathrm{CHO}+\phi_{3} \mathrm{P}=\mathrm{CH} \phi^{\star} \longrightarrow \begin{gathered}
\phi \mathrm{CH}=\mathrm{CHCH}_{2} \mathrm{CH}_{3} \\
\mathrm{E}+\mathrm{Z}
\end{gathered}
$$

$\begin{array}{lcr}\mathrm{C}_{6}{ }^{\mathrm{H}} 5 & 73-82 & 18-27 \\ \mathrm{C}_{6}{ }^{\mathrm{H}}{ }_{6}, \mathrm{L \perp Br} & 73-77 & 23-27 \\ \mathrm{C}_{2}{ }^{\mathrm{H}}{ }_{5} \mathrm{OH} & 48-53 & 47-52 \\ \left(\mathrm{CH}_{3}\right)^{2} \mathrm{NCHO} & 54-61 & 39-46 \\ \left(\mathrm{CH}_{3}\right)_{2} \mathrm{NCHO}+\mathrm{LiBr} & & 41-46\end{array}$

* Benzilideno fosforanas são chamadas de fosforanas semi-estabilizadas. Sua estereosseletividade geralmente é baixa [90]. 
3. Em solvente polar aprótico: baixa seletividade, mas predominantemente $\mathrm{E}$.

Os mesmos argumentos utillzados no Item anterior seriam vạ lidos aqui. No entanto, a "complexação" do solvente polar aprōtico com a betaina deve ser menos eficiente, permitindo a eliminação mais rápida de fosfinóxido e diminuindo assim o deslocamento do equilíbrio no sentido do intermediário mais estável (eritro solvata do) . 


\section{B. Fosforanas não estabilizadas}

Como acabamos de ver, existem explicações satisfatōrias para o decurso estērico da reação entre fosforanas estabilizadas e com postos carbonilicos. No entanto, se seguirmos a mesma linha de raciocínio para explicar o decurso estérico da reação com fosforanas não estabilizadas, chegaremos a conclusões totalmente contrárias aos fatos experimentais. Desse modo, se considerarmos a reação ocorrendo em solvente apolar e na ausência de sais de lítio, esperaríamos que a conformação mais estável para a betaina fosse a sinclinal, uma vez que não temos nenhum fator de estabilização, a não ser a atração entre o fósforo positivo e o oxigênio negativo.

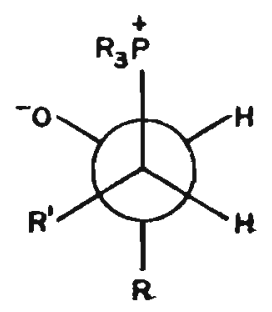

Isso sendo verdadeiro (o que nos parece lógico) a forma treo sinclinal seria mais estável do que a forma eritro sinclinal. Consequentemente deverlamos esperar uma baixa proporção $\mathrm{Z} / \mathrm{E}$, o que 
não é observado na prática. Além disso, quanto mais volumoso é R", maior é a seletividade com relação ao isômero z [83].*

Pelo que acabamos de expor, fica claro que o modelo acima não é adequado para explicar o decurso estērico da reação de Wittig com fosforanas não estabilizadas. O modelo mais condizente com os resultados experimentais é o formulado por schneider [100], jā apre sentado para fosforanas estabilizadas, onde a ligação fósforo-oxigê nio e não carbono-carbono é a que se forma inicialmente.

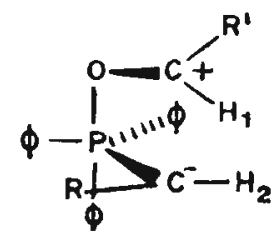

FIGURA 15

Este intermediário possui o grupo R" do aldeído (volumoso) dirigido para cima, em direção oposta à dos substituintes equatori-

* Soluções de fosforanas não establl1zadas livres de sais podem ser obtidas faclimente empregando-se $\mathrm{NaN}\left(\mathrm{Si}(\mathrm{Me})_{3}\right)_{2}$ como base. Após a preparação da fosforana a solução é filtrada, obtendo-se desse modo percentagens elevadas de olefina $\mathrm{z}$ pela reação com o composto carbo nilico $[20]$. 
ais, e o $H$ do aldeỉdo dirigido para baixo, no sentido da trissecção menos impedida do plano equatorial, entre um grupo fenila ligado ao fósforo e o hidrogênio do carbono da fosforana $\left(\mathrm{H}_{2}\right)$. A ligação car bono-carbono será estabelecida facilmente se fizermos uma ligeira rotação no sentido anti-horário em torno do eixo da ligação carbono-oxigênio, o que levará ao intermediário eritro.
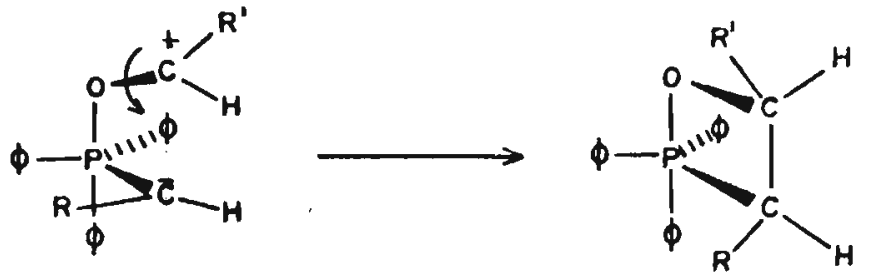

FIGURA 16

Para se chegar ao intermediārio treo, seria necessária uma rotação maior no sentido horário, causando séria interação entre o grupo $R^{\prime \prime}$ e o grupo fenila equatorial (durante a rotação) .
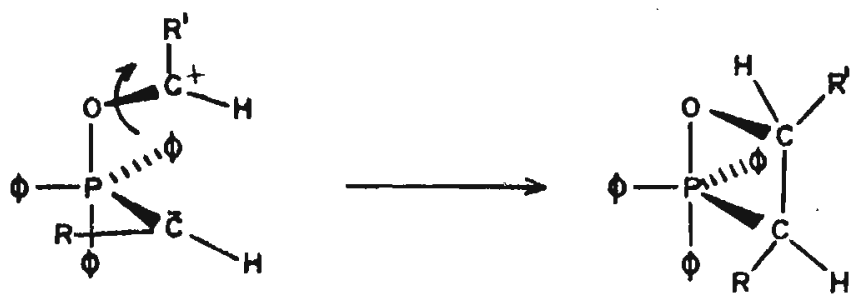

FIGURA 17 
Este modelo explicaria a elevada proporção $\mathrm{Z} / \mathrm{E}$, além de res ponder pela maior seletividade em relação ao isômero $\mathrm{z}$ com 0 aumento no tamanho de $\mathrm{R}^{\prime \prime}$.

Como no caso das fosforanas estabilizadas, este modelo não explicaria as consequênclas estereoquímicas da presença de ácidos de Lewis no meio reacional, que determina uma seletividade elevada com relação ao isômero $\mathrm{E}$.

Para explicar esse fenômeno schlosser $[90]$ sugere um intermediārio envolvendo um anel de sels membros numa conformação "barco torcida", da qual faria parte o sal de lítio.

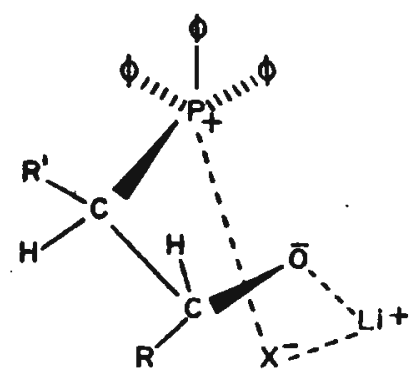

FIGURA 18

$\mathrm{Na}$ conformação "barco torcida" as ligações exocíclicas dos carbonos $\alpha$ e $\beta$ estariam semiecilpsadas, evitando assim uma 1nteração mais desfavorável entre a lıgação $C \alpha-C \beta$ e um grupo fenila, permi- 
tindo, alēm disso, uma perfeita interação dipolo-dipolo.

Como jā vimos anteriormente, a presença de àcidos de Lewis retarda a decomposição da betaina em olefina e fosfinóxido. Se admitirmos a formação preferencial da betaina eritro, a presença de ācidos de Lewis retardaria a decomposição da mesma (2â. barreira -

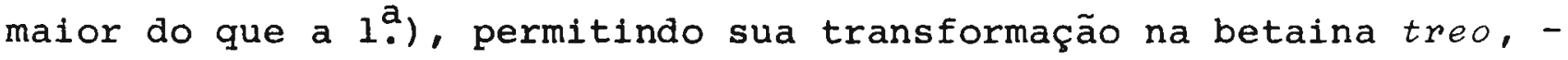
mais estāvel (de acordo com o modelo acima), o que determina elevada seletividade com relação ao isômero $E$.

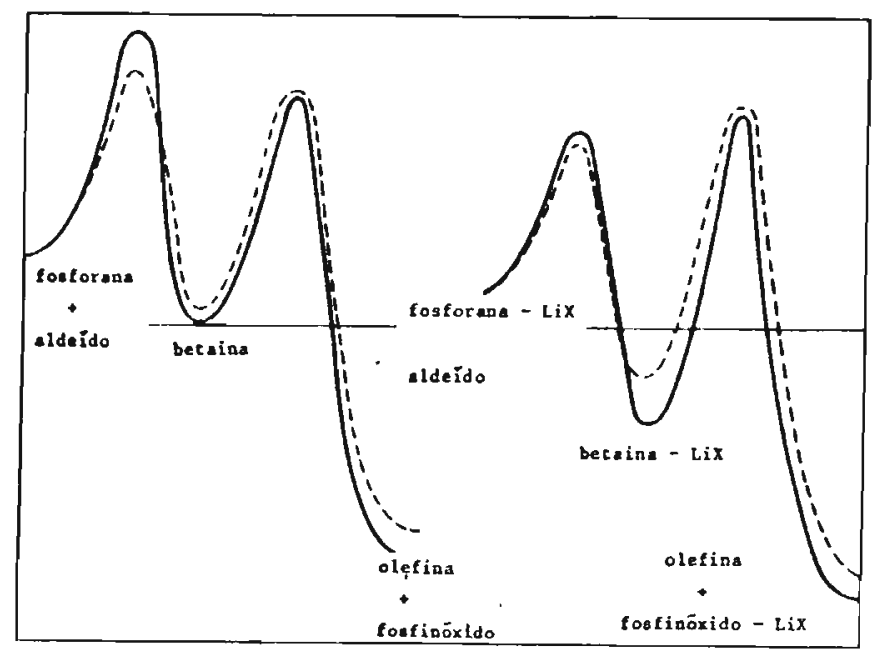

FIGURA 19

Um ponto de vista completamente diferente, semelhante ao já exposto para fosforanas estabilizadas, fol expresso recentemente $[116]$.

A espécie formada inicialmente não seria a betaina, mas a oxifosfetana, a qual se originaria atravēs de uma reação de cicloadição. 
108.

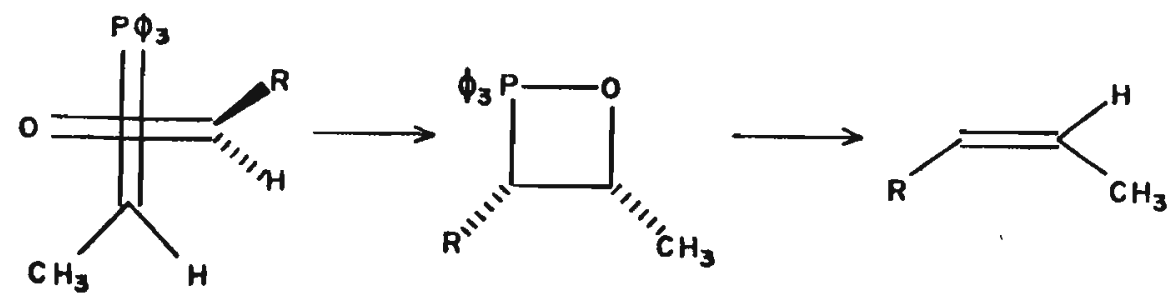

Esta abordagem explicaria o aumento na seletividade em rela Ção à olefina $z$ à medida em que $\mathrm{R}^{\prime \prime}$ se torna mais volumoso. A aproxí mação ortogonal dos orbitais $\Pi$ da fosforana e do composto carbonIlico se daria segundo a orientação menos impedida, levando à oxifosfetana mais impedida (eritro) por uma cicloadição. 
C. Estereoquimica da reação de Wittig modificada (reação de Horner-Emmons)

A reação de Wittig envolvendo fosfinōxidos e fosfonatos,comumente chamada reação de Horner-Emmons, fornece preferencialmen te $\mathrm{O}$ isômero $\mathrm{E}$.

Essa preferência pode ser explicada facilmente examinando - se modelos das betainas exitro e treo. A forma eritro em sua con formação mais estável apresenta, além das interações estéricas prô nunciadas, uma interação desfavorável dipolo-dipolo entre o oxigênio ligado ao fósforo e o oxigênio do aldeido. Essas interações estão ausentes na forma treo [17].

ESQUEMA 4

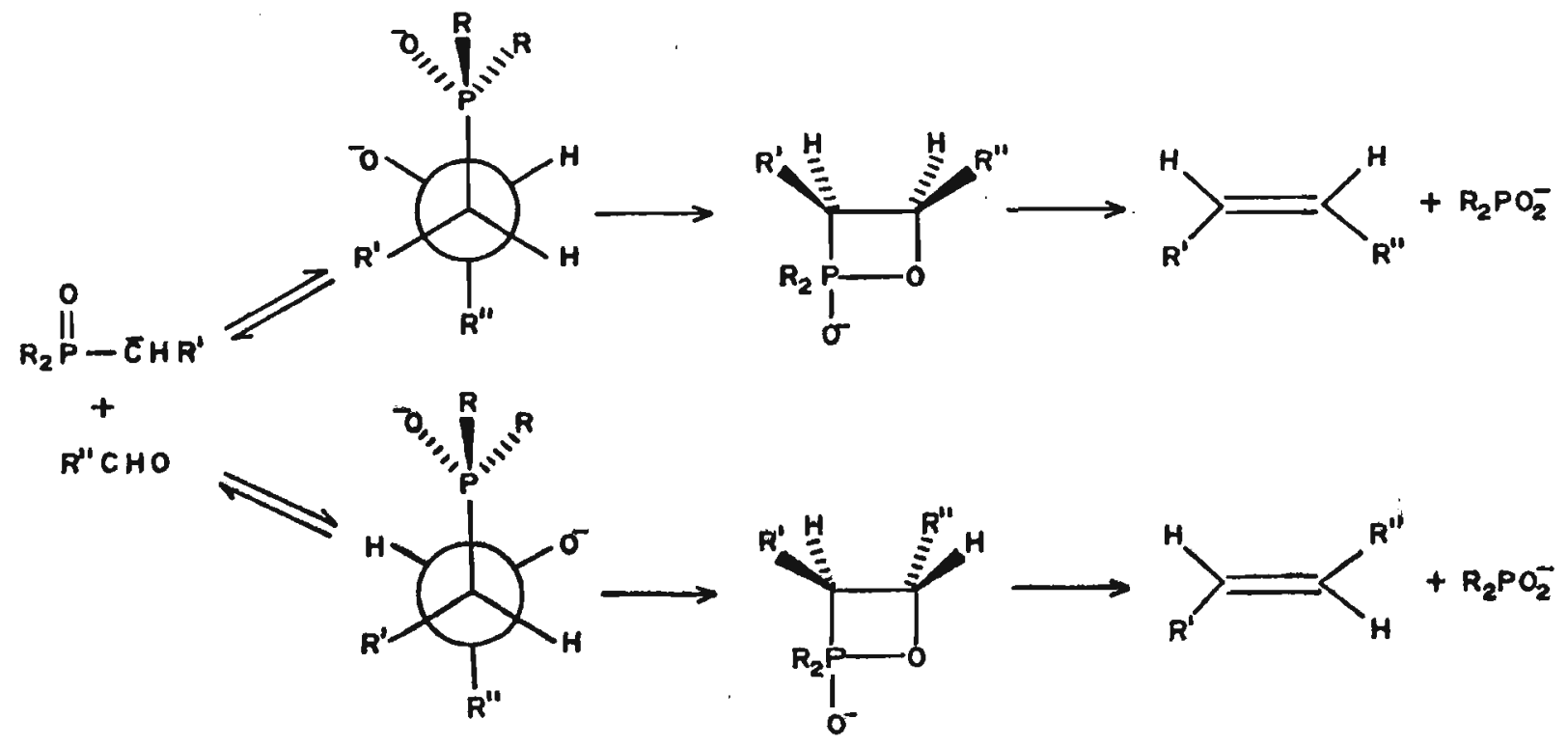


Isso, juntamente com o fato de que a primeira etapa é rápida e a segunda lenta, permitindo que a eliminação ocorra em condiçães de equilíbrio, determinaria a elevada seletividade com relação ao isômero $\mathrm{E}[49]$.

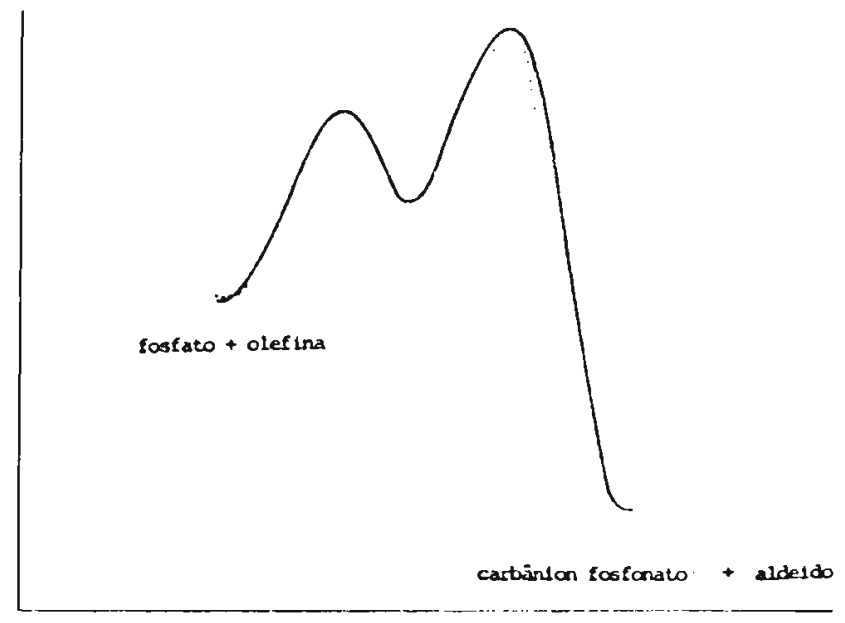

FIGURA 20

O fato de $\mathrm{R}^{\prime}$ ser um grupamento dipolar, no entanto, não parece ter grande importância, uma vez que fosfonatos onde $R^{\prime}$ é um grụ pamento capaz de estabilizar cargas negativas, mas que não possui ca ráter dipolar, leva tambēm a uma predominância do isômero $\mathrm{E}$.

Ex.: $\left(\mathrm{C}_{2} \mathrm{H}_{5} \mathrm{O}\right){ }_{2} \mathrm{P}(\mathrm{O}) \mathrm{CH}_{2} \mathrm{CO}_{2} \mathrm{CH}_{3} \underset{\mathrm{DME}}{\stackrel{\mathrm{NaH}}{\mathrm{DME}, 25^{\circ}}}>\frac{\mathrm{CH}_{3} \mathrm{CHO}}{\mathrm{DM}}$ $\mathrm{CH}_{3} \mathrm{CH}=\mathrm{CHCO}_{2} \mathrm{CH}_{3}$
$96 \% \mathrm{E}$
$48 \mathrm{Z}$

$$
\begin{gathered}
\left(\mathrm{C}_{2} \mathrm{H}_{5} \mathrm{O}\right) \\
2
\end{gathered}
$$


Quando as interações estēricas no produto se tornam pronun ciadas, observa-se a perda dessa seletividade [51]. Em alguns casos ocorre inclustve predominância do isômero $\mathrm{z}$.

\section{TABELA XII}

$$
\begin{gathered}
\left(\mathrm{C}_{2} \mathrm{H}_{5} \mathrm{O}\right){ }_{2} \mathrm{P}(\mathrm{O}) \overline{\mathrm{C}}\left(\mathrm{C}_{2} \mathrm{H}_{5}\right) \mathrm{CO}_{2} \mathrm{C}_{2} \mathrm{H}_{5}+\mathrm{RCHO} \frac{\mathrm{DME}}{15^{\mathrm{O}}} \longrightarrow \stackrel{\mathrm{H}_{2} \mathrm{O}}{\longrightarrow} \mathrm{RCH}=\mathrm{C}\left(\mathrm{C}_{2} \mathrm{H}_{5}\right) \mathrm{CO}_{2} \mathrm{C}_{2} \mathrm{H}_{5}[44] \\
\mathrm{E}+\mathrm{Z}
\end{gathered}
$$

R

$\mathrm{CH}_{3}$

$\mathrm{C}_{2} \mathrm{H}_{5}$

$\mathrm{CH}\left(\mathrm{CH}_{3}\right)_{2}$

$\mathrm{C}\left(\mathrm{CH}_{3}\right)_{3}$
82

59

10

45
Z \%

18

41

84

55

Esse efeito é observado também quando $R$ é mantido constan te no composto carbonilico e varia-se o substituinte no fosfonato $[55]$. 


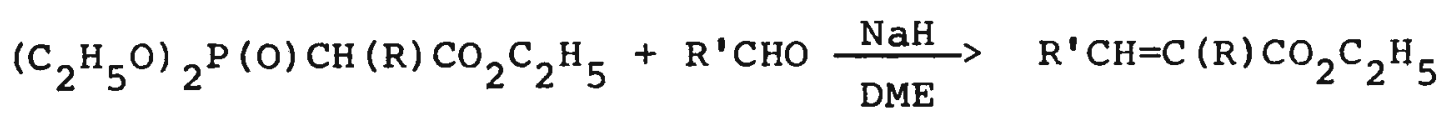

$$
\begin{aligned}
& E+Z
\end{aligned}
$$

\begin{tabular}{|c|c|c|}
\hline $\mathbf{R}$ & $R^{\prime}$ & $\mathrm{Z} 8$ \\
\hline $\mathrm{H}$ & $\operatorname{Pr}^{i}$ & não detectado \\
\hline $\mathrm{CH}_{3}$ & $\operatorname{Pr}^{i}$ & 62 \\
\hline $\mathrm{C}_{2} \mathrm{H}_{5}$ & $\operatorname{Pr}^{i}$ & 84 \\
\hline $\mathrm{H}$ & $\mathrm{Bu}^{t}$ & não detectado \\
\hline $\mathrm{CH}_{3}$ & $\mathrm{Bu}^{t}$ & 50 \\
\hline $\mathrm{C}_{2} \mathrm{H}_{5}$ & $\mathrm{Bu}^{t}$ & 55 \\
\hline
\end{tabular}

Até o presente não fol apresentada nenhuma explicação plausivel para esse fato.

No entanto, em vista da semelhança estrutural entre fosforá 
113.

nas estabilizadas e fosfonatos ou fosfinóxidos (ambos possuem grupos capazes de conjugar no carbono em $\alpha$ ao fósforol, podemos propor para os últimos o mesmo estado de transição proposto para fosforanas esta bilizadas (página 93), no qual a dupla ligação carbono-carbono em formação se encontra conjugada com o substituinte do carbono em $\alpha$ ao fósforo.
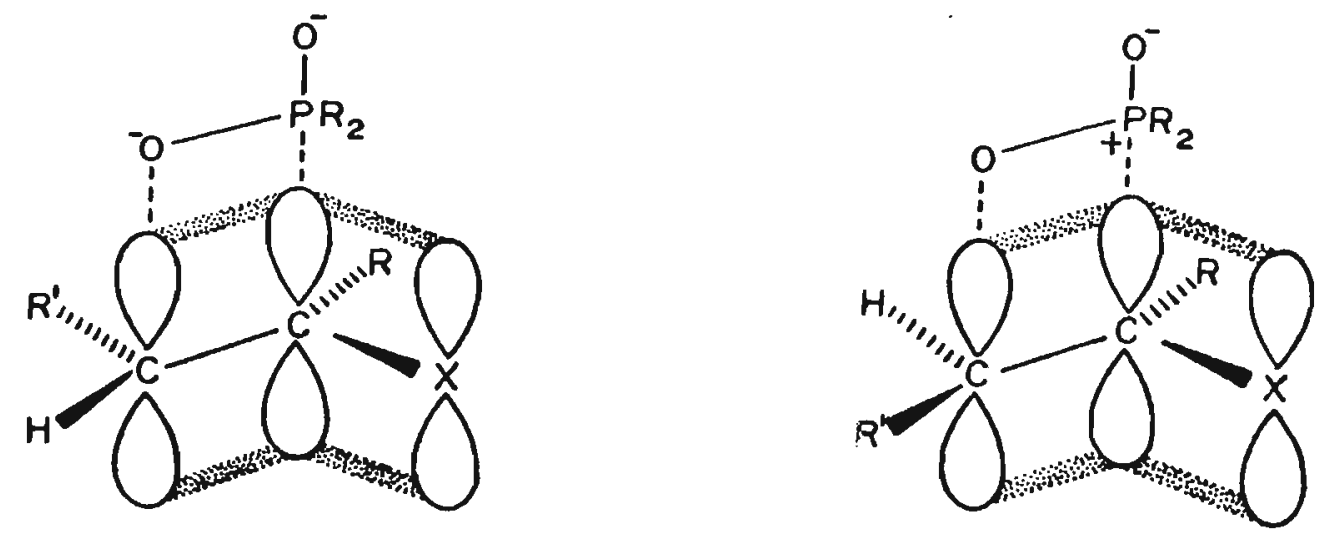

FIGURA 21

Se $R$ e R' forem grupos volumosos, pode-se chegar a uma situação (pelo aumento progressivo no tamanho de um deles) em que os requisitos estéricos de ambos se tornam muito pronunciados, fazendo com que o intermediário não seja mais planar. Com isso a estabilida de da forma treo pode se tornar igual (proporção $\mathrm{Z} / \mathrm{E} \sim 1$ ) ou, em casos extremos, menor do que a da forma eritro, caso em que passaria- 
114.

mos a ter uma elevada percentagem de olefina $\mathrm{z}$ (quando as interações entre $R^{\prime}$ e $X$ forem menores do que as interações entre $R^{\prime} e$ ). Influência dos cátions presentes e da polaridade do solvente

Existem poucos estudos sobre a influência do solvente e dos sais presentes no melo reacional sobre o decurso estérico da reação de fosfonatos e fosfinóxidos com compostos carbonilicos. Além disso as poucas informações existentes são contraditōrias (ver ref. [17, 24,33 ]. Em vista disso não discutiremos esse particular. Salienta mos apenas que os resultados de Deschamps e col. [33] assemelham-se aos nossos (ver capitulo seguinte): uso de HMPA como solvente aumenta a percentagem de olefina $\mathrm{z}$.

Outro fato interessante a anotar è que a seletividade com relação ao isômero $\mathrm{Z}$ aumenta à medida em que o cátion da base utilizada se torna mals volumoso [80] diminuindo o caráter covalente da ligação com o oxigênio. 


\section{CAPITULO VI}

EstereoguImica da Reação de Wittig e Horner-Emmons entre (fenilseseleno) fosforanas e aldeídos.

\section{A. Reação de Wittig}

Esta reação, conforme foi visto no capítulo III, fol efetua da com aldeldos alifátícos e aromátícos, usando-se como solvente THF ou benzeno. No primeiro solvente a reação se processou na presença de brometo de 1It1o, formado pela reação entre o sal de fosfónio e n-BuLi. No segundo solvente o sal de litio fol removido por filtração antes da adição do composto carbonilico. Os resultados obtidos encontram-se na tabela a seguir. As proporções $\mathrm{z} / \mathrm{E}$ foram determinadas por cgl e confirmadas por rmp. 
116.

TABELA XIV

$\phi_{3} \mathrm{P}=\mathrm{C}(\operatorname{se} \phi) \mathrm{R}+\mathrm{R}^{\prime} \mathrm{CHO} \longrightarrow \mathrm{R}^{\prime} \mathrm{CH}=\mathrm{C}(\operatorname{Se} \phi) \mathrm{R}+\phi_{3} \mathrm{PO}$

\begin{tabular}{|c|c|c|c|c|}
\hline $\mathrm{R}$ & $R^{\prime}$ & solvente & $\mathrm{Z} / \mathrm{E} \&$ & ref. \\
\hline $\mathrm{H}$ & $\phi-$ & THF & $39 / 61$ & 84 \\
\hline $\mathrm{H}$ & $\phi_{-}$ & $\mathrm{C}_{6} \mathrm{H}_{6}$ & $53 / 47$ & 76 \\
\hline $\mathrm{H}$ & $\phi-$ & HMPA & & \\
\hline $\mathrm{H}$ & $\mathrm{p}-\mathrm{CH}_{3} \phi_{-}$ & THF & $36 / 64$ & 84 \\
\hline $\mathrm{H}$ & $\mathrm{p}-\mathrm{NO}_{2} \phi-$ & THF & $36 / 64$ & 84 \\
\hline $\mathrm{H}$ & $\mathrm{CH}_{3} \mathrm{CH}_{2}-$ & THF & $50 / 50$ & 84 \\
\hline $\mathrm{H}$ & $\mathrm{CH}_{3} \mathrm{CH}_{2}-$ & $\mathrm{C}_{6} \mathrm{H}_{6}$ & $25 / 75$ & 76 \\
\hline $\mathrm{H}$ & $\mathrm{CH}_{3}\left(\mathrm{CH}_{2}\right)_{5}^{-}$ & THF & $50 / 50$ & 84 \\
\hline $\mathrm{H}$ & $\mathrm{CH}_{3}\left(\mathrm{CH}_{2}\right)_{5}$ & $\mathrm{C}_{6}{ }^{\mathrm{H}} 6$ & $33 / 67$ & 76 \\
\hline $\mathrm{CH}_{3}$ & $\phi-$ & THF & $32 / 68$ & 84 \\
\hline $\mathrm{CH}_{3}$ & $\mathrm{CH}_{3} \phi_{-}$ & THF & $38 / 62$ & 84 \\
\hline $\mathrm{CH}_{3}$ & $\mathrm{CH}_{3} \mathrm{CH}_{2}-$ & THF & $50 / 50$ & 84 \\
\hline $\mathrm{CH}_{3}$ & $\mathrm{CH}_{3}\left(\mathrm{CH}_{2}\right)_{5}^{-}$ & THF & $50 / 50$ & 84 \\
\hline
\end{tabular}


A estereoquímica da reação de Wittig entre (fenilseleno)fos foranas mostrou-se complexa e dificil de interpretar. Quando a reação foi efetuada em THF e na presença de sais de lítio, as (fenilseleno)fosforanas se comportaram como fosforanas semi-estabilizadas, fornecendo com aldeídos aromáticos maior percentagem de olefina E, mas com baixa seletividade. Com aldeídos alifáticos, nas mesmas con dições, a reação mostrou-se totalmente não estereosseletiva.Efetuando-se a reação em benzeno e na ausência de sais de lítio, obteve-se maior percentagem de olefina $z$ na reação com benzaldeído e maior per centagem de olefina $\mathrm{E}$ na reação com aldeídos alifáticos. Usando-se HMPA como solvente e benzaldeído como composto carbonílico, observamos uma elevada seletividade com relação à olefina $z$.

Os resultados acima indicam que a estereoquímica da reaçäo com selenofosforanas depende não só da estrutura da fosforana, mas tambēm da natureza do composto carbonilico, sendo este um ponto pou co explorado na literatura. A quase totalidade dos autores ignora a influência da natureza do composto carbonílico no decurso estērico da reação de Wittig.

A seguir tentaremos interpretar os resultados da tabela ut lizando os principlos desenvolvidos na capitulo anterior.

1. Reação na ausência de sais de lítio em solvente apolar a. Aldeídos alifáticos: maior quantidade de olefina E. 
A primeira fase desta reação é rápida, tendo em vista o carāter fortemente eletrofilico do carbono carbonflico. A segun da fase deve ser lenta (estado de transição pouco estabilizado por conjugação), permitindo que se estabeleça um equilíbrio entre a forma eritro e a treo.

Como vimos no capítulo anterior, na ausência de ácidos de Lewis a forma treo é a menos impedida estēricamente, donde concluímos que nos casos em que a reversibilidade da la etapa é facilitada a forma treo deve ser favorecida.

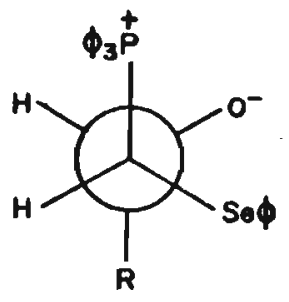

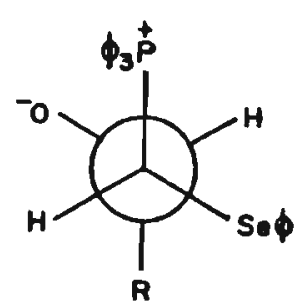

F.IGURA 22

A predominância do intermediário treo determinaria a maior percentagem de 1sômero E na mistura de produtos.

\section{b. Aldeidos aromäticos: malor guantidade de olefina} $\underline{2}$, mas com batxa seletividade.

A primeira fase desta reação deve ser mais lenta do que 
a etapa correspondente com aldeídos alifáticos, tendo em vista a menor eletrofilicidade do composto carbonilico. A segunda fase deve ser rápida lestado de transição estabilizado por conjugação com o anel aromático). Uma vez que a forma eritro (produto cinético) è formada mais rapidamente do que a treo e o estabelecimento do equilí brio é dificultado pela rápida eliminação de trifenilfosfinóxido, a forma eritro deve predominar, determinando a maior percentagem do isômero $\mathrm{z}$ no produto final.

\section{Reação na presença de sais de lítio}

A presença de sais de lítio irá dificultar a eliminação đe trifenilfosfinóxido, fazendo com que a reação se processe em condições de equilíbrio.

\section{a. AldeIdos alifáticos: ausência de estereosseletividaủe}

Já foi visto que na presença de ácidos de Lewis a forma mais estável è a eritro, devido à maior estabilidade da conformação antiperiplanar dos intermediälos. Na ausência de outros fatores (estabilização do estado de transição por conjugação) os fatores estēricos devem prevalecer. 


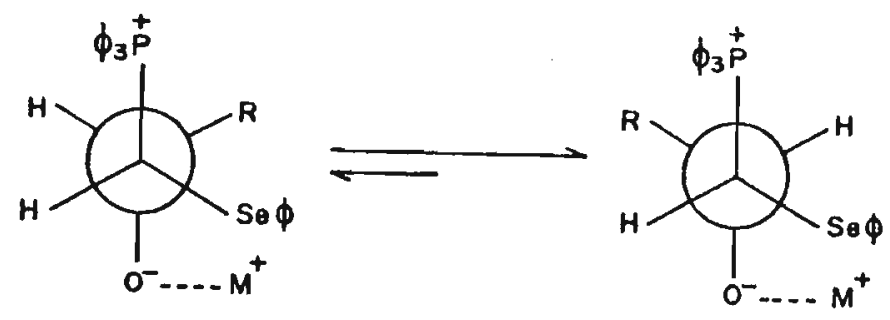

FIGURA 23

Em vista disso a forma eritro será favorecida no equilíbrio ocorrendo um aumento na percentagem do isômero $\mathrm{Z}$.

b. Aldeídos aromäticos: maior quantidade de isômero E, mas com baixa seletividade

A primeira fase da reação com aldeídos aromáticos é lenta, a segunda rápida. No entanto na presença de sais de lítio a segunda fase passa a ser lenta, o que permitirá o estabelecimento de um equi librio entre as duas formas. Esse equilibrio favorecerá o estado de transição mals estável, proveniente aa forma treo lestabilizado por conjugação com o anel aromāticol, o que leva a urna percentagem maior do isōmero $\mathrm{E}$. 
3. Reação de benzaldeido em HMPA na presença de sais de lítio: elevada seletıvidade com relação ao isômero $\mathrm{z}$.

Como já vimos, a primeira fase desta reação é lenta e a segunda rápida. Neste caso, apesar da presença de sais de lítio no meio reacional, os mesmos não irão interferir, pois se encontram for temente solvatados pelo solvente polar aprótico [69], deixando o oxi gênio livre. Alēm disso o solvente polar irá conferir uma estabilização extra ao estado de transıção, que não ocorre quando a reação é efetuada em benzeno na ausência de sais de litio.

Esses dois fatores farão com que o intermediārio se decomponha em condições cinēticas, fornecendo elevada percentagem de olefina $\mathrm{Z}$. 


\section{B. Reação de Horner-Emmons}

De acordo com o que expusemos no capítulo $\mathrm{V}$, os fosfonatos apresentam uma elevada seletividade com relação ao isômero E. Os se lenofosfonatos comportam-se conforme o esperado, fornecendo uma per centagem elevada do isômero E, como pode ser Visto na tabela XV.

TABELA XV

$(\mathrm{EtO}){ }_{2} \mathrm{P}(\mathrm{O}) \mathrm{CH}(\mathrm{Se} \phi) \mathrm{R} \stackrel{\text { base }}{\longrightarrow} \stackrel{\mathrm{R}^{\prime} \mathrm{R}^{\prime \prime} \mathrm{CO}}{\longrightarrow} \mathrm{R}^{\prime} \mathrm{R}^{\prime \prime} \mathrm{C}=\mathrm{C}(\mathrm{Se} \phi) \mathrm{R}$

\begin{tabular}{|c|c|c|c|c|}
\hline $\mathbf{R}$ & $\mathrm{R}^{\prime \prime}$ & $R^{\prime}$ & SOLVENTE & $\mathrm{Z} / \mathrm{E} \mathrm{q}$ \\
\hline $\mathrm{H}$ & $\mathrm{H}$ & $\phi$ & THF & $95 \mathrm{E}$ \\
\hline $\mathrm{H}$ & $\mathrm{H}$ & $\phi$ & THF / HMPA & $6 / 94$ \\
\hline $\mathrm{H}$ & $\mathrm{H}$ & $\phi$ & HMPA & $16 / 84$ \\
\hline $\mathrm{H}$ & $\mathrm{H}$ & $\mathrm{p}-\mathrm{CH}_{3} \phi$ & THF / HMPA & $4 / 96$ \\
\hline $\mathrm{H}$ & $\mathrm{H}$ & $\mathrm{NO}_{2} \phi$ & THF & $4 / 96$ \\
\hline $\mathrm{H}$ & $\mathrm{H}$ & $\mathrm{CH}_{3}\left(\mathrm{CH}_{2}\right)_{2}-$ & THF & $5 / 95$ \\
\hline $\mathrm{H}$ & $\mathrm{H}$ & $\mathrm{CH}_{3}\left(\mathrm{CH}_{2}\right)_{5}^{-}$ & THF & $5 / 95$ \\
\hline $\mathrm{H}$ & $\mathrm{CH}_{3}$ & $\phi$ & THF & só E \\
\hline $\mathrm{CH}_{3}$ & $\mathrm{H}$ & $\phi$ & THF / HMPA & $13 / 87$ \\
\hline $\mathrm{CH}_{3}$ & $\mathrm{H}$ & $\phi$ & HMPA & $47 / 53$ \\
\hline $\mathrm{CH}_{3}$ & $\mathrm{H}$ & $\mathrm{p}-\mathrm{CH}_{3} \phi$ & THF / HMPA & $8 / 92$ \\
\hline $\mathrm{C}_{2} \mathrm{H}_{5}-$ & $\mathrm{H}$ & $\phi$ & THF / HMPA & $8 / 92$ \\
\hline $\mathrm{C}_{2} \mathrm{H}_{5}^{-}$ & $\mathrm{H}$ & $\mathrm{p}-\mathrm{CH}_{3} \phi$ & THF/HMPA & $18 / 82$ \\
\hline $\mathrm{C}_{4} \mathrm{H}_{9}$ & $\mathrm{H}$ & $\phi$ & THF / HMPA & $25 / 75$ \\
\hline $\mathrm{C}_{4} \mathrm{H}_{9}$ & $\mathrm{H}$ & $\mathrm{p}-\mathrm{CH}_{3} \phi$ & THF / HMPA & $25 / 75$ \\
\hline $\mathrm{C}_{8} \mathrm{H}_{17}$ & $\mathrm{H}$ & $p-\mathrm{CH}_{3} \phi$ & THF / HMPA & $23 / 77$ \\
\hline
\end{tabular}

a) proporção $2 / \mathrm{E}$ por $\mathrm{cgl}$;

b) proporção $2 / E$ por rmp. 
Esses resultados podem ser interpretados examinando-se os intermediários eritro e treo.
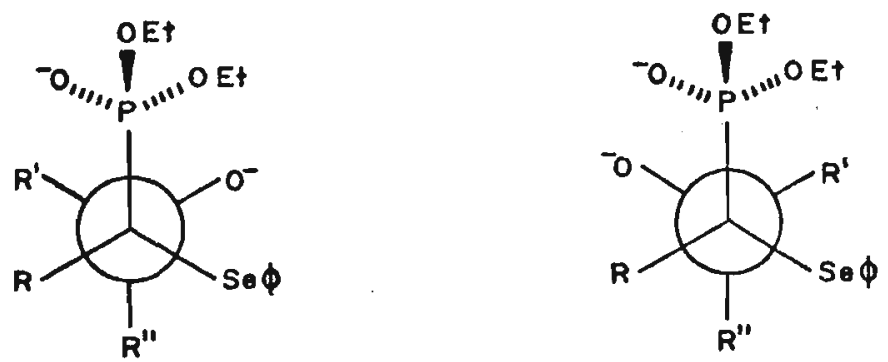

$R^{\prime}>R^{\prime \prime}>R$

FIGURA 24

Pelas razões expostas (pāgina 113) a forma mais estável será a treo, o que determina uma maior percentagem do isômero $E$. $O$ aumento na percentagem do isômero $z$, à medida em que $R$ se torna mais volumoso, pode ser explicado pelas interferênclas estéricas no estado de transição.
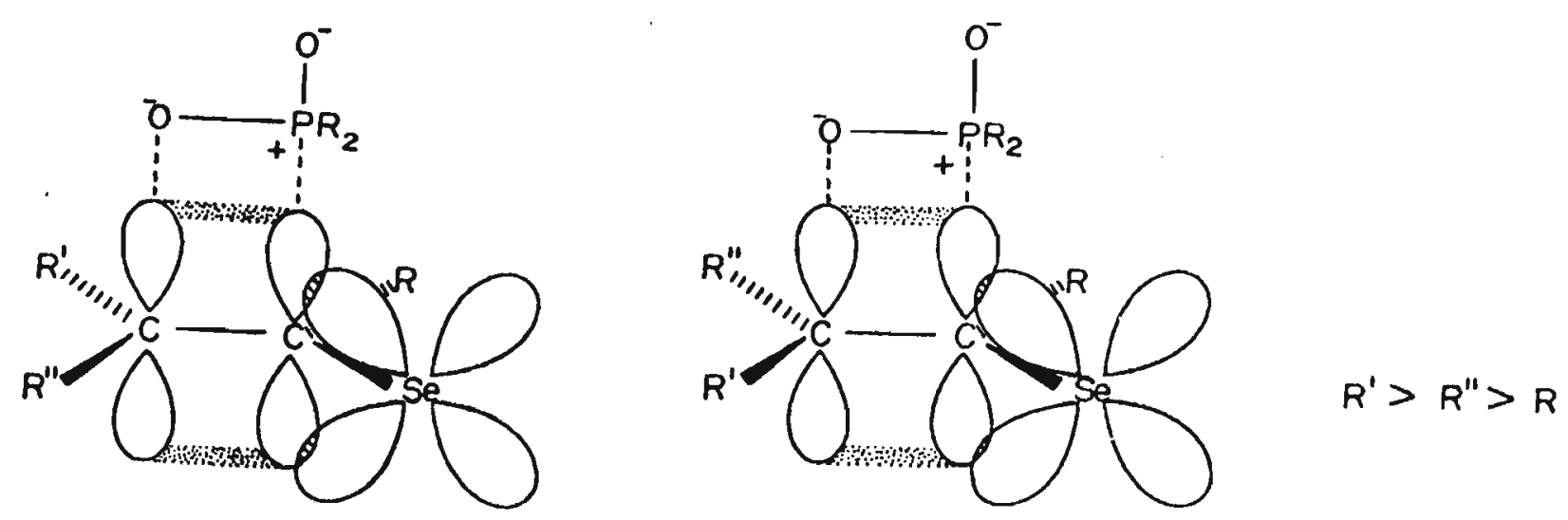

FIGURA 25 
124.

Conforme pode ser visto na tabela XV, mudança do solvente de THF:HMPA 10:1 para HMPA puro determina um aumento na percentagem do isômero Z. Esse aumento poderia ser explicado usando-se argumen tos semelhantes aos utilizados para explicar o decurso estērico da reação entre selenofosforanas e benzaldeído em HMPA, uma vez que os intermediários eritro e treo se assemelham em ambos os casos. A me nor seletividade neste caso seria devida à maior dificuldade de eli minação de fosfato com relação a fosfinóxido, o que favoreceria o equilibrio. 


\section{PARTE EXPERIMENTAL}

\section{Introdução}

a. Os pontos de fusãó (pf) foram determinados num bloco Kofler (Reichert) com um termômetro não aferido.

b. Os espectros de absorção no infravermelho (iv) foram registrados num espectrômetro Perkin-Elmer $457 \mathrm{~A}$.

c. Os espectros de ressonância magnētica protônica (rmp) foram registrados em espectrômetros Varian T-60 (no Instituto de Química da Universidade de São Paulo), Varian XI-100 (NPPN, Rio de Janeiro, sob a direção do Prof. Paul Baker) e Varian XI-100 (No Ing tituto de Quimica da Universidade de são Paulo). Os deslocamentos químicos $(\delta)$ estão relatados em partes por m1 Ihão em relação do tetrametilsilano (TMS) utilizado como padrão interno, colocando entre parênteses a multiplicidade (s-singlete, d-dublete, t-quarteto e m-multiplete), o número de hidrogênios deduzido da integral relativa e a constante de acoplamento (J) em Hertz (Hz).

d. Os espectros Raman foram registrados num espectrômetro Raman laser, duplo cromador, Jarrel-Ash, modelo 25-300, utilizando-se como fonte de excitação laser do íon argônio (488.0 e 514.5 $\mathrm{nm})$. As amostras sólidas foram colocadas em tubo de vidro de $2 \mathrm{~mm}$ 
de diâmetro interno e as amostras em solução numa cela de $1 \mathrm{ml}$ e $3 \mathrm{~cm}$ de comprimento.

e. Os espectros de absorção no infravermelho afastado $\left(180-500 \mathrm{~cm}^{-1}\right)$ foram registrados num espectrofotômetro Perkin -Elmer IR-180. Todos os espectros foram registrados em estado sólido, usando-se uma suspensão em nujol entre placas de polietí leno.

f. As análises elementares foram efetuadas no labora tório de microanälise do Instituto de QuImica da Universidade de São Paulo, sob a direção da Dra. Riva Moscovici, e no Instituto de Pesquisas Tecnológicas da Universidade de São Paulo.

g. As cromatografias em camada delgada analíticas $(0,25 \mathrm{~mm})$ e preparativas $(1,50 \mathrm{~mm})$ foram realizadas utilizando-se sillica gel G, segundo stahl, da Merck A.G.

h: As cromatografias gás-líquido (cgl) foram efetuadas num cromatōgrafo Varian 2800, utilizando-se detector de ioni zação de chama a $250^{\circ}$, com o injetor a $250^{\circ}$. Utilizaram-se co lunas de $3 \%$ SE 30 e $10 \%$ FFAP em Chromossorb W (60/80) (đ̈imensões $\left.5^{\prime} \times 1 / 8 "\right)$.

1. Para as dest1lações empregou-se, quando não especificado, um aparelho de destilação horizontal (Kugelröhr) Btlch1. As temperaturas registradas referem-se à temperatura da estufa. 
j. Para concentrar as soluções orgânicas foi utilizado um evaporador rotatório Błlch1, operando a pressão reduzida $(\sim 20 \mathrm{~mm})$.

1. Os solventes foram purificados e secados antes do uso, conforme normas usuais. Os reagentes comerciais foram conve nientemente purificados $[70]$. o tetrahidrofurano (THF) e o éter etilico foram destilados sobre $\mathrm{LiAlH}_{4}$ imediatamente antes do uso. o ēter de petróleo utilizado fol o de faixa de ebulição de $30-50^{\circ}$. 


\section{Matérias primas (geral)}

As seguintes matérias primas foram preparadas por métodos descritos na 11teratura:

Selenofenol [35], disseleneto de difenila [21], brometo de fenilselenenila [21], brometo de trifenilmetilfosfónio [123], brometo de trifeniletilfosfônio [124], iodometildietilfosfonato [25], benzildifenilfosfinóxido [34]. 
İ - Reação de Wittig entre (fenilseleno) fosforanas e compostos carbo$\underline{\text { nilicos }}$

A. Preparação das matérias primas

1. Fenil(bromometil) seleneto (5)

a. A partir de selenofenóxido de sódio e dibromometano

A uma suspensão de $\mathrm{NaH}(1,10 \mathrm{~g}, 45 \mathrm{mmol}$, de uma dispersão a $57 \%$ em óleo), previamente lavada com hexano, em $10 \mathrm{ml}$ de THF (temp. ambiente, atmosfera de nitrogênio e agitação magnética) foi adicionada gota a gotauma solução de selenofenol $(6,20 \mathrm{~g}, 40 \mathrm{mmol})$ em $10 \mathrm{ml}$ de THF., tendo-se observado desprendimento de $\mathrm{H}_{2}$.

Após 15 minutos de agitação a suspensão resultante foi adicionada lentamente a uma solução de $\mathrm{CH}_{2} \mathrm{Br}_{2}(20 \mathrm{ml})$ em $20 \mathrm{ml}$ de THF.

Após uma hora de agitação à temperatura ambiente a mistura foi filtrada e o solvente e o excesso de $\mathrm{CH}_{2} \mathrm{Br}_{2}$ evaporados. Destilação do resíduo ("short path") forneceu duas frações:

$$
\mathrm{C}_{6} \mathrm{H}_{5} \mathrm{SeCH}_{2} \mathrm{Br} \quad \text { p.e. } 79-99^{\circ}(25 \mathrm{~mm})
$$

Rendimento: $5,0 \mathrm{~g}(50 \%)$

rmp: $\delta\left(\mathrm{CCl}_{4}\right) 4,65\left(\mathrm{~s}, 2 \mathrm{H},-\mathrm{CH}_{2}\right) ; 7,2-7,7$ (m,5H,aromático $)$. 


$$
\left(\mathrm{C}_{6} \mathrm{H}_{5} \mathrm{Se}\right){ }_{2} \mathrm{CH}_{2} \quad \text { p.e. } 165^{\mathrm{O}}(0,2 \mathrm{~mm})
$$

Rendimento: $2,9 g(45 \%)$

rmp: $\delta\left(\mathrm{CCl}_{4}\right) 4,06\left(\mathrm{~s}, 2 \mathrm{H},-\mathrm{CH}_{2}-\right) ; 7,0-7,7(\mathrm{~m}, 10 \mathrm{H}$, aromático $)$

iv: de acordo com a literatura $[77]$.

Resultados semelhantes foram obtidos aquecendo a mistura de reação a refluxo por 1,5 horas.

\section{b. A partir de brometo de fenilselenenila e diazometano}

A uma solução etérea de diazometano (preparado a partir de Diazald*, $80 \mathrm{ml}, 0,3 \mathrm{M}$ e $\mathrm{KOH}$ [1l] for adicionada gota a gota uma solução de brometo de fentlselenenila $(5,0 \mathrm{~g}, 21 \mathrm{mmol})$ em $100 \mathrm{ml}$ de ëter etilico $\left(0^{\circ} \mathrm{C}\right.$, agitação magnética). Observou-se desprendimento de nitrogênio.

Apōs 30 minutos de agitação a temperatura ambiente a solução foi evaporada e o resíduo destilado ("Short path") fornecendo fenil(bromometil) seleneto $(2,50 \mathrm{~g}, 50 \%)$ e 1,1-bis(fenilseleno)etano $(1,6 \mathrm{~g}, 50 \%)$

rmp: idênticos aos produtos da reação anterior

A mesma reação efetuada a $-78^{\circ} \mathrm{C}$, partindo de $2,36 \mathrm{~g}$ (10 mmol) de brometo de lenilselenentla e uma quantidade equimolar de $\mathrm{CH}_{2} \mathrm{~N}_{2}$ for neceu $1,90 \mathrm{~g}(808)$ do composto (5).

* (N-Metil-N-nitroso-p-toluenosulfonamida. Procedência: Aldrich). 
131.

2. Fenil(1-bromoetil) seleneto (6)

a. Tentatívas de obtenção a partir de 1,1 dihalogenoetano e selenofenóxido de sódio

Tentativas de preparação de (6) a partir de 1,1-dibromo- ou 1,1-dicloroetano e selenofenōxido de sōdio (seguindo o procedimento descrito em I-A.a a temperatura ambiente ou a temperatura de refluxo) forneceu apenas 1,1-bis(fenilseleno)etano

$$
\begin{aligned}
& \text { p.e.: } 110-112^{\circ}(0,0025 \mathrm{~mm}) \\
& \text { rmp: } \delta\left(\mathrm{CCl}_{4}\right) 1,8\left(\mathrm{~d}, 3 \mathrm{H}, \mathrm{J}=7,-\mathrm{CH}-\mathrm{CH}_{3}\right) ; 4,45 \quad\left(\mathrm{q}, 1 \mathrm{H}, \mathrm{J}=7,-\underline{\mathrm{CH}}-\mathrm{CH}_{3}\right) ;
\end{aligned}
$$
$7,1-7,7(\mathrm{~m}, 10 \mathrm{H}$, aromātico $)$.

\section{b. A partir de brometo de fenilselenenila e diazoetano}

Uma solução etērea de diazoetano foi preparada tratando N-nitroso-etilaminoisobutil-metil cetona com ciclohexanoato de sódio 79 - A solução foi titulada pela reação com ăcido benzóico seguida de neutralização com $\mathrm{NaOH} 3$.

A solução acima preparada (230 ml de solução 0,175 M, $4 \mathrm{mmol}$ ) foi adicionada gota a gota a uma solução de brometo de fenilseleneni la $(9,44 \mathrm{~g}, 4 \mathrm{mmol})$ em $50 \mathrm{ml}$ de éter $\left(0^{\circ}\right.$, agitação magnētica). Obser vou-se desprendimento de nitrogênio.

o solvente foi evaporado num evaporador rotatōrio, fornecen 
do $\log (95 \%)$ do produto bruto. Tentativas de destilação levaram a decomposição.

rmp: $\delta\left(\mathrm{CCl}_{4}\right) 2,10\left(\mathrm{~d}, 3 \mathrm{H}, \mathrm{J}=7,-\mathrm{CH}-\mathrm{CH}_{3}\right) ; 5,30\left(\mathrm{q}, 1 \mathrm{H}, \mathrm{J}=7,-\underline{\mathrm{CH}}-\mathrm{CH}_{3}\right) ;$ $7,7(\mathrm{~m}, 5 \mathrm{H}$, aromático $)$.

\section{Brometo de (fenilseleno)metiltrifenilfosfónio (4a)}

Uma solução de trifenılfosfina (11,5g; 43 mmol) e fenil(bromometil) seleneto $(9,0 \mathrm{~g}, 36 \mathrm{mmol})$ em $35 \mathrm{ml}$ de benzeno foi aquecida a temperatura de refluxo por 16 horas. O produto cristalino foi recolhido por filtração e recristalizado de diclorometano/acetato de eti la.

Rendimento: $16,5 \mathrm{~g}(908) ;$ p.f. $218-223^{\circ}$

$\mathrm{rmp}: \delta\left(\mathrm{CDCl}_{3}\right) 5,21\left(\mathrm{~d}, 2 \mathrm{H}, \mathrm{J}_{\mathrm{PH}}=7,-\mathrm{CH}_{2}-\right) ; 6,96-8,1(\mathrm{~m}, 20 \mathrm{H}$, aromāti $\mathrm{col}$.

\section{Brometo de 1-(fenilseleno)etiltrifenilfosfônio (4b)}

Foi preparado seguindo-se o procedimento descrito no ítem anterior a partir de trifenilfosfina (1l,5 g, 43mol) e fenil(1-bromoetil) seleneto $(9,5 \mathrm{~g}, 36 \mathrm{mmol})$.

Rendimento: $15,5 \mathrm{~g}(80 \%)$; p.f. $184-186^{\circ}$

rmp: $\delta\left(\mathrm{CDCl}_{3}\right) 1,75\left(\mathrm{q}, 3 \mathrm{H}, \mathrm{J}_{\mathrm{HH}}=7, \mathrm{~J}_{\mathrm{PH}}=20,-\mathrm{CH}-\mathrm{CH}_{3}\right) ; 6,50$ (quinte to, $\left.1 \mathrm{H}, \mathrm{J}_{\mathrm{HH}}=7,-\underline{\mathrm{CH}}-\mathrm{CH}_{3}\right) ; 7,0-8,2(\mathrm{~m}, 2 \mathrm{H}$, aromático). 
B. Reação de (fenilseleno) fosforanas com aldeidos: selenetos vinilicos (3)

\section{Via transilidação}

A uma solução da alquilidenotrifenilfosforana (coloração ver melha), preparada a partir do brometo de alquiltrifenilfosfônio correspondente (5 mmol) e $\mathrm{n}$-Buli (em hexano, $5 \mathrm{mmol}$ ), em $5 \mathrm{ml}$ de THF (at mosfera de nitrogênio, temperatura ambiente e agitação magnētica), foi adicionada gota a gota uma solução de brometo de fenilselenenila $(0,59 \mathrm{~g}, 2,5 \mathrm{mmol})$ em $3 \mathrm{ml}$ de THF. Formou-se um precipitado cristaljno e a coloração da solução mudou para alaranjado.

Após 30 minutos de agitação, adicionou-se o aldeido (puro quando líquido, dissolvido em $3 \mathrm{ml}$ de THF quando sólido). A mistura foi refluxada por 1 hora e filtrada.

O precipitado cristalino foi identificado (pf e rmp) por com paração com os brometos de alquiltrifenilfosfōnio autènticos.

O filtrado foi diluido com éter de petróleo (30 ml), lavado

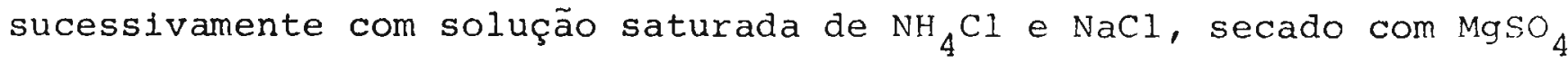
e o solvente evaporado num evaporador rotatório. O resíduo foi dissolvido em $2 \mathrm{ml}$ de THF e a solução tratada gota a gota com ëter de pe tróleo. O trifenilfosfinóxido precipitado foi removido por filtração. *

* O trifenilfosfinóxido pode ser removido filtrando-se o resíduo atra vēs de uma coluna (silica gel 60-Merck, 7g), usando como eluente éter de petróleo. 
134.

Evaporação do filtrado forneceu o produto bruto. Os produtos líquidos foram destilados e os sólidos recristalizados.

Amostras analiticamente puras foram obtidas por cromatografia preparativa em camada delgada.

Em experiências separadas os sais de fosfônio foram removidos, filtrando-se a solução da fosforana para um segundo balão, por melo de um tubo conector de $75^{\circ}$ contendo lã de vidro no interior, an tes da adição do aldeldo. Não foram observadas diferenças nos resul tados com relação a mistura de reação não filtrada.

\section{A partir de sais de (fenilseleno) fosfônio}

n-Buli (em hexano, 2,5 mol) foi adicionado gota a gota a uma suspensão do sal de selenofosfônio em $5 \mathrm{ml}$ de THF (temperatura ambiente, atmosfera de nitrogênio e agitação magnētica), obtendo-se uma solução alaranjada.

O aldeido $(2,5 \mathrm{mmol})$ foi adicionado à solução e após 1 hora sob refluxo ou a temperatura ambiente (ver tabela 1) a mistura foi tratada como em I-B.I.

Duas reações (para preparar os compostos $3 a$ e $3 e$ ) foram efe tuadas em benzeno, removendo-se por filtração os sals precipitados antes da adição do aldeido.

Destilação do produto bruto forneceu butil-fenilseleneto co 
mo produto secundário (30\%, por rmp). Uma amostra de butilfenilseleneto foi preparada para comparação, conforme o procedimento abaixo.

\section{Preparação de butil-fenilseleneto (7)}

A uma suspensão de $\phi \operatorname{SeNa}(10 \mathrm{mmol})$ em $15 \mathrm{ml}$ de THF prepa rada como em 1.2 , foi adicionado bromobutano $(1,37 \mathrm{~g}, 10 \mathrm{mmol})$ em $5 \mathrm{ml}$ de THF.

A mistura foi aquecida a refluxo por 1 hora e filtrada.o solvente foi evaporado e o resíduo destilado a pressão reduzida. Rendimento: $1,5 \mathrm{~g}(728)$; p.e. $55^{\circ}(0,15 \mathrm{~mm})$

$\mathrm{rmp}: \delta\left(\mathrm{CCl}_{4}\right) 0,63-1,96(\mathrm{~m}, 7 \mathrm{H}) ; 2,50(\mathrm{t}, 3 \mathrm{H}, \mathrm{J}=7) ; 6,9-7,6(\mathrm{~m}, 5 \mathrm{H})$. 
C. Reação de (fenilseleno)fosforanas com cetonas: $\alpha$-(fenilseleno)cetonas (8)

\section{Via transilidação}

A uma solução de alquilidenotrifenilfosforana, preparada co mo em I-B.1, a partir de brometo de alquiltrifenilfosfônio (5 mol)e n-Buli (5 mol), foi adicionada gota a gota uma solução de brometo de fenilselenentla $(0,59 \mathrm{~g}, 2,5 \mathrm{mmol})$ em $3 \mathrm{ml}$ de THF.

A selenofosforana resultante foi filtrada (pressão de nitro gênio) para um segundo balão atravēs de um tubo conector de $75^{\circ}$, con tendo lã de vidro no interior.

A cetona foi adicionada gota a gota, ocorrendo formação ime diata de um precipitado cristalino. A mistura de reação foi agitada por 1 hora a temperatura ambiente. O precipitado cristalino foi fil trado e lavado com éter de petróleo. O filtrado foi lavado sucessivamente com solução saturada de $\mathrm{NH}_{4} \mathrm{Cl}$ e $\mathrm{NaCl}$, secado com $\mathrm{MgSO}_{4}$ e $\mathrm{O}$ solvente evaporado.

A mistura de reação pode, tambēm, ser diluida com éter de petróleo, o solvente decantado, repetindo-se o processo vārias vezes. A solução orgânica, lavada, secada e evaporada forneceu o produto com rendimentos semelhantes aos obtidos pelo processo anterior, mas com maior facilidade de extração e destilação.

o resíduo foi destilado a pressão reduzida, fornecendo as 
137.

$\alpha$-selenocetona (características físicas e rendimentos - tabela II). Amostras analiticas foram obtidas por cromatografia preparativa em camada delgada.

Os precipitados cristalinos foram identificados como sendo brometos de alquiltrifenilfosfônio (pf e rmp idênticos aos das amos tras autênticas).

Na reação com acetofenona o produto bruto apresentou traços de 2-fenilpropeno, conforme indicou o espectro de rmp (por comparação com o espectro de uma amostra autēntica).

\section{A partir do sal de (fenilseleno) fosfónio}

A selenofosforana foi preparada como em I-B.2, a partir do sal de selenofosfónio $(2,5 \mathrm{mmol})$ e $\mathrm{n}$-Buli $(2,5 \mathrm{mmol})$.

Adicionou-se a cetona e procedeu-se como no item anterior.

\section{Provas do Mecanismo}

a. Reação do enolato da acetofenona com brometo de metiltrifenilfosfônio: 2-fenilpropeno (9)

Dilsopropilamideto de IItio fol preparado adicionando-se n-BuLi ( 1 mmol) à dilsopropilamina $(1,01 \mathrm{~g}, 1 \mathrm{mmol}$ ) em $10 \mathrm{ml}$ de THF $\left(0^{\circ}\right.$, atmosfera de nitrogênio e agitação magnética).

Após 15 minutos a $0^{\circ}$ a solução foi resfriada a $-78^{\circ}$ e a - 
acetofenona $\left(0^{0}, 12 \mathrm{~g}, 1 \mathrm{mmol}\right)$ foi adicionada gota a gota.

Ao enolato acima foi adicionado (temperatura ambiente, atmosfera de nitrogênio e agitação magnética) brometo de metiltrifenilfosfônio $(0,36 \mathrm{~g}, 1 \mathrm{mmol})$.

Após 24 horas de agitação a temperatura ambiente a mistura foi filtrada e o filtrado diluido com $30 \mathrm{ml}$ de éter etílico, lavado sucessivamente com solução saturada de $\mathrm{NH}_{4} \mathrm{Cl}$ e $\mathrm{NaCl}$, secado com $\mathrm{MgSO}_{4}$ e o solvente evaporado.

A existência de 2-fenilpropeno foi indicada no produto bru to pelos seguintes picos na rmp: $\delta\left(\mathrm{CCl}_{4}\right) 2,10 ; 5,01$ e 5,31 .

A reação foi repetida, mantendo-se a mistura sob refluxo por 2 horas. Após tratamento normal purificou-se o produto por cro matografia preparativa em camada delgada, obtendo-se $80 \mathrm{mg}$ (30\%) de 2-fenilpropeno puro.

rmp: $\delta\left(\mathrm{CCl}_{4}\right) 2,10(\mathrm{~s}, 3 \mathrm{H}) ; 5,01(\mathrm{~m}, 1 \mathrm{H}) ; 5,31(\mathrm{~m}, 1 \mathrm{H}) ; 7,1-7,5(\mathrm{~m}, 5 \mathrm{H})$. De acordo com a literatura $[87]$.

b. $\alpha$-(Fenilseleno) ciclohexanona a partir de ciclohexanona $[84]$

Difsopropilamideto de líto (10 mol) foi preparado como no caso anterior.

A solução de disopropilamideto de litio, resfriada a $-78^{\circ}$, foi adicionada ciclohexanona $(0,98 \mathrm{~g}, 10 \mathrm{mmol})$ e após 15 minutos bro 
meto de fenilselenenila $(2,36 \mathrm{~g}, 10 \mathrm{mmol})$ em $5 \mathrm{ml}$ de THF.

Após 30 minutos a $-78^{\circ}$ a solução foi diluída com éter de petróleo $(30 \mathrm{ml})$, lavada com solução saturada de $\mathrm{NH}_{4} \mathrm{Cl}$ e $\mathrm{NaCl}$, secada com $\mathrm{MgSO}_{4}$ e a mistura de solventes evaporada. O residuo foi destilado a pressão reduzida.

Rendimento: $2,0 \mathrm{~g}(80 \%)$; p.e. $132^{\circ}(0,005 \mathrm{~mm})$

ir e rmp: idênticos aos do produto obtido pela reação entre (fenilseleno)metilenotrifenilfosforana e ciclohexanona (V. tabela II).

c. Reação do enolato da ciclohexanona com brometo de (fenilseleno)metiltrifenilfosfônio [84]

O enolato da ciclohexanona foi preparado como na experiên cia anterior.

A solução do enolato (temperatura ambiente, atmosfera de nitrogênio e agitação magnética) foi adicionado brometo de (fenilseleno)metiltrifenilfosfōnio $(0,512 \mathrm{~g}, 1 \mathrm{mmol})$.

Após 1 hora de agitação a temperatura amblente, o precipí tado foi removido por filtração (rend.: $0,35 \mathrm{~g}, 1008$ ) e identifica do como brometo de metiltrifenilfosfônio (pf e rmp idênticos aos de uma amostra autêntica). Tratamento do filtrado como na experiên cia anterior forneceu $\alpha$-(fentlseleno)ciclohexanona. rendimento: $0,40 \mathrm{~g}(80 \%)$ 
iv e rmp: idênticos aos do produto da reação anterior.

d. Tratamento da mistura de reação entre (fenilseleno)metiltrifenilfosforana e dietilcetona com $\mathrm{CH}_{3} \mathrm{I}$ : formação de 2-metil-2-(fenilseleno)-3-pentanona (8i)

A uma solução de (fenilseleno)metilenotrifenilfosforana preparada como em I-B.2, a partir de brometo de (fenilselno)metiltrifenilfosfônio (1,28 g, 2,5 mmol) e n-Buli $(2,5 \mathrm{mmol})$, foi adicionada go ta a gota dietilcetona $(0,22 \mathrm{~g}, 2,5 \mathrm{mmol})$.

Após 1 hora de agitação à temperatura ambiente adicionou-se um excesso de $\mathrm{CH}_{3} \mathrm{I}$, agitando-se a mistura por um periodo adicional de $1 / 2$ hora. O precipitado cristalino foi separado por filtração e o filtrado lavado sucessivamente com solução saturada de $\mathrm{NH}_{4} \mathrm{Cl}$ e tiossul fato de sódio, secada com $\mathrm{MgSO}_{4}$ e o solvente evaporado num evaporaçor rotatório. O resíduo foi purificado por cromatografia preparativa em camada delgada.

$$
\begin{aligned}
& \text { Rendimento: } 0,18 \mathrm{~g}, 30 \mathrm{q} \\
& \mathrm{rmp}: \delta\left(\mathrm{CCl}_{4}\right) 1(\mathrm{t}, 3 \mathrm{H}, \mathrm{J}=7) ; 1,43(\mathrm{~s}, 6 \mathrm{H}) ; 2,73(\mathrm{q}, 2 \mathrm{H}, \mathrm{J}=7) \\
& 7,0-7,5(\mathrm{~m}, 5 \mathrm{H})
\end{aligned}
$$


141.

D. Reação de (fenilseleno)metilenotrifenilfosforana com acetato de etila

A uma solução de (fenilseleno)metilenotrifenilfosforana $(2,5$ mol) preparada como em I-B.2, adicionou-se acetato de etila $(0,22 \mathrm{~g}$, $2,5 \mathrm{mmol})$.

Não foi observada precipitação imediata. Apenas após aqueci mento observou-se turvação da soluȩão.

Após 24 horas de aquecimento a refluxo o precipitado cristalino fol separado por filtração, sendo identificado como brometo de metiltrifenilfosfōnio. O filtrado apōs tratamento normal e purificação por cromatografia preparativa em camada delgada forneceu o $\alpha$-(fenilseleno) acetato de etila.

Rendimento: $25 \%$

$\mathrm{rmp}: \delta\left(\mathrm{CCl}_{4}\right) 1,21(t, 3 \mathrm{H}, \mathrm{J}=7) ; 3,50(\mathrm{~s}, 2 \mathrm{H}) ; 4,10(\mathrm{q}, 2 \mathrm{H}, \mathrm{J}=7)$; $7,1-7,7(\mathrm{~m}, 5 \mathrm{H})$. 
E. Reação de (fenilseleno)metiltrifenilfosforana com compostos B-dicarbonilicos

\section{Reação efetuada em THF}

A uma solução de (fenilseleno)metilenotrifenilfosforana $(2,5$ mol) preparada como em I-B.2 foi adicionado o composto $\beta$-dicarbonili co $(2,5$ mmol $)$.

Observou-se descoloração da solução com formação imediata de um precipitado incolor.

Apōs uma hora de agitação à temperatura ambiente o precipitạ do foi separado por filtração. O filtrado foi tratado de maneira usu al. Por evaporação do solvente observou-se que não ocorreu formação do produto esperado.

Parte do precipitado se apresentou solúvel em diclorometano. Por adição de acetato de etila à solução em $\mathrm{CH}_{2} \mathrm{Cl}_{2}$ precipitou brometo de (fenilseleno)metiltrifenilfosfônio. (pf e rmp idênticos aos de uma amostra autēntica). A parte insolúvel em diclorometano foi tratada com solução de $\mathrm{HCl}(0,1 \mathrm{~N})$ e éter etillico. A solução orgânica foi se cada com $\mathrm{MgSO}_{4}$ e o solvente evaporado. O resíduo foi identificado co mo sendo o composto $\beta$-dicarbonilico original (por $\mathrm{rmp}$ ).

\section{Reação efetuada em HMPA}

A uma suspensão de brometo de (fenilseleno)metiltrifenilfos- 
fönio $(1,28 \mathrm{~g}, 2,5 \mathrm{mmol})$ em $5 \mathrm{ml}$ de HMPA, foi adicionado gota a gota n-Buti (em hexano, 2,5 mmol).

Ocorreu reação imediata com formação de uma solução de co loração violeta escura.

Por adição do composto $\beta$-dicarbonílico não ocorreu mudança imediata na solução. Apōs aproximadamente 5 minutos a solução ficou mais clara, observando-se a formação lenta de um precipitado cristalino.

Após 1 hora de agitação à temperatura ambiente a solução foi diluida com éter de petróleo $(30 \mathrm{ml})$. O precipitado cristalino foi separado por filtração e ldentificado como brometo de metil trifenilfosfônio ( $\mathrm{pf}$ e rmp idênticos aos de uma amostra autêntica). O filtrado foi tratado com poucos $\mathrm{ml}$ de $\mathrm{HCl}$ 0,1 N. A parte orgâni ca foi secada com $\mathrm{MgSO}_{4}$ e o solvente evaporado num evaporador rota tório. O residuo foi filtrado através de uma coluna (silica gel 60-Merck, $7 \mathrm{~g})$, usando-se como eluente éter etílico.

3. Preparação de amostras autênticas de $\alpha$-fenilseleno derivados de compostos $\beta$-dicarbonílicos

A uma suspensão de $\mathrm{NaH}(0,32 \mathrm{~g}, \quad 7,5 \mathrm{mmol}$, de uma dispersão a $57 \%$ em óleo, previamente lavada com hexanol em $10 \mathrm{ml}$ de THF foi adicionado o composto $\beta$-čicarbonílico ( $5 \mathrm{mmol})$. Ocorreu des prendimento de hidrogênio. 
Apōs 15 minutos de agitação a solução foi resfriada a $0^{\circ} \mathrm{e}$ uma solução de bxometo de fenilselenenila $(1,2 \mathrm{~g}, 5 \mathrm{mmol})$ em $5 \mathrm{ml}$ de THF foi adicionada rapidamente. A solução foi vertida lentamente so bre uma mistura de eter etílico/pentano l:1( $30 \mathrm{ml})$, solução saturada de $\mathrm{NaHCO}_{3}(15 \mathrm{ml})$ e gêlo e em seguida agitada. O extrato orgânico foi lavado com solução saturada de $\mathrm{NaCl}$, secado com $\mathrm{MgSO}_{4}$ e a mistlira de solventes evaporada. O residuo fol destilado à pressão reduz1 da, fornecendo os $\alpha$-fenilseleno derivados (rendimentos indicados na tabela III). 
145.

II. Reação de Horner-Emmons entre (fenilseleno) Eosfonatos e compostos carbonilicos

A - Preparação das matërias primas

1. (Fenilseleno)metilaietilfosfonato (15)

a. A uma solução de iodometildietilfosfonato $(13,2$ g, 47 rimol) em $20 \mathrm{ml}$ de THF foi adicionada uma suspensão de $\phi S e N a$, preparada como em I-A.I.a a partir de $\mathrm{NaH}(2,10 \mathrm{~g}, 50 \mathrm{mmol})$ em 20 $\mathrm{ml}$ de THF e selenofenol, $(13,2 \mathrm{~g}, 47 \mathrm{mmol})$ em $20 \mathrm{ml}$ de THF.

Após uma hora de agitação à temperatura ambiente, a mistú ra resultante foi lavada sucessivamente com solução saturada de $\mathrm{NH}_{4} \mathrm{Cl}$, NaCl, secada com $\mathrm{Na}_{2} \mathrm{SO}_{4}$ e o solvente evaporado. O resíduo foi destilado a pressão reduzida.

(análise, propriedades físicas e espectrais: ver tabela IV).

b. A uma solução de difenildisseleneto $(1,60 \mathrm{~g}, 5,1$ mmol) em $10 \mathrm{ml}$ de THF foi adicionado ácido hipofosforoso $\left(\mathrm{H}_{3} \mathrm{PO}_{2}\right.$, $4,2 \mathrm{ml}) \quad[88]$.

A mistura foi aquecida a refluxo por 20 minutos. Após resfriamento a solução fol extraida com benzeno (25 ml). A solução benzênica fol tratada com hidröxido de sódio $50 \%(0,7 \mathrm{ml})$, formando-se uma suspensão de selenofenóxido de sódio.

A essa suspensão adicionou-se o iodometildietilfosfonato 
$(2,78 \mathrm{~g}, 10 \mathrm{mmol})$.

A mistura foi agitada a temperatura ambiente por 3 horas, lavada sucessivamente com solução saturada de $\mathrm{NH}_{4} \mathrm{Cl}$ e $\mathrm{NaCl}$, secada com $\mathrm{Na}_{2} \mathrm{SO}_{4}$ e evaporada. O produto bruto foi purificado por filtra ção atravēs de uma coluna (sillca gel 60-Merck, 25g). O excesso de difenildisseleneto foi eluido com ēter de petróleo e o (fenilse leno)metildietilfosfonato com ēter etílico.

rmp e iv: idênticos aos do produto preparado pelo procedi mento anterior.

\section{Alquilação do (fenilseleno)metildietilfosfonato}

Ao (fenilseleno)metildietilfosfonato $(4,63 \mathrm{~g}, 15 \mathrm{mmol})$ em $50 \mathrm{ml}$ de $\mathrm{THF}\left(-78^{\circ}\right.$, atmosfera de nitrogênio e agitação magnética) foi adicionado gota a gota n-BuLi (em hexano, 16 mol).

Após 4 horas de agitação a $-78^{\circ}$, adicionou-se uma solução do haleto de alquila (25 mmol) em $20 \mathrm{ml}$ de THF.

A solução foi agitada por uma hora a $-78^{\circ}$ seguindo-se 5 horas de agitação à temperatura ambiente. O solvente foi evaporado e o residuo diluido com èter etilico. A solução foi lavada sucessivamente com solução saturada de $\mathrm{NH}_{4} \mathrm{Cl}$ e $\mathrm{NaCl}$, secada com $\mathrm{Na}_{2} \mathrm{SO}_{4}$

e o solvente evaporado. O resíduo foi destilado a pressão reduzida.

(análise, propriedades físicas e espectrais: ver tabela IV). 


\section{3. (Fenilseleno)difenilbenzilfosfinóxido (18)}

Benzildifenilfosfinóxido $(2,92 \mathrm{~g}, 10 \mathrm{mmol})$ em $40 \mathrm{ml}$ de éter etílico (temperatura ambiente, atmosfera de nitrogênio e agitação magnética) foi tratado com n-Buli (em hexano, $10 \mathrm{mmol}$ ).

Apōs 20 minutos a solução foi resfriada a $-78^{\circ}$ e uma solu Ção de brometo de fenilselenenila $(2,12 \mathrm{~g}, 9 \mathrm{mmol})$ em $20 \mathrm{ml}$ de THF foi adicionada gota a gota. Um precipitado cristalino se formou imediatamente.

Apōs 2 horas a $-78^{\circ}$ deixou-se a mistura alcançar a temperatura ambiente, removendo-se o produto sólido por filtração.

(anālise, propriedades físicas e espectrais: ver tabela IV).

4. Seleneto de bis-(dietilfosfometila) (19)

Iodometildietilfosfonato $(13,9 \mathrm{~g}, 50 \mathrm{mmol}) \mathrm{em} 20 \mathrm{ml}$ de THF foi adicionado a uma suspensão de $\mathrm{Na}_{2} \mathrm{Se}$ (procedência Alfa Ventron) (temperatura ambiente, atmosfera de nitrogênio e agitação magnética) em $30 \mathrm{ml}$ de THF.

A solução resultante fol agitada à temperatura ambiente por 2 horas, lavada sucessivamente com solução saturada de $\mathrm{NH}_{4} \mathrm{Cl}$ e $\mathrm{NaCl}$, secada com $\mathrm{Na}_{2} \mathrm{SO}_{4}$ e o solvente evaporado. O resíduo foi destilado a pressão reduzida.

(análise, propriedades físlcas e espectrais: ver tabela IV). 
148 .

B. Reação de (fenilseleno)fosfonatos com compostos carbonílicos: selenetos vinílicos

\section{Usando hidreto de sódio como base}

A uma mistura de $\mathrm{NaH}(0, \mathrm{~g}, 2,4 \mathrm{mmol}$, de uma dispersão a $57 \%$ em óleo previamente lavada com hexano) e fenilselenofosfonato ( 2 mol) em $10 \mathrm{ml}$ de THF e HMPA $10: 1$, a $80^{\circ}$ (temperatura do banho), sob atmosfera de nitrogênio e agitação magnética, foi adicionado o compos to carbonilico $(2,2 \mathrm{mmol})$ puro quando líquido, dissolvido em $3 \mathrm{ml}$ de THF quando sólido. Observou-se desprendimento de hidrogênio.

A solução foi aquecida (tempo e temperatura de aquecimento indicados na tabela V). A mistura foi resfriada à temperatura ambi ente e diluida com $30 \mathrm{ml}$ de éter de petróleo, lavada sucessivamente com solução saturada de $\mathrm{NH}_{4} \mathrm{Cl}$ e $\mathrm{NaCl}$, secada com $\mathrm{Na}_{2} \mathrm{SO}_{4}$ e a mistura de solventes evaporada.

o resíduo foi filtrado através de uma coluna (silica gel 60-Merck, 7g), usando-se como eluente éter de petróleo. Pela evapo ração do solvente obtiveram-se os selenetos vinílicos puros. No entanto, as análises elementares e os espectros foram efetuados com amostras purificadas por cromatografia preparativa em camada delgada.

Algumas reçções foram efetuadas empregando-se o mesmo procedimento acima, mas usando-se como solvente HMPA puro (temperatura 
do banho $80^{\circ}$, ou uma mistura de HMPA e THF $1: 1$ (ver tabela V).

\section{Usando butil lítio como base}

A uma solução de (fenilseleno)fosfonato $(2,4 \mathrm{mmol}$ ) em $10 \mathrm{ml}$ de $\operatorname{THF}\left(-78^{\circ}\right.$, atmosfera de nitrogênio e agitação magnética) adicionou-se gota a gota $n-B u L i$ (em hexano, 2 mmol).

A mistura fol agitada por 4 horas a $-78^{\circ}$. A seguir adicio nou-se gota a gota o composto carbonílico (2 mmol) puro quando líqui do, dissolvido em $3 \mathrm{ml}$ de THF quando sólido. Continuou-se a agitação a $-78^{\circ}$ por mais uma hora.

Deixou-se a solução atingir a temperatura ambiente e então aqueceu-se (tempo e temperatura de aquecimento indicados na tabela V).

Tratou-se a mistura de reação como no item anterior.

\section{Seleneto de bis-( $\beta$-estirila) (20)}

Uma mistura de seleneto de bis-(dietilfosfometila) $(0,77 \mathrm{~g},-$ 2 mmol), $\mathrm{NaH}(0,2 \mathrm{~g}, 4,8 \mathrm{mmol}$ de uma dispersão a $57 \%$ em óleo, previamen te lavada com hexano) e benzaldeido $(0,42 \mathrm{~g}, 4 \mathrm{mmol})$ em $10 \mathrm{ml}$ de THF e HMPA 10:1 (atmosfera de nitrogênio e agitação magnētica) foi aquecida a refluxo por 2 horas.

A mistura de reação foi tratada como nos itens anteriores,fornecendo um óleo que cristalizou por adição de etanol. (Ver tabela 
V) .

4. Tentativa de reação entre (fenilseleno) benzildifenilfosfinōxido e benzaldeido

Aqueceu-se a refluxo uma mistura de (fenilseleno)benzildifenilfosfinōxido $(0,58 \mathrm{~g}, 2 \mathrm{mmol}), \mathrm{NaH}(0, \mathrm{gg}, 2 \mathrm{mmol}$ de uma disper são a $57 \%$ em óleo, previamente lavada com hexanol e benzaldeido $(0,21 \mathrm{~g}, 2 \mathrm{mmol}$ ) em $10 \mathrm{ml}$ de THF e HMPA 10:1 (atmosfera de nitrogê nio e agitação magnētica).

Após alguns minutos sob refluxo o sólido em suspensão se dissolveu, ficando a solução apenas turva. Com o prolongamento do aquecimento observou-se o reaparecimento do sólido, o qual foi separado por filtração e identificado como sendo o fosfinóxido inicial. O filtrado foi evaporado, recuperando-se o benzaldeido. 
C. Hidrölise de 1-fenil-2-(fenilseleno)-1-buteno: 1-fenil-3-pentanona (25)

\section{Hidrólise efetuada com ácido trifluoroacético}

1-fenil-2-(fenilseleno)-1-buteno $(0,29 \mathrm{~g}, 1 \mathrm{mmol})$ foi dissol vido em $\mathrm{F}_{3} \mathrm{CCOOH}(1 \mathrm{ml})$, à temperatura ambiente. Observou-se imediata formação de difenildisseleneto.

Após duas horas de agitação à temperatura ambiente a mistura foi diluida com água, extraida com éter etílico e a fase orgânica lavada várias vezes com ãgua, secada com $\mathrm{NaSO}_{2}$ e evaporada.

O resíduo foi filtrado através de uma coluna (silica gel 60-Merck, 7g). O difenildisseleneto foi eluido com éter de petróleo e a cetona com éter etílico.

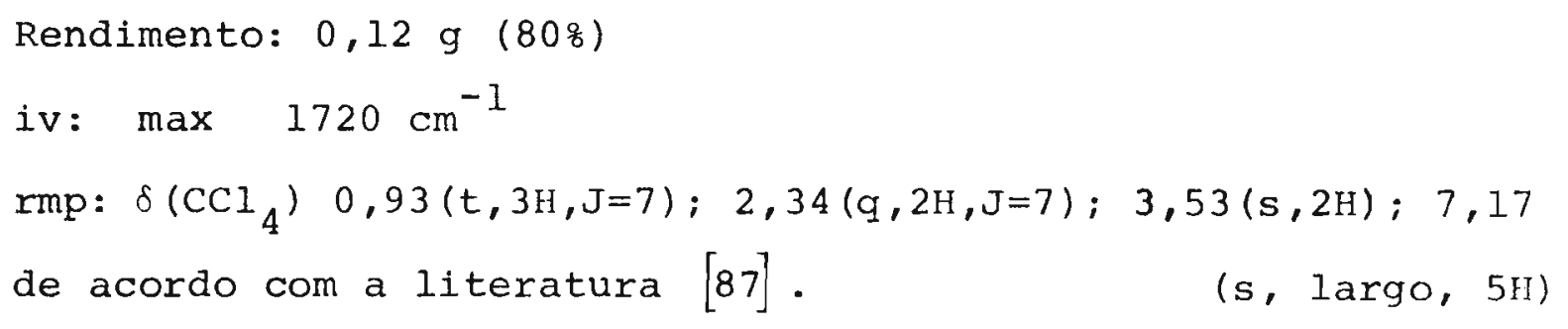

2. Hidrólise efetuada com cloreto de mercúrio

A uma solução de 1-fenil-2-(fenilseleno)-1-buteno $(0,29 \mathrm{~g}$, 1 mmol) em $8 \mathrm{ml}$ de $\mathrm{CH}_{3} \mathrm{CN}$ e $\mathrm{H}_{2} \mathrm{O}(3: 1)$ foi adicionado $\mathrm{HgCl}_{2}(0,55 \mathrm{~g}, 2$ mmol) em $8 \mathrm{ml}$ da mesma mistura de solventes. A mistura foi aquecida 
a $80^{\circ}$ (temperatura do banho) por 70 horas. Observou-se formação de um precipitado cristalino.

o precipitado foi separado por filtração e lavado com eter etílico. O filtrado foi diluído com éter etílico e lavado sucessivamente com solução saturada de $\mathrm{NaHCO}_{3}$ e $\mathrm{NaCl}$, secado com $\mathrm{Na}_{2} \mathrm{SO}_{4}$ e o solvente evaporado. O resíduo foi destilado a pressão reduzida.

Rendimento: $1,42 \mathrm{~g}(95 \%)$ pe $109-113^{\circ} / 15 \mathrm{~mm}$

iv e rmp: idēnticos aos do produto da reação anterior. 


\section{III - Selenetosvinílicos a partir de acetilenos}

\section{A. Preparação de acetilenos dissubstituídos $[89,101]$}

A uma solução do acetileno terminal $(22 \mathrm{mmol})$ em $20 \mathrm{ml}$ de THF $\left(0^{\circ}\right.$, atmosfera de nitrogênio e agitação magnética) foi adicio nado o n-Buli (em hexano, $24 \mathrm{mmol}$ ). Após 15 minutos adicionou-se o haleto de alquila (24 mmol) em $30 \mathrm{ml}$ de HMPA.

A mistura fol mantida sob agitação à temperatura ambiente por 30 minutos. Após esse tempo verteu-se a solução sobre $500 \mathrm{ml}$ de àgua gelada. Extralu-se com éter de petróleo. A fase orgânica foi lavada vārlas vezes com água, secada com $\mathrm{MgSO}_{4}$ e o solvente evaporado. o resíduo fol destilado à pressão reduzida.

$$
\text { ref. rend. : }
$$

$\begin{array}{ll}\mathrm{C}_{6} \mathrm{H}_{5} \mathrm{C} \equiv \mathrm{C}-\mathrm{CH}_{3} \quad[1: \mathrm{l}] & 95\end{array}$

$\begin{array}{ll}\mathrm{C}_{6} \mathrm{H}_{5}-\mathrm{C} \equiv \mathrm{C}-\mathrm{C}_{2} \mathrm{H}_{5} \quad[12] & 89\end{array}$

$\mathrm{C}_{6} \mathrm{H}_{5}-\mathrm{C} \equiv \mathrm{C}-\mathrm{C}_{4} \mathrm{H}_{9}$

$[13]$

92

$\mathrm{CH}_{3}\left(\mathrm{CH}_{2}\right)_{3}-\mathrm{C} \equiv \mathrm{C}-\left(\mathrm{CH}_{2}\right)_{3} \mathrm{CH}_{3} \quad[14]$ 


\section{B. Adição de selenofenol a acetilenos}

\section{1. (fenilseleno)estireno $\mathrm{Z}$}

Fenilacetileno $(0,5 \mathrm{~g}, 5 \mathrm{mmol})$ foi adicionado ao selenofenol $(0,78 \mathrm{~g}, 5 \mathrm{mmol})$. Ocorreu reação imediata com desprendimento de calor. Após 1 hora à temperatura ambiente foram adicionados alguns mi lilitros de etanol, causando cristalização do produto. o produto foi recolhido por filtração e recristalizado de etanol.

Rendimento: $1, \log (90 \%)$ pf $45-47^{\circ}$ (de acordo com a lite
ratura $[52]$ ).

rmp: ver tabela VII.

2. Adição de selenofenol a acetilenos mono- e dissubstituídos

Quantidades equimolares de selenofenol e do acetileno foram mantidas em ampolas fechadas, à temperatura ambiente ou a $130^{\circ}$ (ver tempo de reação na tabela VI).

Após o tempo indicado na tabela VI as ampolas foram abertas e o conteúdo diluído com ēter de petróleo. A solução foi lavada sucessivamente com solução $0,1 \mathrm{~N}$ de hidróxido de sódio e āgua, secadá com $\mathrm{Na}_{2} \mathrm{SO}_{4}$ e o solvente evaporado. O resíduo foi destilado a pressão reduzida fornecendo os selenetos vinilicos com os rendimentos indica dos na tabela VI. (rmp tabela VII). 


\section{Preparação de (fenilseleno) acetilenos (24)}

A uma solução do acetileno $(10 \mathrm{mmol})$ em $10 \mathrm{mI}$ de THF $10^{\circ}$, atmosfera de nitrogênio e agitação magnética) fol adicionado n-BuLi (em hexano, $10 \mathrm{mmol}$ ).

Após 15 minutos de agitação a $0^{\circ}$, foi adicionada gôta a gota uma solução de brometo de fenilselenenila em $5 \mathrm{ml}$ de THF. A solução resultante foi mantida em agitação por 1 hora à temperatura ambiente e então tratada com solução saturada de $\mathrm{NH}_{4} \mathrm{Cl}$. Adicionou-se éter de petróleo $(30 \mathrm{ml})$. A parte orgânica foi lavada com solu ção saturada de $\mathrm{NaCl}$ e secada com $\mathrm{MgSO}_{4}$. A mistura de solventes foi evaporada e o residuo destilado a pressão reduzida, fornecendo os selenetos acetilênicos com os rendimentos indicados na tabela VIII. 
156.

D. Redução de (fenilseleno)acetilenos: Selenetos vinilicos E

A uma suspensão de LAH $(0,3 \mathrm{~g}, 8 \mathrm{mmol})$ em $10 \mathrm{ml}$ de THF (temperatura ambiente, atmosfera de nitrogênio e agltação magnética) foi adicionado o (fenilseleno)acetileno ( $4 \mathrm{mmol}$ ) em $20 \mathrm{ml}$ de THF.

Após duas horas de aquecimento a refluxo, a mistura da reação foi resfriada e tratada sucessivamente com $\mathrm{H}_{2} \mathrm{O}(0,3 \mathrm{ml}), \mathrm{NaOH} 15 \%$ $(0,3 \mathrm{mI})$ e $\mathrm{H}_{2} \mathrm{O}(0,9 \mathrm{ml})$. Formou-se um precipitado cristalino, o qual foi removido por filtração e lavado com éter de petróleo. o filtrado foi secado com $\mathrm{Na}_{2} \mathrm{SO}_{4}$ e a mistura de solventes èvaporada. O resíduo foi destilado fornecendo os selenetos vinilicos com os rendimentos in dicados na tabela IX. 
Espectros de rmp e iv. Quando não mencionado os espectros de rmp foram registrados num espectrometro Varian T-60, usando-se $\mathrm{CCl}_{4}$ como solvente e os espectros de iv num es pectrofotómetro Perkin Elmer, 457 A, usando-se filme líquido entre placas de $\mathrm{NaCl}$. 
158.
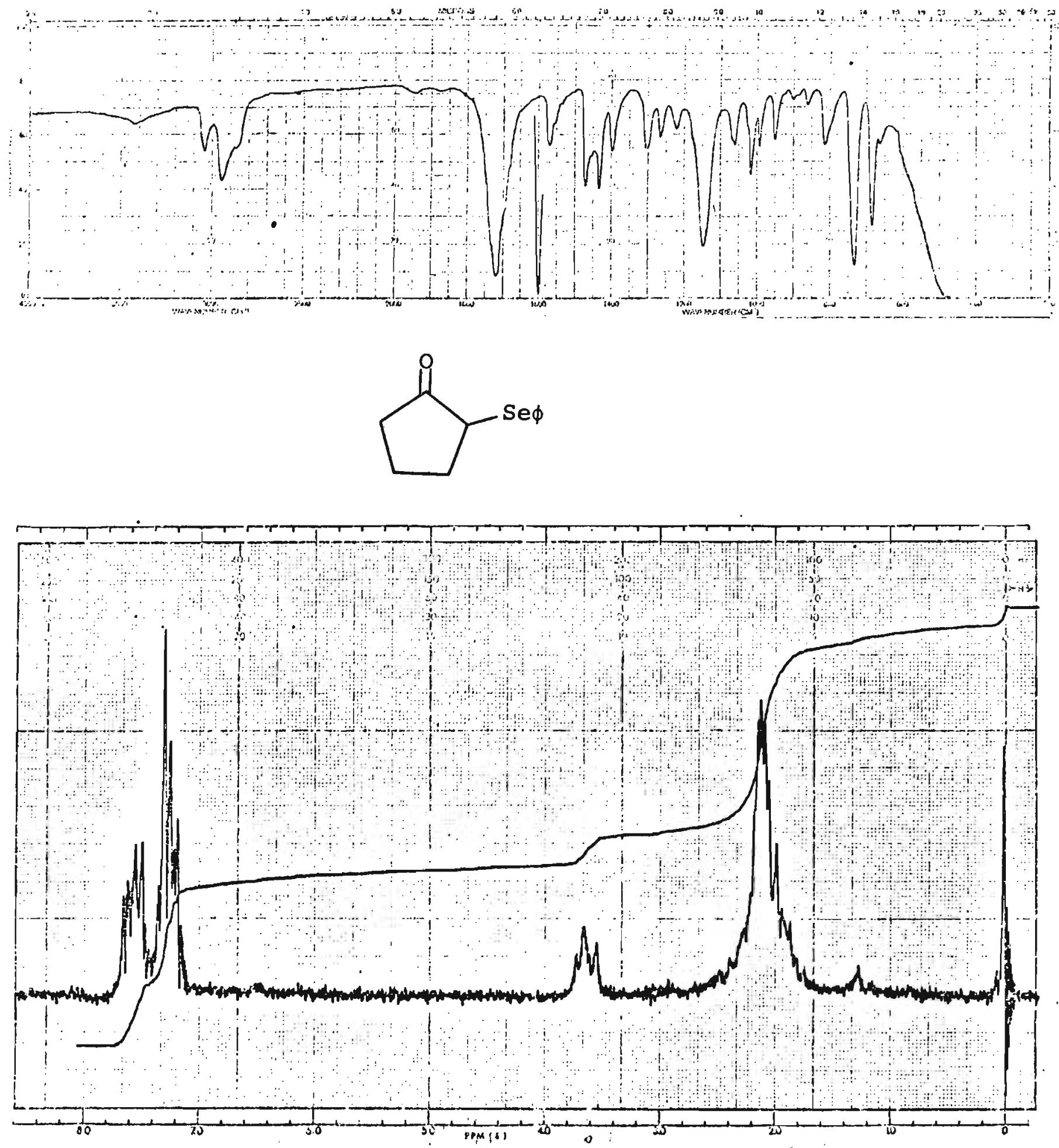

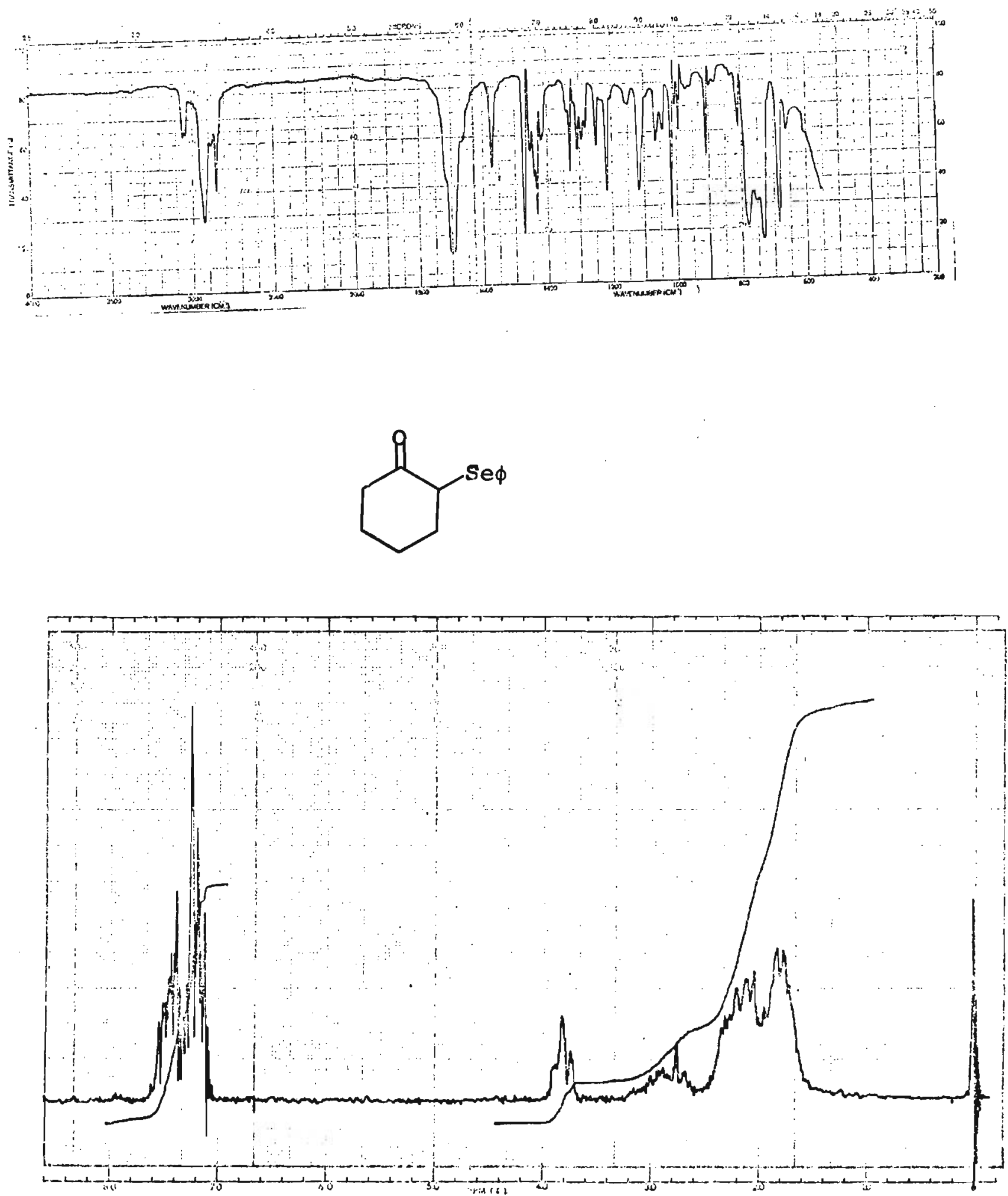

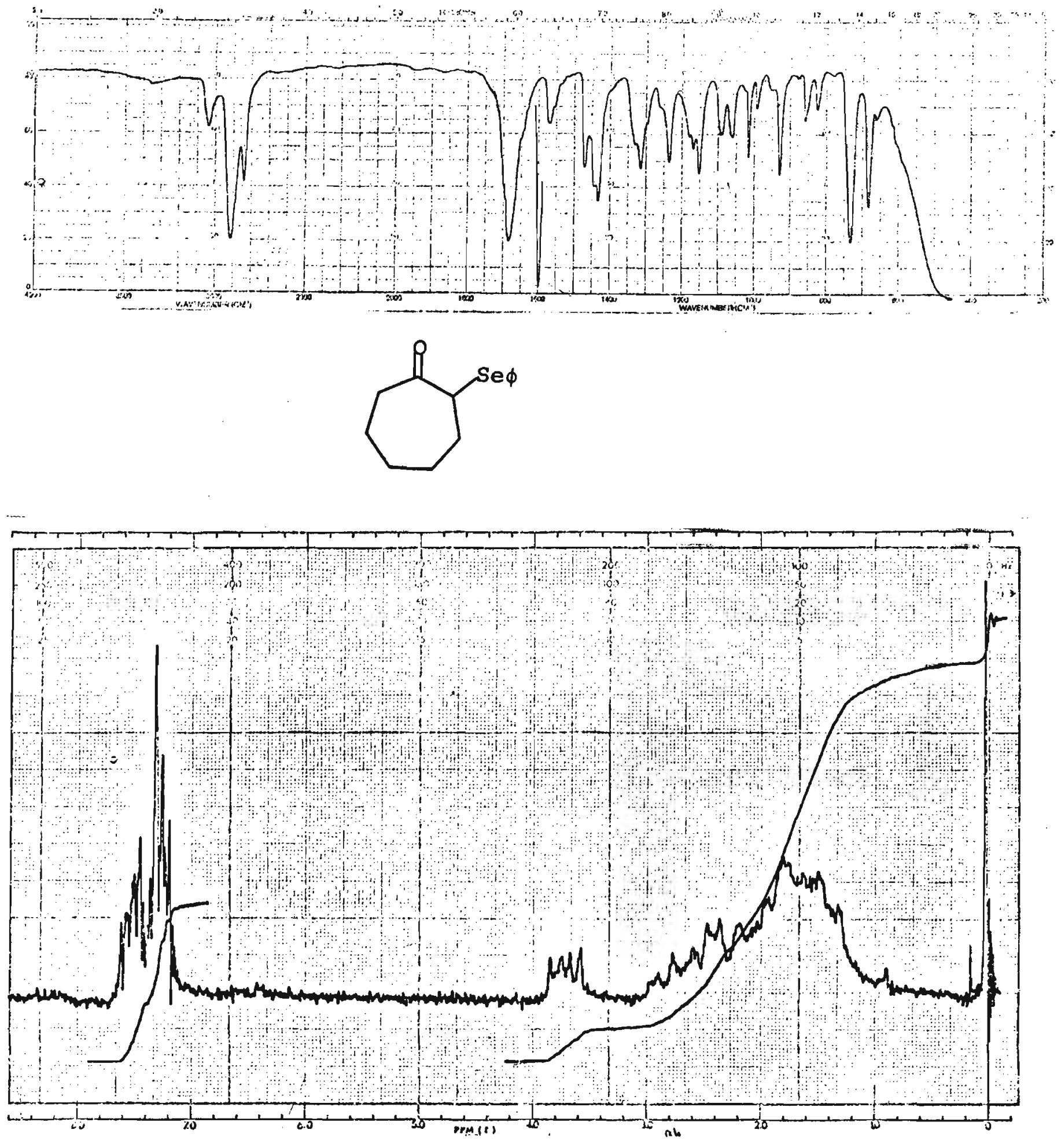

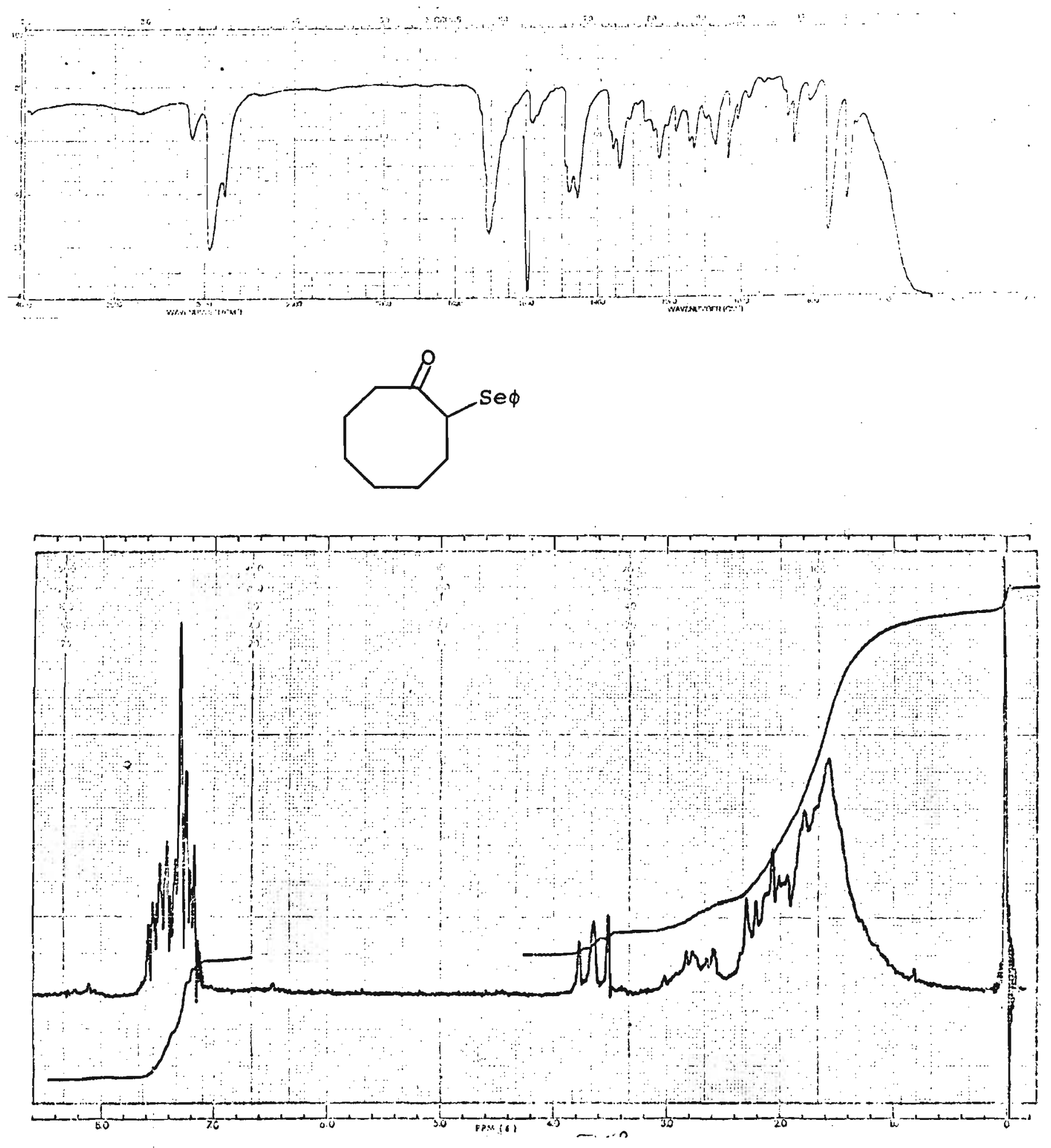
162.
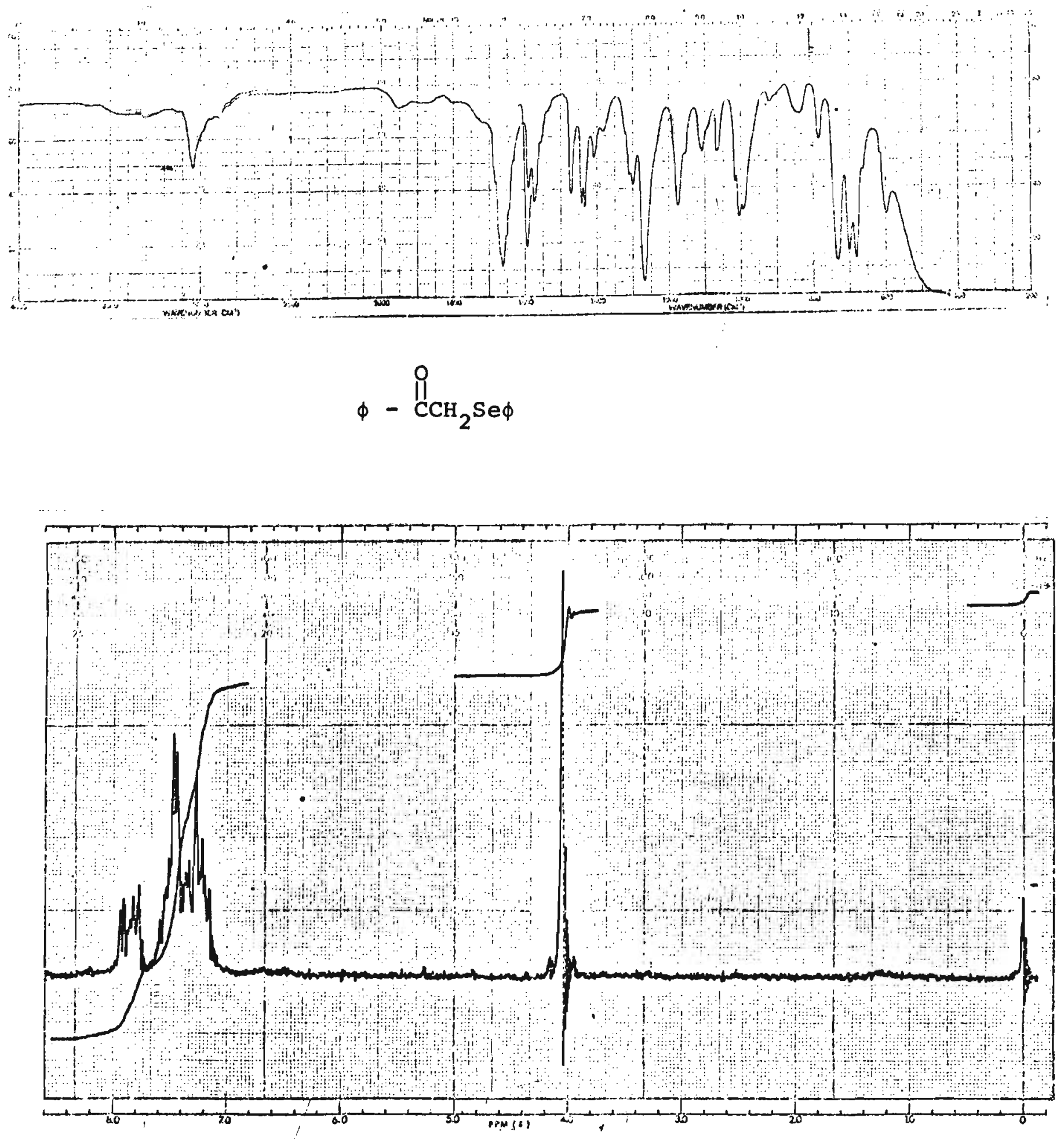


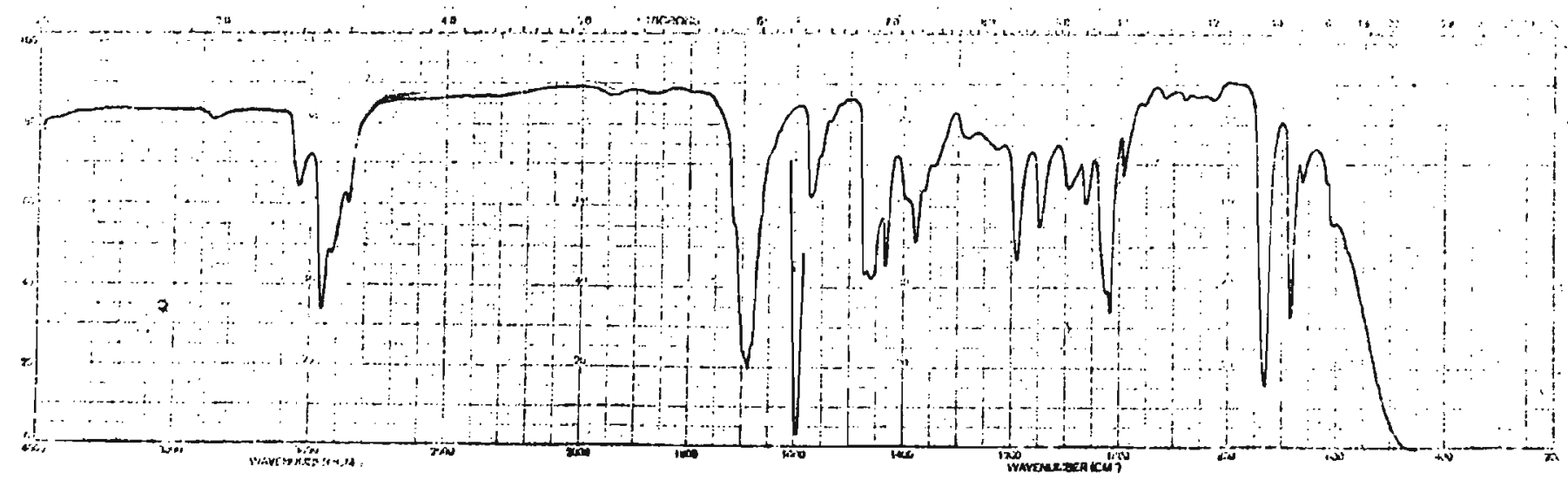

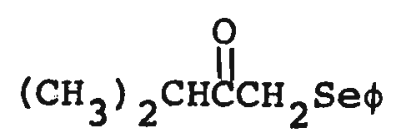

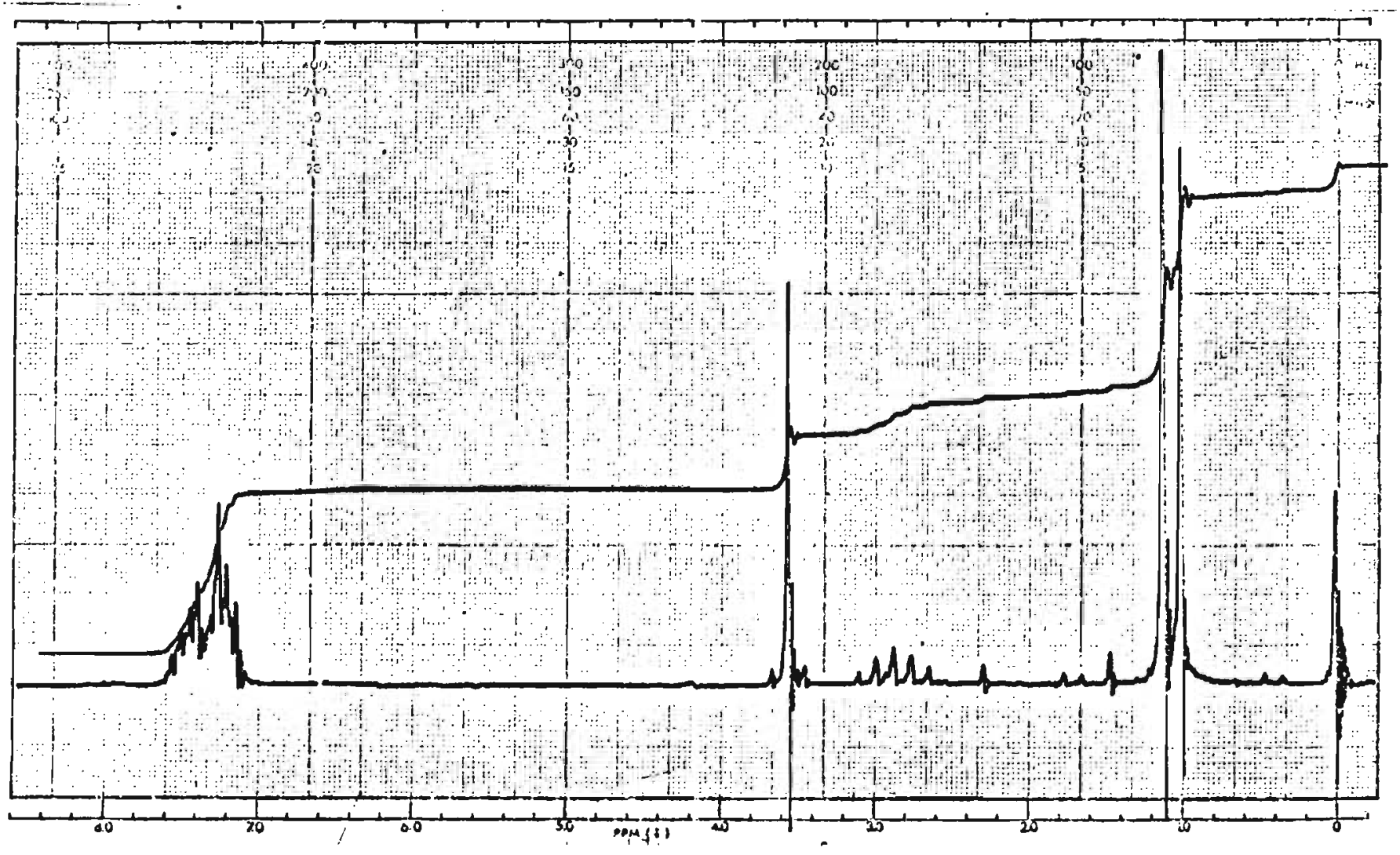


164.
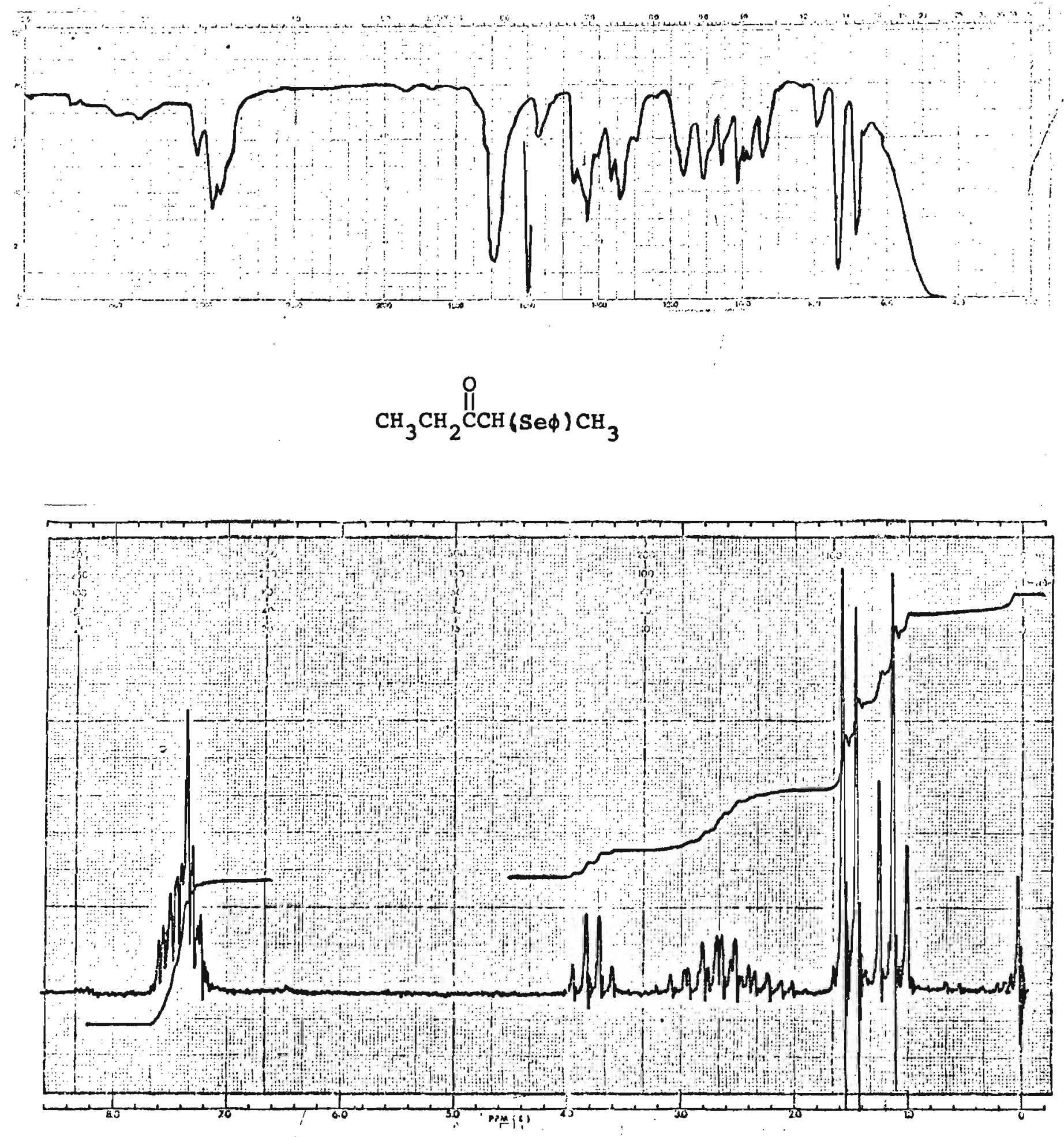


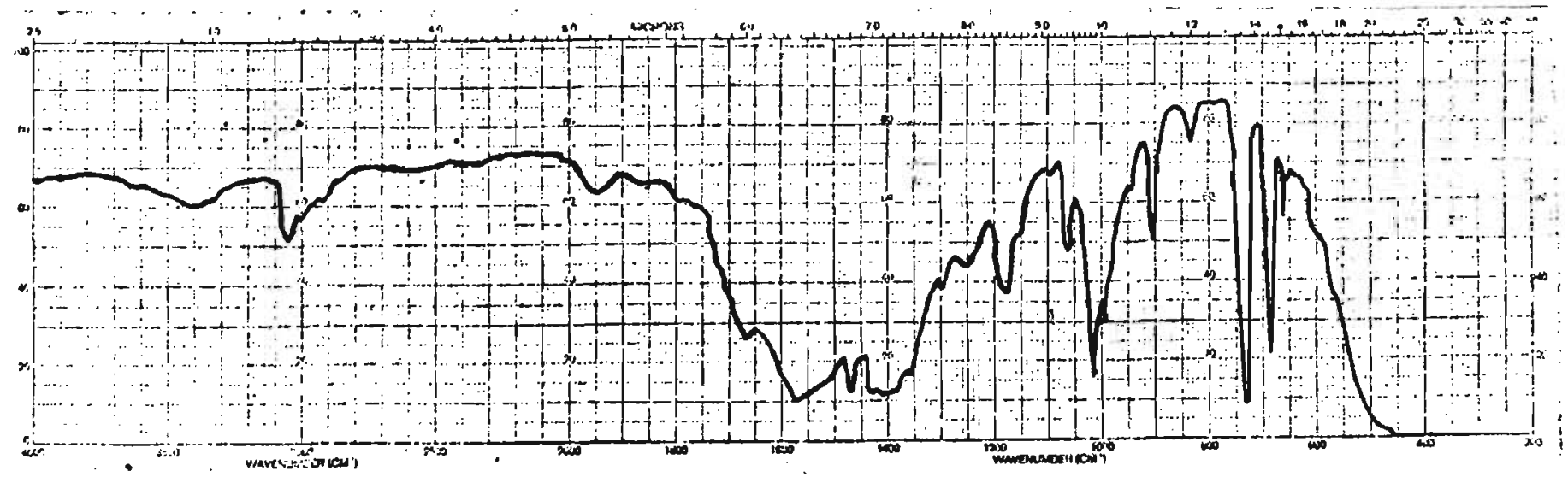

\section{$\mathrm{CH}_{3}{ }_{3}^{\mathrm{CCH}}(\mathrm{Seq}) \mathrm{CCH}_{3}$}

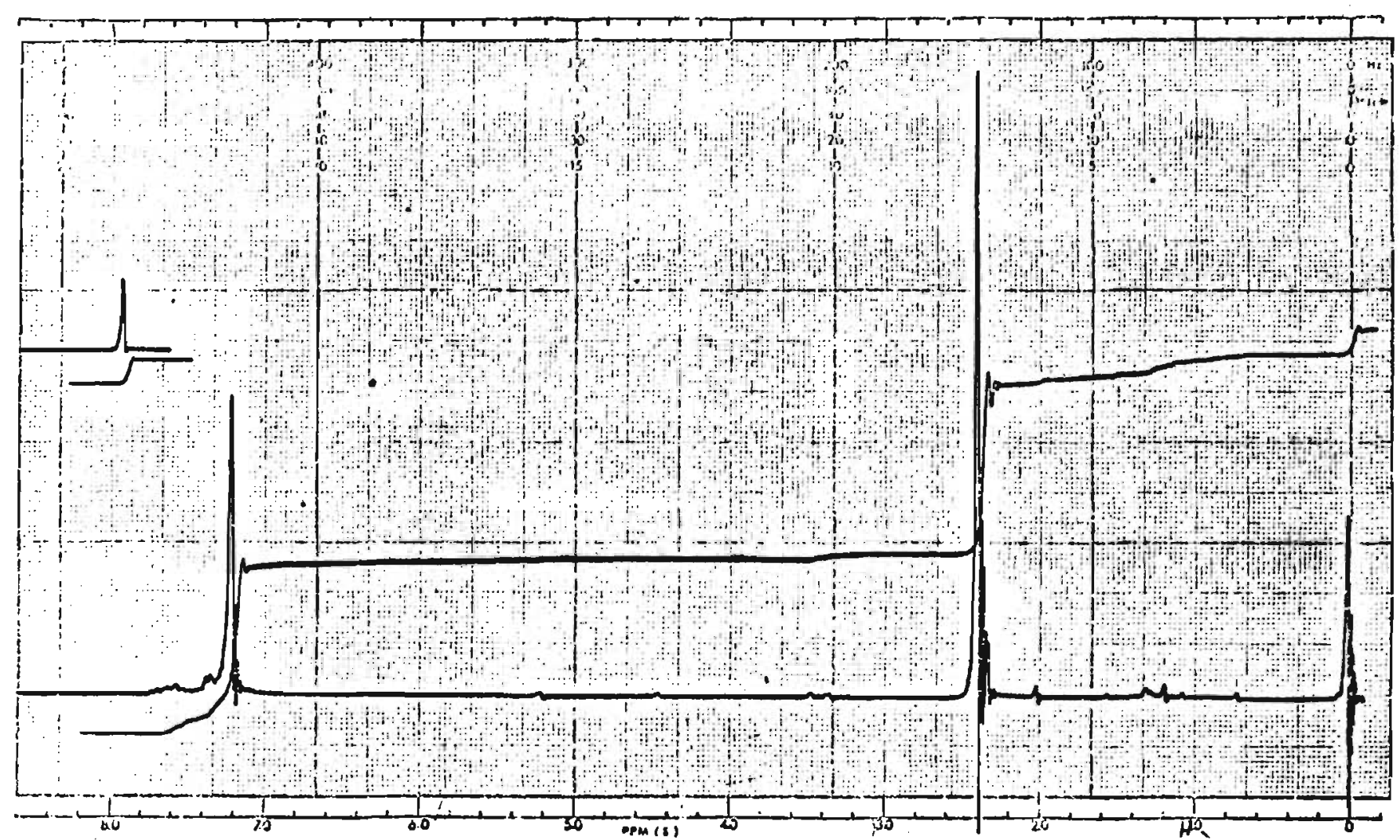




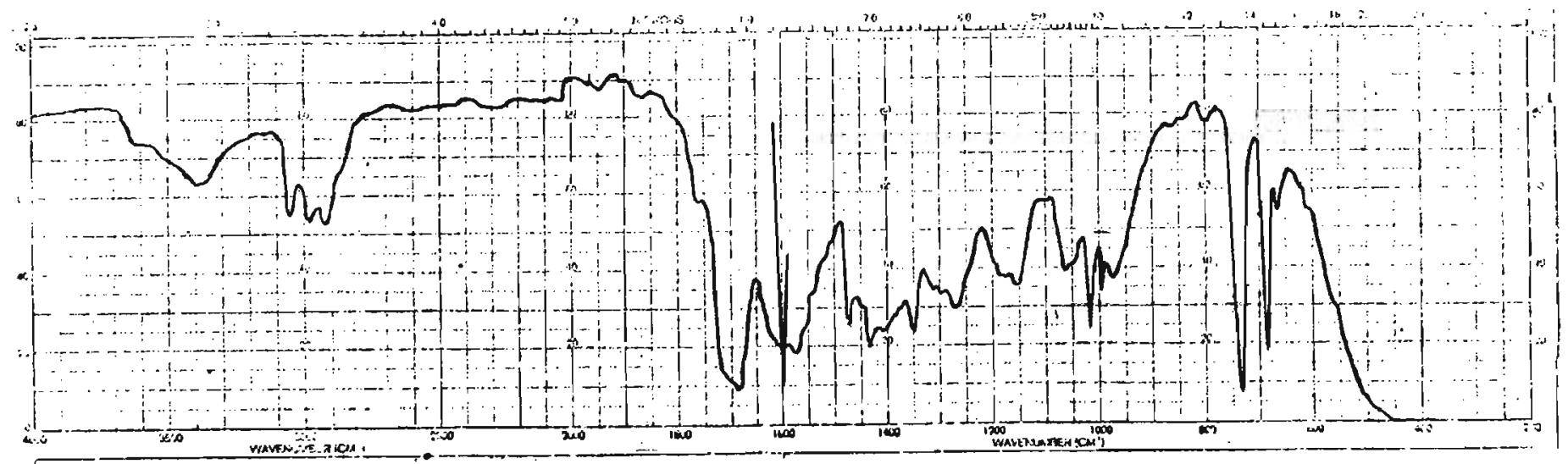

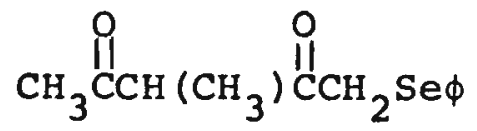

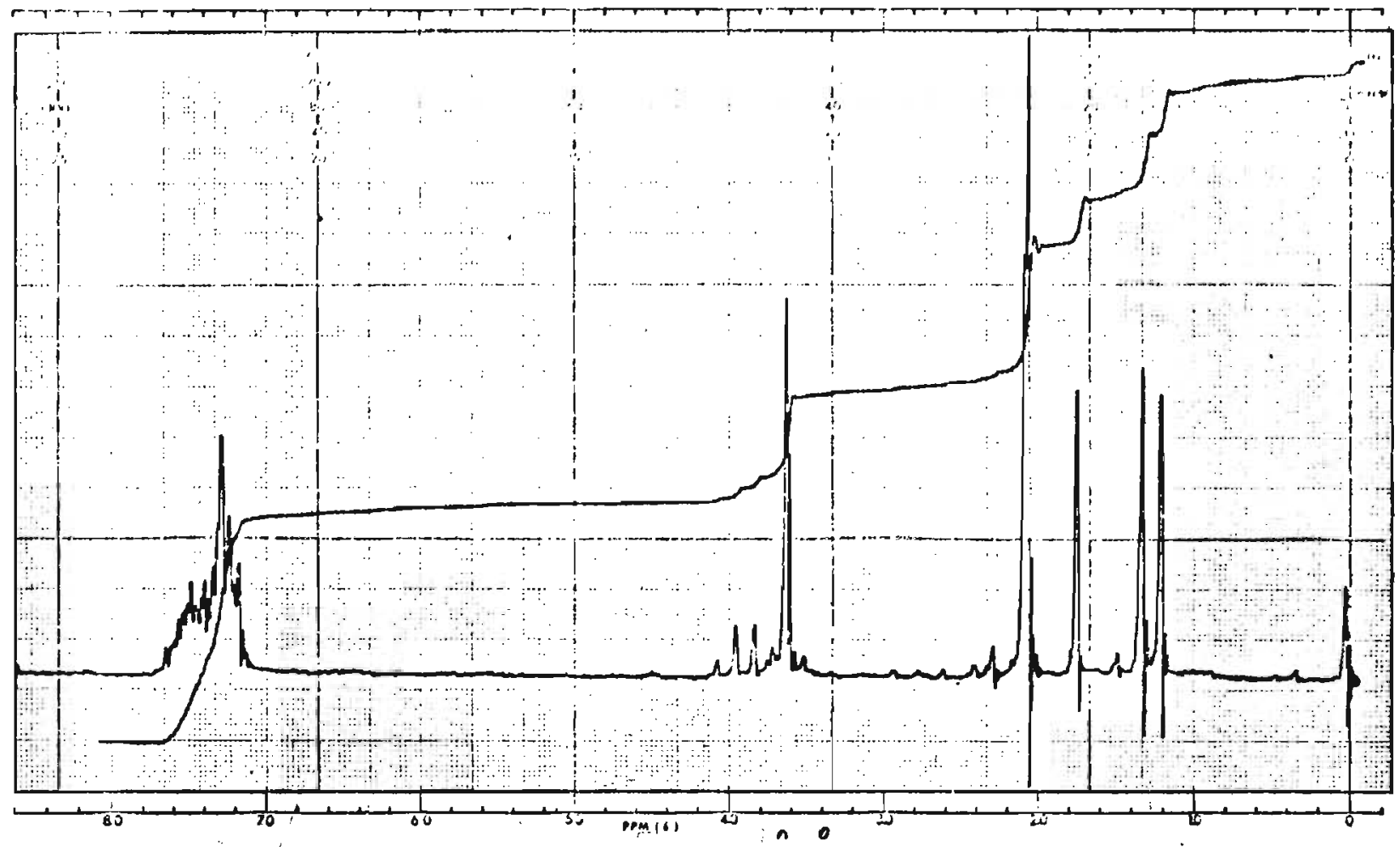




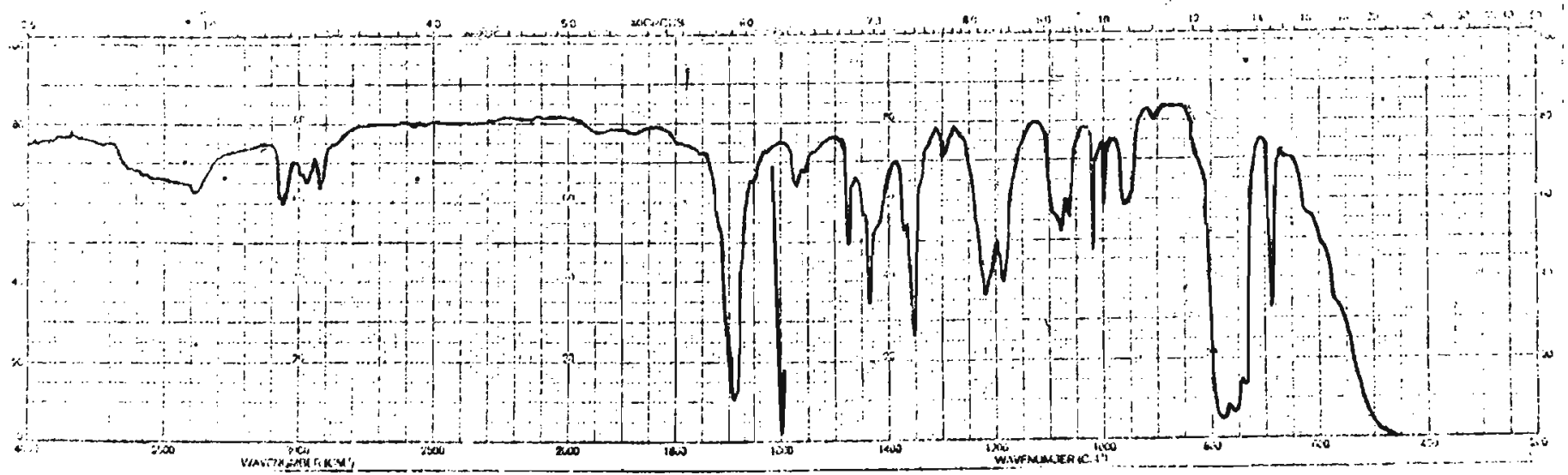

$$
\mathrm{CH}_{3} \prod_{\mathrm{CC}}(\operatorname{se} \phi) \mathrm{CH}_{3} \stackrel{\mathrm{I}}{\mathrm{CCH}_{3}}
$$

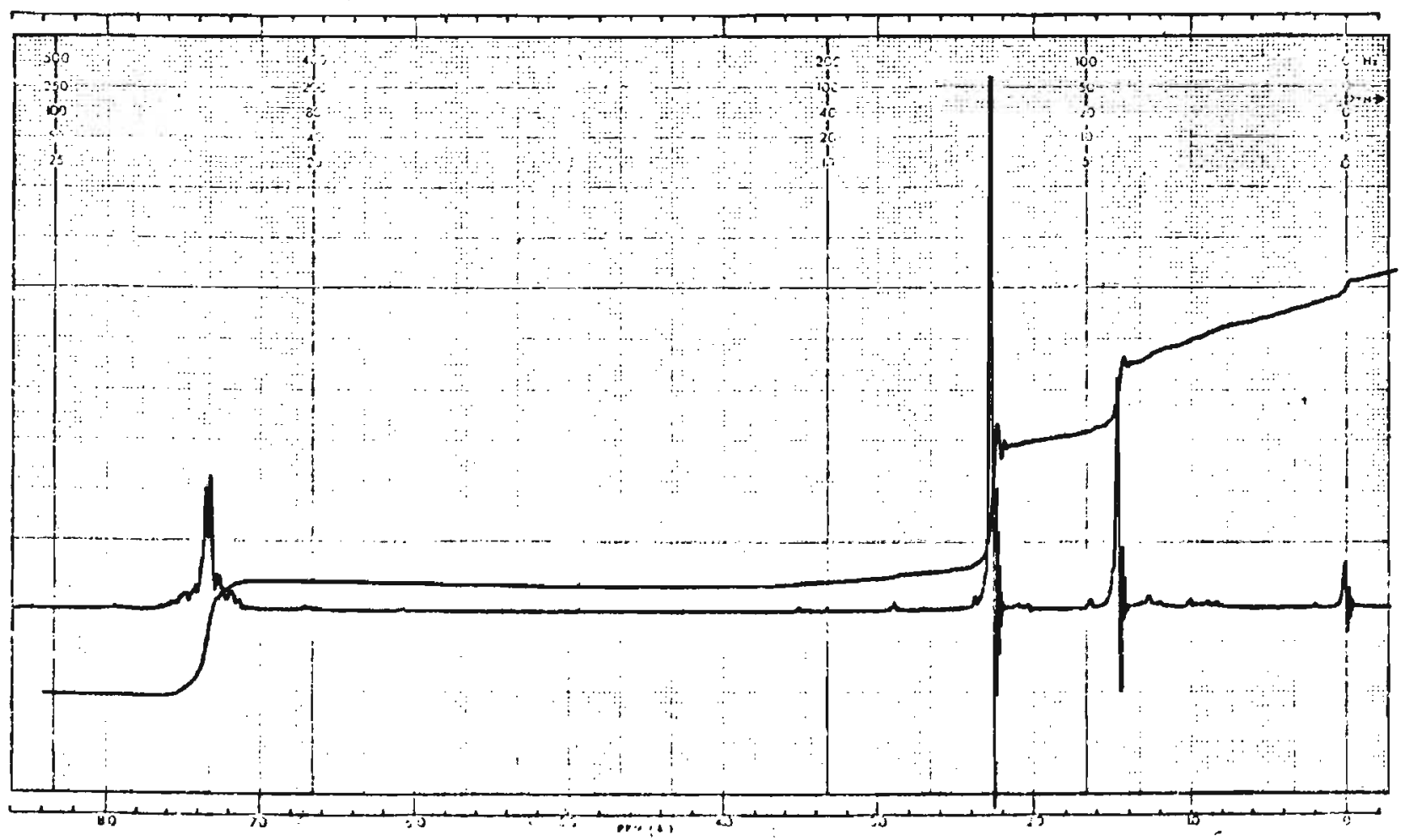




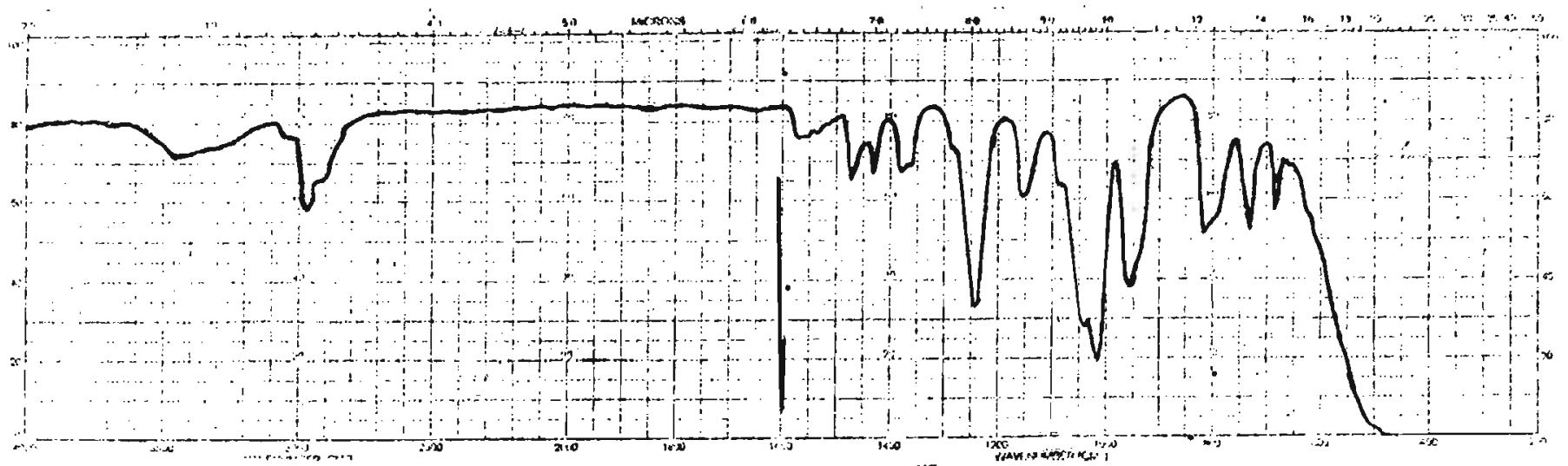

$$
\left(\mathrm{CH}_{3} \mathrm{CH}_{2} \mathrm{O}\right){ }_{2} \mathrm{P}(\mathrm{O}) \mathrm{CH}_{2} \mathrm{Se} \phi
$$

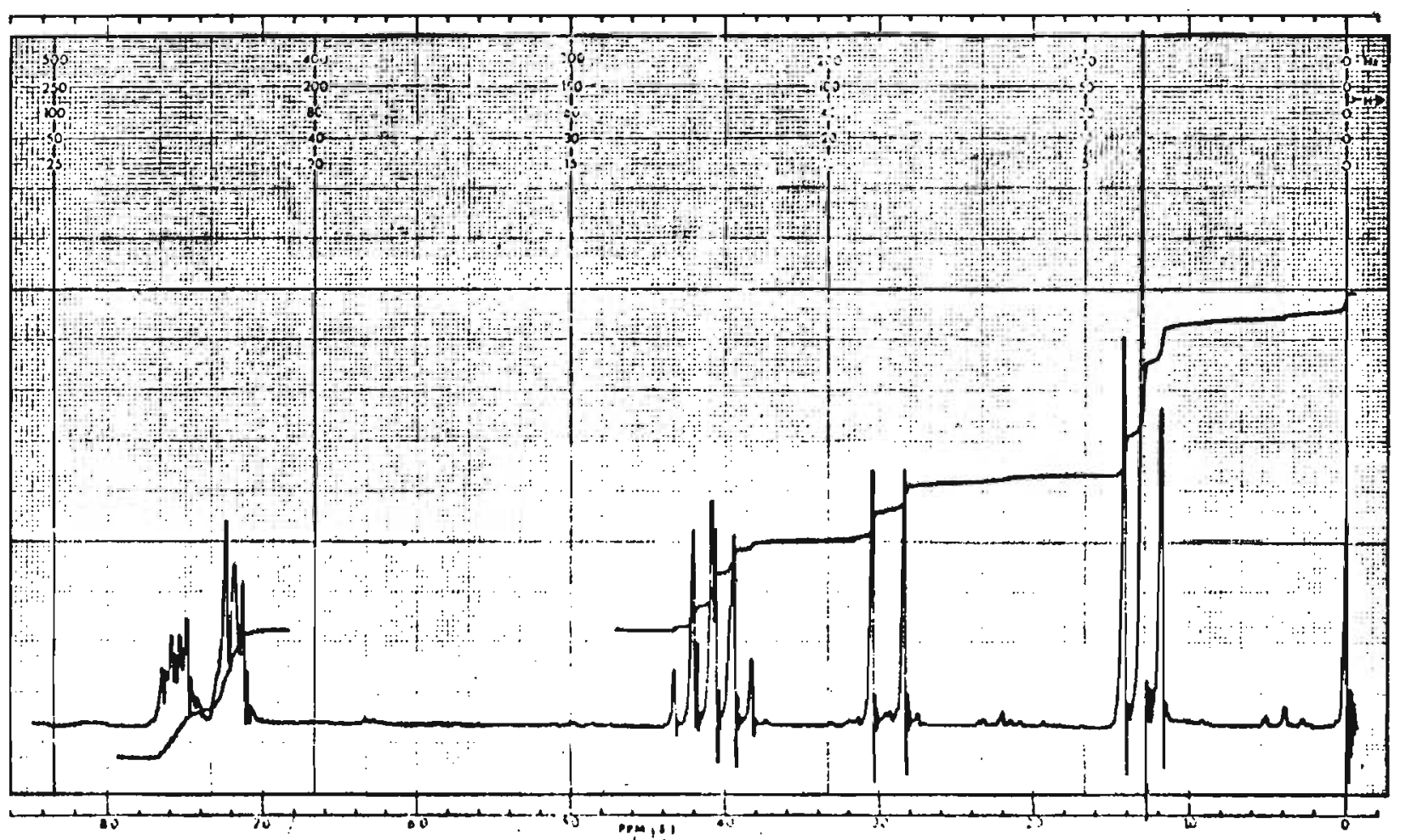




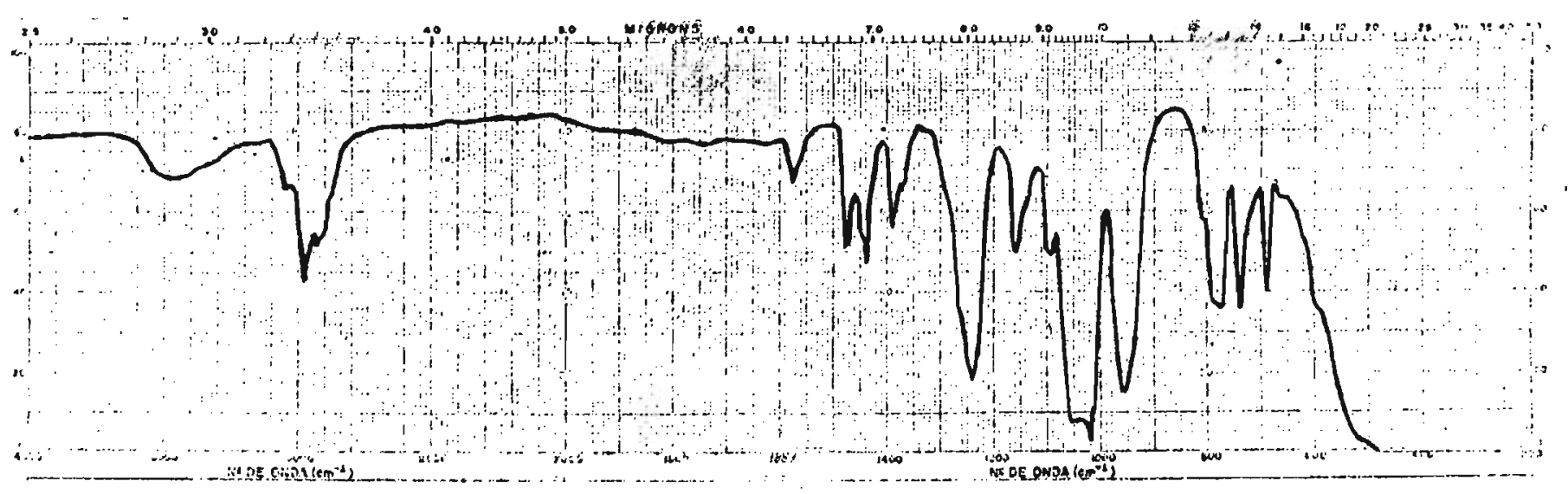

$$
\left(\mathrm{CH}_{3} \mathrm{CH}_{2} \mathrm{O}\right)_{2} \mathrm{P}(\mathrm{O}) \mathrm{CH}(\mathrm{Se} \phi) \mathrm{CH}_{3}
$$

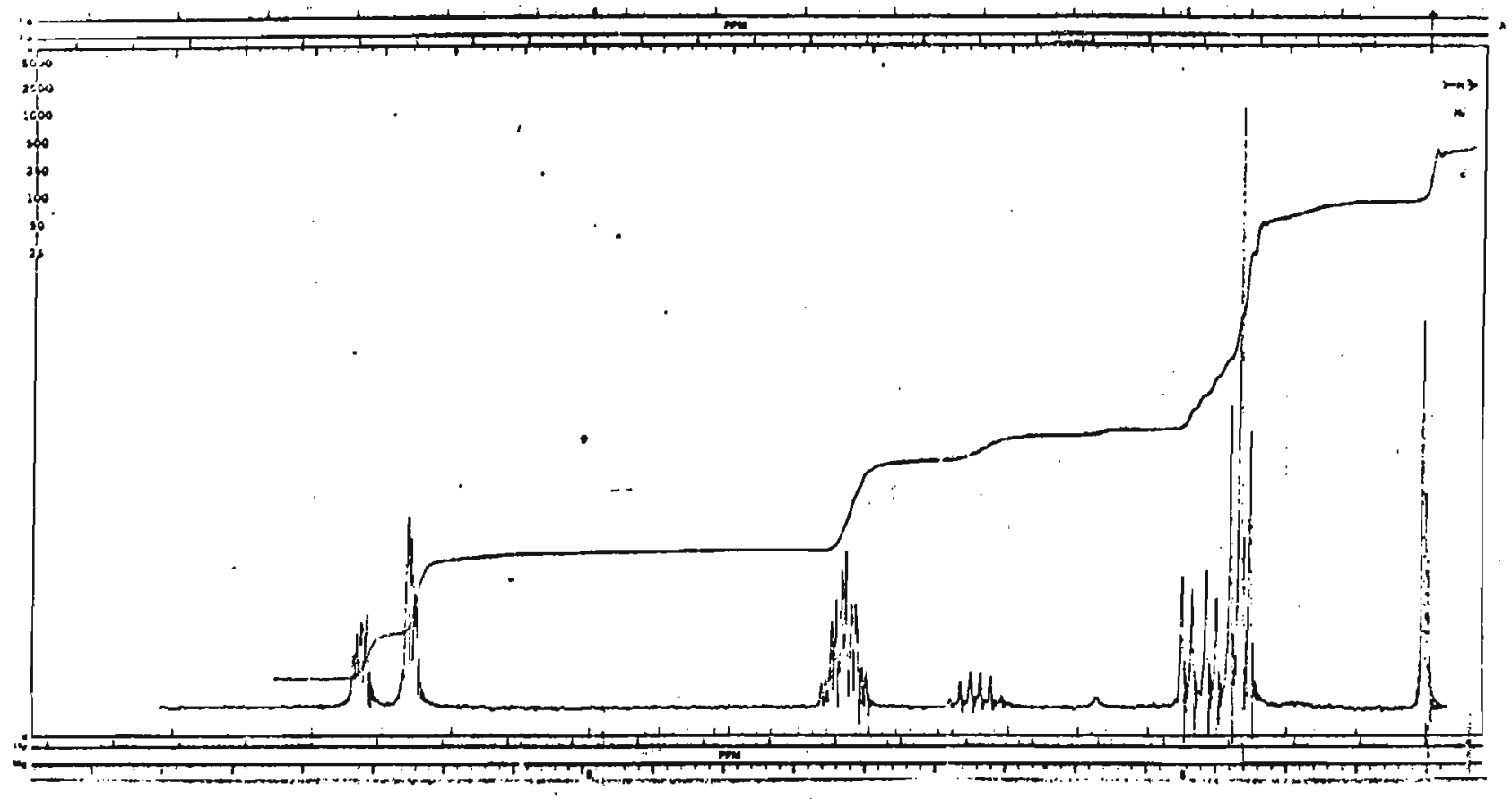


170.

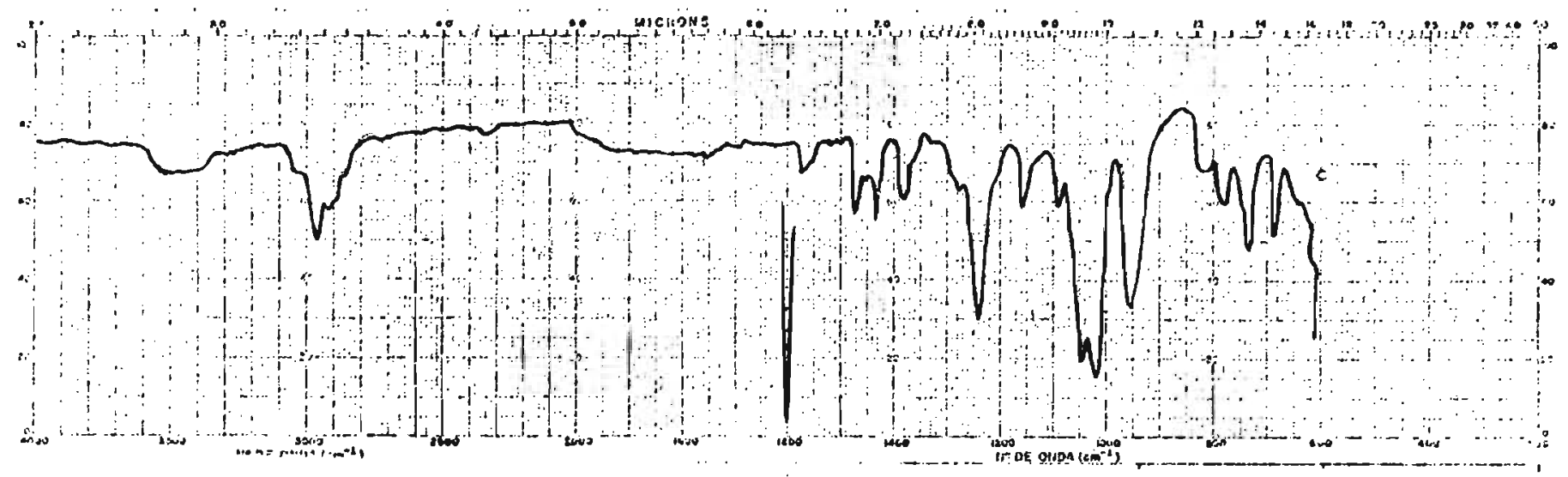

$\left(\mathrm{CH}_{3} \mathrm{CH}_{2} \mathrm{O}\right){ }_{2} \mathrm{P}(\mathrm{O}) \mathrm{CH}(\mathrm{Se} \phi) \mathrm{C}_{2} \mathrm{H}_{5}$

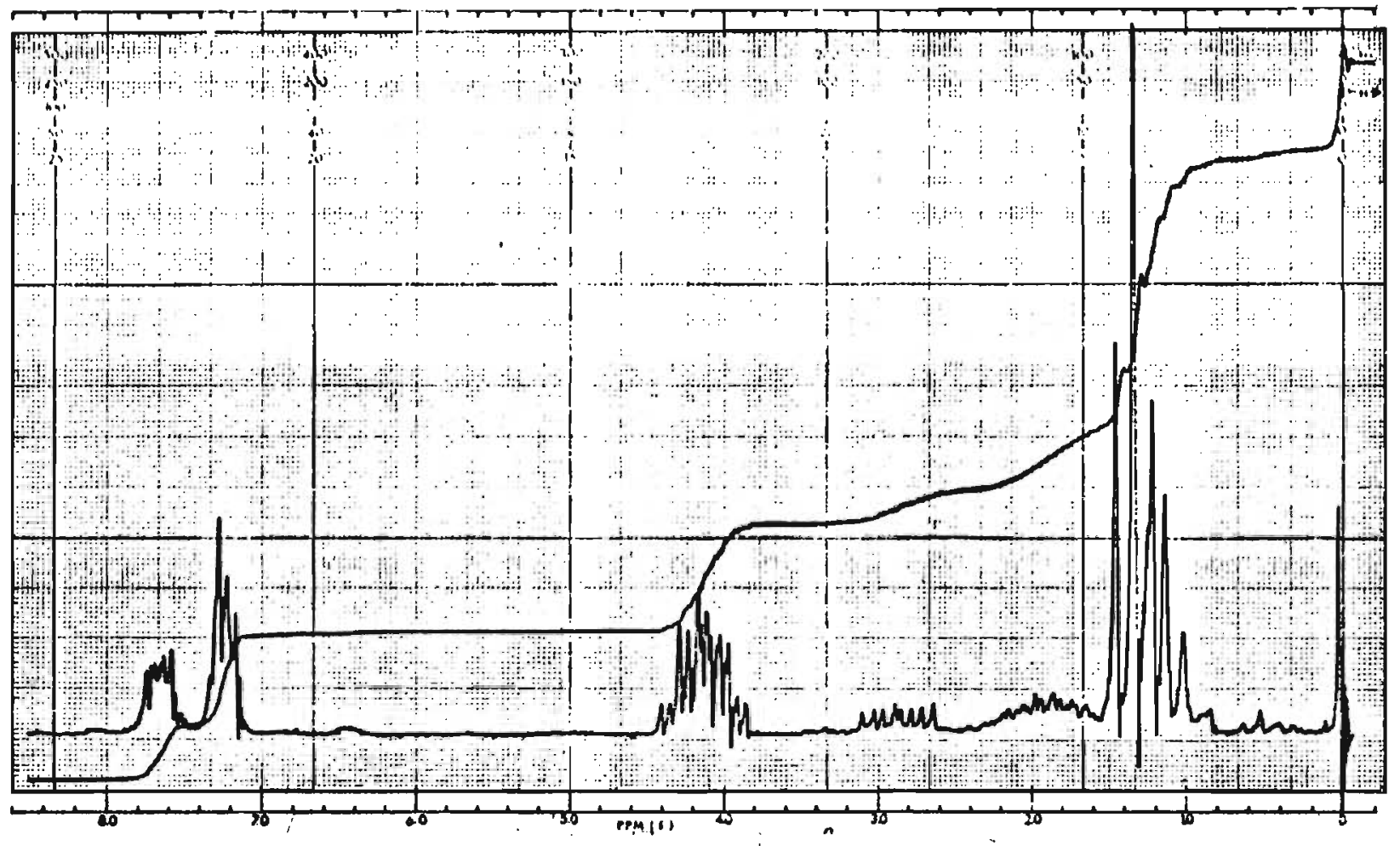




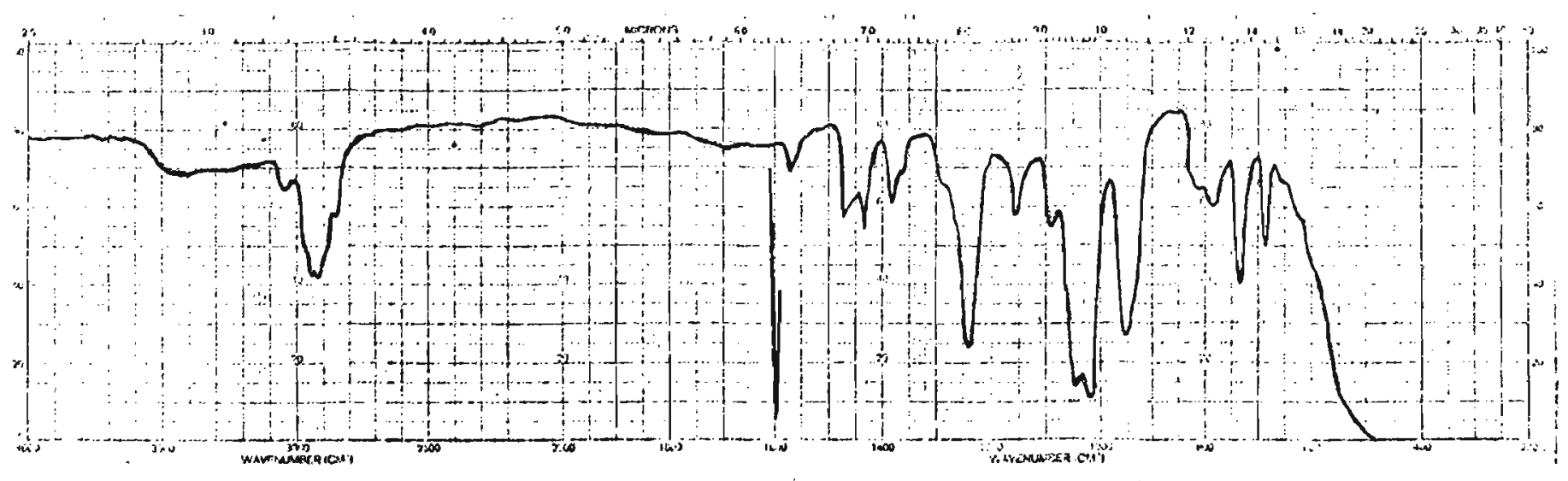

$\left(\mathrm{CH}_{3} \mathrm{CH}_{2} \mathrm{O}\right)_{2} \mathrm{P}(\mathrm{O}) \mathrm{CH}(\mathrm{Se} \phi) \mathrm{C}_{4} \mathrm{H}_{9}$

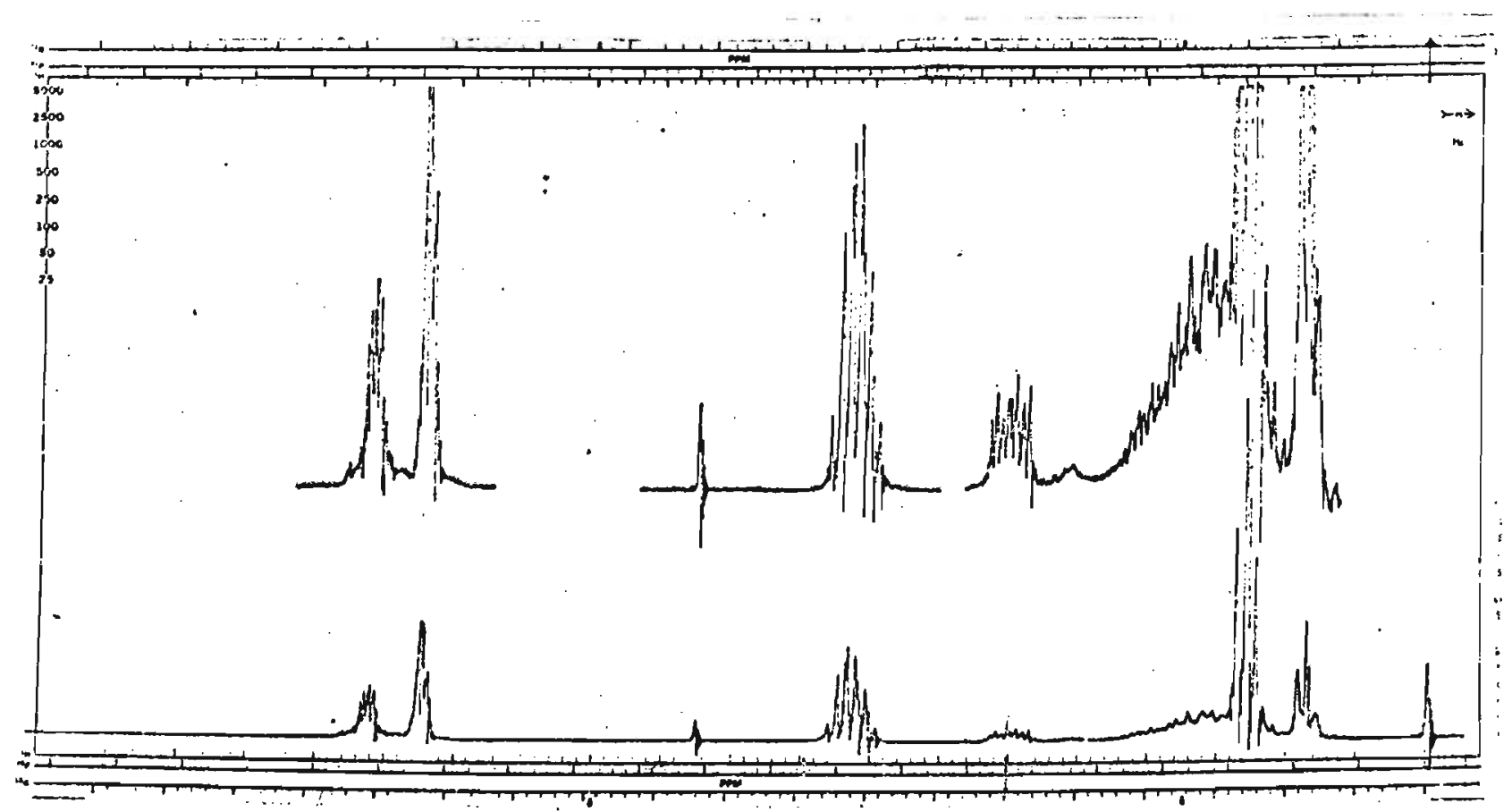




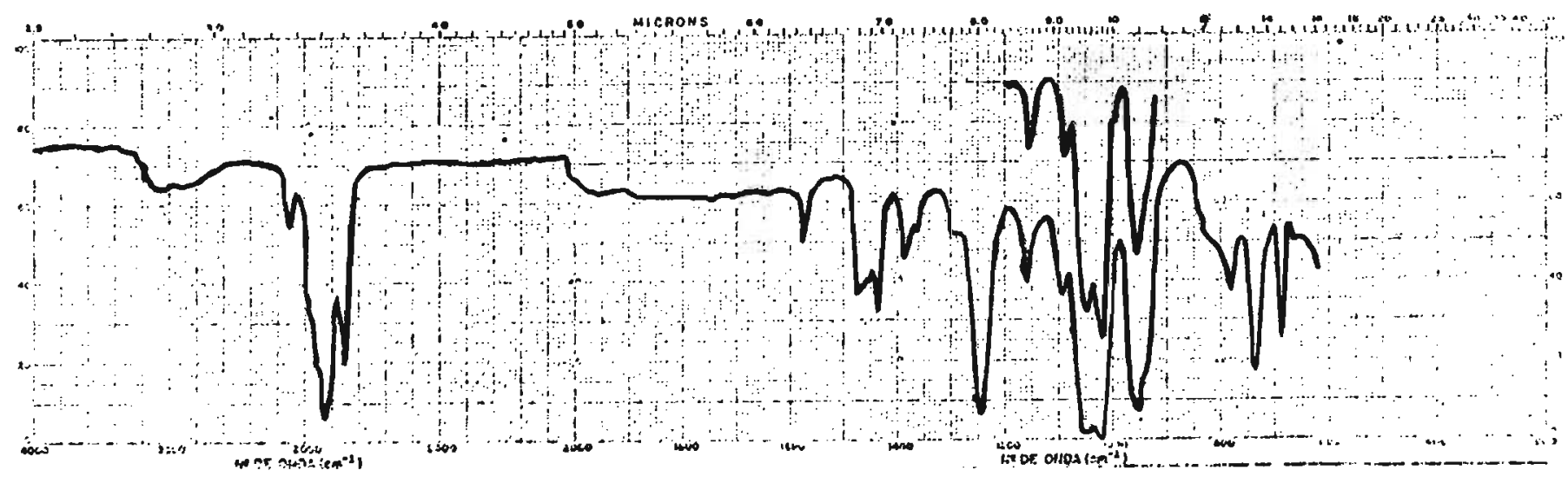

$$
\left(\mathrm{CH}_{3} \mathrm{CH}_{2} \mathrm{O}\right)_{2} \mathrm{P}(\mathrm{O}) \mathrm{CH}(\mathrm{Se} \phi) \mathrm{C}_{8} \mathrm{H}_{17}
$$

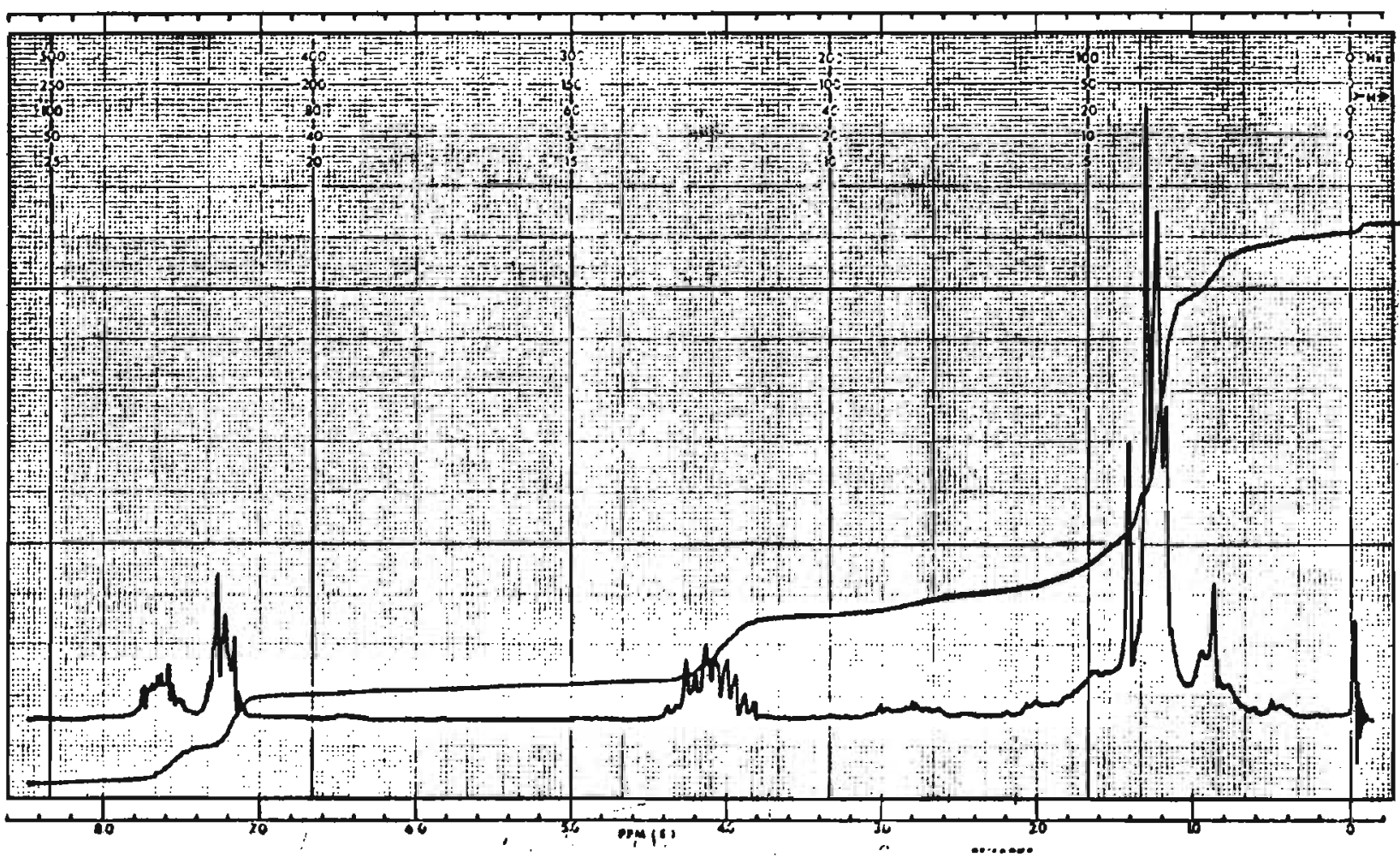


173.

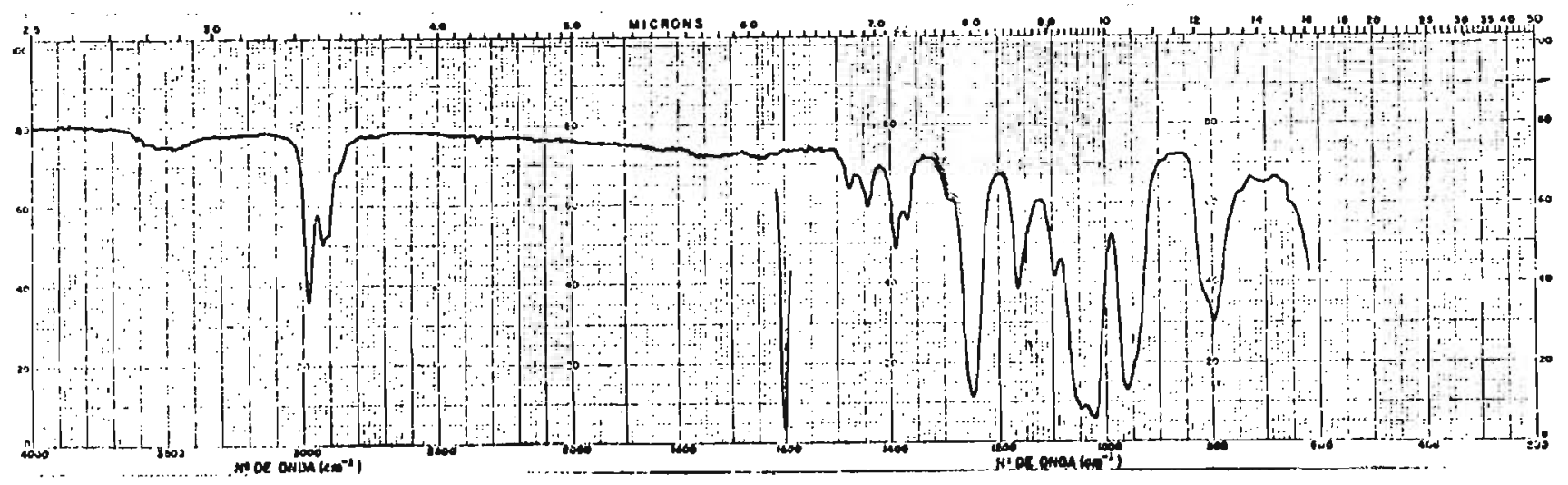

$\left(\mathrm{CH}_{3} \mathrm{CH}_{2} \mathrm{O}\right){ }_{2} \mathrm{P}(\mathrm{O}) \mathrm{CH}_{2} \mathrm{SeCH}_{2} \mathrm{P}(\mathrm{O})\left(\mathrm{OCH}_{2} \mathrm{CH}_{3}\right)_{2}$

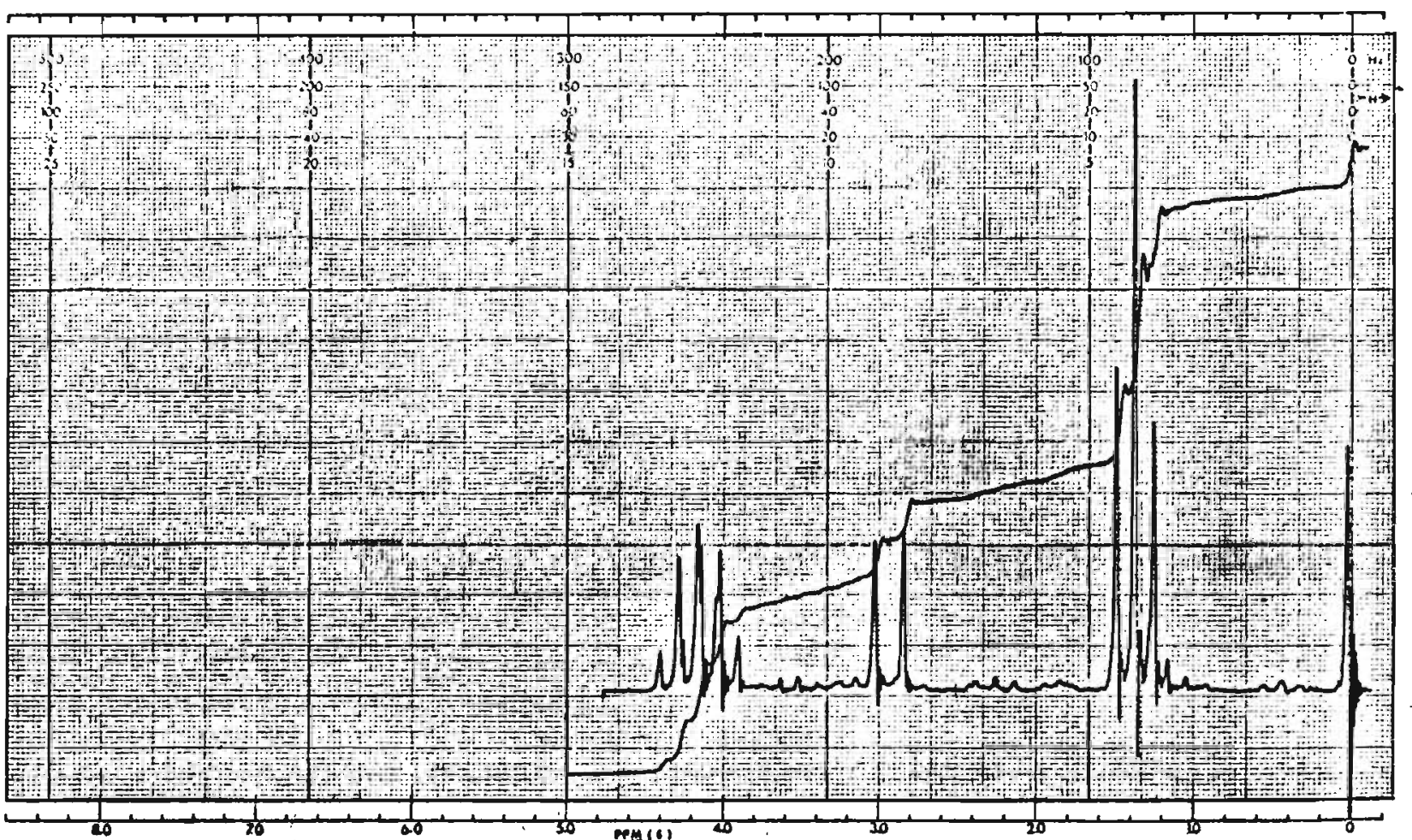


174.

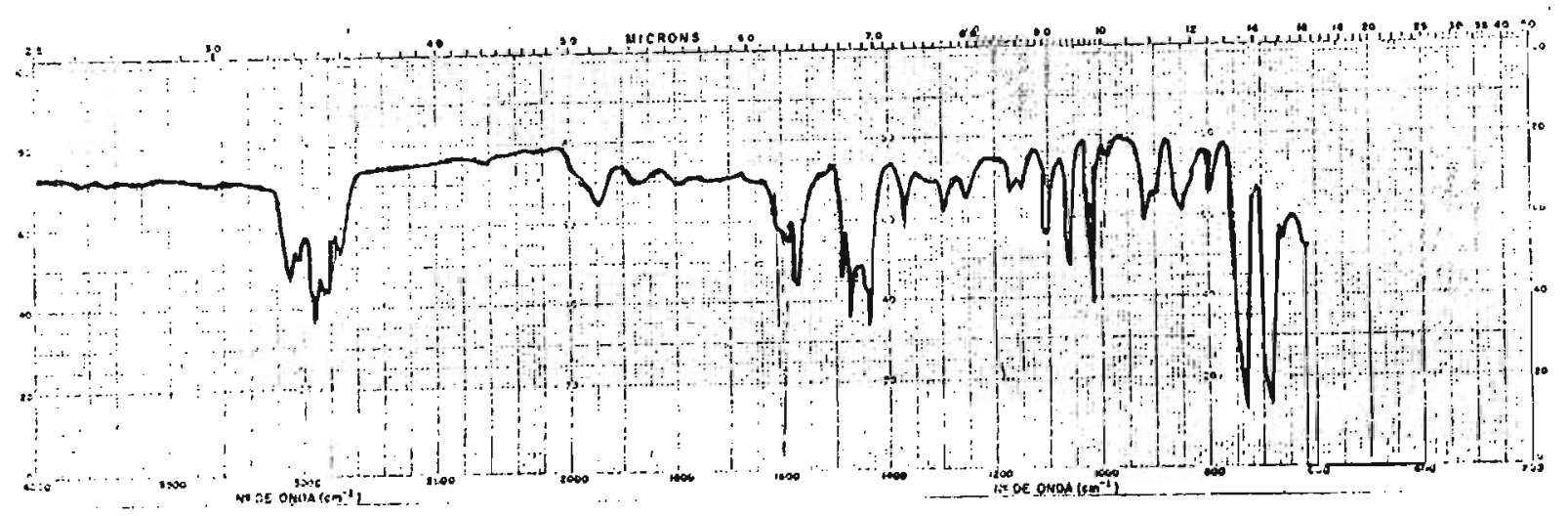

$\phi \mathrm{CH}=\mathrm{C}(\mathrm{Se} \phi) \mathrm{C}_{2} \mathrm{H}_{5}$

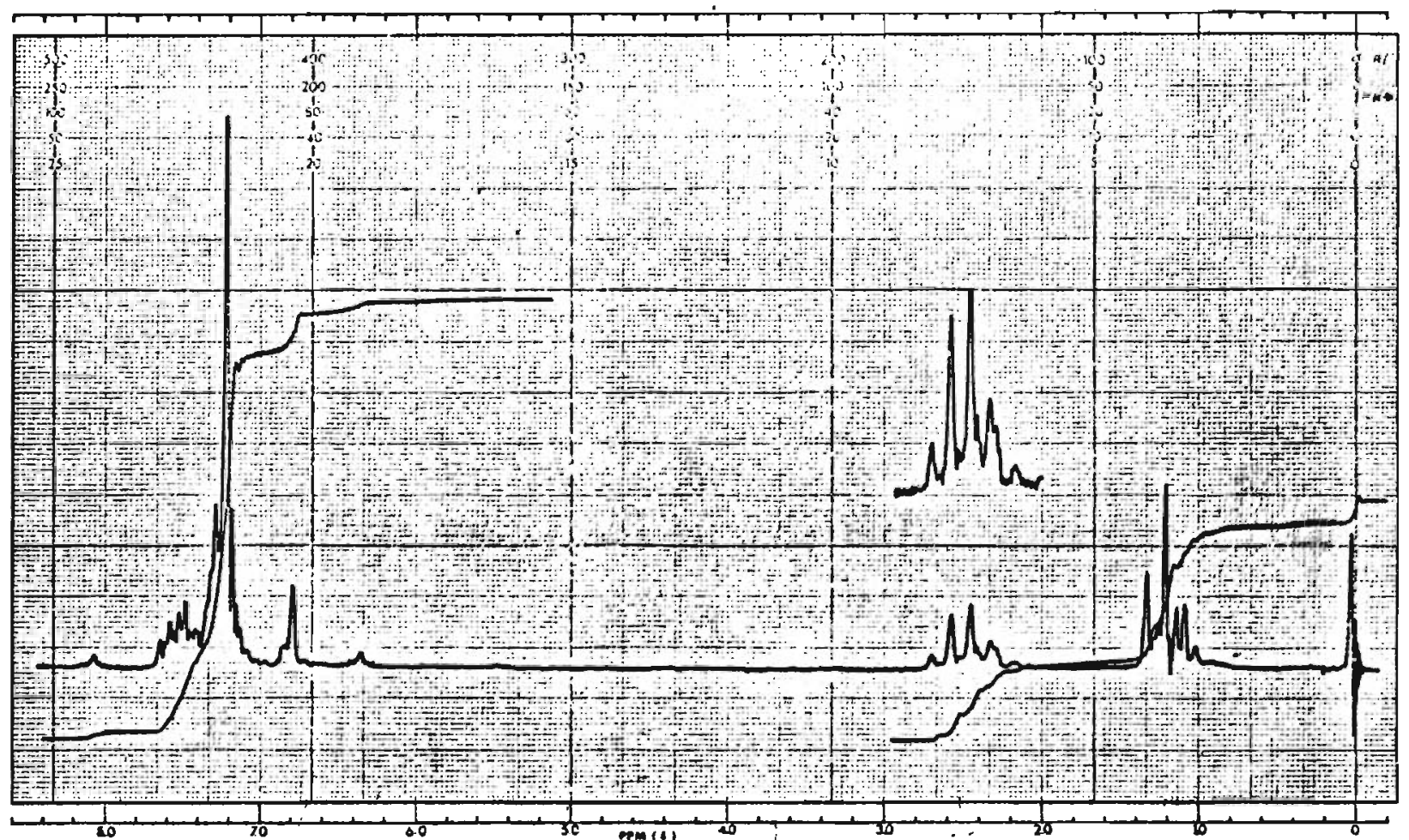




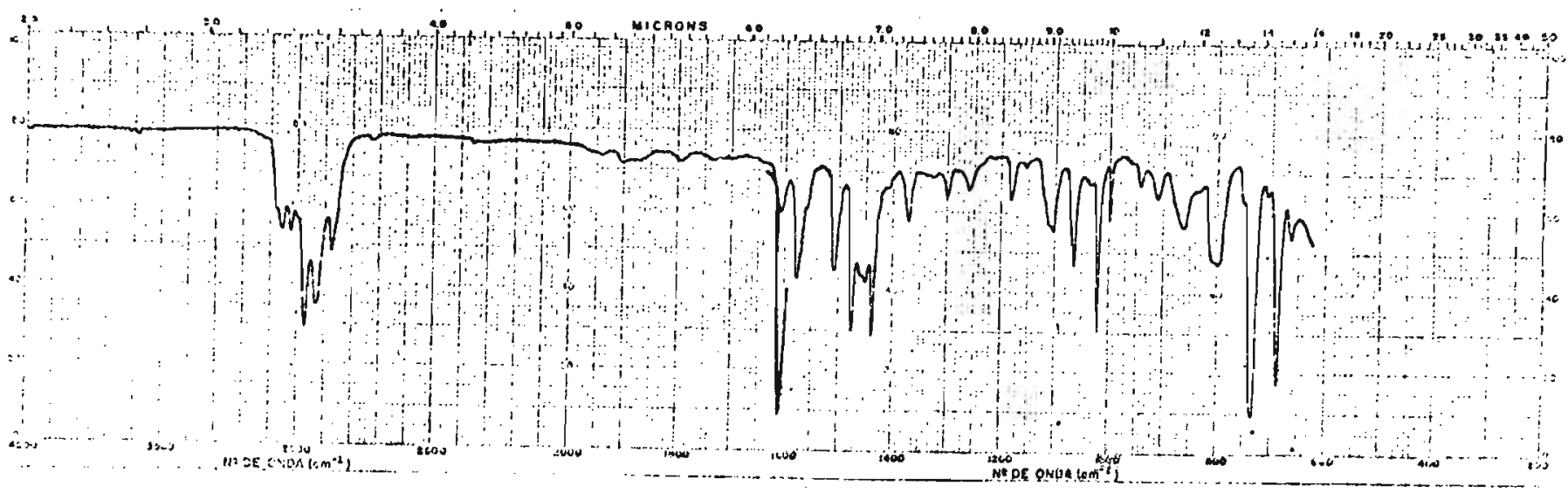

$$
\mathrm{pCH}_{3} \phi \mathrm{CH}=\mathrm{C}(\mathrm{Se} \phi) \mathrm{C}_{2} \mathrm{H}_{5}
$$

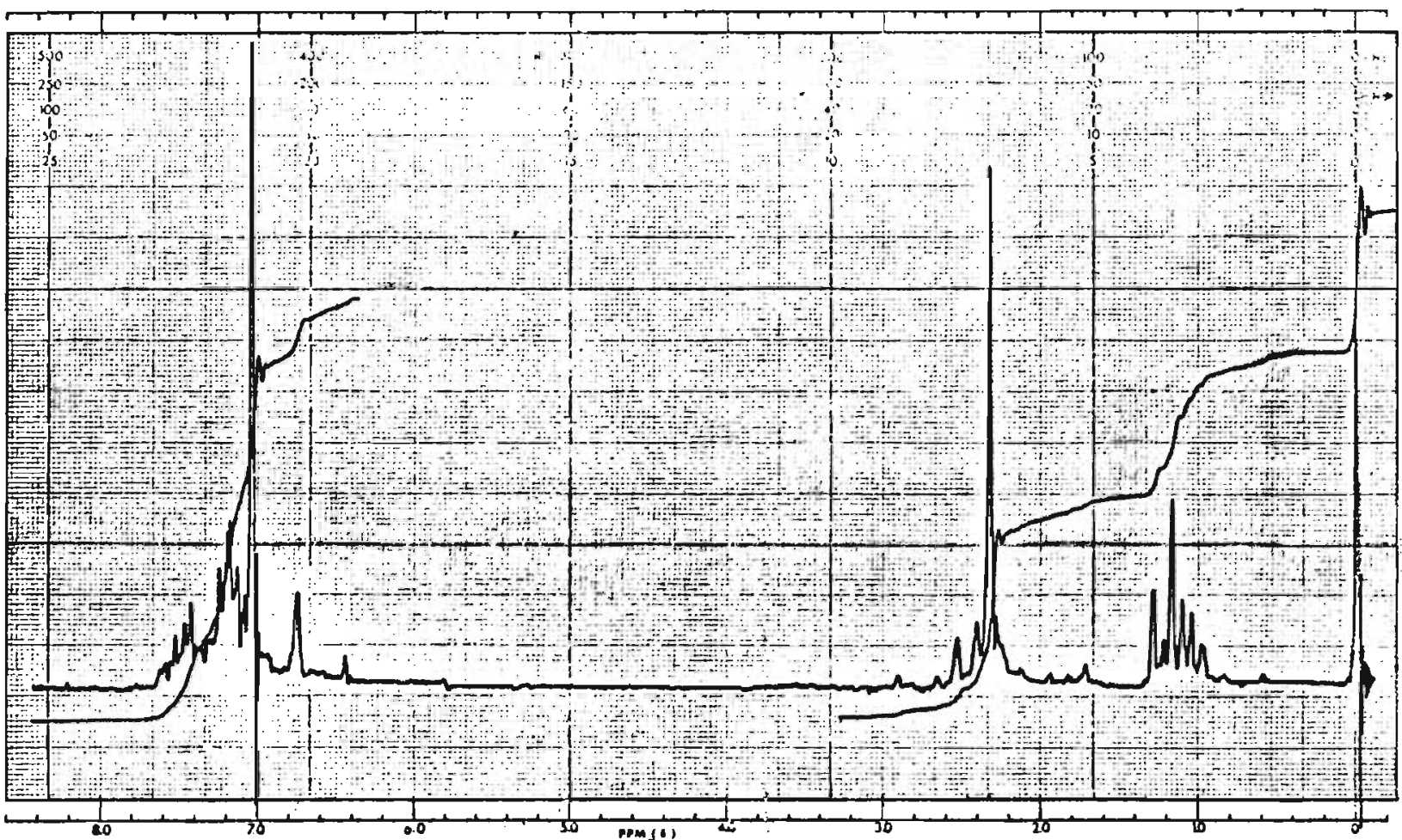


176.

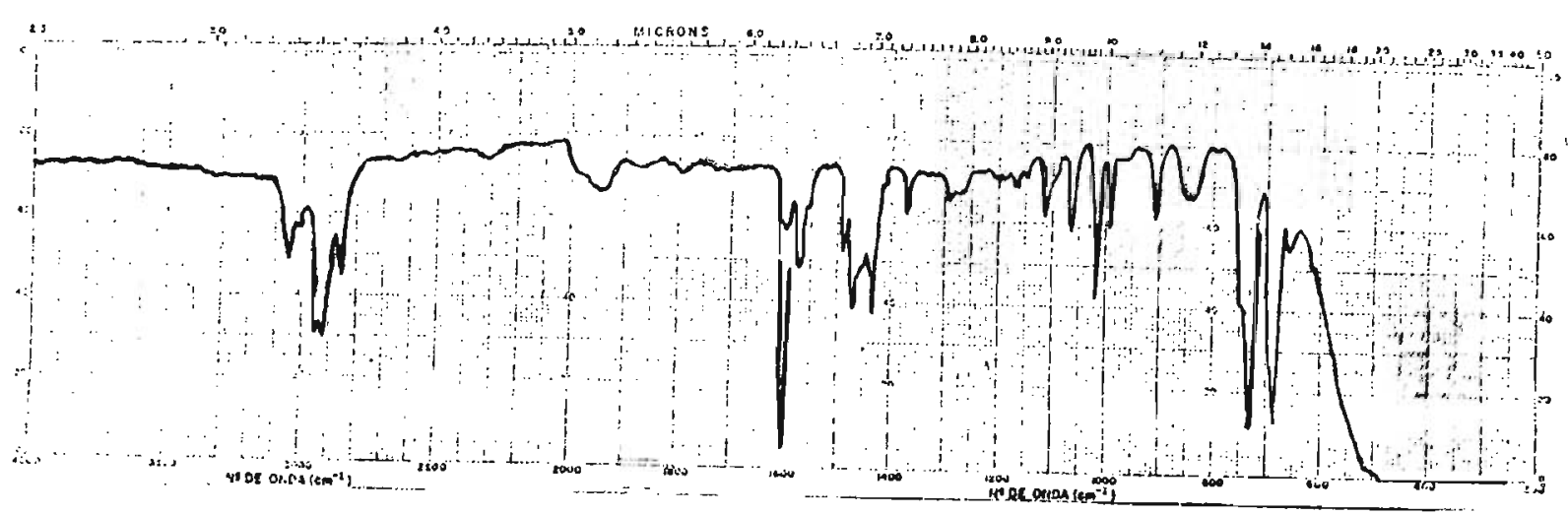

$\phi \mathrm{CH}=\mathrm{C}(\operatorname{se} \phi) \mathrm{C}_{4} \mathrm{H}_{9}$

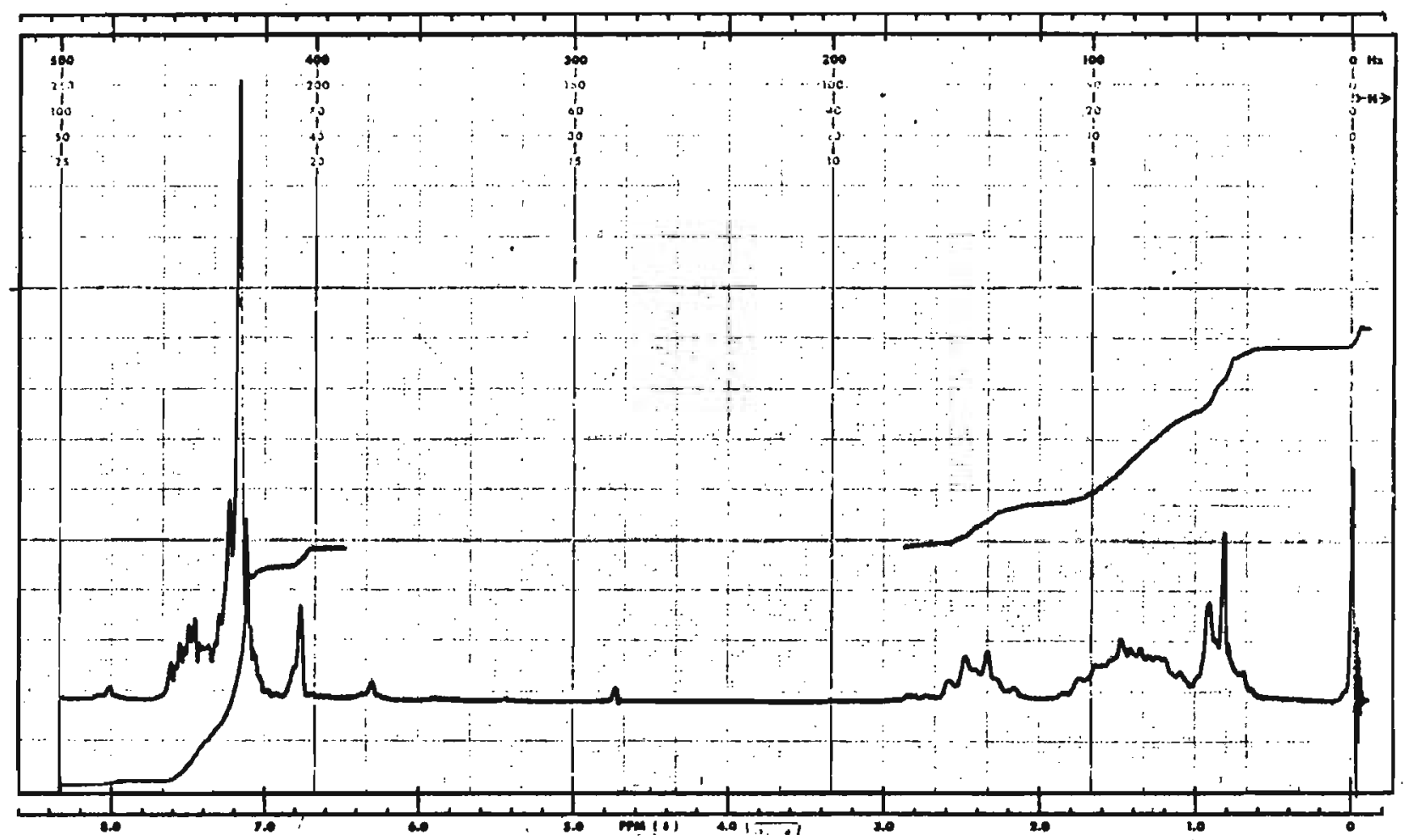




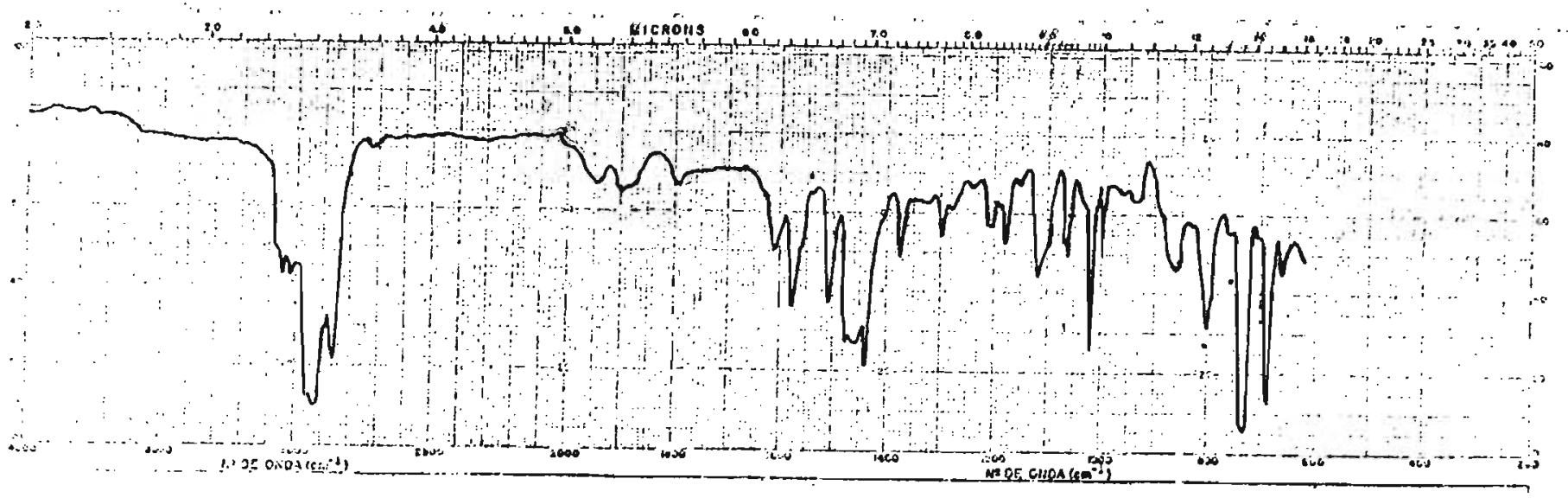

$$
\mathrm{pCH}_{3} \phi \mathrm{CH}=\mathrm{C}(\operatorname{Se} \phi) \mathrm{C}_{4}{ }^{\mathrm{H}} 9
$$

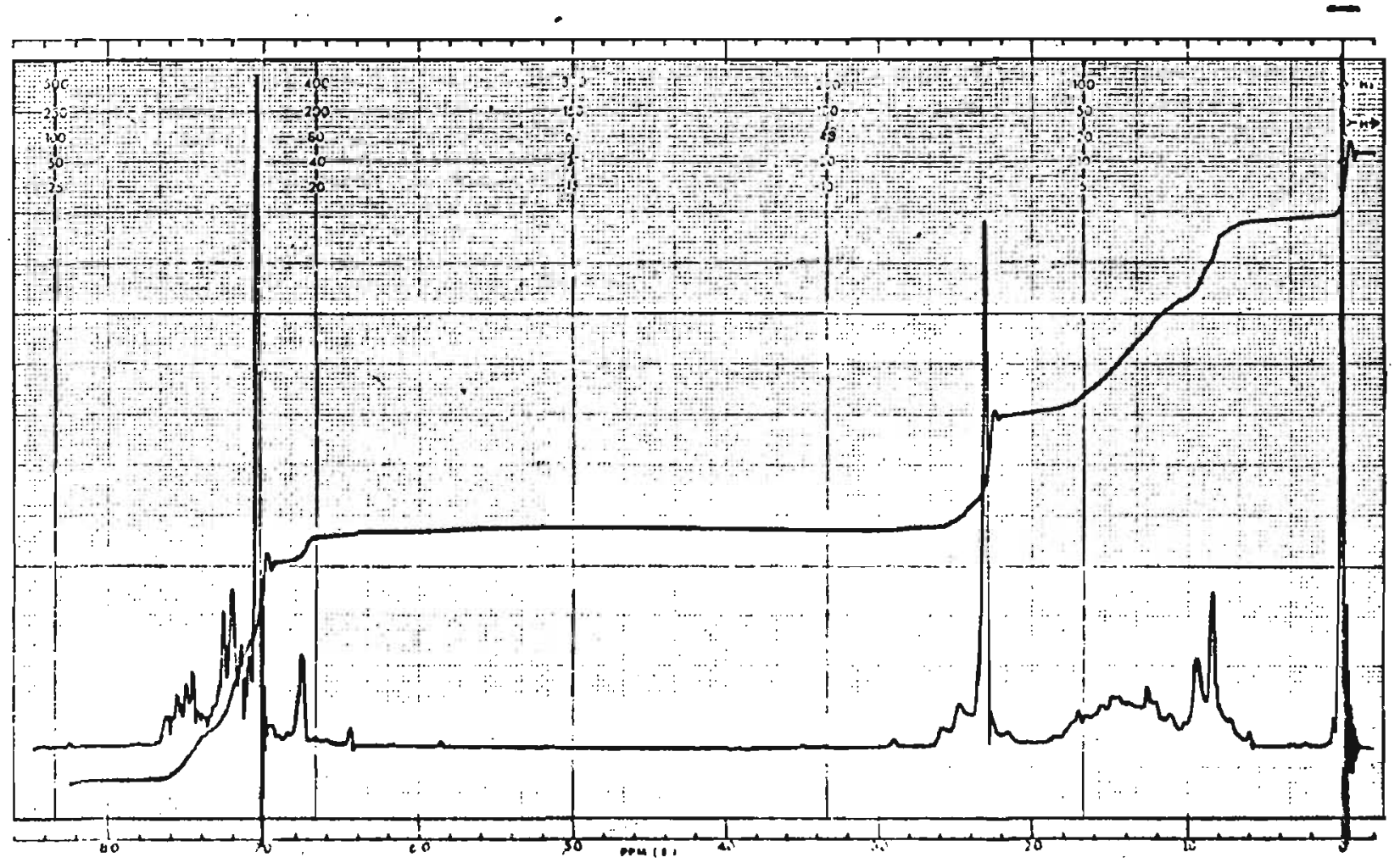




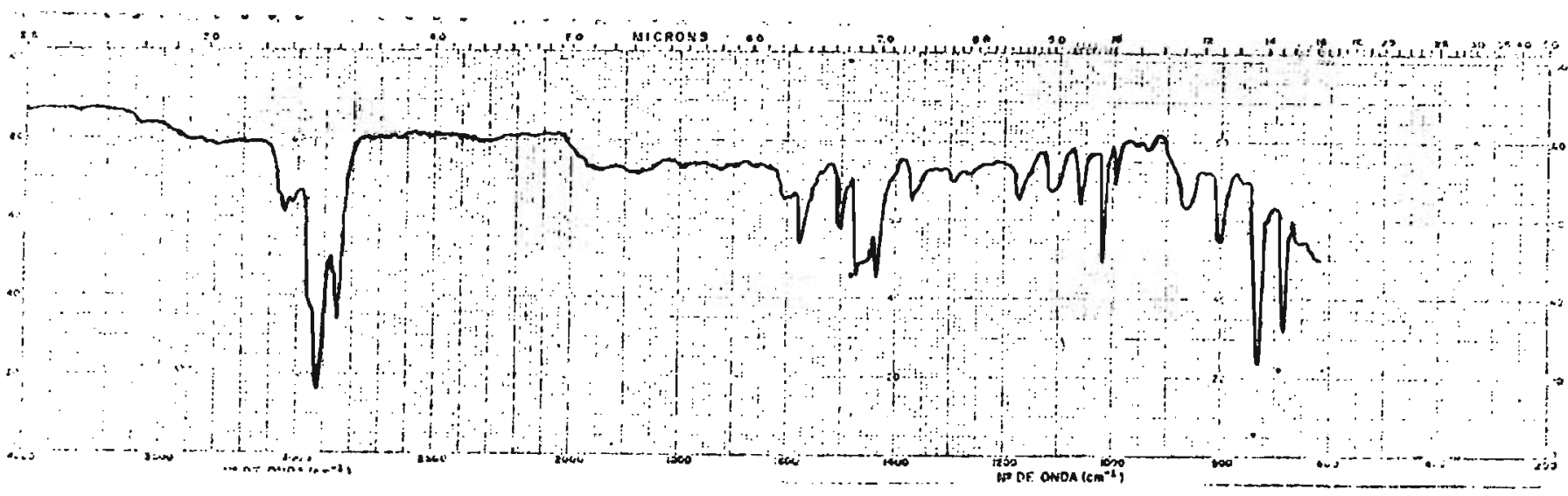

$\mathrm{pCH}_{3} \phi \mathrm{CH}=\mathrm{C}($ Se $\phi) \mathrm{C}_{8} \mathrm{H}_{17}$

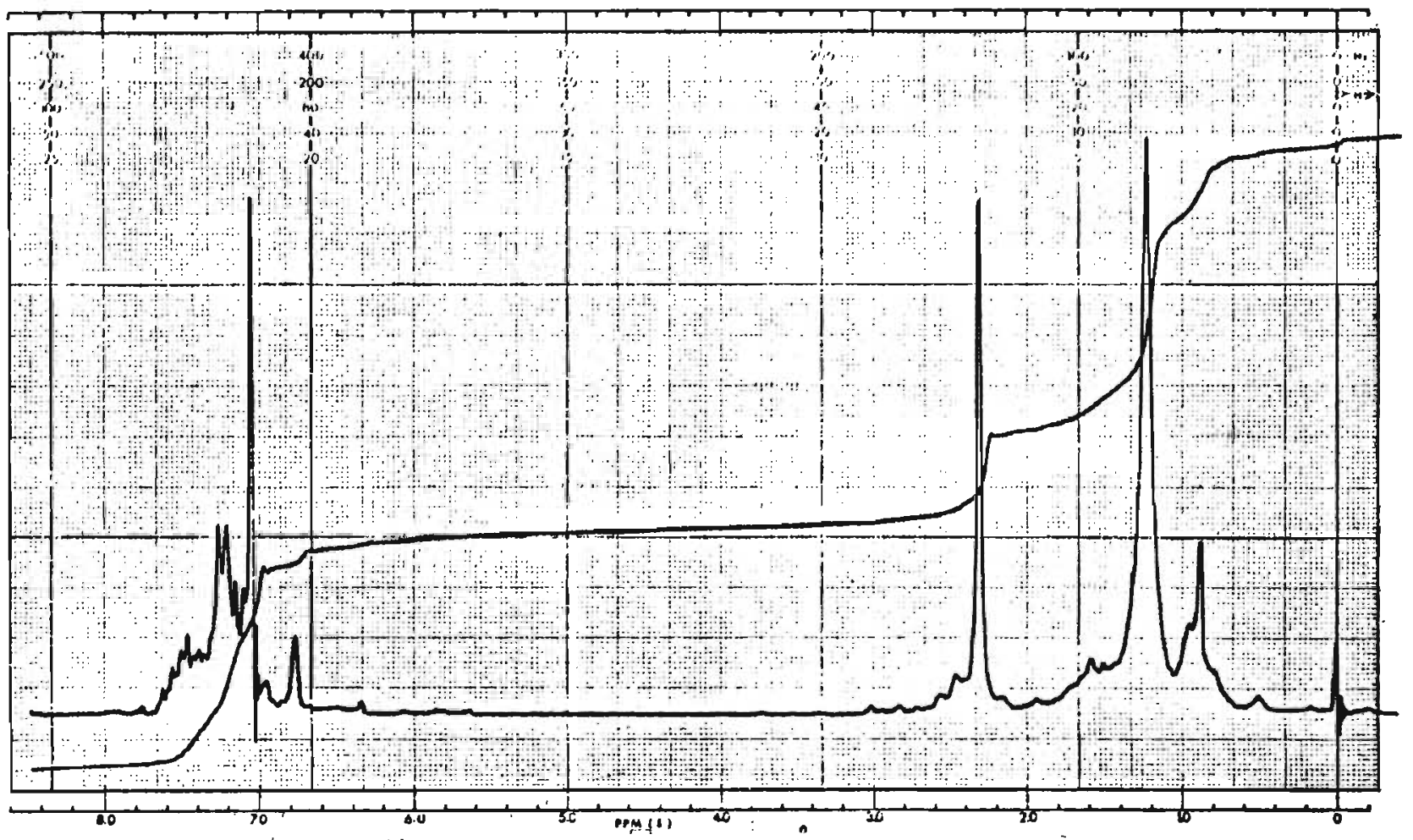




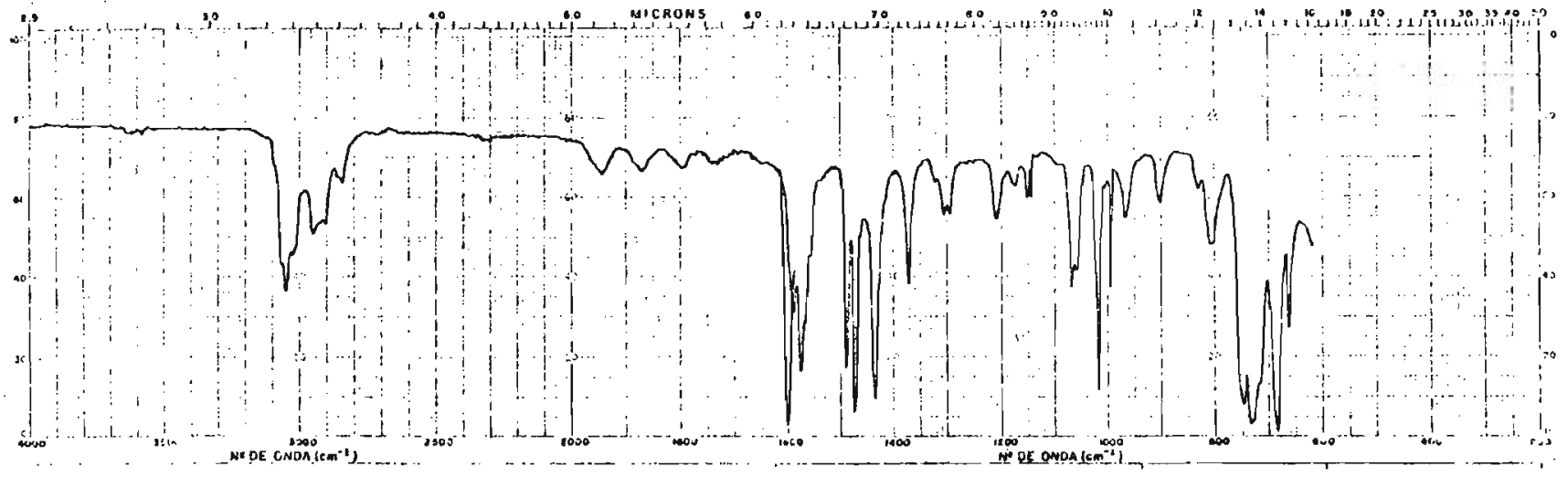

$$
\phi \mathrm{C}\left(\mathrm{CH}_{3}\right)=\mathrm{CHSe} \phi
$$

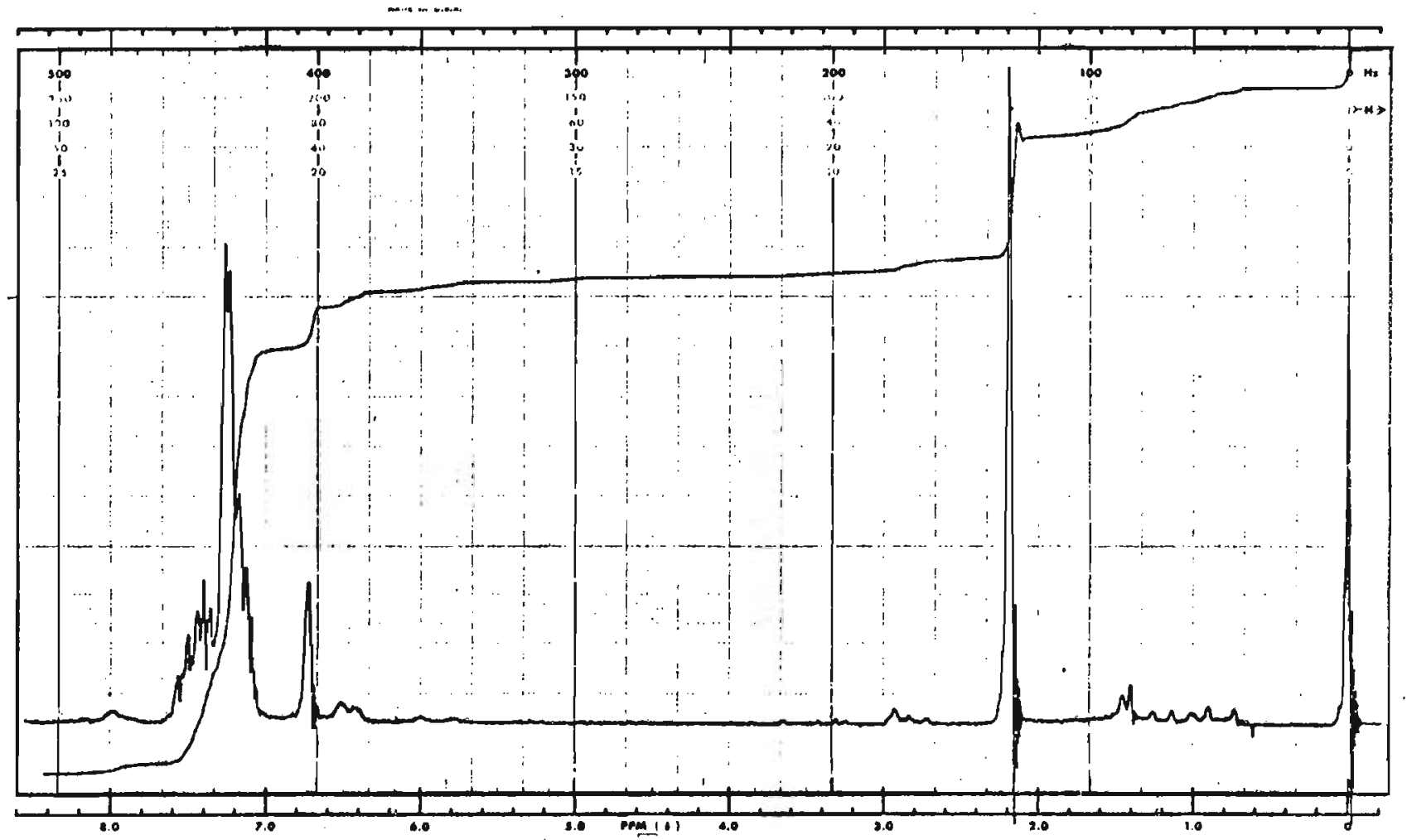




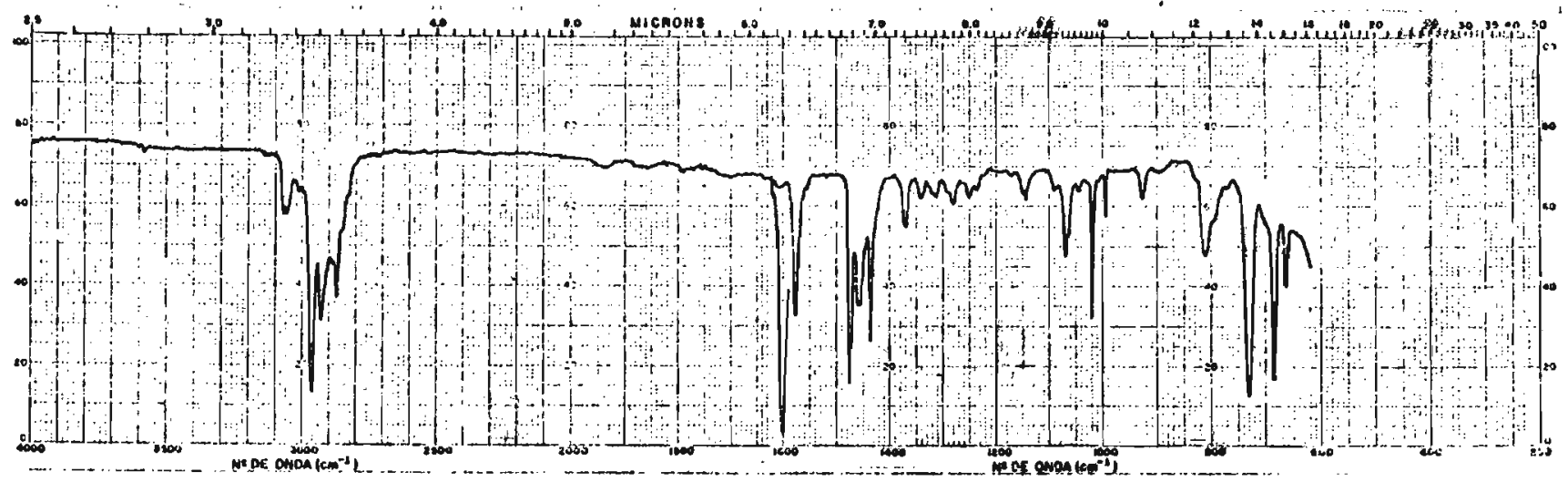

$$
\left(\mathrm{CH}_{3} \mathrm{CH}_{2}\right)_{2} \mathrm{C}=\mathrm{CHSe} \phi
$$

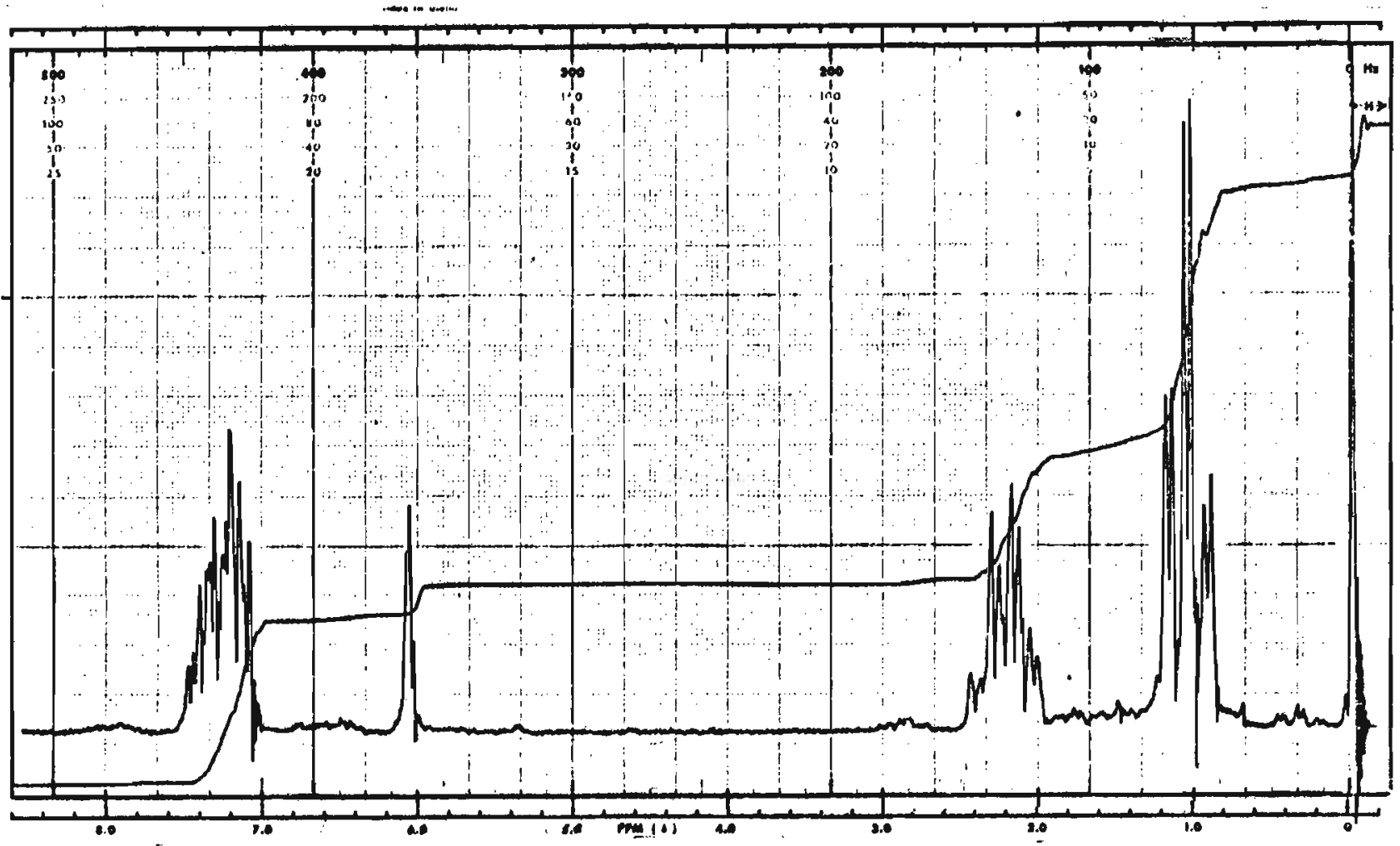



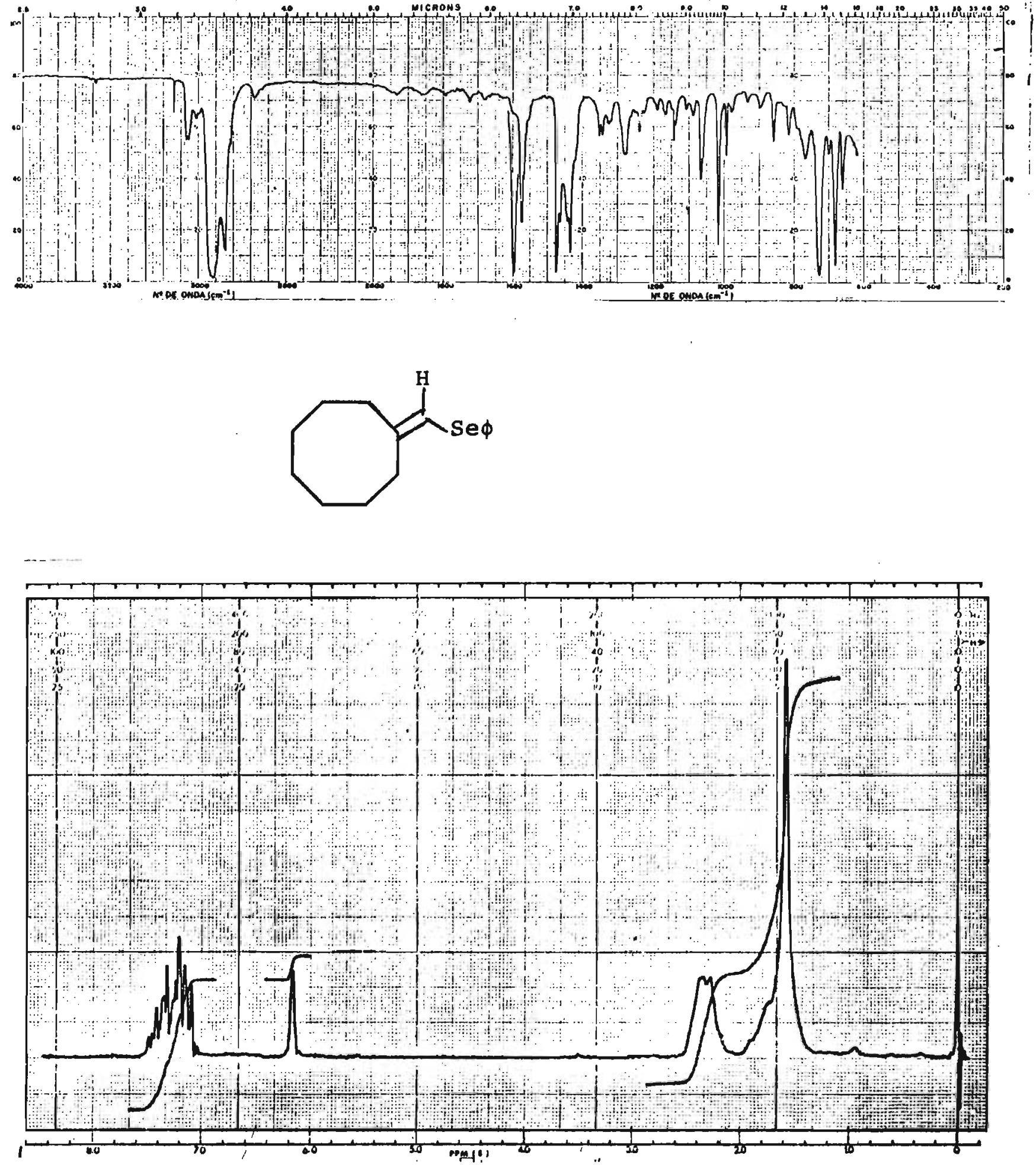

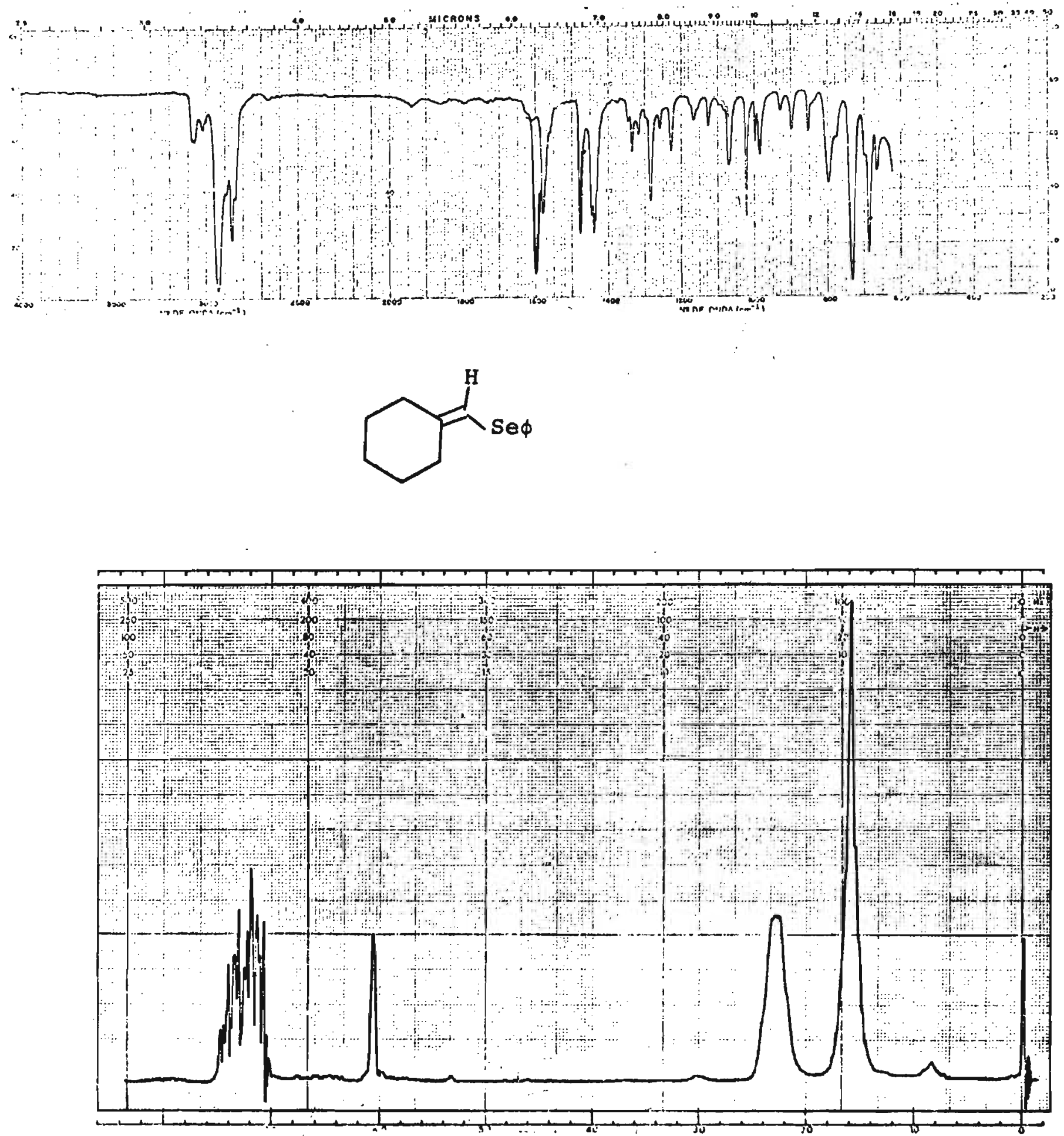
183.
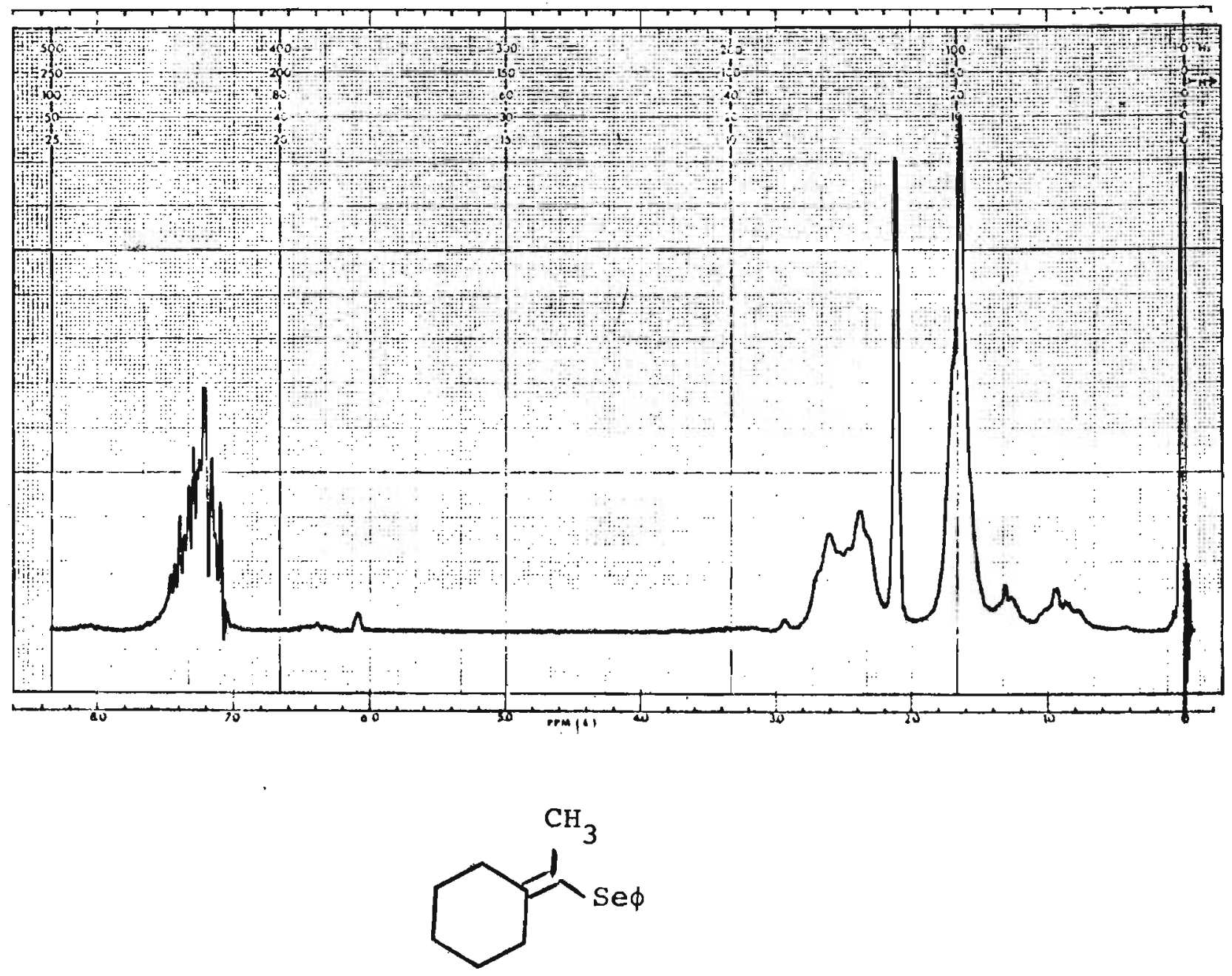
184.

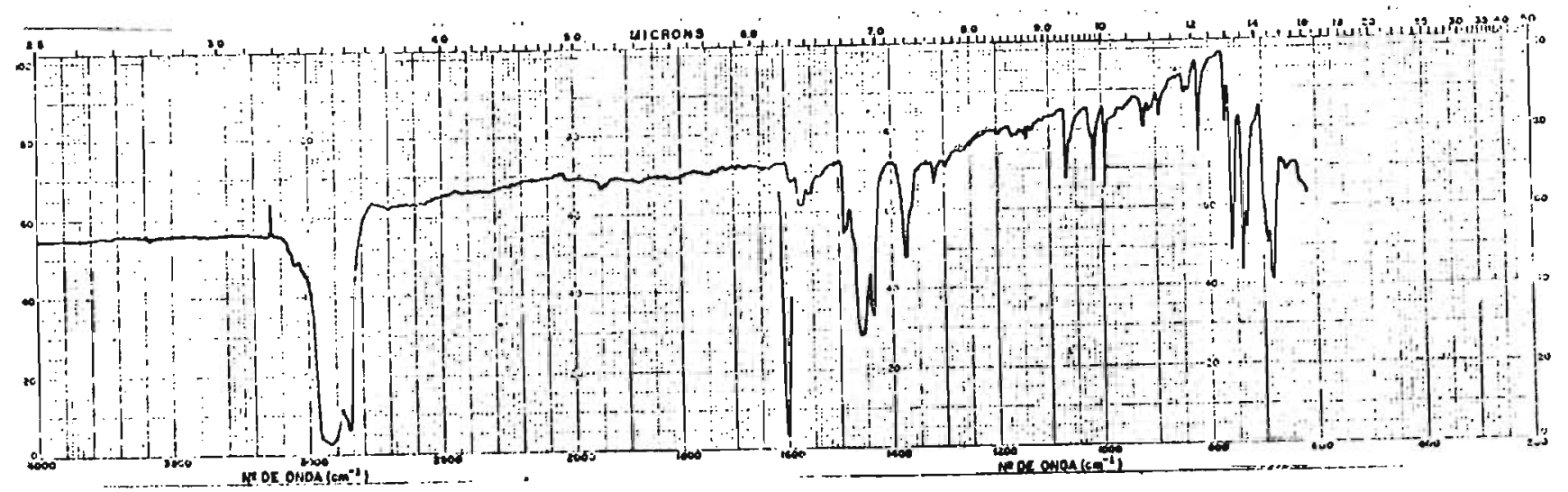

$$
\phi_{2} \mathrm{C}=\mathrm{CHSe} \phi
$$

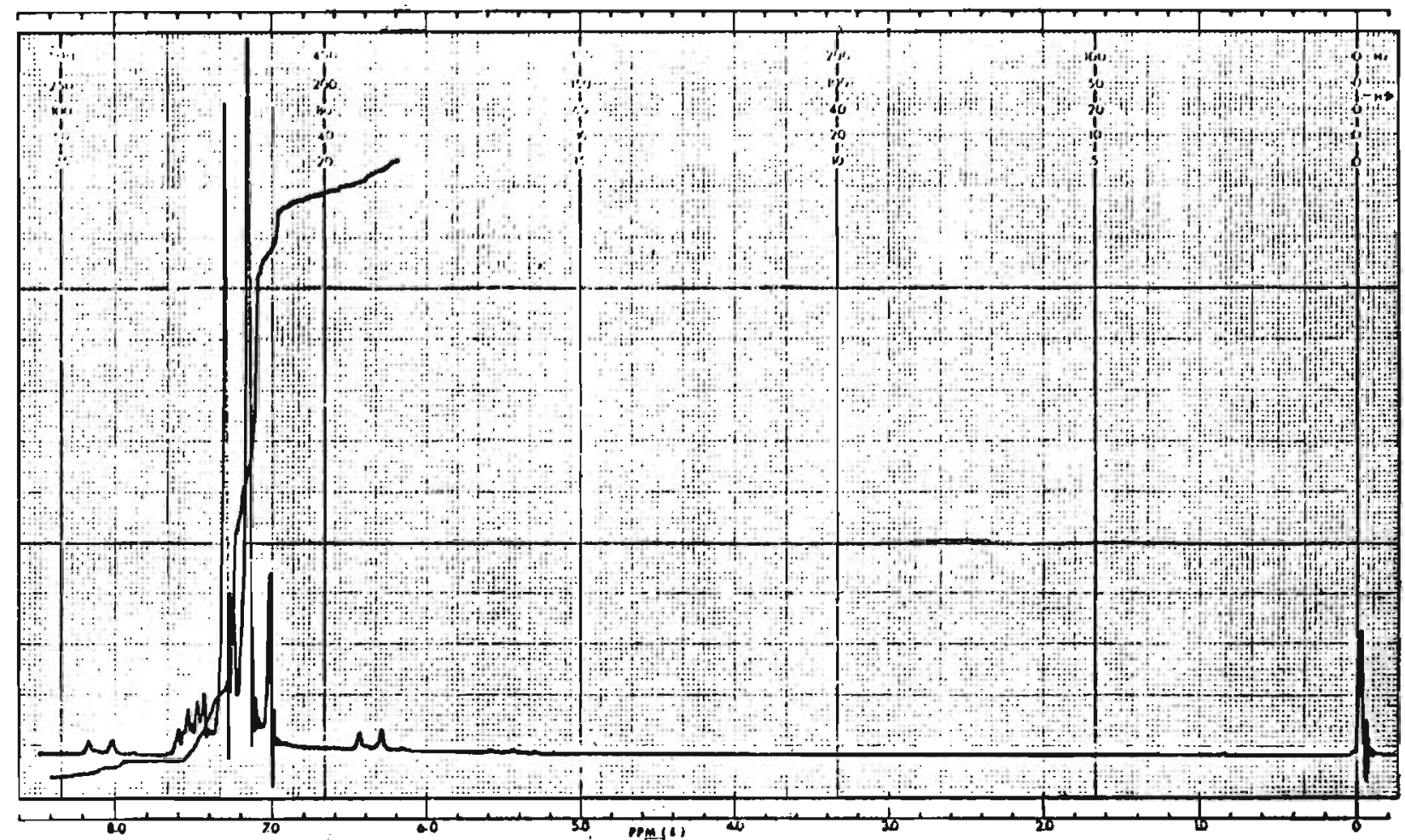




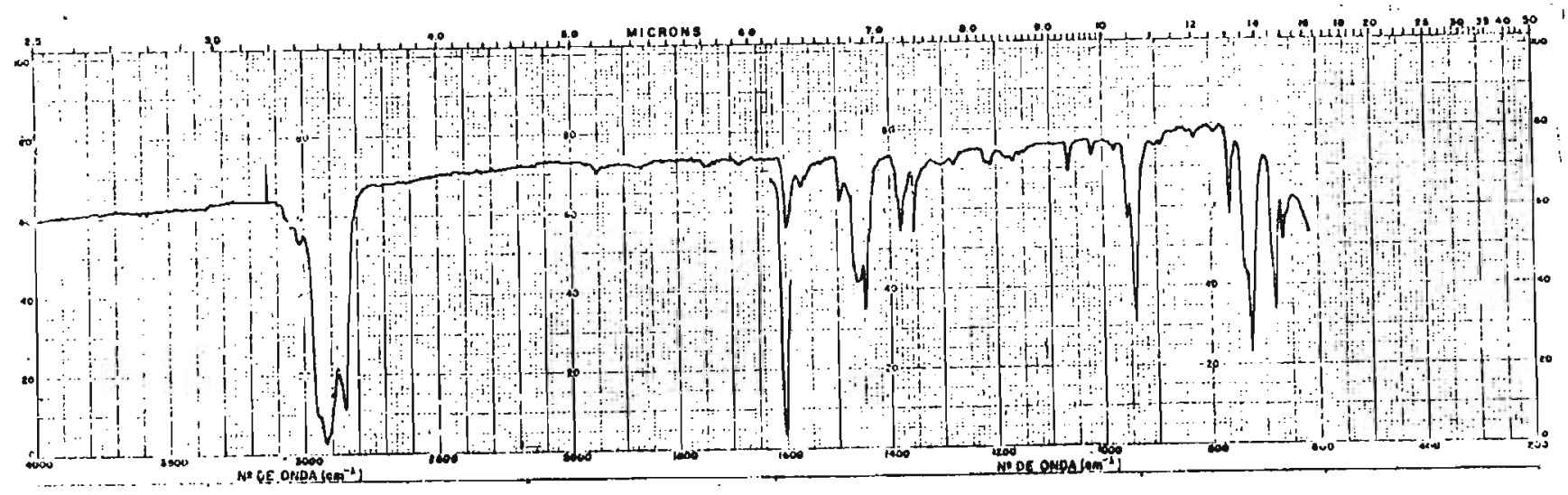

$\phi \mathrm{CH} \approx \mathrm{CHSeCH}=\mathrm{CH} \phi$

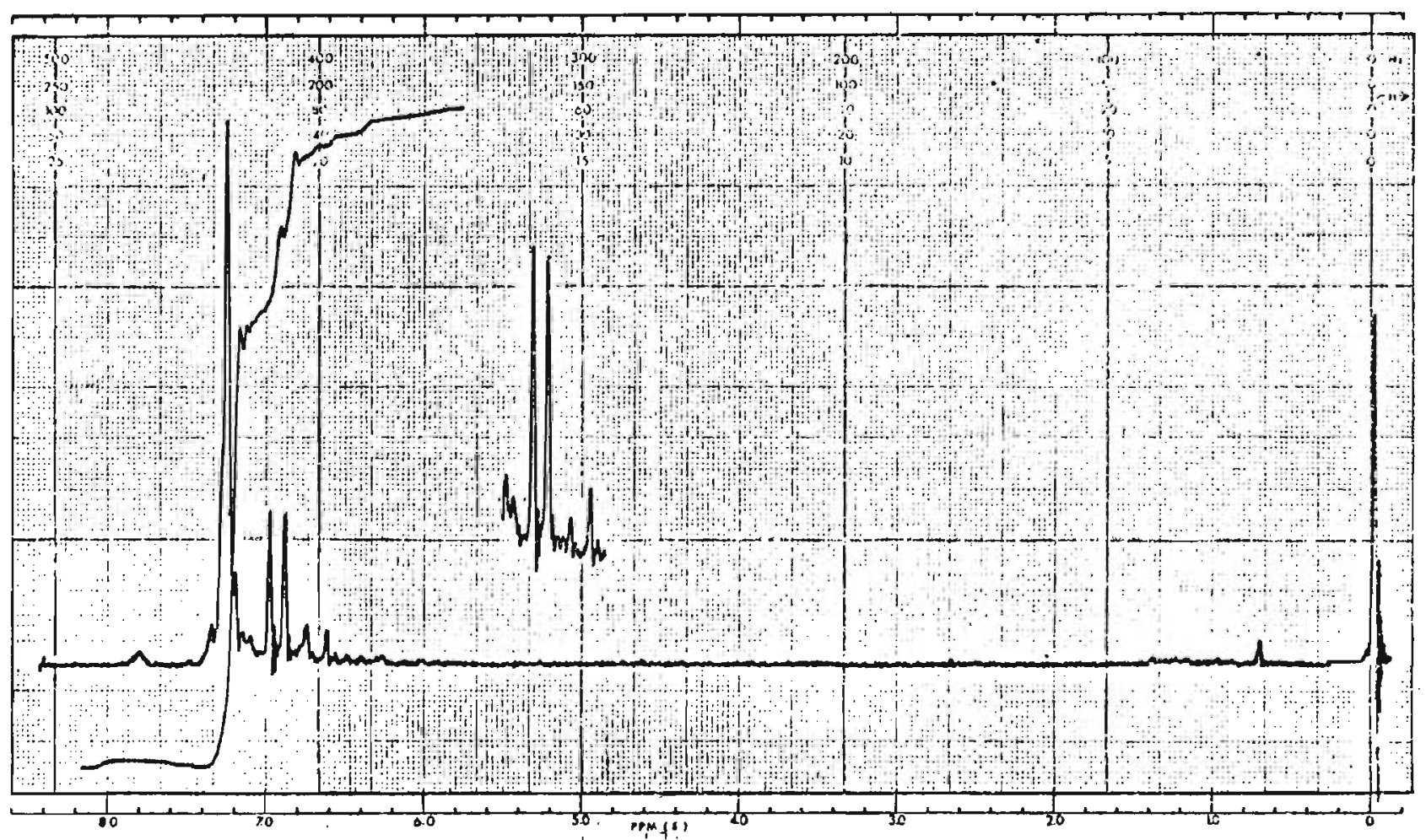




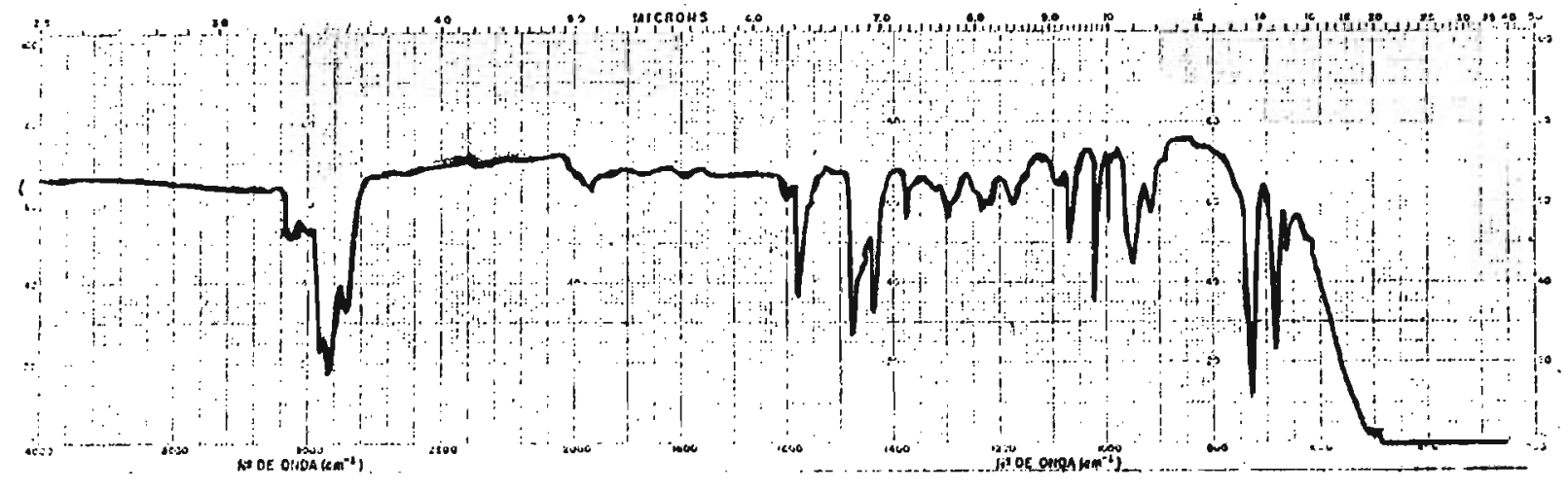

$\mathrm{CH}_{3}\left(\mathrm{CH}_{2}\right)_{3} \mathrm{CH}=\mathrm{CHSe} \phi(\mathrm{E})$

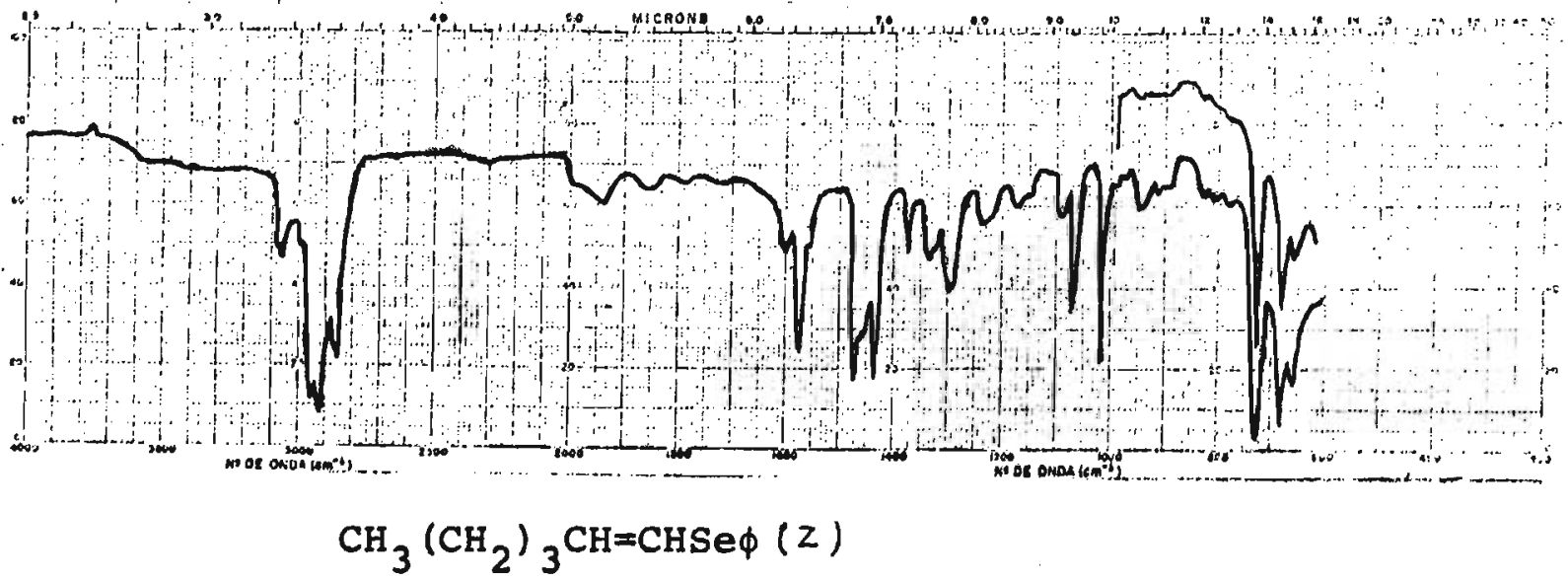




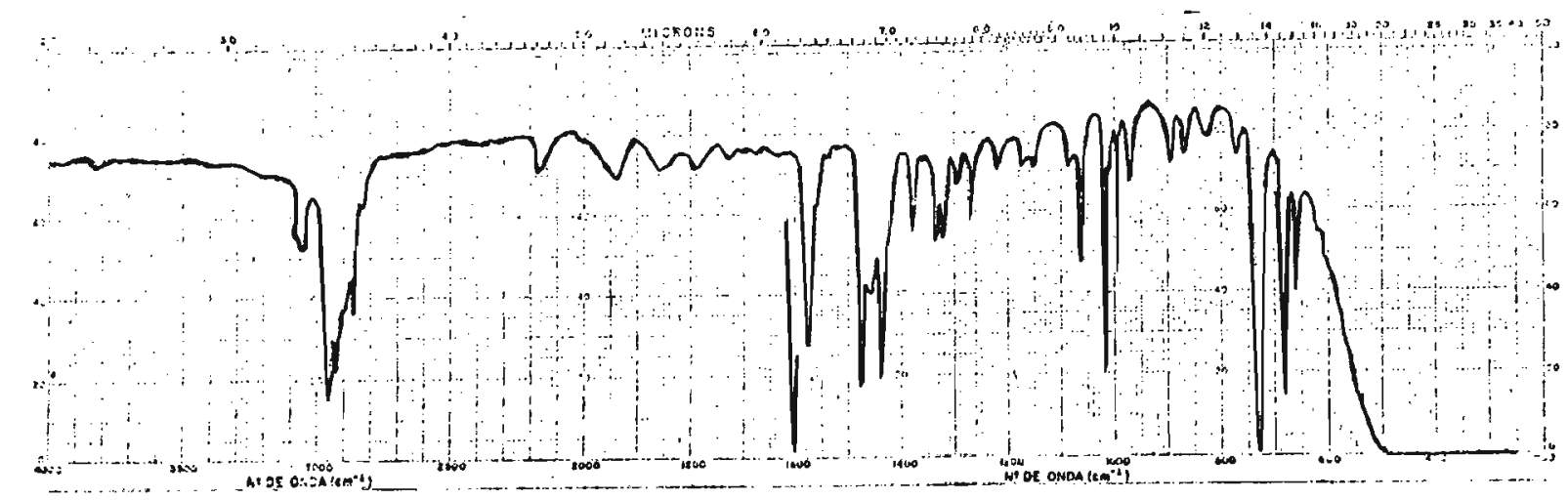

$\mathrm{CH}_{3}\left(\mathrm{CH}_{2}\right)_{2} \mathrm{C} \equiv \mathrm{C}-\mathrm{Se} \phi$

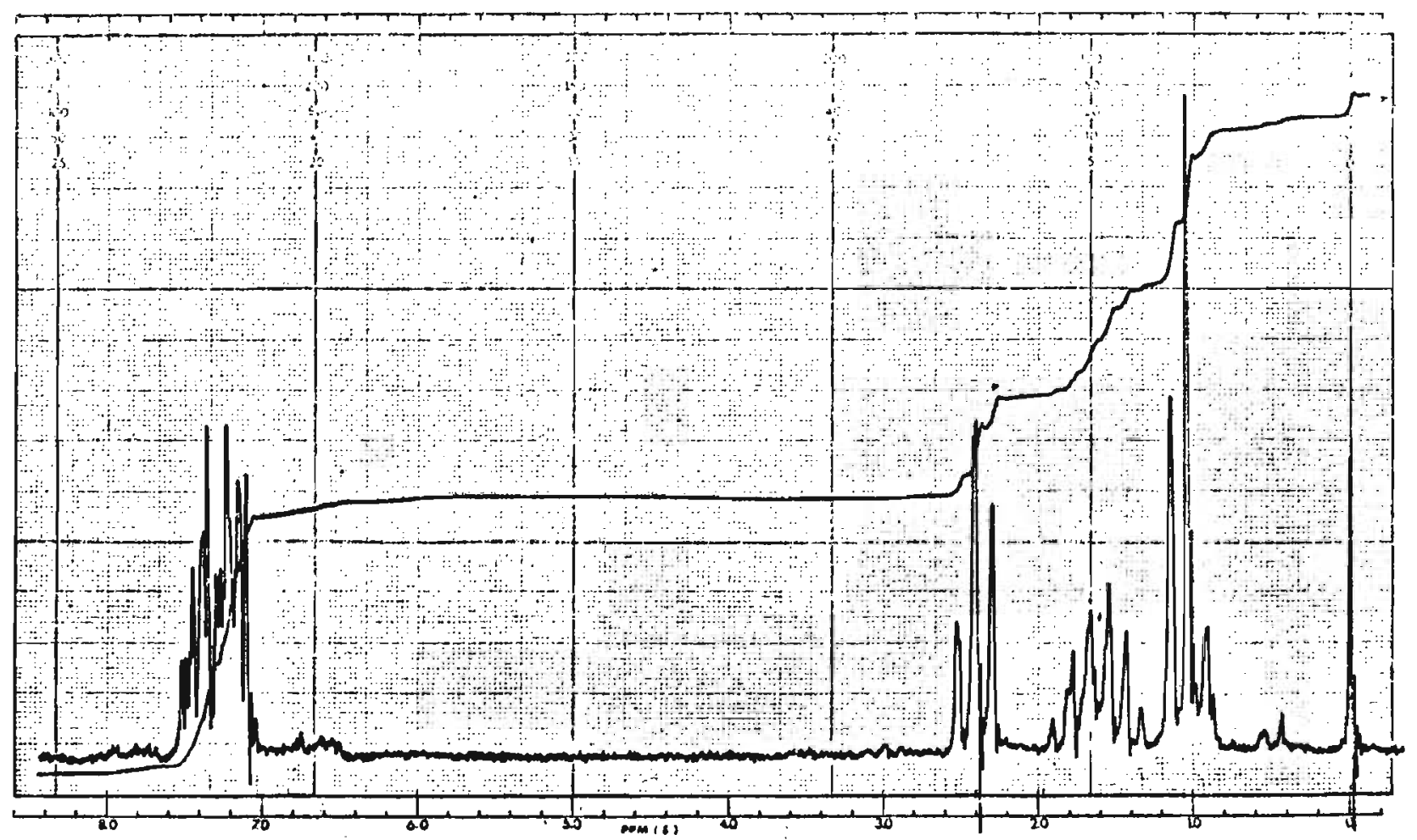


188.

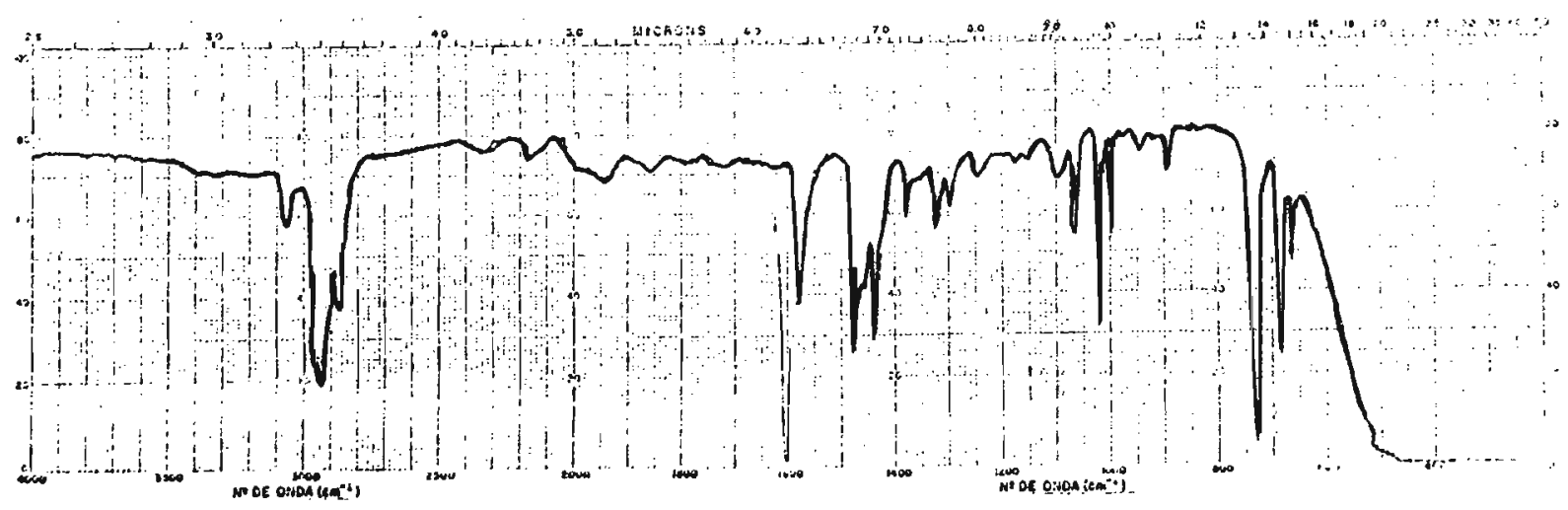

$\mathrm{CH}_{3}\left(\mathrm{CH}_{2}\right)_{3} \mathrm{C} \equiv \mathrm{C}-\mathrm{Se} \phi$

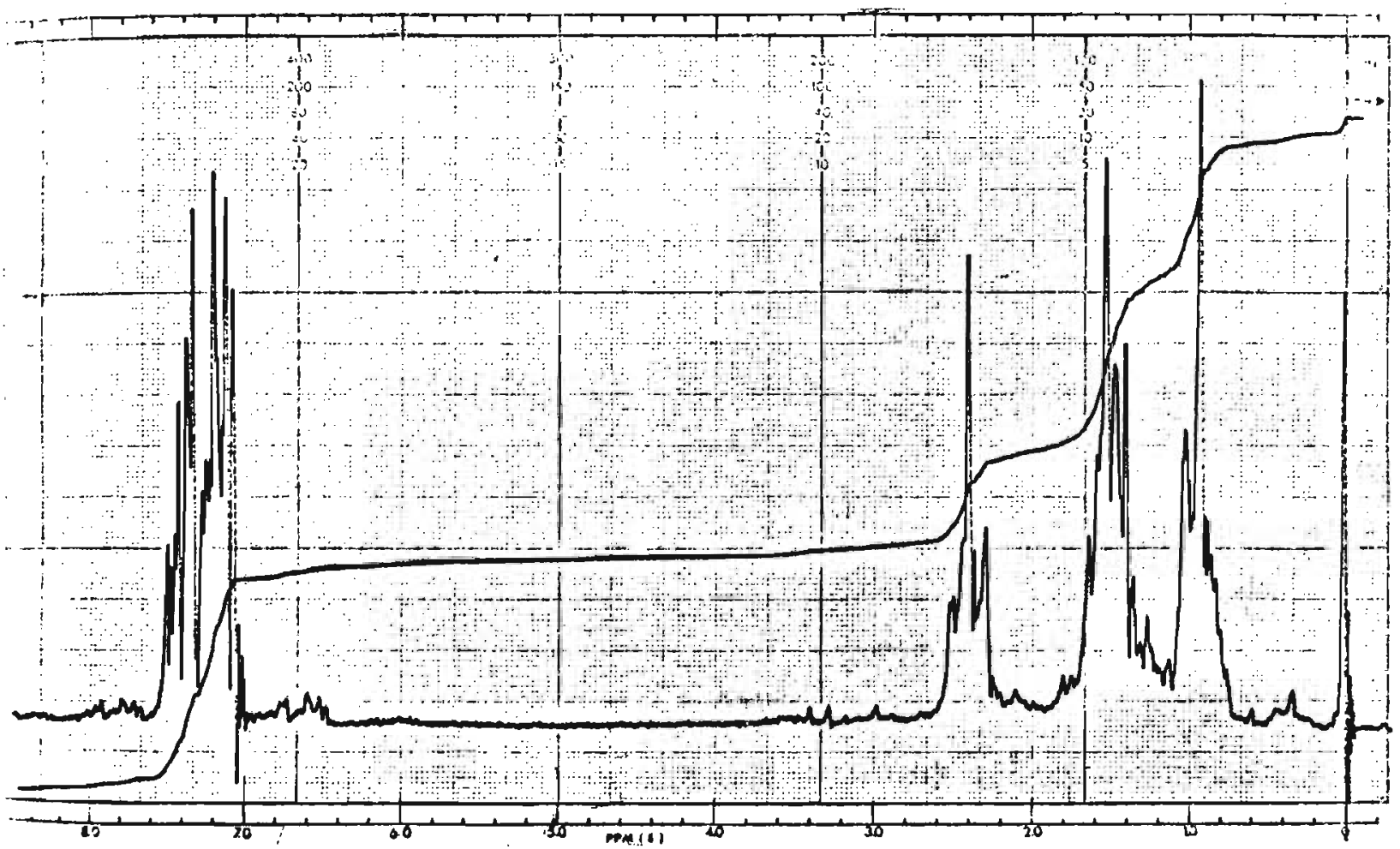




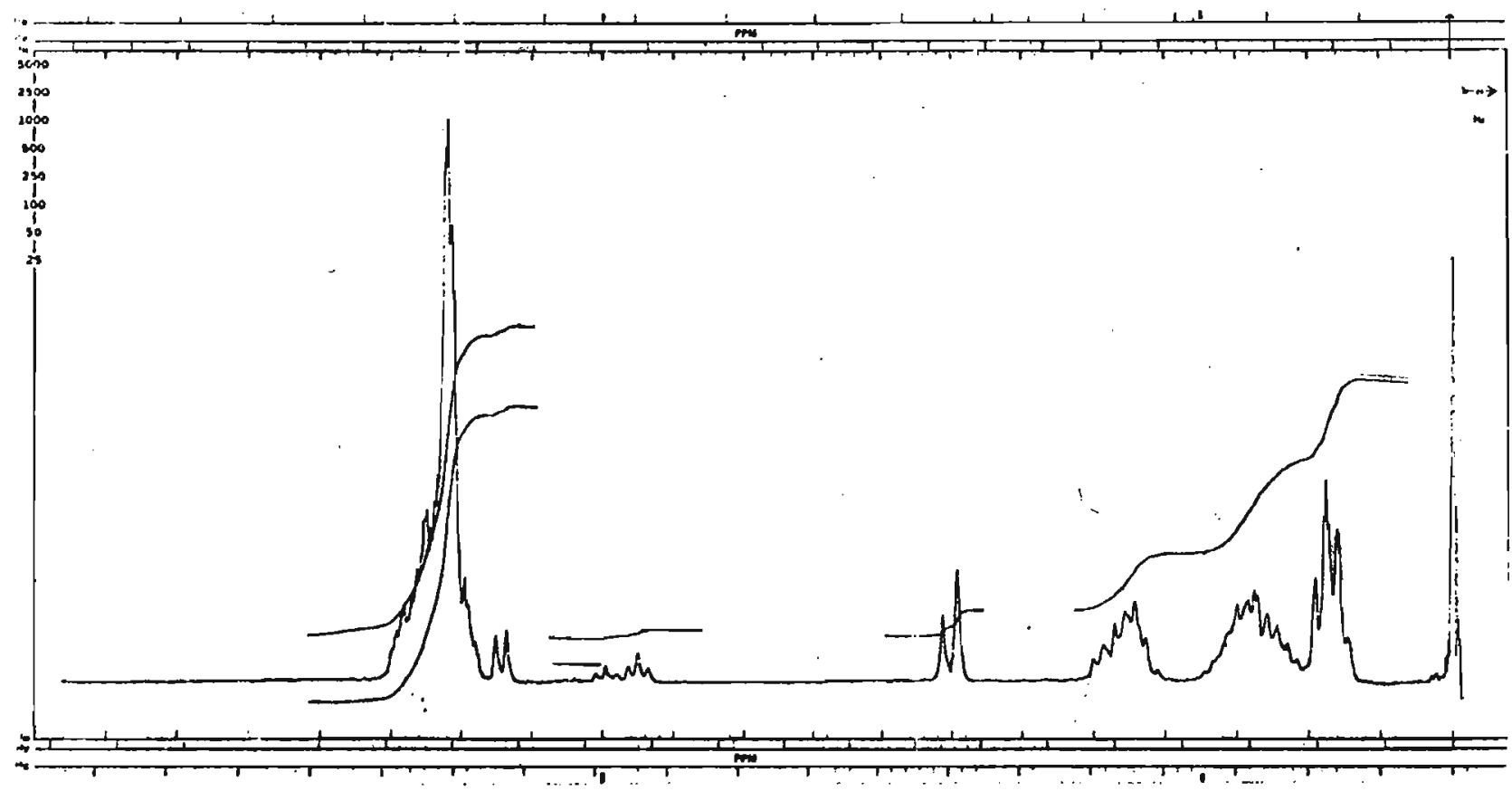

$$
\begin{aligned}
& \phi \mathrm{CH}=\mathrm{C}(\operatorname{Se} \phi) \mathrm{C}_{4} \mathrm{H}_{9}(\mathrm{Z}+\mathrm{E}) \\
& \phi \mathrm{CH}_{2} \mathrm{CH}=\mathrm{C}(\operatorname{Se}) \mathrm{C}_{3} \mathrm{H}_{7}(\mathrm{Z}+\mathrm{E})
\end{aligned}
$$

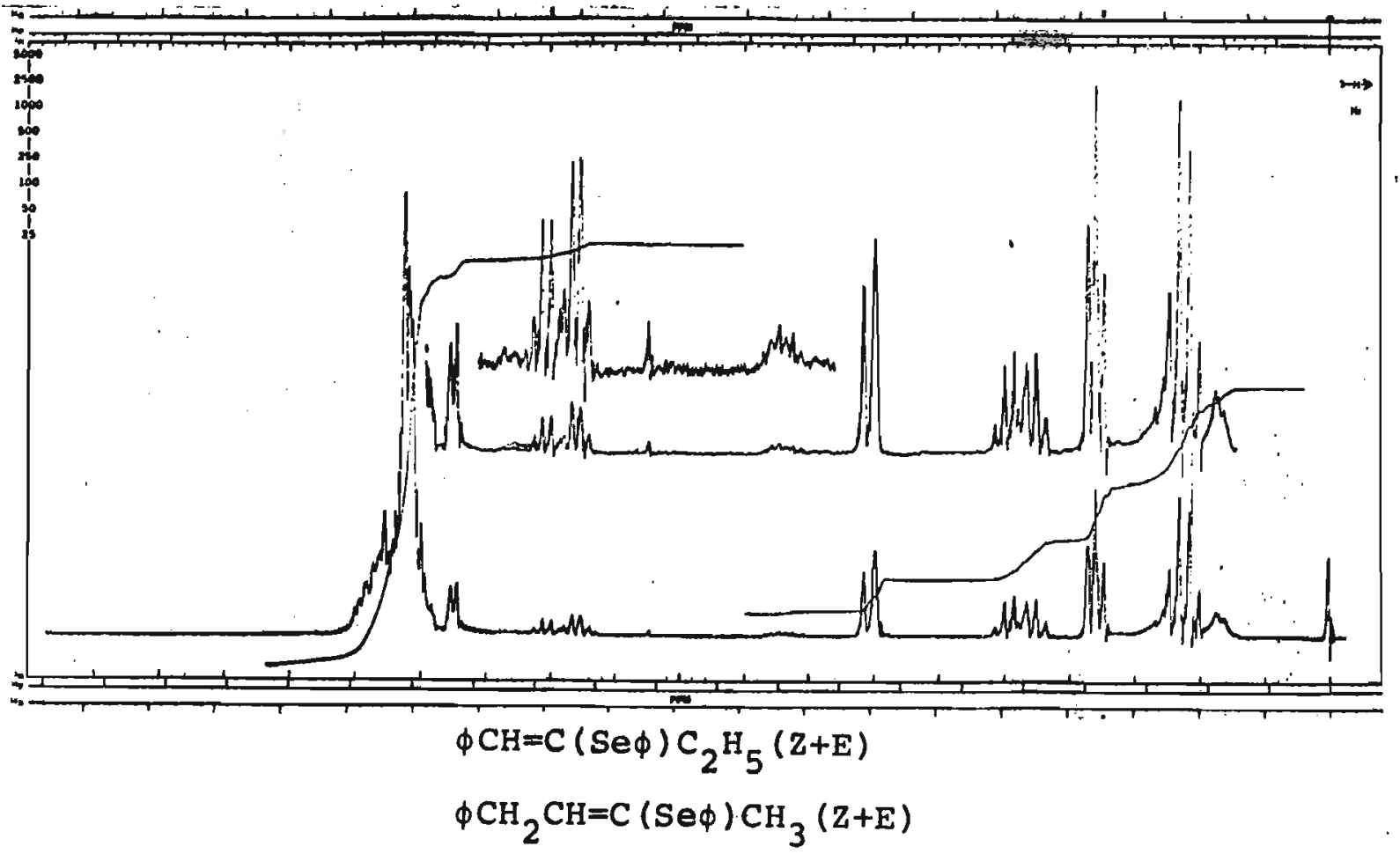




\section{BIBLIOGRAFIA}

190.

1 - Aldrich Chemical Co., Catalog 15, Milwaukee, Wis., 1970, p. 732 .

2 - Anciaux, A., Eman, A., Dumont, W., Van Ende, D. e Krief, A., Tetrahedron Lett., 1613 (1975).

3 - Arndt, F., "Organic Synthesis", Collect. Vol. II, Wiley, New York, 1943, p. 165.

4 - Azerbaev, I.N., Asmanova, A.B., Tso1, L.A., Dok1. Vses. Konf. Kh1m. Atsetilena 4th 1972, 1, 504 (ref. Zh.Kh1m. 1973, Abstr. no 52h479).

5 - Azerbaev, I.N., Asmanova, A.B., Tsoi, L.A. e Dzhamaletdinova, Izv. Akad. Nank Kaz. S.S.R., Ser.Khim. 20, 75 (1970).

6 - Azerbaev, I.N., Asmanova, A.B., Tso1, L.A. e Von, G.P., Khim.Atsetilena Teknnol. Karbida Kal'tsiya 1972, 100 (Ref. Zh.KhIm. 1973 Abstr. no 97h574).

7 - Azerbaev, I.N., Asmanova, A.B., Tso1, L.A., Von, G.P. e Mashurova, R.A., KhIm. Atsetilena Teknnol. Karbida Kal'tsiya 1972, 98 (Ref. Zh.Khim. 1973, Abstr. no 9 zh573).

8 - Azerbaev, I.N., Tso1, L.A., Asmanova, A.B. e Bazal1tskaya, V.S., Izv.Akad.Nauk.Kaz.S.S.R., Ser. KhIm. 27,36 (1977).

9 - Barfield, M., Spear, R.J., Sternhell, S., Chem.Rev., 76, 596 (1976).

10 - Bauman, R.A., Synthesis, 870 (1974). 
11 - Beilstein Handbuch der Organischen Chemie, 5, 514.

12 - Beilstein Handbuch der Organischen Chemie, 5, 517.

13 - Beilstein Handbuch der Organischen Chemie, 5, (38 Erganzunswerk) 1378 .

14 - Beilstein Handbuch der Organischen Chemie, 1, (38 Erganzunswerk) 1017.

15 - Bergelson, L.D., Barsukov, L.I. e Shemyakin, M.M., Tetrahedron, 23, 2709 (1967).

16 - Bergelson, L.D. e Shemyakin, M.M., Tetrahedron, 19, 149 (1963).

17 - Bergelson, L.D. e Shemyakin, M.M., Pure Appl. Chem., 9, 271 (1964).

18 - Bernardi, F., Crizmadia, I.G., Mangini, A., Schlegel, H. B., Whangbo, M.H. e Wolfe, S., J.Amer.chem.Soc., 97, 2209 (1975).

19 - Bestman, H.J., "Newer Methods of Preparative Organic Chemistry", Academic Press, New York, 1968, p.1.

20 - Bestman, H.J., Stransky, W. e Vortrowsky, O., Chem.Ber., 109,1694 (1976).

21 - Betagel, O. e Seibert, H., Ber., 65, 815 (1932).

22 - Blackwood, J.E., Gladys, C.L., Loening, K.L., Petrarca, A.E. e Rush, J.E., J. Amer.chem. Soc., 90, 509 (1968).

23 - Blatcher, P., Grayson, J.I., Warren, S., Chem.Comm., 547 (1976).

24 - Boutagy, J. e Thomas, R., Chem.Rev., 74, 871 (1974). 
25 - Cade, J.A., J.Chem.Soc., 2266 (1959).

26 - Carruthers, w., "Some Modern Methods of Organic Synthesis", Cambridge University Press, 1971.

27 - Chierici, L. e Montanari, F., Gazz.Chim.It. 1269 (1956).

28 - Comasseto, J.V. e Petragnani, N., J. Organometal. Chem. (no prelo).

29 - Comasseto, J.V. e Petragnani, N., manuscrito em preparação.

30 - Comasseto, J.V. e Petragnani, N., resultados nãn publica dos.

31 - Corey, E.J. e Shulman, J.J., J.org.Chem., 35, 777 (1970).

32 - Coutrot, P., Laurenco, C., Petrova, J. e Savignac, P., Synthesis, 107 (1976).

33 - Deschamps, B., Lefebvre, G., Redjal, A. e Seyden-Penne, J., Tetrahedron, 29, 243 (1973).

34 - Dorken, C., Ber., 21, 1505 (1888).

35 - Foster, D.G., "Organic Synthesis", Coll. Vol. III, Wiley, New York, 1955, p. 771.

36 - Frøyen, P., Acta Chem.Scand., 2163 (1972).

37 - Gallagher, M.J. e Jenkings, I.D., "Topics in Stereochemistry", $\underline{3}, 1$ (1968).

38 - Gilman, H. e Tomas1, R.A., J.Org.Chem., 27, 3647 (1962).

39 - Gosselck, J., Angew.Chem. Int. Ed. Engl., 2, 660 (1963). 
40 - Gosselck, J. e Wolters, E., Z.Naturforsch., 17 b, 131 (1962).

41 - Green, M., J.Chem.Soc., 1324 (1963).

42 - Gröbel, B.T. e Seebach, D., Synthesis, 357 (1977).

43 - Horner, L., Hoffman, H. e Wippel, H.G., Chem.Ber., 91 , 61 (1958).

44 - House, H.O., "Modern Synthetic Reactions", $2^{\text {nd }}$ ed., W.A. Benjamin, Menlo Park, California, 1972.

45 - Issleib, K. e Lindner, R., Ann., 699, 40 (1966).

46 - Issleib, K. e Lindner, R., Ann., 707, 112 (1967).

47 - IUPAC, J.Org.Chem., 35, 2849 (1970).

48 - Jackman, L.M. e Sternhell, S., "Applications of Nuclear Magnetic Ressonance spectroscopy in Organic Chemistry", $2^{\text {nd }}$ ed., Pergamon Press, Oxford, 1969.

49 - Johnson, A.W., "Ylid Chemistry", Academic Press, New York, 1966.

50 - Jones, G.H., Hamamura, K.K. e Moffatt, J.G., Tetrahedron Lett. , 5731 (1968).

51 - Jones, G. e Maisey, R.F., Chem.Comm., 543 (1968).

52 - Kataev, E.G. e Petrov, V.N., Z. Obsh. Khim., 32, 3699 (1962).

53 - Kataeva, M.. Anonimova, I.V., Yuldasheva, L.K. e Kataev, E.G., Z. Obs. Khim., 32, 3965 (1962).

54 - Kato, S., Kato, T., Mizuta, M., Itoh, K. e Ishi1, Y., J.Organometal.Chem., 51, 167 (1973). 
55 - Kinstle, T.H. e Mandanas, B.Y., Chem.Comm., 1699 (1968).

56 - Klayman, D.L. e Günther, W.H.H., "Organic selenium Compounds: Their Chemistry and Biology", Wiley, New York, 1973.

57 - Lavielle, G. e Sturtz, G., Bull.Soc.Chim.Fr., 1369 $(1970)$.

58 - Lischka, H., J.Amer.Chem.Soc., 99, 353 (1977).

59 - Maercker, A., "Org. Reactions", Vol. 14, Wiley, New York, 1965, p. 270 .

60 - Magoon, E.F. e Slaugh, L.H., Tetrahedron, 23, 4509 (1967).

61 - McEwen, W. e Berlin, K.D. (Editors) "Organophosphorus stereochemistry, part. II", Dowden, Hutchinson e Ross, stroudsburg, Pennsylvania, 1975.

62 - Michaelis, A. e Gimborn, H.V., Ber., 27, 272 (1894).

63 - Mikolajczyk, M., Grzejszczak, S., Midura, W.e Zatorski, A., Synthesis, 869 (1974).

64 - Mikolajczyk, M., Grzejszczak, S., Midura, W. e Zatorski, A., Synthesis, 278 (1975).

65 - Mikolajczyk, M., Grzejszczak, S., Midura, W. e Zatorski, A., Synthesis, 396 (1976).

66 - Mukaiyama, T., Fukuyama, S. e Kumamoto, T., Tetrahedron Lett. , 3787 (1968).

67 - Mukaiyama, T., Kumamoto, T., Fukuyama, S. e Taguchi, T., Bu11.Chem.Soc. Jap., 43, 2870 (1970). 
68 - Nakanishi, K. e Solomon, P.H., "Infrared Absorption Spectroscopy", 2nd ed., Holden Day, San Francisco, 1977.

69 - Parker, A.J., "Advances in Organic Chemistry", Vol.5, Interscience, Wiley, New York, 1965, p.1.

70 - Perrin, D.D., Armarego, W.L.F. e Perrin, D.R.,"Purification of Laboratory Chemicals", Pergamon Press, London, 1966.

71 - Petragnani, N., Ann. N.Y. Acad.Sci., 192, 10 (1972).

72 - Petragnani, N. e Comasseto, J.V., "Proceedings XVIII International Conference on Coordination Chemistry", São Paulo, 1977, p. 35.

73 - Petragnani, N., Comasseto, J.V., Rodrigues, R. e Brocksom, T.J., J.Organometal.Chem., 124, 1 (1977).

74 - Petragnan1, N. e Moura Campos, M., Chem. and Ind., (London), 1461 (1964).

75 - Petragnani, N. e Rodrigues, R., Chem. Scripta 8A, 110 (1975).

76 - Petragnani, N., Rodrigues, R. e Comasseto, J.V., J. Organometal. Chem:, 114, 281 (1976).

77 - Petragnani, N. e Schill, G., Chem.Ber., 103, 227 (1970).

78 - Raucher, S., J.Org.Chem., 42, 2950 (1977).

79 - Redemann, C.F., RIce, F.D., Roberts, R. e Ward, H.P., "Organ1c synthesis", Coll., Vol. III, Wiley, New York, 1963, p. 244.

80 - Redjal, A. e Seyden-Penne, J., Tetrahedron Lett., 1733 (1974). 
81 - Reich, M.J. e Chow, F., Chem.Comm., 790 (1975).

82 - Reich, H.J., Renga, J.M. e Reich, I.L., J.Amer.Chem. Soc., 97,5434 (1975).

83 - Reucroft, J. e Sammes, P.G., quart.Rev., 25, 135 (1971).

84 - Rodrigues, R., "Reações de Wittig envolvendo Selenofos foranas", Dissertação de Mestrado apresentada ao Ins tituto de Quimica da Universidade de São Paulo, 1975.

85 - Rutledge, T.F., "Acetylenes and Allenes", Rheinhold, New York, 1969 , p. 35.

86 - Sadtler Standard Spectra (NMR), no 547.

87 - Sadtler Standard Spectra (NMR), n8 9908.

88 - Salmon, W.G., Barta, M.A., Cain, A.M. e Sobala, M.C., Tetrahedron Lett., 1683 (1977).

89 - Schill, G. e Keller, U., Synthesis, 621 (1972).

90 - Schlosser, M., "Topics in Stereochemistry", $\underline{5}, 1$ (1970).

91 - Schlosser, M. e Christmann, K.F., Angew.Chem. Int. Ed. Eng 1. , 4, 689 (1965).

92 - Schmidbaur, H., Chem.Ber., 105, 1084 (1972).

93 - Schmidbaur, H., Räthlein, K.H. e Reutov, O.A., J. organometa1.Chem., 4,202 (1965).

94 - Schm1dbaur, H. Trontch, W., Chem.Ber., 100, 1032 (1967).

95 - Schmidbaur, H. e Tronich, W., Chem.Ber., 101, 595 (1968). 
96 - Schmidbaur, H. e Tronich, W., Chem.Ber., 101, 604 (1968).

97 - Schmidbaur, H. e Tronich, W., Chem.Ber., 101, 3545 (1968).

98 - Schmidbaur, H. e Vornberger, W., Angew.Chem. Int.Ed., Engl., 9, 737 (1970).

99 - Schmidt, A., Chem.Ber., 101, 4015 (1968).

100 - Schneider, W.P., Chem.Comm., 785 (1969).

101 - Schwarz, M. e Walters, R.M., Synthesis, 567 (1972).

102 - Sevrin, M., Dumont, W. e Krief, A., Tetrahedron Lett., 3835 (1977).

103 - Seyfert, D., Angew.Chem., 72, 36 (1960).

104 - Seyfert, D. e Brändle, K.A., J.Amer.Chem.Soc., 83, 2055 (1961).

105 - Seyfert, D. e Green, S.0., J.Amer.Chem.Soc. , 83, 1610 (1961).

106 - Seyfert, D. e Green, S.0., J.Amer.Chem.Soc., 83, 1613 (1961).

107 - Seyfert, D. e Singh, G., J.Amer.Chem.Soc., 87, 4156 (1965).

108 - Slaugh, L.H. , Tetrahedron, 22, 1741 (1966).

109 - Streitwieser, A. e Ewig, S.P., J.Amer.Chem.Soc., 97, 190 (1975).

110 - Tarbell, D.S. e McCall, M.A., J.Amer.Chem.Soc., 74, 48 (1952). 
111 - Trindle, C., Hwang, J.T. e Carey, F.A., J.Org.Chem., $\underline{38}, 2664$ (1973).

112 - Trippett, S., Quär.Rev., 17, 406 (1963).

113 - Trippett, S., "Organophosphorus Chemistry", A Specialist Periodical Report, The Chemical Society, London.

114 - Van Leusen, A.M., Reith, B.A., Iedema, A.J.W. e Strating, J., Recueil, 91, 37 (1972).

115 - Varughese, P., J.Chem.Ed., 54, 666 (1977).

116 - Vedjs, E. e Snoble, K.A.J., J.Amer.Chem.Soc., 95,5778 (1973).

117 - Vogel, E., "XXIII rd International Congress of Pure and Applied Chemistry", Vol. I, Boston, 1971.

118 - Volger, H.C. e Arens, J.F., Rec.Trav.Chim., 77, 1170 (1958).

119 - Wadsworth, W.S. e Emmons, W.D., J.Amer.Chem.Soc., 83, 1733 (1961).

120 - Wittig, G. e Geissler, G., Ann., 580, 44 (1953).

121 - Wittig, G. e Schlosser, M., Chem.Ber., 94, 1373 (1961).

122 - Wittig, G., Böll, W. e Kruck, K.H., Chem.Ber., 95, 2514 (1962).

123 - Wittig, G. e Schollkopf, V., "Organic Synthesis" Vol. 40, Wiley, New York, 1960 , p. 66.

124 - Wittig, G. e Wittenberg, D., Ann., 606, I (1959). 